\title{
Hydraulic, Geochemical, and Thermal Monitoring of an Aquifer System in the Vicinity of Mammoth Lakes, Mono County, California, 2015-17
}

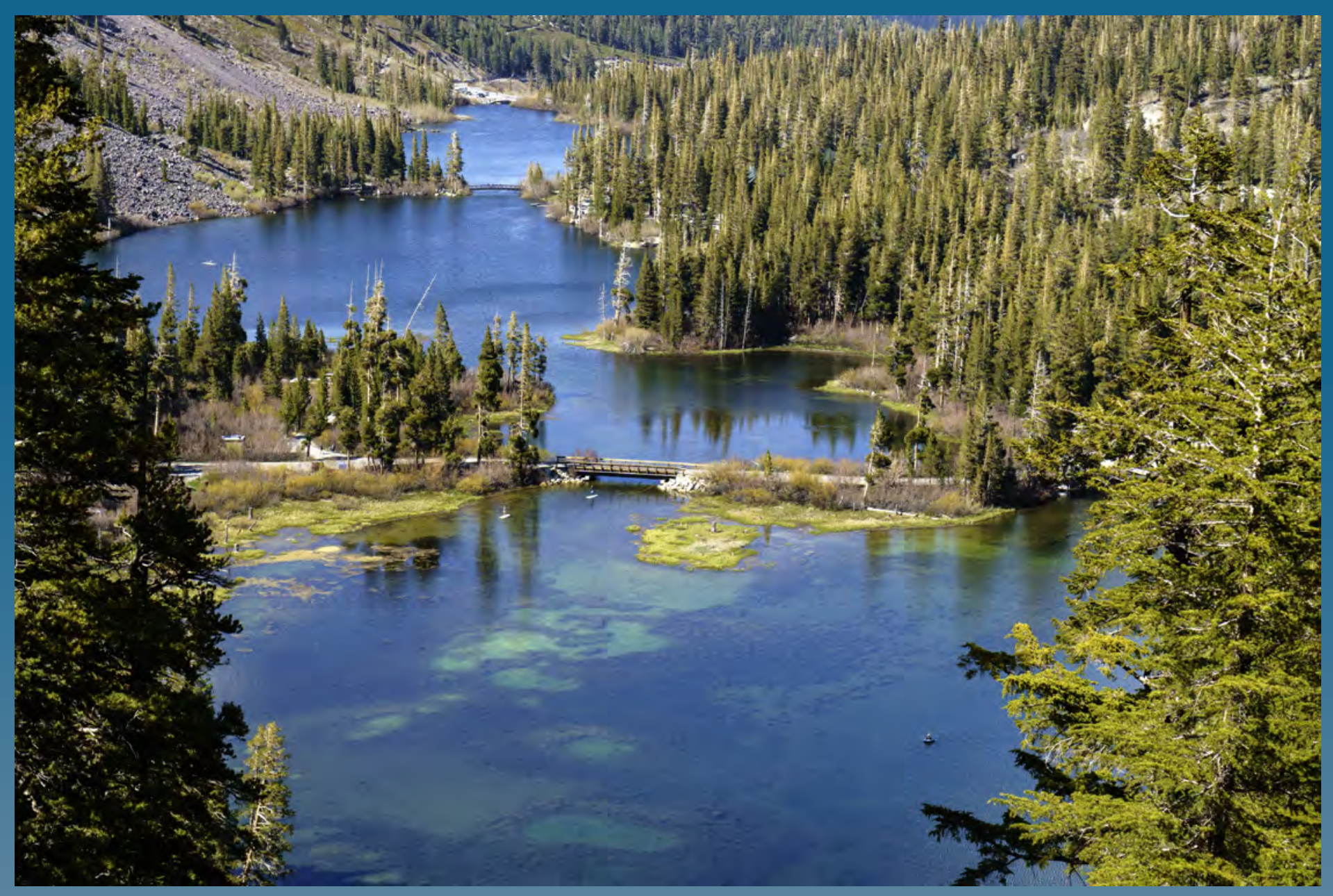

Open-File Report 2019-1063

U.S. Department of the Interior U.S. Geological Survey 
Cover photo: View of Twin Lakes near Mammoth Lakes, California. Photograph ${ }^{\oplus i S t o c k p h o t o . c o m / R i v e r N o r t h P h o t o g r a p h y . ~}$ 


\section{Hydraulic, Geochemical, and Thermal Monitoring of an Aquifer System in the Vicinity of Mammoth Lakes, Mono County, California, 2015-17}

By James F. Howle, William C. Evans, Devin L. Galloway, Paul A. Hsieh,

Shaul Hurwitz, Gregory A. Smith, and Joseph Nawikas

Open-File Report 2019-1063 


\title{
U.S. Department of the Interior DAVID BERNHARDT, Secretary
}

\author{
U.S. Geological Survey \\ James F. Reilly II, Director
}

U.S. Geological Survey, Reston, Virginia: 2019

For more information on the USGS - the Federal source for science about the Earth, its natural and living resources, natural hazards, and the environment-visit https://www.usgs.gov or call 1-888-ASK-USGS.

For an overview of USGS information products, including maps, imagery, and publications, visit https://store.usgs.gov.

Any use of trade, firm, or product names is for descriptive purposes only and does not imply endorsement by the U.S. Government.

Although this information product, for the most part, is in the public domain, it also may contain copyrighted materials as noted in the text. Permission to reproduce copyrighted items must be secured from the copyright owner.

Suggested citation:

Howle, J.F., Evans, W.C., Galloway, D.L., Hsieh, P.A., Hurwitz, S., Smith, G.A., and Nawikas, J., 2019, Hydraulic, geochemical, and thermal monitoring of an aquifer system in the vicinity of Mammoth Lakes, Mono County, California, 2015-17: U.S. Geological Survey Open-File Report 2019-1063, 90 p., https://doi.org/10.3133/ofr20191063. 


\section{Acknowledgments}

Funding for the drilling of the multiple-completion monitoring wells $14 \mathrm{~A}-25$ and $28 \mathrm{~A}-25$, which were installed by the U.S. Geological Survey (USGS), was provided through Mono County; the sources were a California Energy Commission grant and Ormat Technologies, Inc. (grantee). Funding for the subsequent USGS monitoring work at these wells was provided by Ormat through a joint funding agreement with Mono County. The funding for monitoring water chemistry in eight Mammoth Community Water District (MCWD) wells was provided to the USGS by the MCWD through a joint funding agreement with the USGS. Funding for the drilling of the multiple-completion monitoring well BLM-1, also installed by the USGS, was provided by the Bureau of Land Management.

Steve Ingebritsen, Michael Rosen, and John Izbicki of the USGS provided constructive technical reviews and suggested numerous improvements to the main text. Kolja Rotzoll and Andy Long of the USGS provided constructive technical reviews of the "Development of Digital AtmosphericLoading and Earth-Tide Filters" section of the main text and appendix 2. Wes Hildreth of the USGS provided insightful discussions regarding the geology of the study area and described drill cuttings from the monitoring wells 14A-25, 28A-25, and BLM-1. 


\section{Contents}

Acknowledgments .........................................................................................................................ii

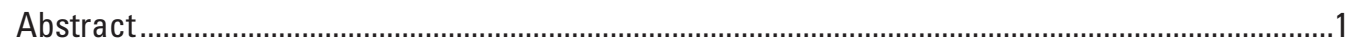

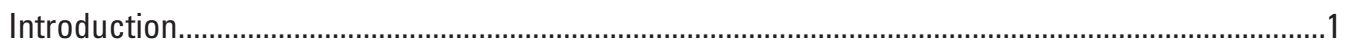

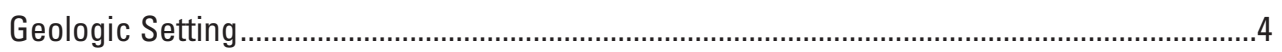

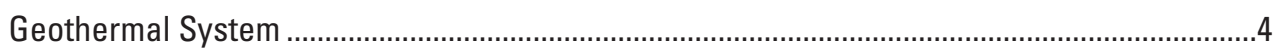

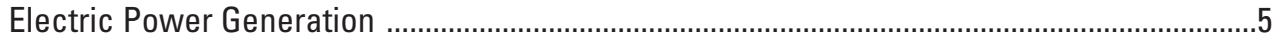

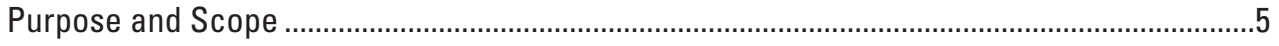

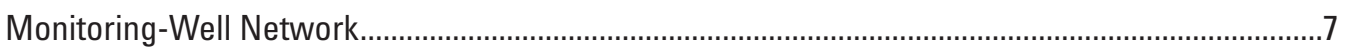

Shallow Multiple-Completion Monitoring Wells.....................................................................

Deep Geothermal Monitoring Well .................................................................................

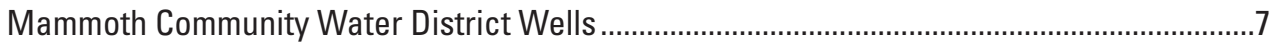

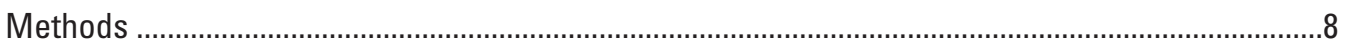

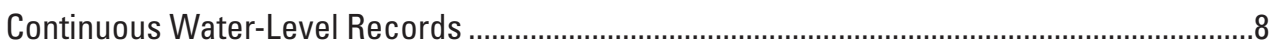

Water-Level Sensors in the Warm Monitoring Wells .........................................................

Development of Digital Atmospheric-Loading and Earth-Tide Filters..............................10

Collection of Water-Temperature Profiles.........................................................................12

Collection of Water-Chemistry Samples ..........................................................................

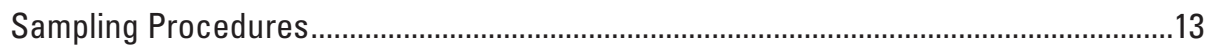

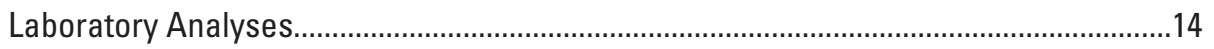

Quality Assurance and Quality Control .......................................................................14

Equipment Blank Samples for Wells 14A-25 and 28A-25 ......................................14

Quality-Control Measures at Mammoth Community Water District Wells .............15

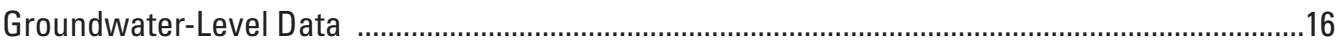

Pre-Filtered Groundwater-Level Data ................................................................................16

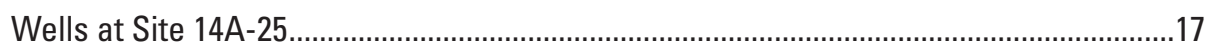

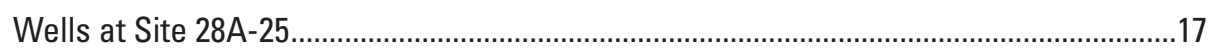

Digitally Filtered Groundwater-Level Data ...........................................................................18

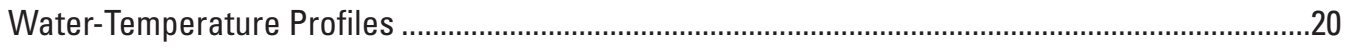

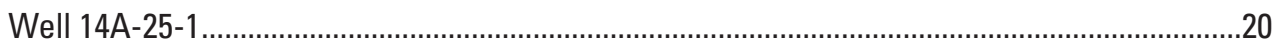

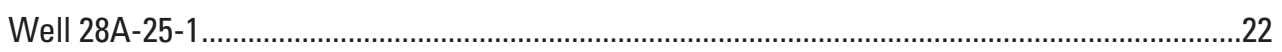

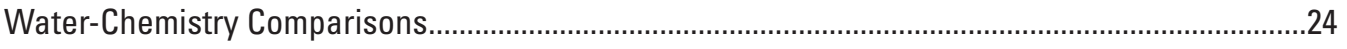

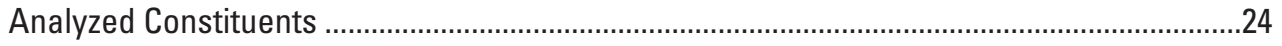

Chloride Concentrations in Groundwater from Mammoth Community Water District

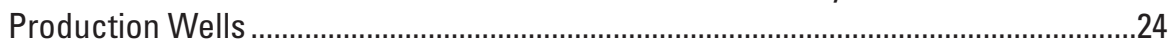

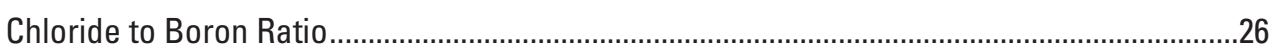

Chloride to Bromide and Chloride to Lithium Ratios ..........................................................28

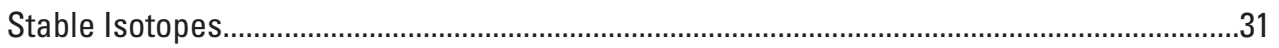

Water-Level Variations During a Flow Test of a Geothermal Production Well.................................32

Description of Flow Test ................................................................................................

Filtered Water-Levels at Sites 14A-25 and 28A-25 Before, During, and After the

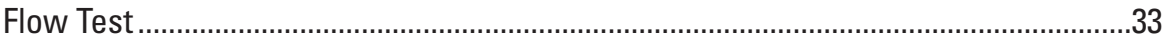

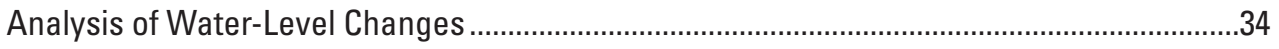

Potential Physical and Chemical Influences on Water-Level Data ................................................34

Temperature-Induced Density Changes ..............................................................................35 


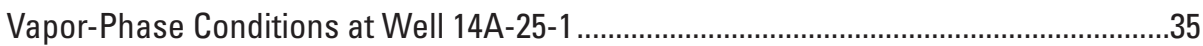

Thermal Conduction Due to Nearby Production Well 14-25...........................................36

Variations in Water-Temperature Profiles During the Flow Test .......................................36

Gas-Temperature Changes Above the Water Column …………………………………....37

Chemistry-Induced Density Changes .....................................................................................37

Summary of Potential Physical and Chemical Influences on Water-Level Data .....................38

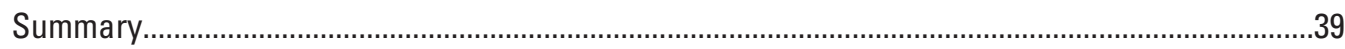

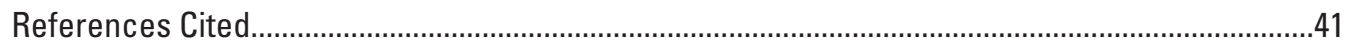

Appendix 1. U.S. Geological Survey Research Drilling Program Drilling Methods, Borehole Geophysical Techniques and Well-Construction Schematics for Wells 14A-25,

28A-25, and BLM-1 near Mammoth Lakes, California ..........................................................45

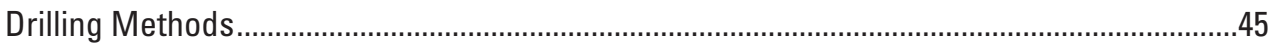

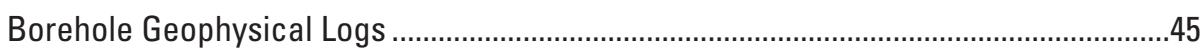

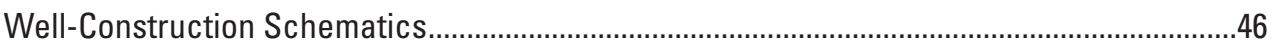

Appendix 2. Development of Digital Atmospheric-Loading and Earth-Tide Filters..........................49

Water-Level Responses to the Solid Earth Tide......................................................................5

Preliminary Earth-Tide Analyses of Parsed Series ..........................................................62

Earth-Tide Analysis of Discrete Segments of Select 14A-25-1 Time Series ....................62

Digital Earth-Tide Filters for 14A-25-1 Time Series........................................................69

Frequency Responses of Water Levels to Atmospheric Loading ............................................74

Idealized Well and Aquifer Response to Atmospheric Loading........................................74

Computed Frequency Responses ................................................................................

Digitally Filtered Water-Level Time Series...................................................................

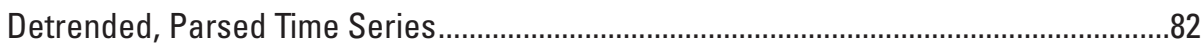

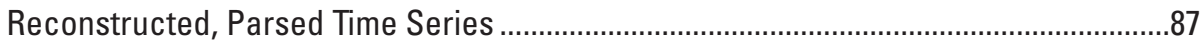

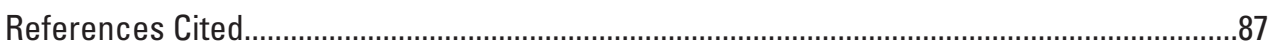

Appendix 3. Water-Temperature Profiles for Wells in the Vicinity of Mammoth Lakes,

California, 2015-17

\section{Figures}

1. Map showing location of study area, selected thermal springs, and wells in Long Valley Caldera, Mono County, California

2. Map of the Mammoth Lakes area, California, showing the location of monitoring sites and other features.................................................................................................

3. Map of the Casa Diablo IV project area showing the locations of monitoring sites and selected features in the Mammoth Lakes area, California.

4. Photograph showing a typical U.S. Geological Survey hot-water-well fluidpressure monitoring system consisting of an up-hole pressure transducer, continuous-flow nitrogen gas regulator, and fixed-depth nitrogen gas line..

5. Diagram of the simplified workflow process used to develop the digital atmospheric-loading and Earth-tide filters for water levels from monitoring wells 14A-25-1, 28A-25-1, and 28A-25-2, Mammoth Lakes area, California

6. Photograph showing portable water-temperature logging equipment used in the Mammoth Lakes area, California, study

7. Photographs showing data collection equipment used to collect water-chemistry samples from wells in the Mammoth Lakes area, California 
8. Graph showing daily median and instantaneous water levels, depth below land surface, 2015-17, for wells 14A-25-1 and 14A-25-2 in the Mammoth Lakes area, California

9. Graph showing daily median and instantaneous water levels, depth below land surface, 2016-17, for wells 28A-25-1 and 28A-25-2 in the Mammoth Lakes area, California

10. Graph showing hourly barometric pressure, water-level depth below land surface data, and filtered water-level depth below land surface for well14A-25-1 in the Mammoth Lakes area, California, from August 12 to October 6, 2017

11. Graph showing hourly barometric pressure, water-level depth below land surface data, and filtered water-level depth below land surface for well 28A-25-1 in the Mammoth Lakes area, California, from August 16 to October 6, 2017

12. Graph showing hourly barometric pressure, water-level depth below land surface data, and filtered water-level depth below land surface for well 28A-25-2 in the Mammoth Lakes area, California, from August 12 to October 6, 2017.

13. Graph showing water-temperature by depth below top of casing for well 14A-251, Mammoth Lakes area, California, 2016

14. Graph showing water-temperature by depth below top of casing for well 14A-251, Mammoth Lakes area, California, 2017

15. Graph showing water-temperature profiles in well 14A-25-1 for the depth interval from 440 to 490 feet below top of casing from 2016 to 2017 in the Mammoth Lakes area, California

16. Graph showing water-temperature profiles for the depth interval 560 to 600 feet below top of casing for well 14A-25-1 from 2016 to 2017, Mammoth Lakes area, California

17. Graph showing water-temperature by depth below top of casing for well 28A-251, Mammoth Lakes area, California, 2016

18. Graph showing water-temperature by depth below top of casing for well 28A-251, Mammoth Lakes area, California, 2017

19. Graph showing time series of chloride concentrations in groundwater from Mammoth Community Water District production wells, 2015-17, Mammoth Lakes, California.

20. Graph showing correlation of chloride and boron concentrations in groundwater from a suite of Long Valley Caldera, California, geothermal wells and thermal springs in Hot Creek Gorge and at Big Alkali Lake sampled in 2005-07 and from the Long Valley exploratory well and warm springs at the fish hatchery sampled in 1999-2001

21. Plot of chloride and boron data for groundwater from Mammoth Community Water District wells and monitoring wells for samples collected 2015-17 and warm springs at the fish hatchery sampled in 1999-2001, Mammoth Lakes area, California

22. Graph showing correlations of chloride to lithium and chloride to bromide concentrations for water samples from sites shown in figure 20, including geothermal wells 44-16, 57-25, and 66-25 and Big Alkali Lake, Long Valley Caldera, California

23. Graph showing correlation of chloride and bromide concentrations for groundwater from Mammoth Community Water District wells and monitoring wells collected in 2015-17, Mammoth Lakes area, California 
24. Graph showing correlation of chloride and lithium concentrations for groundwater from Mammoth Community Water District wells and monitoring wells collected during 2015-17, Mammoth Lakes area, California

25. Graph showing relation between stable isotope ratios of hydrogen and oxygen in water for Mammoth Community Water District wells and monitoring wells for samples collected 2015-17 in Mammoth Lakes area, California

26. Graph showing digitally filtered water-level data for wells 14A-25-1, 28A-25-1, and 28A-25-2, Mammoth Lakes area, California, from August 12 to October 6, 2017......33

27. Graph showing well 14A-25-1 water-temperature profiles in August and November of 2017, Mammoth Lakes area, California, and boiling-point depth curve ....35

28. Graph showing well 14A-25-1 in Mammoth Lakes area, California, watertemperature profiles measured during 2017 and a hypothetical cooling profile ..............36

29. Graph showing water-temperature profiles measured in well 28A-25-1 in Mammoth Lakes area, California, from December 2016 to November 2017 and hypothetical warming profile.

30. Graph showing time series of total dissolved solids (TDS) concentration in well 14A-25-1 in Mammoth Lakes area, California, during calendar years 2016-17, and hypothetical increase in the TDS concentrations.

31. Graph showing time series of total dissolved solids (TDS) concentrations in water from well 28A-25-1 in Mammoth Lakes area, California, showing the low variability in TDS concentrations during calendar years 2016-17.

1-1. Borehole geophysical logs, well construction, and lithology summary for monitoring well 14A-25, Mammoth Lakes, California

1-2. Borehole geophysical logs, well construction, and lithology summary for monitoring well 28A-25, Mammoth Lakes, California

1-3. Borehole geophysical logs, well construction, and lithology summary for monitoring well BLM-1, Mammoth Lakes, California.

2-1. Diagram of the workflow process used to develop the digital atmosphericloading and Earth-tide filters for water levels from monitoring wells 28A-25-1, 28A-25-2, and 14A-25-1 in the area of Mammoth Lakes, California

2-2. Graphs showing continuous time-series pieces for wells 28A-25-1, 28A-25-2, and 14A-25-1 in the area of Mammoth Lakes, California

2-3. Graphs showing parsed, coincident (paired) water-level and barometricpressure time series for wells in the area of Mammoth Lakes, California ...

2-4. Graphs showing trended and detrended water-level and barometric-pressure parsed time series 28A-25-1_9 during August 16-November 28, 2017, 28A-25-2_4 during May 19-August 16, 2016, and 14A-25-1_8 during February 15-May 24, 2017, from wells 28A-25-1, 28A-25-2, and 14A-25-1 in the area of Mammoth Lakes, California...

2-5. Graphs showing estimates of constant barometric efficiency for detrended, parsed time series 14A-25-1_8, February 15-May 24, 2017, from well 14A25-1 in the area of Mammoth Lakes, California, based on linear least-squares regression of water level on barometric pressure using methods $1,2 \mathrm{a}, 2 \mathrm{~b}$, and $3 \ldots \ldots . . .57$

2-6. Graphs showing digitally filtered water levels fWL:BE2a and fWL:BE2b for detrended, parsed water-level and barometric-pressure time series from wells 28A-25-1, 28A-25-2, and 14A-25-1 in the area of Mammoth Lakes, California...... 
2-7. Graphs showng predicted fits, $\hat{y}_{\text {hpet }}$ (Predicted WL) and $\hat{\varepsilon}_{\text {Areal hp }}$ (Predicted tides), to the high-pass, detrended, parsed water-level ( $y_{h p}$, or WL) and theoretical areal-strain tide, $\varepsilon_{\text {Areal } h p}$ (Theoretical tides) time series, respectively, for 14A-25-1_5 during July 14-August 14, 2016, from well 14A-25-1 in the area of Mammoth Lakes, California.

2-8. Graphs showing predicted discrete amplitudes of the six principal Earth tides shown in table 2-3 computed for the high-pass detrended theoretical arealstrain tide and unscaled and $\mathrm{M}_{2}$-scaled water levels for 14A-25-1_5 during July 14-August 14, 2016, from well 14A-25-1 in the area of Mammoth Lakes, California

2-9. Graphs showing predicted unscaled and $\mathrm{M}_{2}$-scaled water-level responses to the six principal Earth tides shown in table 2-3 for the high-pass detrended water levels; and the tidally filtered, unscaled and $\mathrm{M}_{2}$-scaled, high-pass water levels for 14A-25-1_5 during July 14-August 14, 2016, from well 14A-25-1 in the area of Mammoth Lakes, California

2-10. Graphs showing unscaled and $\mathrm{M}_{2}$-scaled tidally filtered water levels for the detrended, parsed time series 14A-25-1_10 during August 9-November 29, 2017, and 14A-25-1_10mod during October 9-November 29, 2017, from well 14A-25-1 in the area of Mammoth Lakes, California, shown with detrended water levels and barometric pressure

2-11. Cross sections of idealized aquifer systems showing idealized well responses to atmospheric loading with principal sources of attenuation owing to drainage effects and idealized water-level responses to a step increase in barometric pressure or load...

2-12. Graphs showing power spectral densities computed for the parameters listed in table 2-6 for the non-tidally filtered, detrended, parsed series 28A-25-1_9 during August 16 to November 28, 2017, 28A_25-2_4 during May 19 to August 16, 2016, and 14A-25-1_8 during February 15 to May 24, 2017, from wells 28A-25-1, 28A-252, and 14A-25-1, in the area of Mammoth Lakes, California

2-13. Graphs showing computed atmospheric-loading frequency responses of water levels in terms of barometric efficiency, phase shift, and squared coherence for selected, detrended, parsed time series for wells 28A-25-1, 28A-25-2 and 14A25-1 in the area of Mammoth Lakes, California

2-14. Graphs showing filtered, detrended, parsed water-level time series shown with detrended water level and barometric pressure for parsed time series 28A-25-1_1 during January 14-February 22, 2016, 28A-25-1_9 during August 16November 28, 2017, 28A-25-2_1 during January 14-February 23, 2016, 28A-25-2_5 during January 8-February 10, 2017 and 14A-25-1_9 during May 24-August 9, 2017, from wells 28A-25-1, 28A_25-2, and 14A-25-1 in the area of Mammoth Lakes, California.

2-15. Graphs showing filtered, detrended, parsed water-level time series ytreFRF and ytresceBE computed using the frequency response function model reFRF, and the static-confined barometric efficiency rescBE, respectively, shown with detrended, parsed water level and barometric pressure for parsed time series 28A-25-2_7, August 9-0ctober 10, 2017, from well 28A-25-2 in the area of Mammoth Lakes, California, for a period influenced by nearby drilling.... 
2-16. Graphs showing filtered, detrended, parsed water-level time series ytreFRF:ETM2 and ytetrescBE, filtered using the frequency response function model reFRF:ETM2, and the estimated static-confined barometric efficiency etresc $B E$, respectively, shown with detrended, parsed water level and barometric pressure for parsed time series 14A-25-1_10, August 9-November 29, 2017, from well 14A-25-1 in the area of Mammoth Lakes, California, for a period influenced by flow testing in the nearby 14-25 production well

2-17. Graphs showing reconstructed, digitally filtered water-levels trytreFRF or trytreFRF:ETM2 shown with water-level and barometric-pressure for parsed time series from wells 28A-25-1, 28A-25-2, and 14A-25-1 in the area of Mammoth Lakes, California, for the period influenced by the flow test in production well 14-25...86

\section{Tables}

1. Wells monitored or sampled, including site identifiers, data type, and frequency of data collection, Mammoth Lakes vicinity, California, 2015-17

2. Water-quality parameters, U.S. Geological Survey parameter codes, measurement units, and reporting limits for constituents analyzed in groundwater samples, Mammoth Lakes vicinity, California, 2015-17.

3. Water chemistry of selected groundwater samples, Mammoth Lakes vicinity, California

2-1. Parsed time-series parameters for wells 28 A-25-1 during January $14,2016-$ December 31, 2017, 28A-25-2 during January 14, 2016-December 31, 2017, and 14A-25-1 during November 13, 2015-December 18, 2017, in the area of Mammoth Lakes, California...

2-2. Estimates of constant barometric efficiency determined using methods 1, 2a, $2 b$, and 3 for each of the parsed time series shown in table $2-1$, other than those with series numbers in underline font, for wells 28A-25-1, 28A-25-2, and 14A-25-1 in the area of Mammoth Lakes, California.

2-3. Frequencies, periods, and indices used in the analysis of the six principal Earth tides

2-4. Results of tidal harmonic analysis of selected, detrended, parsed time series for wells 28A-25-1 during January 14, 2016-December 31, 2017, 28A-25-2 during January 14, 2016-December 31, 2017, and 14A-25-1 during November 13, 2015November 29, 2017, in the area of Mammoth Lakes, California.

$2-5$. Results of tidal analysis of water-level responses to the six principal Earth tides for discrete segments of selected, detrended, parsed time series from well 14A-25-1 in the area of Mammoth Lakes, California, during November 13, 2015November 9, 2017

2-6. Parameters used to compute frequency-response functions for the parsed time series analyzed for frequency response to atmospheric loading for wells $28 \mathrm{~A}$ 25-1 during January 14, 2016-December 31, 2017, 28A-25-2 during January 14, 2016-December 31, 2017, and 14A-25-1 during November 13, 2015-November 29, 2017, in the area of Mammoth Lakes, California.

3-1. Vertical water-temperature profiles for well 14A-25-1, Mammoth Lakes, California, 2016-17.

3-2. Vertical water-temperature profiles for well 28A-25-1, Mammoth Lakes, California, 2016-17 


\section{Conversion Factors}

U.S. customary units to International System of Units

\begin{tabular}{|c|c|c|}
\hline Multiply & By & To obtain \\
\hline \multicolumn{3}{|c|}{ Length } \\
\hline inch (in.) & 2.54 & centimeter $(\mathrm{cm})$ \\
\hline inch (in.) & 25.4 & millimeter (mm) \\
\hline inch (in.) & $25,400.0$ & micrometer $(\mu \mathrm{m})$ \\
\hline foot $(\mathrm{ft})$ & 0.3048 & meter $(\mathrm{m})$ \\
\hline mile (mi) & 1.609 & kilometer (km) \\
\hline mile, nautical (nmi) & 1.852 & kilometer $(\mathrm{km})$ \\
\hline
\end{tabular}

International System of Units to U.S. customary units

\begin{tabular}{|c|c|c|}
\hline Multiply & By & To obtain \\
\hline \multicolumn{3}{|c|}{ Length } \\
\hline micrometer $(\mu \mathrm{m})$ & 0.00003937 & inch (in.) \\
\hline centimeter $(\mathrm{cm})$ & 0.3937 & inch (in.) \\
\hline meter $(\mathrm{m})$ & 3.281 & foot $(\mathrm{ft})$ \\
\hline meter $(\mathrm{m})$ & 1.094 & yard (yd) \\
\hline \multicolumn{3}{|c|}{ Volume } \\
\hline milliliter (mL) & 0.03381402 & ounce, fluid (fl.oz) \\
\hline liter $(\mathrm{L})$ & 33.81402 & ounce, fluid (fl. oz) \\
\hline \multicolumn{3}{|c|}{ Mass } \\
\hline gram $(\mathrm{g})$ & 0.03527 & ounce, avoirdupois (oz) \\
\hline kilogram (kg) & 2.205 & pound avoirdupois (lb) \\
\hline kilogram per second $(\mathrm{kg} / \mathrm{s})$ & 2.205 & pound per second $(\mathrm{lb} / \mathrm{s})$ \\
\hline \multicolumn{3}{|c|}{ Pressure } \\
\hline kilopascal (kPa) & 0.009869 & atmosphere, standard (atm) \\
\hline kilopascal (kPa) & 0.01 & bar \\
\hline kilopascal (kPa) & 0.2961 & inch of mercury at $60^{\circ} \mathrm{F}$ (in $\mathrm{Hg}$ ) \\
\hline kilopascal (kPa) & 0.1450 & pound-force per inch (lbf/in) \\
\hline \multicolumn{3}{|c|}{ Energy } \\
\hline joule $(\mathrm{J})$ & 0.0000002 & kilowatthour $(\mathrm{kWh})$ \\
\hline
\end{tabular}

Temperature in degrees Celsius $\left({ }^{\circ} \mathrm{C}\right)$ may be converted to degrees Fahrenheit $\left({ }^{\circ} \mathrm{F}\right)$ as

$$
{ }^{\circ} \mathrm{F}=\left(1.8 \times{ }^{\circ} \mathrm{C}\right)+32 .
$$

Temperature in degrees Fahrenheit $\left({ }^{\circ} \mathrm{F}\right)$ may be converted to degrees Celsius $\left({ }^{\circ} \mathrm{C}\right)$ as

$$
{ }^{\circ} \mathrm{C}=\left({ }^{\circ} \mathrm{F}-32\right) / 1.8 .
$$

This report uses dual units (both U.S. customary units and International System of units) to reflect the native measurement units of the various data types presented. 


\section{Datum}

Vertical coordinate information is referenced to the North American Vertical Datum of 1988 (NAVD 88).

Horizontal coordinate information is referenced to the North American Datum of 1983 (NAD 83).

\section{Supplemental Information}

Specific conductance is given in microsiemens per centimeter at 25 degrees Celsius $(\mu \mathrm{S} / \mathrm{cm}$ at $\left.25^{\circ} \mathrm{C}\right)$.

Concentrations of chemical constituents in water are given in either milligrams per liter (mg/L) or micrograms per liter $(\mu \mathrm{g} / \mathrm{L})$.

\section{Abbreviations}

$\begin{array}{ll}\text { BAL } & \text { Big Alkali Lake } \\ \text { BLM } & \text { Bureau of Land Management } \\ \text { BLS } & \text { below land surface } \\ \text { BTC } & \text { below top of casing } \\ \text { C } & \text { Celsius } \\ \text { CD-4 } & \text { Casa Diablo IV Geothermal Power Project } \\ \text { FA } & \text { filtered acidified } \\ \text { FHCD } & \text { Fish Hatchery CD spring group } \\ \text { FU } & \text { filtered untreated } \\ \text { g/kg } & \text { grams per kilogram } \\ \text { g/L } & \text { grams per liter } \\ \text { GMWL } & \text { Global Meteoric Water Line } \\ \text { HCFW } & \text { Hot Creek Gorge Spring } \\ \text { IBW } & \text { inorganic blank water } \\ \text { LVEW } & \text { Long Valley exploratory well } \\ \text { MCWD } & \text { Mammoth Community Water District } \\ \text { NWIS } & \text { National Water Information System } \\ \text { NWOL } & \text { National Water Quality Laboratory } \\ \text { PRT } & \text { platinum resistance temperature } \\ \end{array}$




$\begin{array}{ll}\text { RDP } & \text { Research Drilling Program } \\ \text { RPD } & \text { relative percent difference } \\ \text { TDS } & \text { total dissolved solids } \\ \text { USGS } & \text { U.S. Geological Survey }\end{array}$




\title{
Hydraulic, Geochemical, and Thermal Monitoring of an Aquifer System in the Vicinity of Mammoth Lakes, Mono County, California, 2015-17
}

\author{
By James F. Howle, William C. Evans, Devin L. Galloway, Paul A. Hsieh, Shaul Hurwitz, Gregory A. Smith, and \\ Joseph Nawikas
}

\section{Abstract}

Since 2014, the U.S. Geological Survey has been working in cooperation with the Bureau of Land Management, Mono County, Ormat Technologies, Inc., and the Mammoth Community Water District to design and implement a groundwater-monitoring program for the proposed Casa Diablo IV Geothermal Power Project in Long Valley Caldera, California, to characterize baseline groundwater-level, watertemperature, and water-chemistry conditions at dedicated monitoring wells and municipal supply wells. The publicly available data and the analyses provided here represent quality-assured and peer-reviewed information to help with the management of the thermal and non-thermal water resources beneath and in the vicinity of the town of Mammoth Lakes, California.

The methods of data collection for continuous water levels and quarterly water-temperature profiles for two 600-foot-deep monitoring wells during 2016 through 2017 are discussed. Also discussed are the methods of water-sample collection and characterizations of the water chemistry in numerous wells in the multilayered aquifer system beneath Mammoth Lakes. Additionally, the methodology used to develop digital (mathematical) filters to remove or reduce the effects of barometric pressure and solid Earth tides on the continuous water-level records is discussed.

Digitally filtered water levels for a 2017 flow test of a deep geothermal production well are described, and various aquifer responses observed during the flow test are discussed. These are further considered in a companion evaluation of potential physical and chemical influences on the water-level data collected during the flow test.
The digitally filtered water-level data indicated that some hydraulic communication exists between the deep geothermal aquifer and shallow groundwater aquifer at the location of the flow test, northeast of Mammoth Lakes. Groundwaterchemistry data from three wells indicated that shallow groundwater naturally mixes with a small component of geothermal water along the northern periphery of the shallow aquifer system at Mammoth Lakes.

\section{Introduction}

Since 1987, the U.S. Geological Survey (USGS) has conducted hydrologic monitoring to help assess potential effects from geothermal power development near Mammoth Lakes, California. As part of the Long Valley Hydrologic Advisory Committee (LVHAC), the USGS has monitored fluid pressure (hydraulic heads or water levels) and temperature (Farrar and others, 2010) in the shallow cold-water and deeper thermal aquifers in the south moat of the Long Valley Caldera (fig. 1), temperature and discharge of thermal springs, and water quality of streams and springs. These publicly available data have been provided to the LVHAC, which is composed of representatives of Federal, State, County, and local agencies as well as the geothermal power developer Ormat Technologies, Inc. (Ormat), for the oversight and management of the geothermal resource on public lands. Hydrologic monitoring was initially focused on potential impacts of fluid production and injection at the Casa Diablo geothermal power plant at the intersection of US Highway 395 and California State Route 203, approximately 2.7 miles (mi) east of the town of Mammoth Lakes (fig. 2; Howle and Farrar, 1996, 2001). 


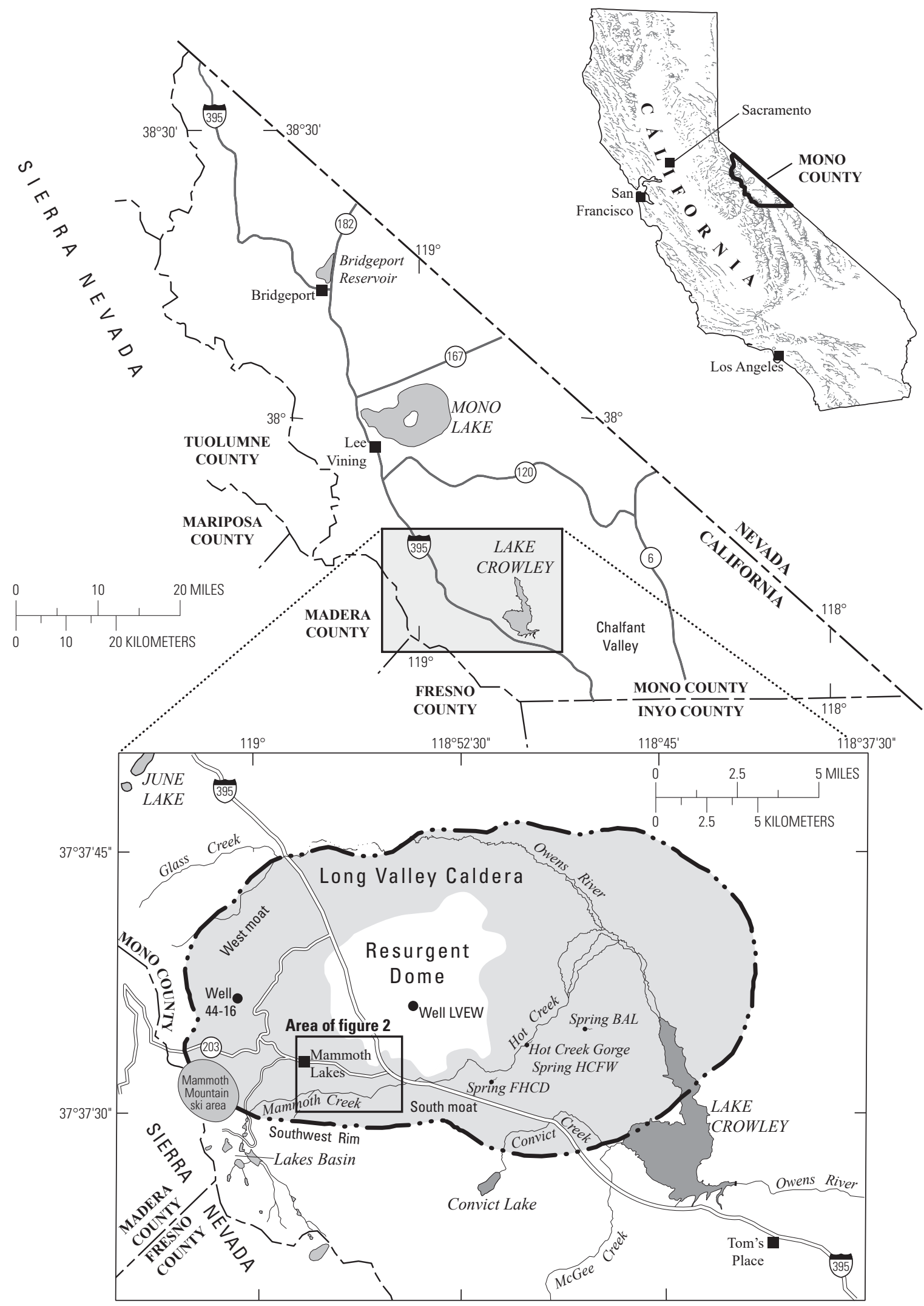

Figure 1. Location of study area, selected thermal springs, and wells in Long Valley Caldera, Mono County, California. LVEW, Long Valley exploratory well. 


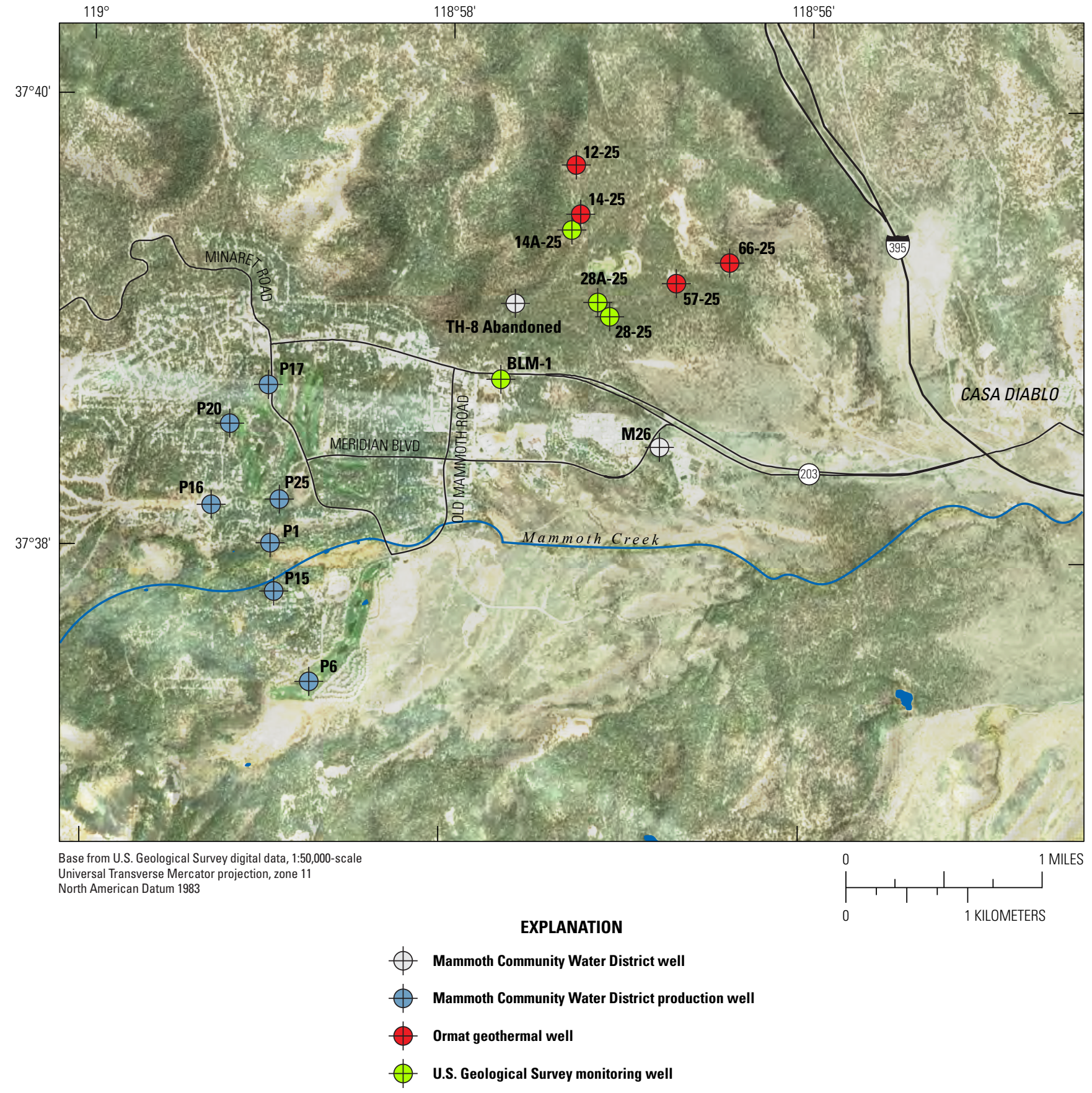

Figure 2. Mammoth Lakes area, California, showing the location of monitoring sites and other features. 
In 2010, Ormat proposed expanding geothermal development to an area that is approximately 1 mi northeast of the town of Mammoth Lakes (fig. 2). This new geothermal power generation facility is the Casa Diablo IV Geothermal Power Project (CD-4 project). The Bureau of Land Management (BLM) is the permitting agency and regulatory authority for use of the subsurface federal mineral estate. All operations conducted on federal geothermal leases are subject to BLM approval. As a condition of approval for the CD-4 project, the BLM required the "development and implementation of a cooperative shallow ground water monitoring plan" (Bureau of Land Management, 2013), known as the Groundwater Monitoring and Response Plan (GMRP). The purpose of the GMRP "is to establish a monitoring program to detect any direct or indirect effects on the municipal water supply for the Town of Mammoth Lakes that may occur from geothermal production and injection associated with the CD-4 Project" (Bureau of Land Management, 2018). The GMRP established a monitoring well network of shallow groundwater and geothermal reservoir wells to be monitored for pressure (water level), temperature, and geochemical parameters, depending on well type. The GMRP also established a frequency schedule and party responsible for the data collection. Since 2014, the USGS has been working in cooperation with the BLM, Mono County, Ormat, and the Mammoth Community Water District (MCWD) to implement this BLM-required groundwatermonitoring program.

\section{Geologic Setting}

The tectonic setting and volcanic history of Long Valley have been discussed by many researchers (for example, Bailey and others, 1976; Hill and others, 1985; Suemnicht and Varga, 1988; Hildreth, 2004, 2017). The massive eruption that formed Long Valley Caldera 767,000 years ago deposited the Bishop Tuff on top of a rapidly subsiding caldera floor. During the next 125,000 years, eruptions in the caldera produced the lavas and pyroclastic deposits of the "early rhyolite" (Bailey and others, 1976). After emplacement, the early rhyolite in the central part of the caldera was uplifted forming the "resurgent dome" (fig. 1). The upper surface of the structurally domed early rhyolite gently slopes toward the caldera walls, which formed "moats" around the resurgent dome. Starting about 190,000 years ago, a sequence of andesitic to basaltic lava flows, interbedded with glacial tills, filled the south moat (Mammoth Creek and Hot Creek drainage, fig. 1) to the current topography (Hildreth and others, 2014). Mammoth Mountain, on the southwest topographic rim of the Long Valley Caldera, was formed during eruptions 50,000 to 100,000 years ago (Hildreth and others, 2014).

Beneath the town of Mammoth Lakes, the shallowgroundwater aquifer system used for the municipal water supply is primarily in the interbedded "south moat" units (lavas and tills). The thickness of south moat units generally decreases northward toward the CD-4 project area where the top of the early rhyolite becomes exposed at the surface. The deep geothermal aquifer used for electric power generation is in the lower part of the early rhyolite and the underlying Bishop Tuff. A fundamental hydrologic question in the Mammoth Lakes and CD-4 project area is, to what degree does the early rhyolite hydraulically isolate the shallow and deep aquifer systems?

\section{Geothermal System}

Uneven collapse of the caldera floor during eruption, simultaneous deposition of the Bishop Tuff, and subsequent offsets between collapse blocks produced near-vertical fracture pathways (faults) to the basement rocks, which facilitated deep fluid convection (Suemnicht and Varga, 1988). In the faultbounded blocks of caldera fill (Bishop Tuff and early rhyolite), there are laterally continuous zones of relatively high fluid permeability, creating near-horizontal flow paths. A simplified conceptual flow-path of the geothermal system in the Long Valley Caldera begins with up-flow of hot water in the west moat of the caldera from a deep source reservoir, followed by lateral flow to the southeast along a near-horizontal aquifer (Sorey, 1985; Sorey and others, 1991; Shevenell and others, 1987; Goff and others, 1991; Brown and others, 2013; Evans, 2017).

The deep source reservoir is thought to be in metamorphic basement rocks approximately 2 miles north of the town of Mammoth Lakes (Peacock and others, 2016). Hot water, at a temperature of approximately 220 degrees Celsius $\left({ }^{\circ} \mathrm{C}\right)$ and a mass flow rate of about 370 kilograms per second $(\mathrm{kg} / \mathrm{s})$, rises from this reservoir but does not reach the land surface north of the town of Mammoth Lakes (Suemnicht and Varga, 1988; Sorey and others, 1991). The ascending water and gas encounter permeable zones hundreds of meters below land surface and flow laterally to the southeast beneath the CD-4 project area and Casa Diablo geothermal well field toward discharge points in the Hot Creek gorge and isolated thermal springs farther east (fig. 1). In the lateral aquifer, the thermal water is progressively diluted by non-thermal groundwater and is chemically altered through reactions with the host rocks. Mixing relations among chloride, boron, and the stable isotopes of hydrogen and oxygen are consistent with a scenario in which (1) the deep geothermal reservoir is recharged by precipitation on the caldera's western rim; (2) water resides in the reservoir long enough to acquire a substantial amount of dissolved solids from the reservoir rocks as well as a distinctive shift in the oxygen-isotope value; (3) the thermal water is diluted as it flows eastward, predominantly by old groundwater recharged in the eastern part of the caldera; and (4) other thermal or non-thermal water does not play a detectable role in controlling water chemistry or isotopic compositions (White and others, 1990; Sorey and others, 1991; Brown and others, 2013; Evans, 2017). 


\section{Electric Power Generation}

Geothermal-water extraction for electric power generation began at Casa Diablo in early 1985 at an initial water production rate of approximately $230 \mathrm{~kg} / \mathrm{s}$ (Howle and others, 2003) and a gross generation capacity of about 10 megawatts electric (MWe). In late 1990, geothermal-water extraction at Casa Diablo was increased to approximately $850 \mathrm{~kg} / \mathrm{s}$ to supply two new electric generation plants that have a combined capacity of $30 \mathrm{MWe}$, bringing the gross power generation capacity to $40 \mathrm{MWe}$. Additional new wells in the CD-4 project area are expected to increase the gross power generation capacity to approximately $80 \mathrm{MWe}$ (Bureau of Land Management, 2018). In late 2006, two new production wells (57-25 and 66-25; figs. 2, 3) were brought on line to replace cooler production wells at Casa Diablo. As of 2019, these two wells, about 1.25 mi northeast of Mammoth Lakes, provided about 50 percent of the geothermal water required to operate the three binary cycle power plants at Casa Diablo. The cooled water is injected into the Bishop Tuff at Casa Diablo. Injection depths are greater than production depths (in the early rhyolite) to minimize thermal breakthrough, but the consequent reduction in pressure support and cooling in the geothermal aquifer have resulted in land-surface subsidence at Casa Diablo (Howle and others, 2003). Pressure reduction in the geothermal aquifer, caused by geothermal water production, has also led to increased boiling in the geothermal aquifer or increased up-flow of steam, producing patches of hot ground (Bergfeld and others, 2006, 2015; Vaughan and others, 2018). Since the geothermal wells 57-25 and 66-25 began producing water (2006), the areal extent of thermal ground, vegetation die off, and carbon dioxide $\left(\mathrm{CO}_{2}\right)$ soilgas emissions has enlarged to include areas near those wells (Bergfeld and others, 2015). During the same time, hydrogen sulfide $\left(\mathrm{H}_{2} \mathrm{~S}\right)$ gas surfaced in the nearby Shady Rest fumarole (fig. 3; Bergfeld and others, 2015). The binary working fluid (isobutane) from the Casa Diablo power plant, which leaked into the geothermal water during heat exchange and prior to reinjection, has migrated $2 \mathrm{mi}$ up-gradient through the geothermal aquifer and has also been detected at the Shady Rest fumarole (Bergfeld and others, 2015). The temporal and spatial association of these gas emissions indicate boiling in the geothermal aquifer in the CD-4 project area (Sorey and others, 1998; Bergfeld and others, 2015) and that fluidflow pathways exist from the geothermal aquifer to the land surface.

\section{Purpose and Scope}

The purposes and scope of this report are to (1) describe the monitoring well network in the Mammoth Lakes area as of late 2017 ; (2) document the methods used to collect groundwater-level data, groundwater-temperature profiles, groundwater-chemistry data, and associated quality-control measures; (3) describe the development of digital filters used to remove or reduce barometric pressure and Earth-tide effects in water-level data; (4) present baseline water-level and temperature datasets collected from late 2015 to 2017; (5) compare the chemical constituents, constituent ratios, and isotopic values in groundwater to those of the deep geothermal water; (6) discuss the digitally filtered water-level records from the monitoring wells during a 28-day flow test of a geothermal well (14-25); (7) demonstrate the accuracy of water-level data collected at the shallow monitoring wells; and (8) demonstrate the utility of water-level, water-temperature, and water-chemistry data from wells to evaluate the degree of hydrologic connection between shallow groundwater and deep geothermal water. This report is not intended to be a comprehensive assessment of the shallow groundwater and deep geothermal systems in the Mammoth Lakes area, but rather an initial evaluation of monitoring data collected for the period 2015 to 2017.

The purpose of the USGS groundwater-monitoring program related to the $\mathrm{CD}-4$ project is to provide highquality, publicly available data to Federal, State, County, and municipal agencies responsible for making resourcemanagement decisions regarding the thermal and cold groundwater resources. The scope of the USGS monitoring program includes data collection from a network of shallow and deep wells such as continuous water-level (equivalent hydraulic head or fluid pressure) data, quarterly watertemperature profiles, and quarterly water-chemistry data. At two locations, the groundwater-monitoring program uses wells that are in hydraulic communication with the shallowgroundwater aquifer and a nearby well that taps the underlying geothermal system (wells 14A-25 and 14-25, 28A-25 and $28-25$; fig. 3). A primary hydrologic topic of interest is the degree of hydraulic connection between the deep geothermal aquifer and shallow-groundwater system. 


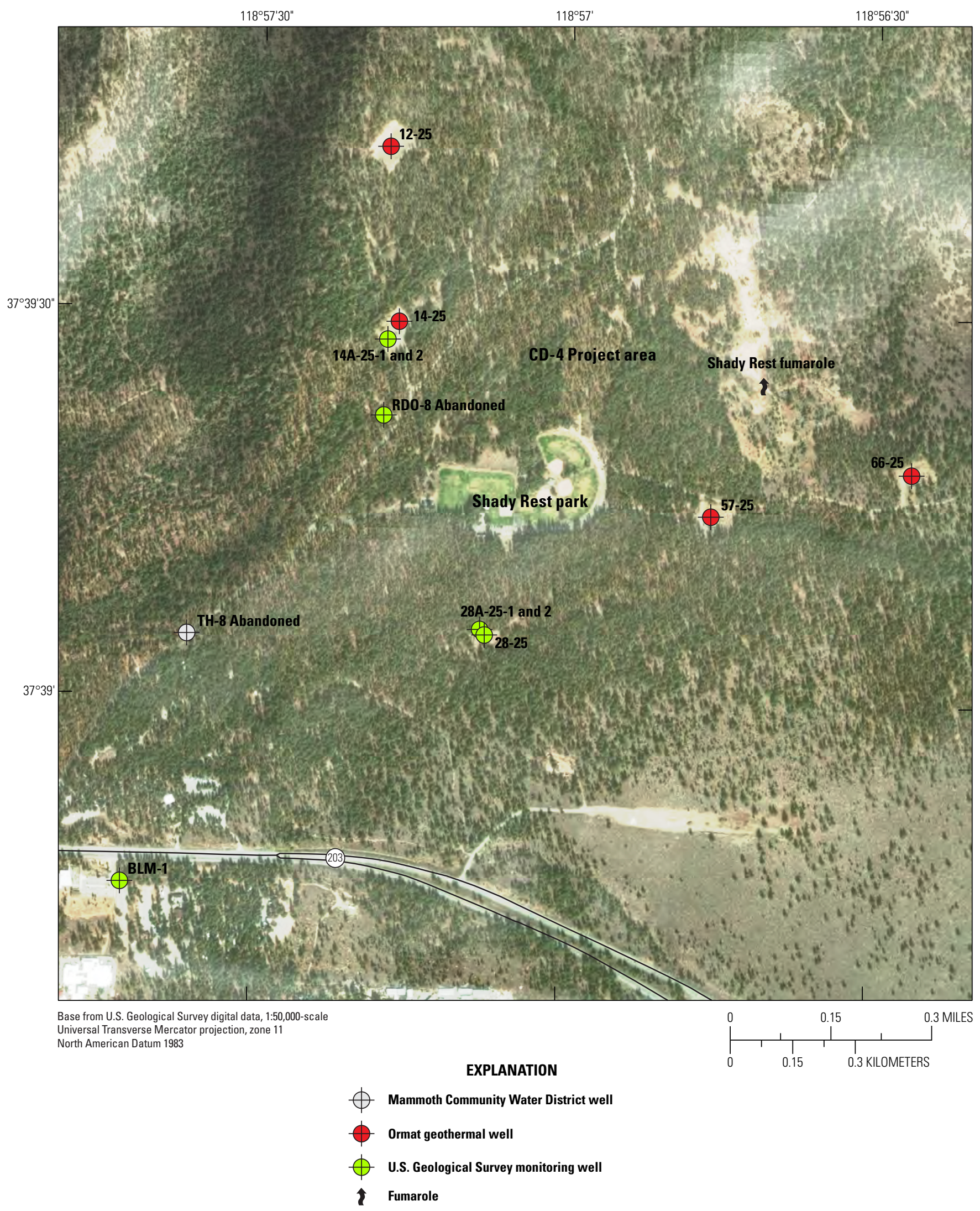

Figure 3. Casa Diablo IV project area showing the locations of monitoring sites and selected features in the Mammoth Lakes area, California. 


\section{Monitoring-Well Network}

\section{Shallow Multiple-Completion Monitoring Wells}

In August of 2015, two multiple-completion monitoring wells (14A-25 and 28A-25, fig. 3) were drilled by the USGS Research Drilling Program (RDP). The depths of these wells, about 600 feet (ft) below land surface (BLS), were based on drillers' logs of the nearest wells (TH8 and M26, fig. 2) and were designed to penetrate the shallow-aquifer system. Both monitoring wells were constructed as multiple-completion wells such that screens in the 2-inch-diameter casings provide hydraulic communication with the surrounding formation at different depth intervals that are hydraulically isolated from each other in the well bore by geothermal-grade grout. The multiple-completion construction allows for the static fluid pressure (hydraulic head) to be measured for discrete depth intervals. Both the 14A-25-1 and 28A-25-1 wells were constructed with a screened interval open to the surrounding formation from 575 to $595 \mathrm{ft} \mathrm{BLS}$ (appendix 1). Shallower wells were also constructed at both sites, with screened intervals from 470 to $490 \mathrm{ft}$ BLS in 14A-25-2 and from 440 to $460 \mathrm{ft}$ BLS in 28A-25-2. The depths of the screened intervals were based on a suite of borehole geophysical logs collected from the open well bores after the target well-bore depths were reached.

In December 2017, a third multiple-completion monitoring well (BLM-1; fig. 3) was drilled by the USGS RDP to a total depth of $602 \mathrm{ft}$ BLS. The deeper well (BLM1-1) was screened from 520 to $540 \mathrm{ft} \mathrm{BLS}$, and the shallow well (BLM-1-2) from 415 to $435 \mathrm{ft}$ BLS. For details regarding the drilling methods, borehole geophysical logging, and construction of wells at sites 14A-25, 28A-25 and BLM-1, see appendix 1 .

At the 14A-25 site, none of the south moat units, previously discussed, were evident in drill cuttings, but the early rhyolite was identified from 200 to $600 \mathrm{ft}$ BLS (appendix fig. 1-1). At the 28A-25 site, approximately $2,600 \mathrm{ft}$ southeast of the 14A-25 site (fig. 3), "south moat" lavas were encountered from 39 to $75 \mathrm{ft}$ BLS, which overlie the early rhyolite that extends from 85 to $602 \mathrm{ft}$ BLS (appendix fig. 1-2). The lithology at the BLM-1 site, approximately 3,400 ft southwest of the 28A-25 site (fig. 3), is composed entirely of the interbedded south moat lavas and tills (appendix fig. 1-3). Although the lithology at the $14 \mathrm{~A}-25,28 \mathrm{~A}-25$, and BLM-1 monitoring wells sites varies horizontally, the potentiometric head at the three sites (watersurface elevations in the wells) was within an approximate 30 -ft elevation range (https://waterdata.usgs.gov/nwis), and the potentiometric surface gently sloped to the north (highest at BLM-1 and lowest at 14A-25).

\section{Deep Geothermal Monitoring Well}

In October of 2017, a deep geothermal monitoring well (28-25, fig. 3) was drilled by Geodrill LLC, a subsidiary drilling company of Ormat, close to the shallower monitoring wells at site 28A-25 (fig. 3). The well, approximately $1,618 \mathrm{ft}$ deep, penetrates the geothermal aquifer (about $190{ }^{\circ} \mathrm{C}$ ) at approximately $1,400 \mathrm{ft} \mathrm{BLS}$. A 2-inch-diameter casing that has slotted perforations from 1,397 to 1,612 ft BLS is open to approximately the lower $100 \mathrm{ft}$ of the early rhyolite and upper $100 \mathrm{ft}$ of the underlying Bishop Tuff. Future waterlevel, temperature, and chemistry data collected from this deep well and the shallower monitoring site BLM-1 are important additions to the monitoring program.

\section{Mammoth Community Water District Wells}

Beginning in February of 2015, the USGS began a quarterly schedule of water-chemistry sampling of eight MCWD wells (seven production wells and one monitoring well; table 1 and fig. 2). The purpose of the sampling is to characterize the natural variability of water chemistry in the shallow-aquifer system prior to the expansion of geothermal development. The MCWD well P17 has been sampled intermittently by the USGS since 2011, allowing for a longer time series of some, but not all, of the water-chemistry constituents analyzed. 
Table 1. Wells monitored or sampled, including site identifiers, data type, and frequency of data collection, Mammoth Lakes vicinity, California, 2015-17.

[BLM, Bureau of Land Management; ID, identifier; MCWD, Mammoth Community Water District; USGS, U.S. Geological Survey; —, not applicable]

\begin{tabular}{|c|c|c|c|c|}
\hline \multirow[b]{2}{*}{ Well owner and name } & \multirow[b]{2}{*}{ USGS site ID } & \multicolumn{3}{|c|}{ Data type and frequency } \\
\hline & & Water-level & $\begin{array}{c}\text { Vertical } \\
\text { temperature profile }\end{array}$ & Water chemistry \\
\hline BLM-1_01 (deep) & 373845118574201 & Continuous & Quarterly & Quarterly \\
\hline BLM-1_02 (shallow) & 373845118574202 & Continuous & Quarterly & Quarterly \\
\hline BLM 14A-25_01 (deep) & 373927118571701 & Continuous & Quarterly & Quarterly \\
\hline BLM 14A-25_02 (shallow) & 373927118571702 & Continuous & Quarterly & Quarterly \\
\hline BLM 28A-25_01 (deep) & 373904118570701 & Continuous & Quarterly & Quarterly \\
\hline BLM 28A-25_02 (shallow) & 373904118570702 & Continuous & Quarterly & Quarterly \\
\hline Ormat $28-25$ & 373905118570701 & Continuous & Quarterly & Quarterly \\
\hline MCWD P1 & 373803118585901 & - & - & Quarterly \\
\hline MCWD P6 & 373727118583901 & - & - & Quarterly \\
\hline MCWD P15 & 373748118585201 & - & - & Quarterly \\
\hline MCWD P16 & 373811118591801 & - & - & Quarterly \\
\hline MCWD P17 & 373843118585901 & - & - & Quarterly \\
\hline MCWD P20 & 373833118590801 & - & - & Quarterly \\
\hline MCWD P25 & 373813118585401 & - & - & Quarterly \\
\hline MCWD M26 & 373829118564801 & - & - & Quarterly \\
\hline
\end{tabular}

\section{Methods}

This section describes the methods used to collect waterlevel data, water-temperature profiles, and water-chemistry samples at monitoring sites 14A-25, 28A-25, and BLM-1 and water-chemistry samples from the MCWD wells. Also described is the development of digital filters used to remove or reduce the effects of barometric pressure and Earth tides in the water-level records at monitoring sites 14A-25 and 28A-25. The use of the term "filter" or "filtered" with respect to water levels refers to mathematical filters or digital filters, as opposed to the physical filters used to remove suspended particles in water-quality samples.

\section{Continuous Water-Level Records}

A continuous record of groundwater level (equivalent hydraulic head) is typically collected with a submersible pressure transducer that measures the height of the water column above the transducer. Initially, the height of the water column above the transducer is coupled with a physical measurement of the water-level depth below land surface to establish a transducer datum relative to the land surface. Subsequent transducer output values (height of the water column above the transducer) are subtracted from the transducer datum to yield a water level BLS.

During regular site visits, calibration checks of a pressure transducer's accuracy are made by comparing an instantaneous measurement of the water level BLS (made with a calibrated electric water-level sounder; Fulford and Clayton, 2015) to a corresponding instantaneous transducer output value. The height of the water column above the transducer (output value) is subtracted from the transducer datum to yield an instantaneous computed water level BLS. The computed value is compared to the measured value, and the difference, if any, is applied to the computed water-level time series as a linear prorated correction between sequential calibration checks. A complete description of qualityassurance procedures for water-level records is available at https://pubs.usgs.gov/tm/1a1/pdf/GWPD16.pdf.

\section{Water-Level Sensors in the Warm Monitoring Wells}

Submersible pressure transducers were originally installed in the shallow and deep wells at site 28A-25, but the premature failure of these submersible transducers was likely due to elevated water temperature in the wells (about $50^{\circ} \mathrm{C}$ ), which was near the maximum operable temperature of most commercially available submersible transducers. Consequently, an alternative gas-bubbler technique (Sauer and Turnipseed, 2010), consisting of an up-hole pressure transducer connected to a nitrogen-gas-filled line, was used to measure hydraulic head changes in both wells at site 28A25 . This same technique was used at site $14 \mathrm{~A}-25$ because the water temperature at all depths in both wells was greater than $60{ }^{\circ} \mathrm{C}$. The up-hole pressure transducer system converted gaspressure changes in the nitrogen-gas-filled line to equivalent water-level changes. When the water level in the well rose, the gas pressure in the line rose. Conversely, when the water level in the well declined, the gas pressure sensed by the transducer declined proportionally. 
A gas line made of high-density polyethylene tubing (fig. 4) was securely attached to a weighted stainless-steel cable to prevent the tubing from stretching due to heat or gravity. The weighted cable kept the open end of the gas line (orifice) at a constant depth below land surface. The constant depth ensured that the transducer output value (height of the water column above the orifice) reflected water-level changes in the well and not movement of the gas line. The anchored upper end of the gas line was connected to a continuous-flow (conoflow) regulator (fig. 4). The conoflow provided a steady flow of nitrogen gas through the gas line and had a monitoring port for the up-hole pressure transducer.

In both monitoring wells at sites $14 \mathrm{~A}-25$ and $28 \mathrm{~A}-25$, Paroscientific ${ }^{\circledR}$ model PS-2 up-hole pressure transducers were used. The PS-2 transducers have a pressure range of 0-22 pounds per square inch (PSI), or approximately $50.78 \mathrm{ft}$ of water, and are gaged relative to atmospheric pressure. The accuracy of the PS-2 transducers is equivalent to $0.01 \mathrm{ft}$ of water.
Similar to procedures for a submersible transducer previously described, the height of the water column above the orifice (transducer output value) was initially combined with a physical measurement of the water level BLS to establish an orifice datum relative to the land surface. Subsequent transducer output values were subtracted from the orifice datum to yield a water level BLS.

Also similar to those for a submersible transducer, the calibration checks of an up-hole pressure transducer's accuracy were assessed by comparing an instantaneous measurement of the water level BLS with a corresponding instantaneous transducer output value (Cunningham and Schalk, 2011). The height of the water column above the orifice was subtracted from the orifice datum to yield an instantaneous computed water level BLS. The computed value was compared to the measured value, and any difference was applied to the computed water-level time series as a linear prorated correction between sequential calibration checks.

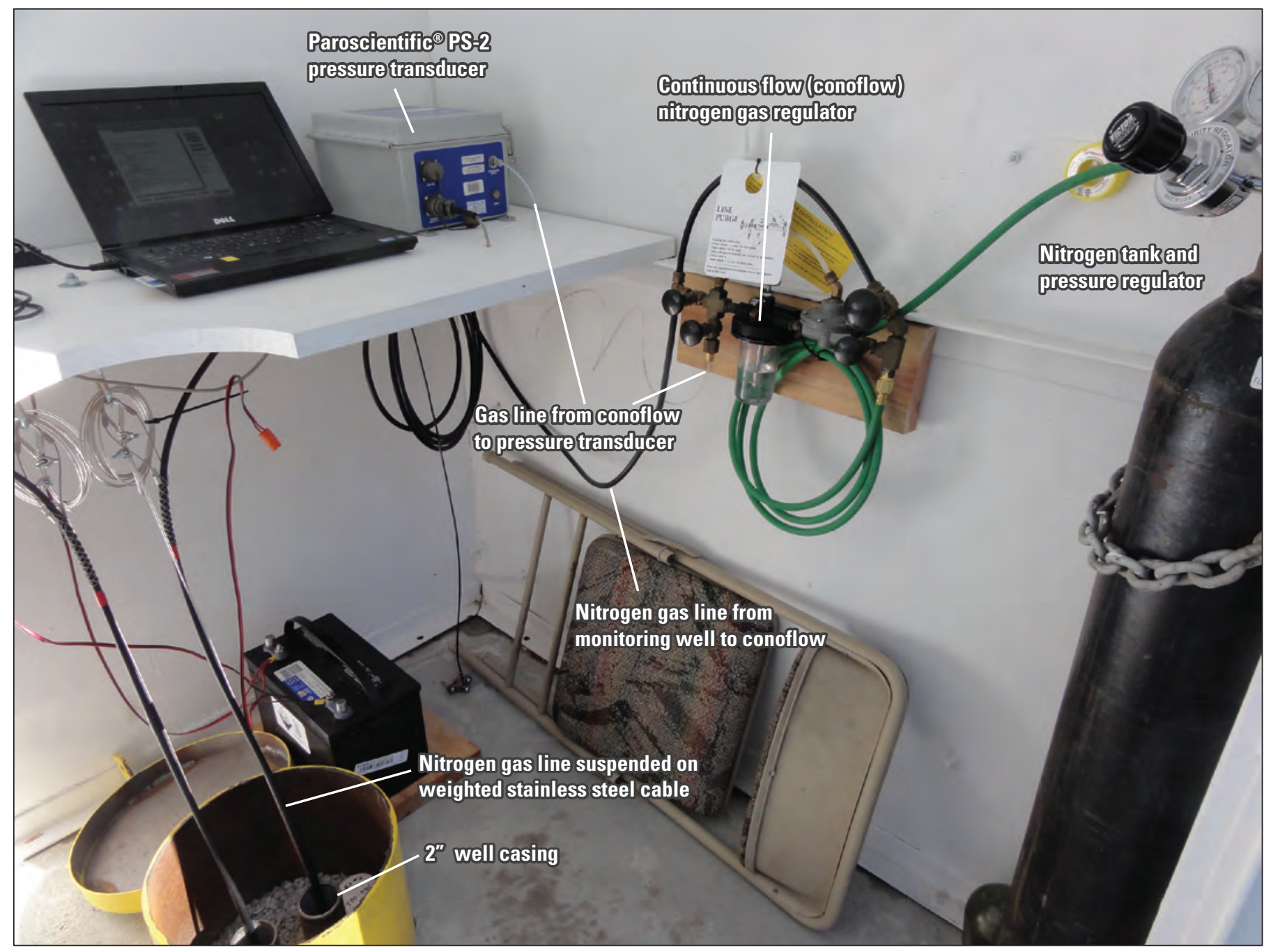

Figure 4. Typical U.S. Geological Survey hot-water-well fluid-pressure monitoring system consisting of an up-hole pressure transducer, continuous-flow nitrogen gas regulator, and fixed-depth nitrogen gas line. 


\section{Development of Digital Atmospheric-Loading and Earth-Tide Filters}

Because water-level responses to barometric-pressure variations (atmospheric loading) and solid Earth tides can potentially mask subtle water-level responses to other hydrologic stresses, it is essential to filter water-level records to mitigate atmospheric-loading and Earth-tide effects. For monitoring wells 14A-25-1, 28A-25-1, and 28A-25-2, digital filters were developed to remove the water-level responses to atmospheric loading from the water-level records. A simplified version of the workflow process that was used to develop the digital atmospheric-loading and Earth-tide filters applied to the water-level time series is shown in figure 5. A detailed overview of the workflow including intermediate steps (appendix fig. 2-1), specific details of the methods used to develop the digital atmospheric-loading and Earth-tide filters, and the resulting filtered water-level responses are presented in appendix 2. The water-level and barometric-pressure data were processed into continuous, unpaired, variable-length (accounting for data gaps) water-level and barometric-pressure time series (referred to here as "pieces"). The individual pieces were resampled at hourly intervals, and data gaps less than or equal to 3 hours were filled using cubic spline interpolation. The individual pieces (with one exception, see appendix 2) were subsequently parsed to achieve the largest length of coincident, paired, continuous, hourly sampled time series (referred to as a "parsed" series here). The parsed barometric-pressure and water-level series were detrended using either a linear or higher-order polynomial determined by least-squares regressions of barometric pressure and water level on time. Detrending was aimed at removing the longer period (seasonal) hydrologic effects. Prior to developing the atmospheric-loading filters, harmonic analysis for the exact frequencies of six principal Earth tides was done to evaluate whether the wells responded to Earth tides. A distinct response to the principal lunar tide $\left(\mathrm{M}_{2}\right)$ and weaker responses to five other principal Earth tides in the well 14A-25-1 parsed water-level time series were filtered from the parsed waterlevel time series for that well. The mean ratio of the waterlevel amplitude to the theoretical areal-strain amplitude for the $\mathrm{M}_{2}$ tide, the computed areal-strain amplitudes for each of the Earth tides, and the mean phase shift of the waterlevel response for the $\mathrm{M}_{2}$ tide were used to filter Earth-tide responses from the parsed water-level time series.

The computed barometric efficiency $(B E)$ of the well and aquifer system formed the basis of the atmospheric-loading filters. For a well open to the atmosphere and screened below the water table in an aquifer system, the $B E$ is defined as the negative ratio of the change in water level to the change in barometric pressure (Jacob, 1940):

$$
B E=-\frac{\Delta y}{\Delta x}=-\frac{\Delta y}{\left(\Delta p_{x} /\left(\rho_{w} g\right)\right)}
$$

where

$$
\begin{aligned}
\Delta y & \text { is the change in water level, and } \\
\Delta x & \text { is the change in barometric pressure expressed } \\
\Delta p_{x} & \text { in equivalent units of head, } \\
\rho_{w} & \text { is the density of water, and } \\
g & \text { is the gravitational acceleration constant. }
\end{aligned}
$$

The $B E$ is a positive quantity that generally ranges from 0 to about 1 . The negative sign in equation 1 reflects that for a well open to the atmosphere, changes in barometric pressure cause opposite changes in water level.

Because application of single-valued, time-invariant $B E$ computed using one of various linear regression models of water level on barometric pressure could not adequately account for the atmospheric-loading responses measured in the parsed water-level time series for each well, the $B E$ was computed using single-input, single-output frequencyresponse functions for selected parsed time series of barometric pressure as input and water level as output, following the methods presented by Quilty and Roeloffs (1991). The selected parsed time series were those determined to be unaffected by earthquakes or hydrologic disturbances related to flow testing or drilling in nearby wells and included truncated versions (referred to as "modified" parsed series in appendix 2) of original parsed series in which the truncated version omits the affected portion of the original parsed series. This is described more fully in appendix 2 along with the naming convention adopted for the parsed series. This approach assumes that the outputs (water levels) can be represented as linear combinations of the frequency components of the input (barometric pressure), which are scaled relative to the barometric pressure input, and provides estimates of $B E$ and phase as functions of frequency $(f)$. The amplitude response $(B E)$ and phase $(\phi)$ of the complex valued frequency-response function $(H(f))$ were calculated as follows:

$$
\begin{aligned}
& B E(f)=|H(f)| \\
& \phi(f)=\arg (H(f))
\end{aligned}
$$

where

$|H(f)| \quad$ is the modulus or magnitude of $H(f)$, and

$\arg (H(f)) \quad$ is the arctangent (computed using atan2, the two-argument arctangent) of $H(f)$. 


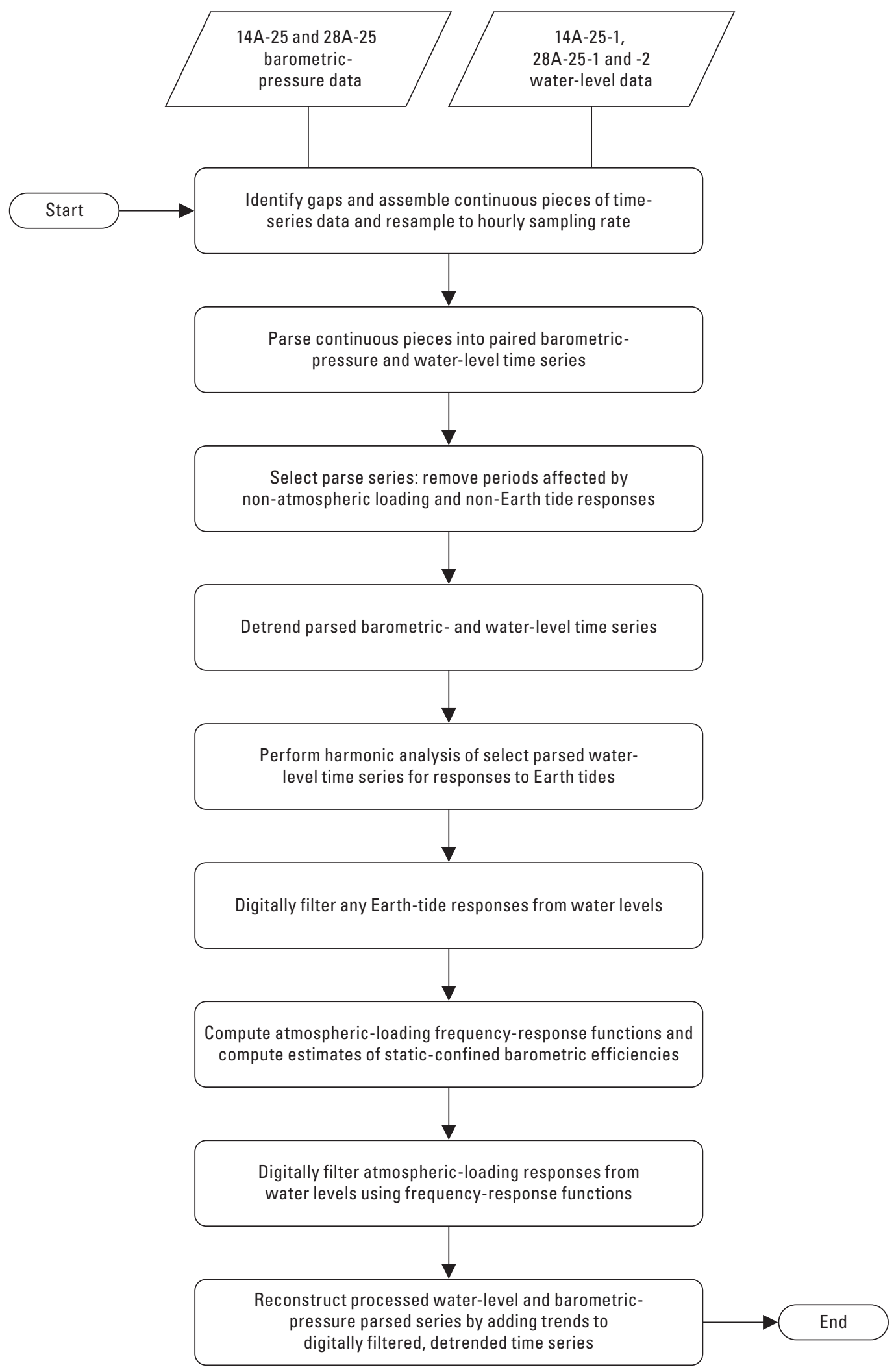

Figure 5. Simplified workflow process used to develop the digital atmospheric-loading and Earth-tide filters for water levels from monitoring wells 14A-25-1, 28A-25-1, and 28A-25-2, Mammoth Lakes area, California. 
The method has been used successfully to evaluate the frequency dependence of the water-level response in wells to atmospheric loading (Rojstaczer, 1988a, 1988b; Galloway and Rojstaczer, 1989; Rojstaczer and Agnew, 1989; Spane, 2002).

The computed atmospheric-loading frequency-response functions $(H(f))$ were used to digitally filter the effects of barometric-pressure variations on water levels from the parsed time series. The method is described in detail, and examples are shown in appendix 2 . The selected parsed time series for which frequency-response functions were computed and two other parsed time series affected by non-atmospheric loading and non-tidal responses (one in well 28A-25-1 affected by nearby drilling and one in well 14A-25-1 affected by flow testing in the nearby geothermal production well 14-25) were corrected in this way, and the filtered water-level time series are listed in Galloway (2019).

\section{Collection of Water-Temperature Profiles}

High-resolution water-temperature profiles were measured in the deep wells 14A-25-1 and 28A-25-1 at 10-ft increments through the water column. A platinum resistance temperature (PRT) probe, similar to the equipment previously used for measuring water temperature in many other wells in Long Valley Caldera (Farrar and others, 2010; Hurwitz and others, 2010) was used to take the high-resolution (plus or minus $0.1^{\circ} \mathrm{C}$ ) temperature measurements. The PRT probe, suspended from an armored logging cable, was lowered into the well over a sheave with a portable hand-cranked reel (fig. 6). Mechanical and digital depth counters were attached to the sheave. The PRT output and digital depth counter were connected to an electronic data logger programmed to display and record the temperature and depth values at 5 second intervals.

The temperature measurements were logged from the top of the water column downward, so that the thermal equilibrium of the water column was least disturbed by logging. Once the target depth was reached, the PRT probe was allowed to equilibrate for approximately 2 minutes. If after approximately 2 minutes the displayed temperature was stable at the $0.1{ }^{\circ} \mathrm{C}$ level, the probe was lowered to the next 10 -ft increment. Otherwise, logging was continued until the displayed temperature was stable within $0.1{ }^{\circ} \mathrm{C}$. The recorded data file was post-processed for each $10-\mathrm{ft}$ increment by averaging the last 10 recorded values or the last 50 seconds of data collected. Times-series plots of water-temperature against the depth below the top of the casing (BTC) were used to track changes in water-temperature profiles through time.

Calibration of the PRT probe was checked periodically in a temperature-controlled water bath using an American Society for Testing and Materials (ASTM) certified mercury thermometer in a USGS laboratory in Menlo Park, California. In September of 2015, a 6-point calibration between 42 and $89^{\circ} \mathrm{C}$ had a linear regression coefficient (coefficient of determination, or $\mathrm{R}^{2}$ ) of 1.00 ; the average variance was $-0.01{ }^{\circ} \mathrm{C}$, and the maximum observed variance was $0.08^{\circ} \mathrm{C}$. A 9-point calibration between 22 and $97{ }^{\circ} \mathrm{C}$ in March of 2017 also had an $\mathrm{R}^{2}$ value of 1.00 ; the average variance was $0.01{ }^{\circ} \mathrm{C}$, and the maximum observed variance was $0.19^{\circ} \mathrm{C}$. A third, 18-point calibration between 21 and $90{ }^{\circ} \mathrm{C}$ in June of $2018 \mathrm{had}$ an $\mathrm{R}^{2}$ value of 1.00 ; the average variance was $-0.04{ }^{\circ} \mathrm{C}$, and the maximum observed variance was $0.11^{\circ} \mathrm{C}$. On the basis of these calibration checks no corrections were applied to the recorded water temperature logs, which were assumed to have a temperature resolution within $0.1^{\circ} \mathrm{C}$ and a depth resolution conservatively estimated at within $0.5 \mathrm{ft}$.

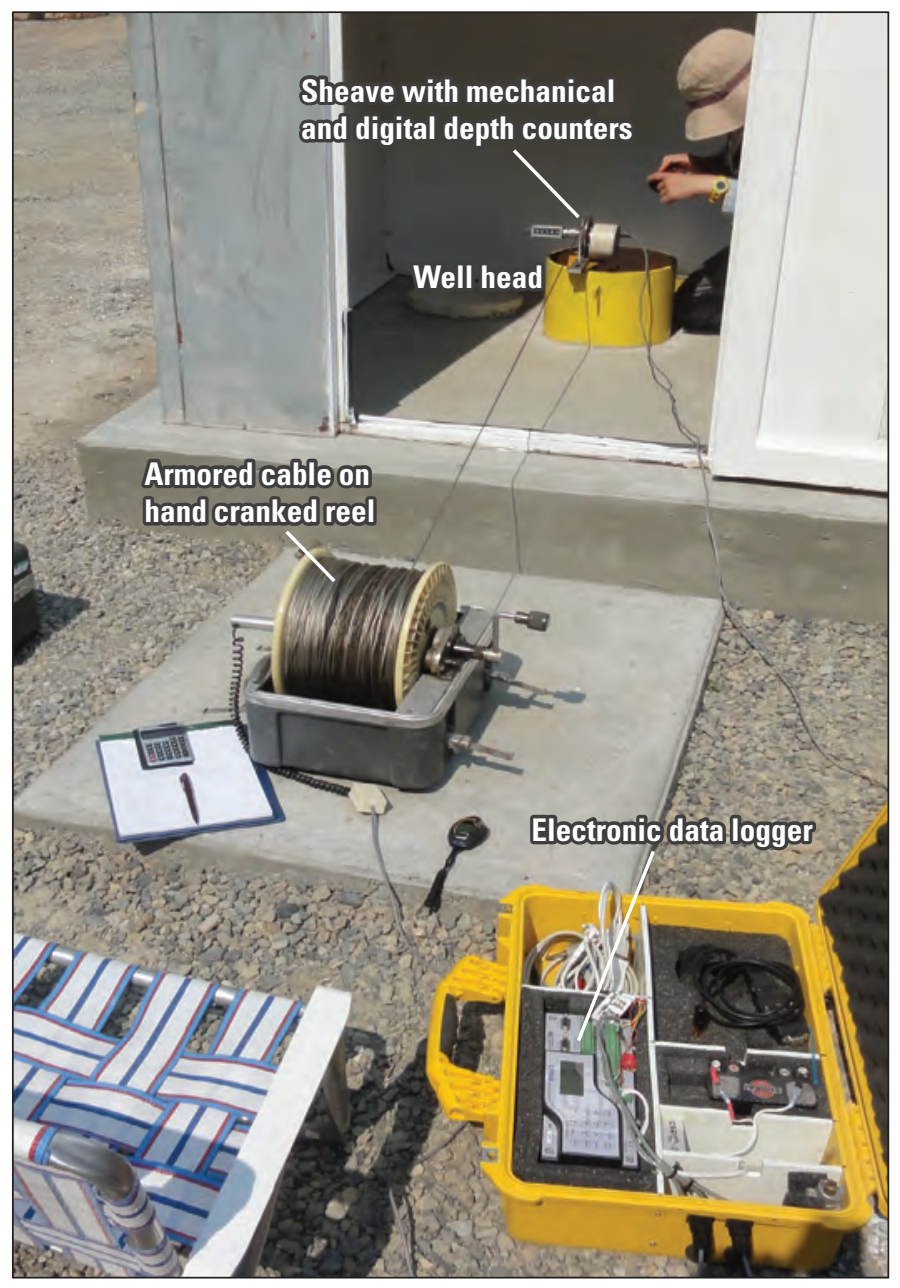

Figure 6. Portable water-temperature logging equipment used in the Mammoth Lakes area, California, study. 


\section{Collection of Water-Chemistry Samples}

This section describes the USGS procedures and protocols used for the collection of water-chemistry samples at the monitoring wells (sites 14A-25 and 28A25 ) and the MCWD wells. Also discussed are the various laboratories used by the monitoring program, the chemical constituents analyzed, and the quality-assurance and quality-control measures.

\section{Sampling Procedures}

Water-chemistry samples were collected from wells at sites $14 \mathrm{~A}-25$ and $28 \mathrm{~A}-25$ on a quarterly schedule starting in February of 2016. Sampling procedures followed protocols described in the USGS National Field Manual (NFM;

U.S. Geological Survey, 2014).

Water samples were collected using a submersible, positive pressure, air-driven pump (fig. $7 A$ ) that was lowered to a depth below the pumping water level but above the top of the perforated interval of well casing. To ensure that the sampled water was representative of the formation water, three well-casing volumes were purged before sample water was collected (NFM protocol). The 500-foot-long tubing bundle (water-discharge line) connecting the submersible pump and relay tubing to a sampling chamber in a nearby mobile waterquality laboratory were made of Teflon with stainless-steel fittings. During purging, a log of water temperature, specific conductance, and $\mathrm{pH}$ was recorded and monitored to assess the efficacy of purging. Typically, the water temperature, specific conductance, and $\mathrm{pH}$ stabilized by the time two casing volumes had been purged.

Once a well was purged, raw (unfiltered) water was collected for the immediate determination of field water temperature, specific conductance, and $\mathrm{pH}$. This was followed by collection of water samples for analysis of constituents that required no filtration. Raw samples for the analysis of bromide were collected in acid-rinsed, polyethylene bottles supplied by the analyzing lab, discussed later. Raw samples for analysis of stable isotopes in water were collected in 40-milliliter (ml) glass bottles. After filling, the glass bottles were sealed with a conical, plastic screw cap and taped to preclude leakage and evaporation prior to analysis.

\section{A}

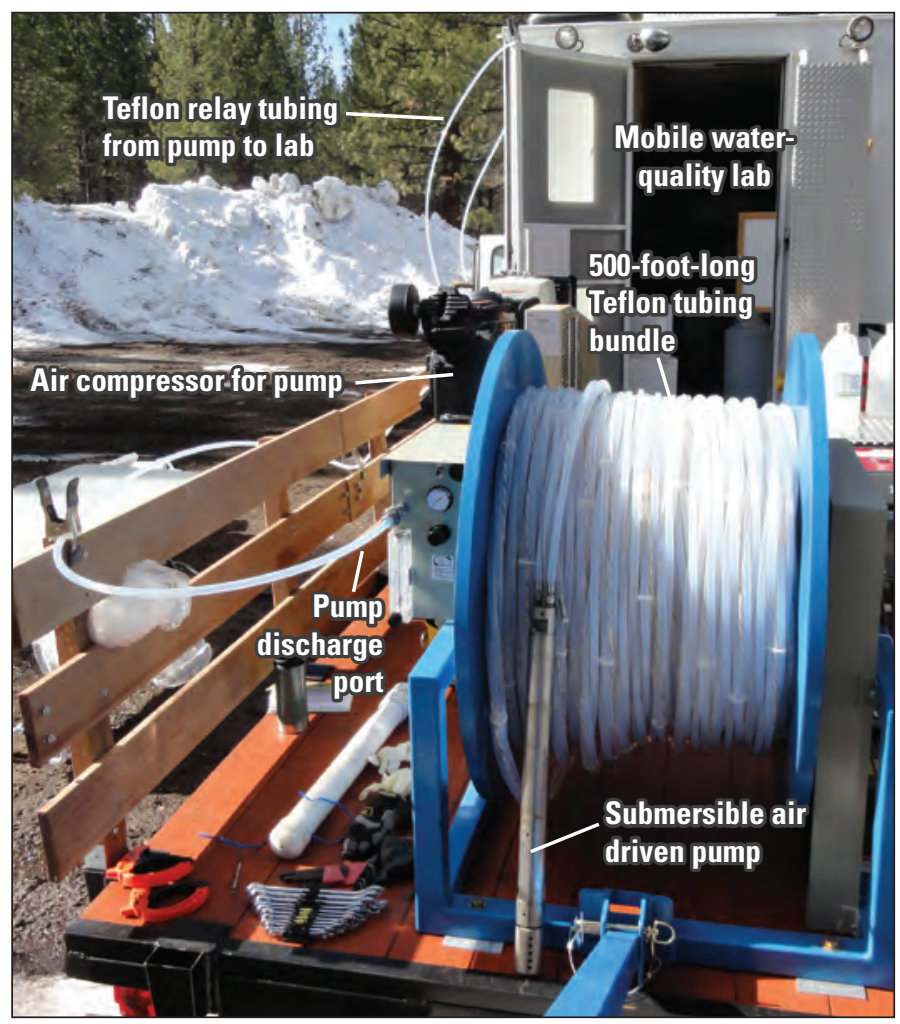

$B$

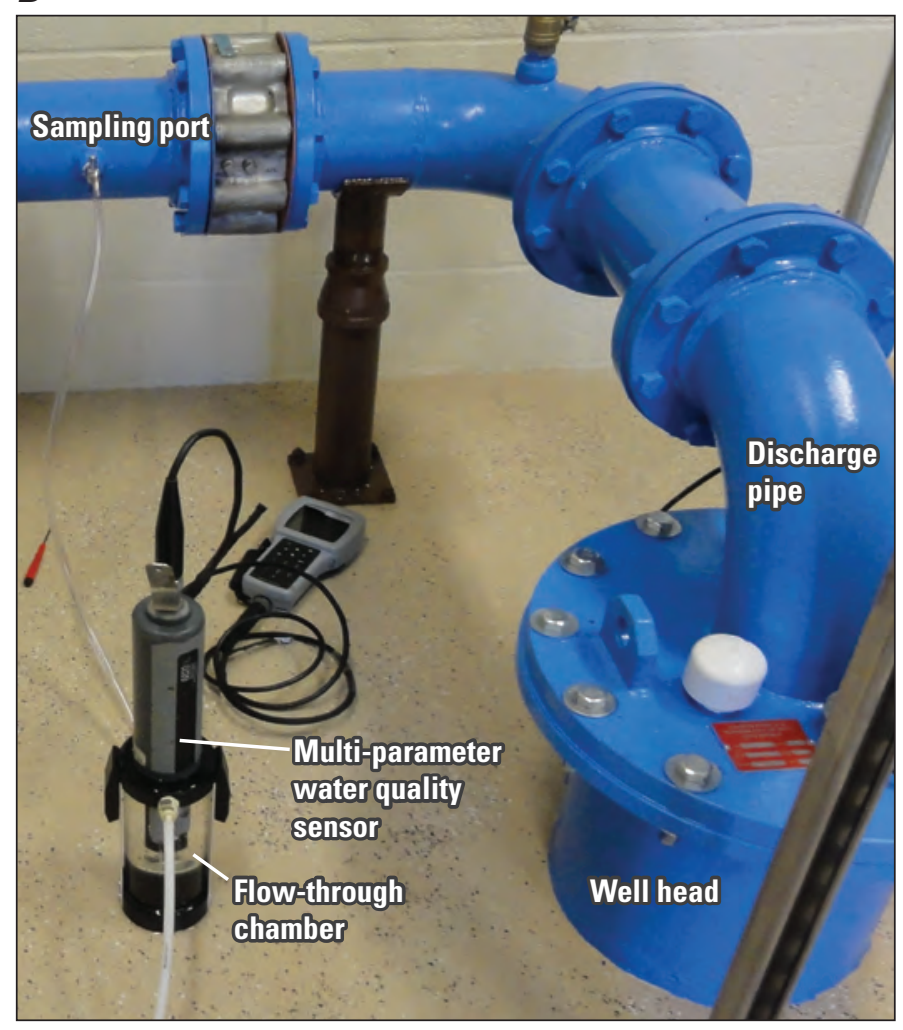

Figure 7. Data collection equipment used to collect water-chemistry samples from wells in the Mammoth Lakes area, California: $A$, submersible air-driven pump and related equipment components; $B$, typical well-head sampling port and multi-parameter water-quality sensor. 
After the raw samples were collected, a 0.45 -micrometer $(\mu \mathrm{m})$ capsule filter (polyethersulfone membrane in a polypropylene housing) was attached to the outlet end of the relay tubing to collect filtered sample water. The capsule filter was rinsed with at least 1 liter of sample water prior to collecting a sample. Filtered, untreated samples were collected in clear polyethylene bottles first. Then, filtered water for analysis of major and minor cations and trace elements was collected in clear polyethylene bottles and acidified to a $\mathrm{pH}$ of less than or equal to 2 by addition of $6 \mathrm{~N}$ (normal) ultra-pure nitric acid. For nutrient sampling, filtered water collected in dark-brown polyethylene bottles was stored and shipped on ice to the laboratory.

Sample collection from the seven MCWD production wells (P-series in table 1) and monitoring well M26 followed the same methods described previously, and the only difference was that down-hole permanently installed pumps were used to obtain the sampled water. A purge volume of at least three casing volumes was pumped before a water sample was collected. During purging, water was diverted from sampling ports near the well head to a flow-through chamber attached to a multi-parameter water-quality sensor (fig. $7 B$ ). Water temperature, specific conductance, and $\mathrm{pH}$ were recorded and monitored to assure that these field parameters had stabilized before sampling. Raw water sample bottles were filled directly from the sampling ports near the well head (fig. 7B). The only other difference in the sampling procedures was that the water for filtered samples was collected in 4-liter polyethylene containers, dedicated to each well site, and then pumped with a peristaltic pump through the capsule filters as described before.

\section{Laboratory Analyses}

A few different laboratories were used to analyze the chemistry and isotopes of water samples collected for this study. Major ions, minor and trace elements, and nutrients were analyzed by various methods at the USGS National Water-Quality Laboratory (NWQL) in Denver, Colorado. Stable hydrogen and oxygen isotopes of water were analyzed by the USGS Stable-Isotope Laboratory in Reston, Virginia (RSIL). Low-level bromide analyses were done at Eurofins Eaton Analytical (EEA) in Monrovia, California, following the laboratory's protocol of injecting undigested, unfiltered water through a coarse $30-\mu \mathrm{m}$ filter into the analyzer.

Table 2 provides a complete list of constituents analyzed for water samples collected at the wells listed in table 1 . These data are available at https://waterdata.usgs.gov/nwis.

\section{Quality Assurance and Quality Control}

To assess possible contamination of samples resulting from collection and processing procedures and to evaluate the repeatability of the laboratory analyses (analytical precision), quality-assurance procedures were used for the sample collection and quality-control (QC) measures were used to assess potential sources of contamination in the samples collected.

\section{Equipment Blank Samples for Wells $14 \mathrm{~A}-25$ and $28 \mathrm{~A}-25$}

During the quarterly sampling of wells $14 \mathrm{~A}-25$ and 28A25 , it was standard procedure to collect an equipment blank. The purpose of the equipment blank was to assess potential contamination of the samples due to sampling equipment or sampling procedure. Inorganic blank water (IBW) supplied by the USGS NWQL was used to prepare a raw and untreated (RU) and a raw and acidified (RA) blank-water QC sample. In the event that sample contamination resulting from sample collection or processing was suspected, these samples could be submitted for analysis to assess whether the IBW is the source of contamination. Then, IBW was progressively pumped through each component of the sampling equipment (air-driven pump, 500-foot-long Teflon tubing bundle and relay tubing), and a set of RU and RA samples were collected after the IBW was passed through each component. These samples could be analyzed to identify the source of suspected contamination. Finally, the IBW was pumped through each component of the sampling equipment and a capsule filter, and filtered untreated (FU) and acidified (FA) samples were collected. This final set of FU and FA samples was submitted to the appropriate laboratories and analyzed for the list of laboratory parameters in table 2 . If any of the constituents were measured at concentrations above the reporting limit (table 2), the other sets of equipment blank samples were submitted for analysis to isolate the source of contamination.

For February 2016 through January 2018, nine equipment blank samples were analyzed for all constituents listed in table 2. Of those nine samples, two had an analyte concentration above the reporting limit (table 2). In February 2016 and August 2017, the reported manganese concentrations were 0.57 and 0.93 micrograms per liter $(\mu \mathrm{g} / \mathrm{L})$, respectively, and the reporting limit for manganese was $0.2 \mu \mathrm{g} / \mathrm{L}$. For both, the source of contamination was isolated to the capsule filter. The non-detection level for manganese attributed to the capsule filter was $0.50 \mu \mathrm{g} / \mathrm{L}$ according to manufacturer specifications. Low-level manganese contamination has been documented from USGS tests of these filters (see Office of Water Quality Technical Memorandum 2016.05, https://water.usgs.gov/admin/memo/QW/qw2016.05.pdf). Because the analysis of manganese in this study was primarily done to assess the cation to anion balance, the February 23, 2016, and August 8, 2017, samples were not considered to be compromised by the low-level contamination. 
Table 2. Water-quality parameters, U.S. Geological Survey parameter codes, measurement units, and reporting limits for constituents analyzed in groundwater samples, Mammoth Lakes vicinity, California, 2015-17.

[Bromide analyzed by Eurofins Eaton Analytical laboratory; stable isotopes analyzed by USGS Reston Stable Isotope Laboratory; other laboratory analytes determined at USGS National Water Quality Laboratory. See table 1 for list of sampled well sites. $\delta \mathrm{D}$ is the shift in the ratio of deuterium to hydrogen and $\delta^{18} \mathrm{O}$ is the shift in the ratio of oxygen-18 to oxygen-16, both relative to Vienna Standard Mean Ocean Water. Abbreviations: $\mathrm{CaCO}_{3}$, calcium carbonate; $\mathrm{mg} / \mathrm{L}$, milligrams per liter; ${ }^{\circ} \mathrm{C}$, degrees Celsius; $\mathrm{NO}_{2}$, nitrite; $\mathrm{NO}_{3}$, nitrate; $\mu \mathrm{g} / \mathrm{L}$, micrograms per liter; $\mu \mathrm{S} / \mathrm{cm}$, microsiemens per centimeter]

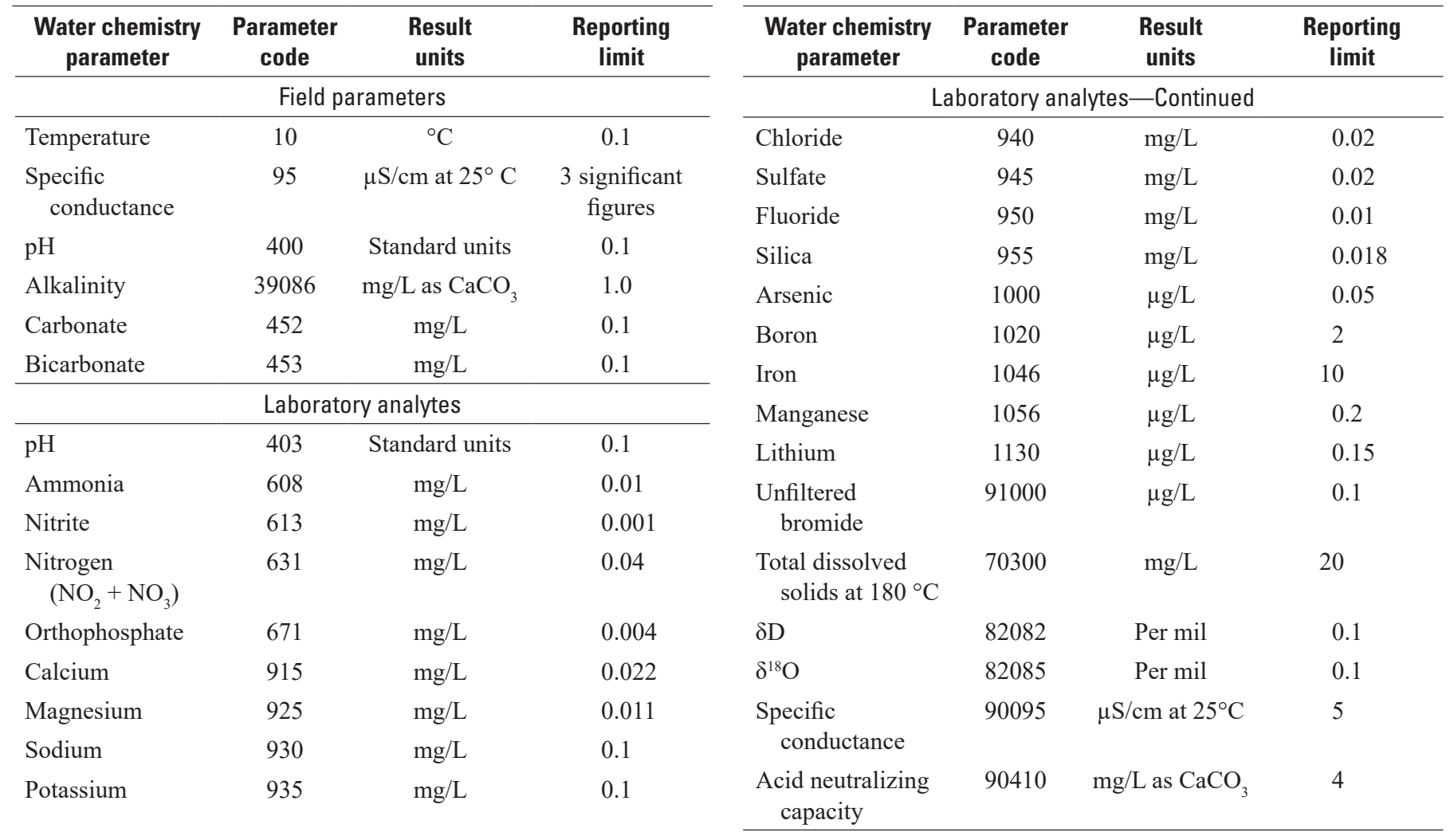

\section{Quality-Control Measures at Mammoth Community Water District Wells}

Equipment blanks were also collected during sampling of the MCWD wells. The only difference in the procedure was the equipment components (4-liter polyethylene container and Teflon tubing used with a peristaltic pump) that were assessed for contamination. As in the procedures described previously, the IBW was systematically processed through a randomly chosen polyethylene container and section of Teflon tubing, and RU and RA samples were collected for both items of equipment. These samples could be analyzed to assess which part of the equipment was the source of suspected contamination. Then, the IBW was pumped from the sample container through the section of Teflon tubing and a capsule filter to collect the FU and FA samples submitted to the NWQL.

For February 2015 to January 2018, six equipment blank samples were analyzed for the suite of constituents listed in table 2. Of those six samples, one (January 2016) had reported arsenic $(0.27 \mu \mathrm{g} / \mathrm{L})$ and lithium $(1.34 \mu \mathrm{g} / \mathrm{L})$ concentrations above the reporting limits of 0.1 and $0.22 \mu \mathrm{g} / \mathrm{L}$, respectively (table 2). Once again, the source of contamination was isolated to the capsule filter. The non-detection level for arsenic attributed to the capsule filter was $0.2 \mu \mathrm{g} / \mathrm{L}$, and the nondetection level for lithium attributed to the capsule filter was $0.03 \mu \mathrm{g} / \mathrm{L}$, according to manufacturer specifications.

If the reported level of arsenic contamination was present in the suite of environmental samples collected at the MCWD wells during January 2016, the arsenic results could have been overestimated by as much as 5.7 percent (for the sample from well P1, which had with the lowest arsenic concentration of the group). If the reported level of lithium contamination was present in the suite of environmental samples collected at the MCWD wells during January 2016, the lithium concentrations could have been overestimated by as much as 2.6 percent (for the sample from well P15, which had the lowest lithium concentration of the group). These errors are comparable to analytical uncertainties and are less than the natural temporal variability of samples from the MCWD wells. 
In addition to equipment blanks, sequential replicate samples were collected twice each year. The sequential replicate samples were collected such that the entire suite of bottle types was filled for the environmental sample, followed by a replicate. The purpose of these samples was to assess the repeatability of the laboratory results (precision of analyses). Replicate samples were analyzed for the suite of constituents (table 2) evaluated in the environmental samples. Replicate samples were submitted for analysis to the appropriate laboratory (NWQL, RSIL, and EEA), and the replicate results were compared to the corresponding environmental samples to assess variability (Mueller and others, 2015).

For February 2015 to January 2018, seven pairs of sequential replicate samples were analyzed for the suite of constituents listed in table 2. For those seven pairs, none of the reported concentrations of constituents for the replicate QC sample differed by more than 20 percent relative percent difference (RPD) from the paired samples' mean concentration. The average and maximum RPD of the seven pairs of replicate samples for the principle constituents of interest (chloride, boron, bromide, and lithium) follow. For chloride, the average RPD was 0.49 percent, and the maximum was 4.15 percent; for boron, the average was 2.5 percent, and the maximum was 17.7 percent; for bromide, the average was 0.18 percent, and the maximum was 5.41 percent; and for lithium, the average was 0.33 percent, and the maximum was 2.23 percent. With the exception of one replicate analysis of boron, all of the maximum RPD percentages were far below the maximum allowable 20 percent RPD from the paired samples' mean concentration.

\section{Groundwater-Level Data}

\section{Pre-Filtered Groundwater-Level Data}

Continuous pre-filtered water-level data (sampled at 10 minute or higher frequency intervals) were used to compute daily median values for sites $14 \mathrm{~A}-25$ and 28A-25 from late 2015 through 2017 . The computed daily median values of water depth BLS and the corresponding instantaneous waterlevel measurements that were used to calibrate pressuretransducer readings are shown in figures 8 and 9. These data are available at https://waterdata.usgs.gov/nwis.

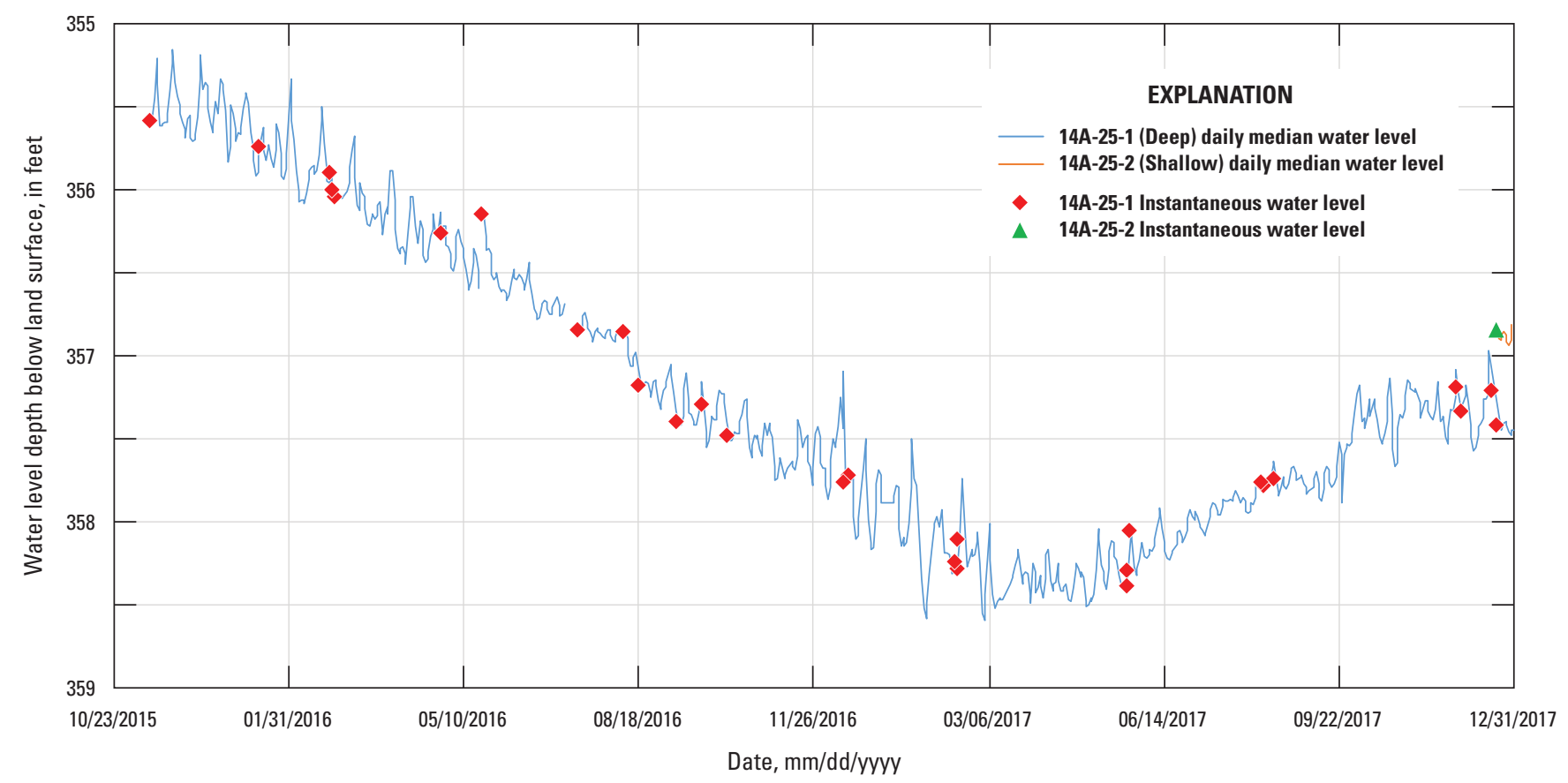

Figure 8. Daily median and instantaneous water levels, depth below land surface, 2015-17, for wells $14 A-25-1$ and $14 A-25-2$ in the Mammoth Lakes area, California. 


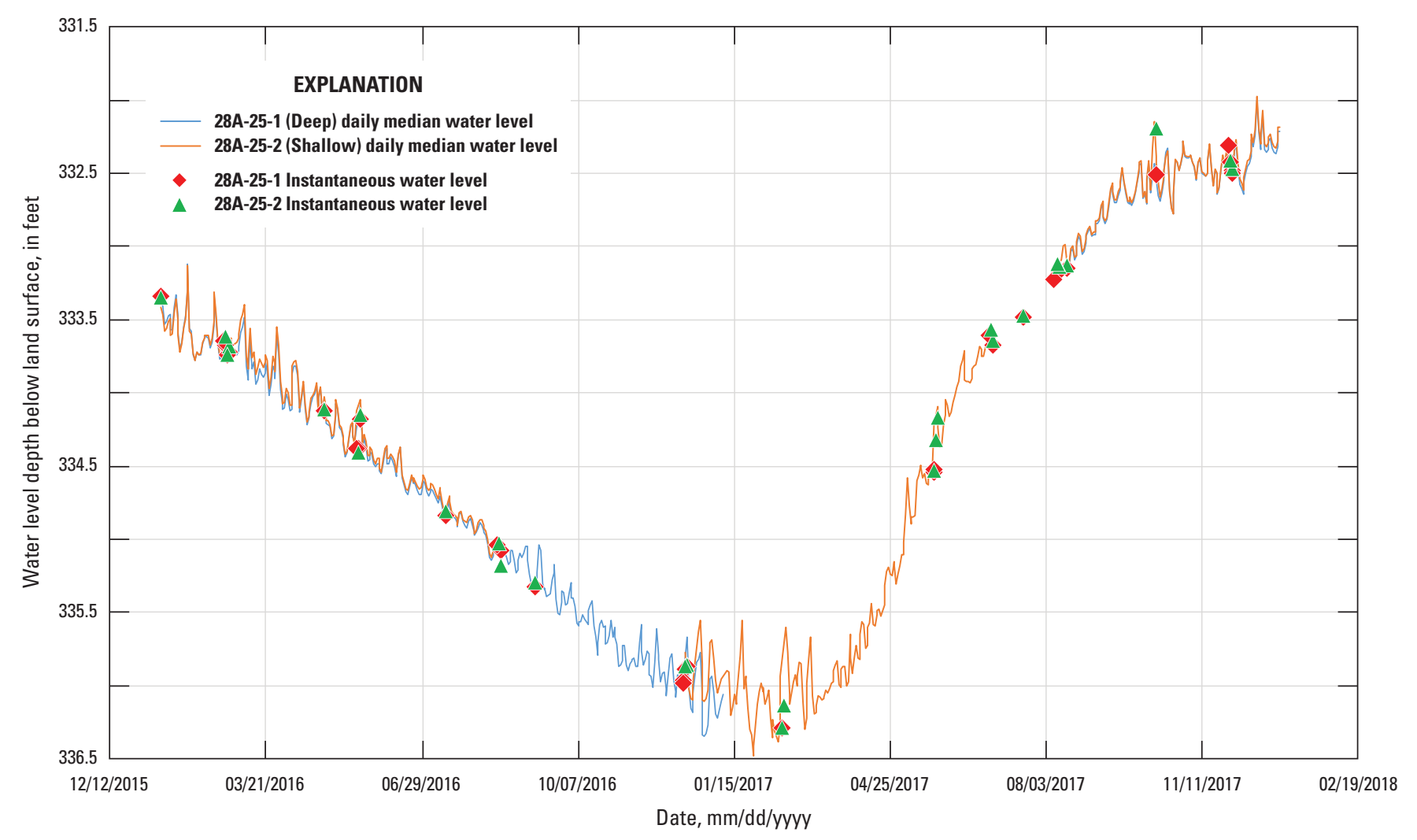

Figure 9. Daily median and instantaneous water levels, depth below land surface, 2016-17, for wells 28A-25-1 and 28A-25-2 in the Mammoth Lakes area, California.

\section{Wells at Site 14A-25}

Well 14A-25-2 (shallow) initially was not fully developed (by air-lifted flowing) after drilling. Consequently, residual rock flour in the well bore, left behind from the rotary airhammer drilling (appendix 1), could have impeded fluid movement through the well screen. Because of the potentially impeded hydraulic communication with the surrounding formation, the fluid-pressure (water-level) record for late 2015 through most of 2017 was removed from the public National Water Information System (NWIS) database. In December of 2017, the 14A-25-2 well was fully developed, and the subsequent data were representative of hydraulic head in the adjacent formation. Although the residual rock flour in the bore hole of well 14A-25-2 could have impeded hydraulic communication through the well screen, this was not thought to affect the water chemistry because the purging of three casing volumes prior to water sampling would have drawn in representative formation water despite the impeded flow through the well screen.

From late 2015 to early March 2017, the groundwater level in well 14A-25-1 steadily declined about 3 feet in response to years of below-normal precipitation (fig. 8). After the above-normal-precipitation winter of 2016-17, the groundwater level in well 14A-25-1 began rising in early May 2017 and continued to rise through late 2017, but the water level only recovered about one-half of the decline from its late 2015 level (fig. 8).

\section{Wells at Site 28A-25}

The periods of missing water-level records from both wells at site 28A-25 (fig. 9) were due to the premature failure of the submersible pressure transducers, which was attributed to high water temperatures, as previously discussed. Where data exist for both wells, the water-level variations closely matched each other in phase and amplitude (fig. 9), demonstrating that one record was a reasonable surrogate for the other at this site.

The water-level trends in wells 28A-25-1 and 28A-25-2 were comparable to the record at well 14A-25-1, discussed previously, because groundwater levels in both wells steadily declined about 3 feet through 2016 in response to years of below-normal precipitation (fig. 9). Beginning in early March of 2017, the groundwater levels in both wells began rising rapidly. The rate of water-level rise slowed during the summer and fall of 2017, but water levels continued to rise through the end of the calendar year for a gain of about 4 feet by late 2017, surpassing the early 2016 level (fig. 9). The larger water-level rise in wells at site 28A-25 compared to well 14A-25-1 for the same period (fig. 8) indicates that the response to recharge was greater in the shallow-aquifer system south of well 14A-25-1. 


\section{Digitally Filtered Groundwater-Level Data}

This section presents examples of digitally filtered groundwater-level data for wells 14A-25-1, 28A-25-1, and 28A-25-2 from mid-August to early October 2017. For well 14A-25-1, the water-level data were digitally filtered to remove the effects of solid Earth tides and atmospheric loading, but for wells 28A-25-1 and 28A-25-2, the waterlevel data were only filtered for atmospheric loading, because no solid Earth tide effects were detected in these water-level records. The hourly values of barometric pressure, unfiltered water level, and filtered water-level data for wells 14A-25-1,
28A-25-1, and 28A-25-2 are shown in figures 10, 11, and 12, respectively (hourly data available from Galloway, 2019). In each of the figures, the inverse relationship between barometric pressure and the unfiltered water-level data is evident. The sinusoidal effects of atmospheric loading can obscure subtle water-level responses to other hydrologic stresses, which are evident in the filtered water-level data (figs. 10, 11, and 12). The filtered water-level data during this approximately 2-month period are discussed in detail in a later section ("Water-Level Variations During a Flow Test of a Geothermal Production Well").

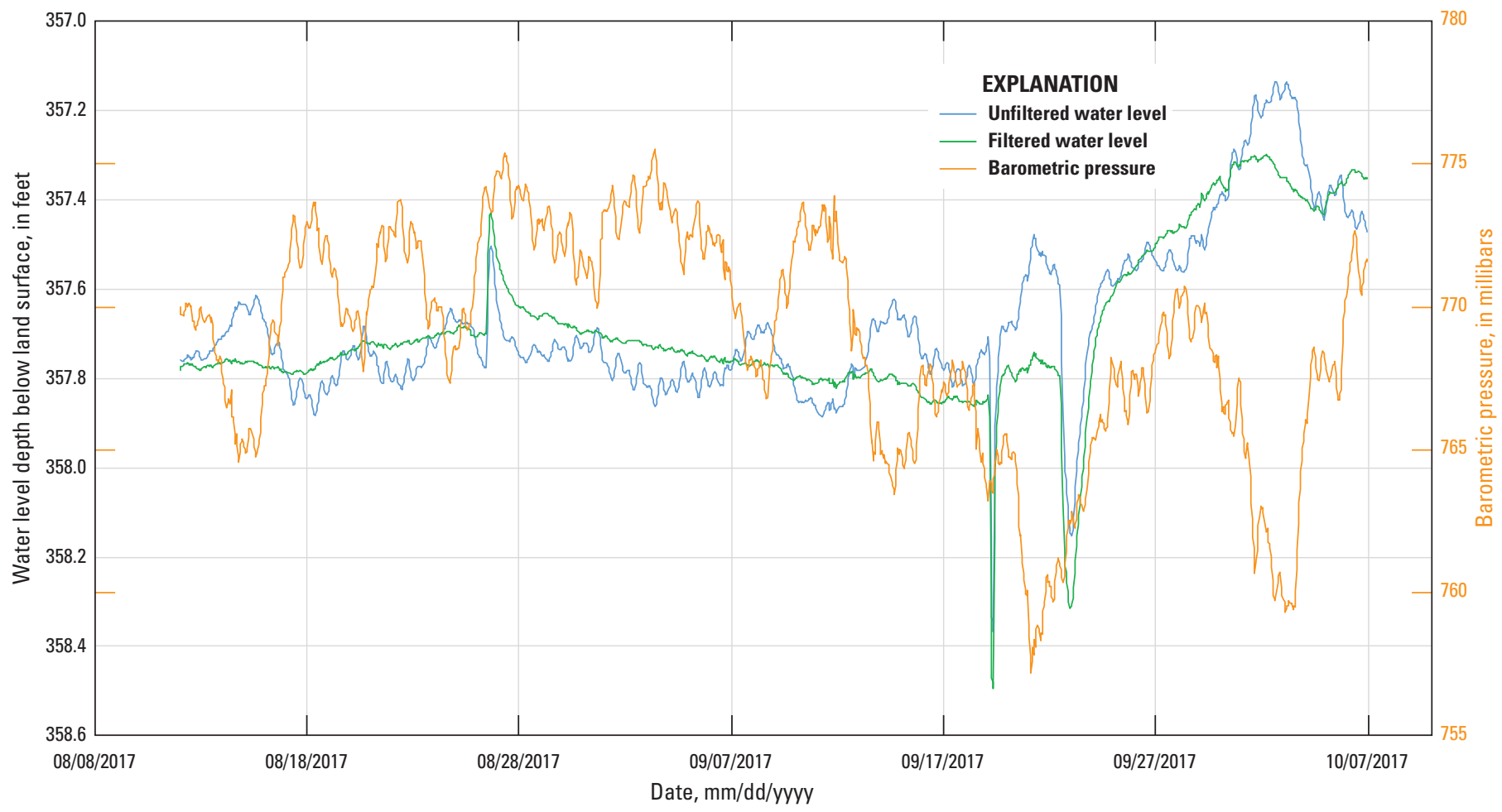

Figure 10. Hourly barometric pressure, water-level depth below land surface data, and filtered water-level depth below land surface for well14A-25-1 in the Mammoth Lakes area, California, from August 12 to October 6, 2017. 


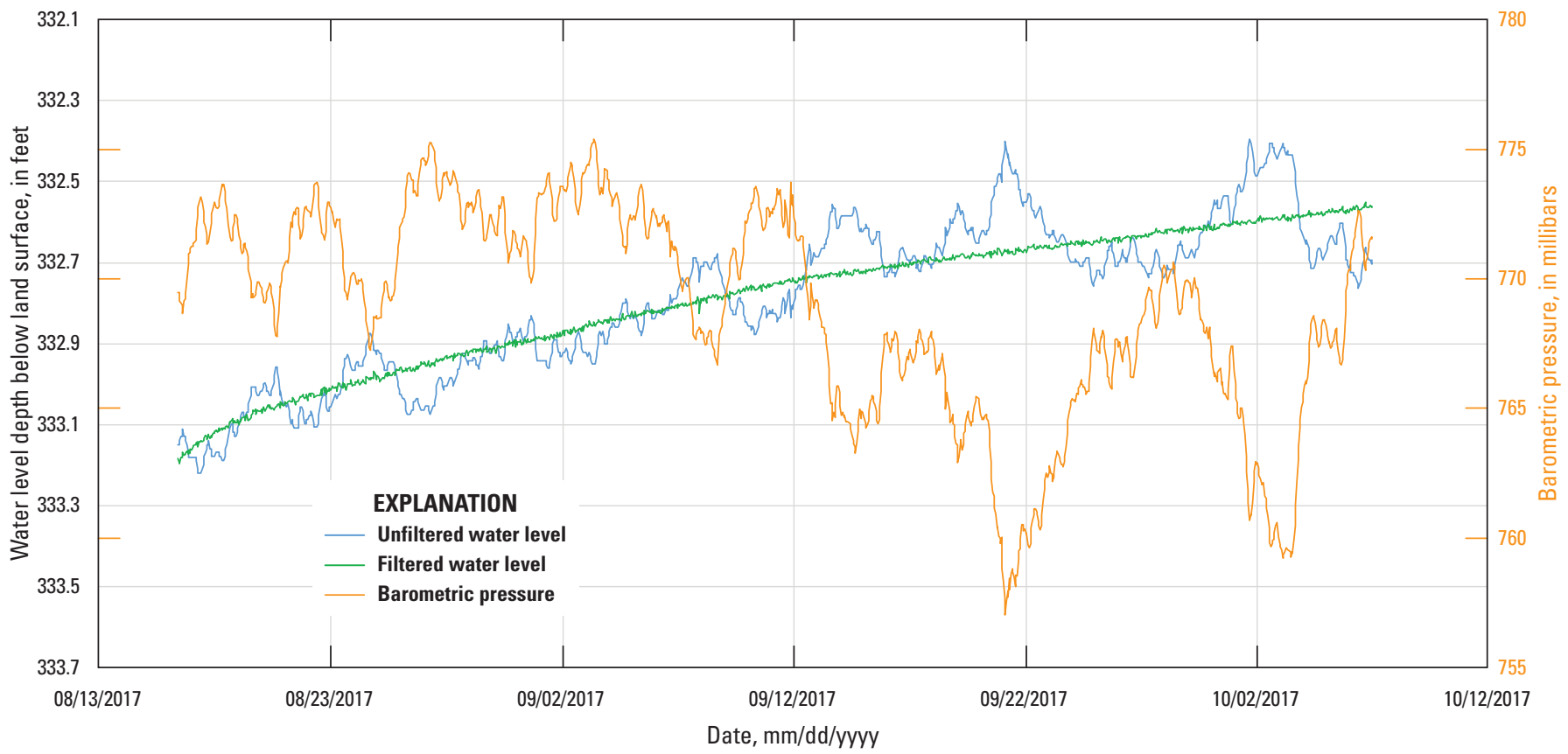

Figure 11. Hourly barometric pressure, water-level depth below land surface data, and filtered water-level depth below land surface for well 28A-25-1 in the Mammoth Lakes area, California, from August 16 to October 6, 2017.

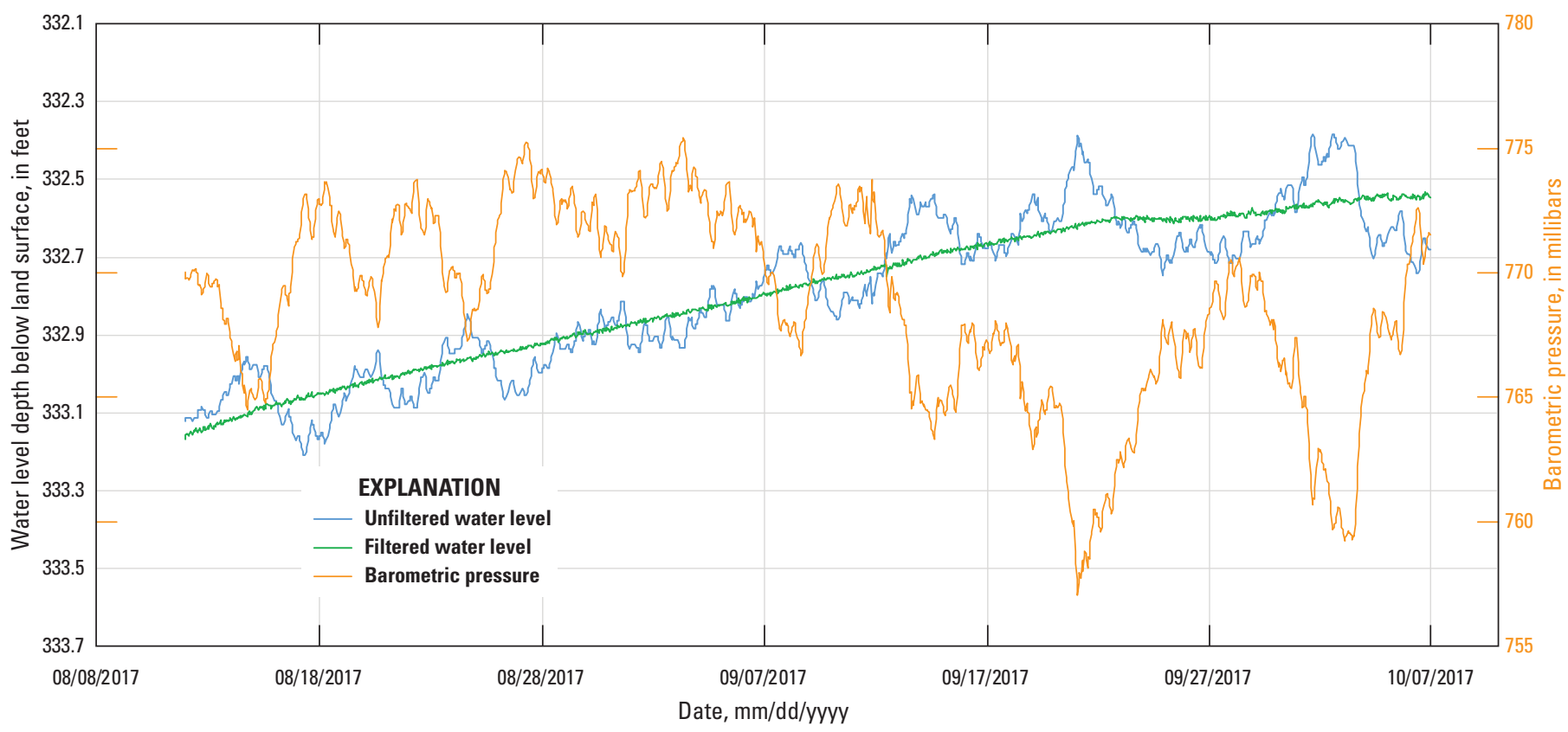

Figure 12. Hourly barometric pressure, water-level depth below land surface data, and filtered water-level depth below land surface for well 28A-25-2 in the Mammoth Lakes area, California, from August 12 to October 6, 2017. 


\section{Water-Temperature Profiles}

\section{Well 14A-25-1}

The water-temperature profiles at well 14A-25-1 are characterized by an upper 80-ft-long section (360 to $440 \mathrm{ft} \mathrm{BTC}$ ) that had an average temperature gradient of 0.18 degree Celsius per foot $\left({ }^{\circ} \mathrm{C} / \mathrm{ft}\right)$, a middle 50 -ft-long section (440 to $490 \mathrm{ft} \mathrm{BTC)}$ ) that had an average temperature gradient of $0.05{ }^{\circ} \mathrm{C} / \mathrm{ft}$, and a lower 110 -ft-long section (490 to $600 \mathrm{ft} \mathrm{BTC)}$ that had an average temperature gradient of $0.23{ }^{\circ} \mathrm{C} / \mathrm{ft}$ (figs. 13 and 14). The temperature continuously increased with depth; the maximum water temperature, which varied between 104.4 and $106.9^{\circ} \mathrm{C}$, was measured at the bottom of the well (600 ft BTC), where the average temperature between February 2016 and December 2017 was $105.1{ }^{\circ} \mathrm{C}$. See appendix table $3-1$ for water-temperature profile data in well 14A-25-1 during 2016 to 2017.

The middle, low-gradient temperature section corresponded to a zone of high permeability where the shallower well 14A-25-2 is open to the adjacent formation
(446-496 ft BLS and includes the permeable sand pack above and below the screened interval of 470-490 ft BLS; appendix fig. 1-1). For the 450-490 ft interval BTC (zone of high permeability where the shallower well 14A-25-2 is open to the adjacent formation), there was a 0.4 to $0.5^{\circ} \mathrm{C}$ temperature decline during 2016 and a further 0.2 to $0.3{ }^{\circ} \mathrm{C}$ temperature decline during 2017 (figs. 13 and 14). From February 2016 to May 2017, the water temperature at $490 \mathrm{ft} \mathrm{BTC} \mathrm{(the} \mathrm{bottom}$ of the shallow open interval in well 14A-25-2) steadily declined by $0.8^{\circ} \mathrm{C}$ (fig. 15). After May 2017, and for the remainder of 2017 the water temperature in the 440-490-ft BLS interval had stabilized within the $0.1{ }^{\circ} \mathrm{C}$ resolution of the measurements (fig. 15).

The deep well 14A-25-1 is open to the adjacent formation from 555 to $600 \mathrm{ft}$ BLS (including the sand pack above and below the screened interval of 575 to $595 \mathrm{ft}$ BLS). During 2016 , there was also a general cooling trend at the open interval (555 to $600 \mathrm{ft}$ BLS) of the well 14A-25-1 (fig. 16). The cooling near the bottom of the well stabilized by February 2017, and the temperatures through the remainder of 2017 averaged within $0.3^{\circ} \mathrm{C}$ at any given depth.

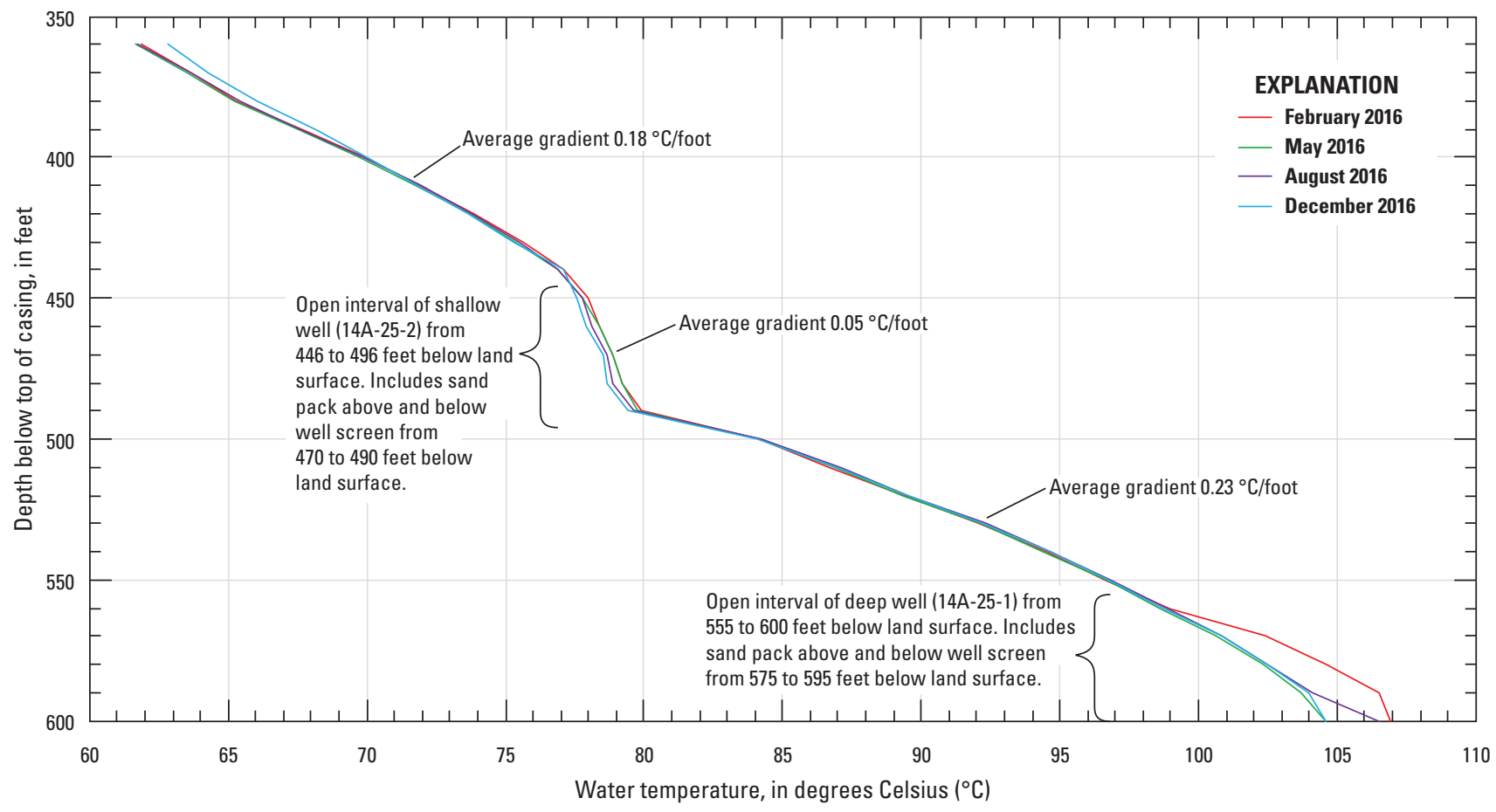

Figure 13. Water-temperature by depth below top of casing for well 14A-25-1, Mammoth Lakes area, California, 2016. ${ }^{\circ} \mathrm{C} /$ foot, degree Celsius per foot. 


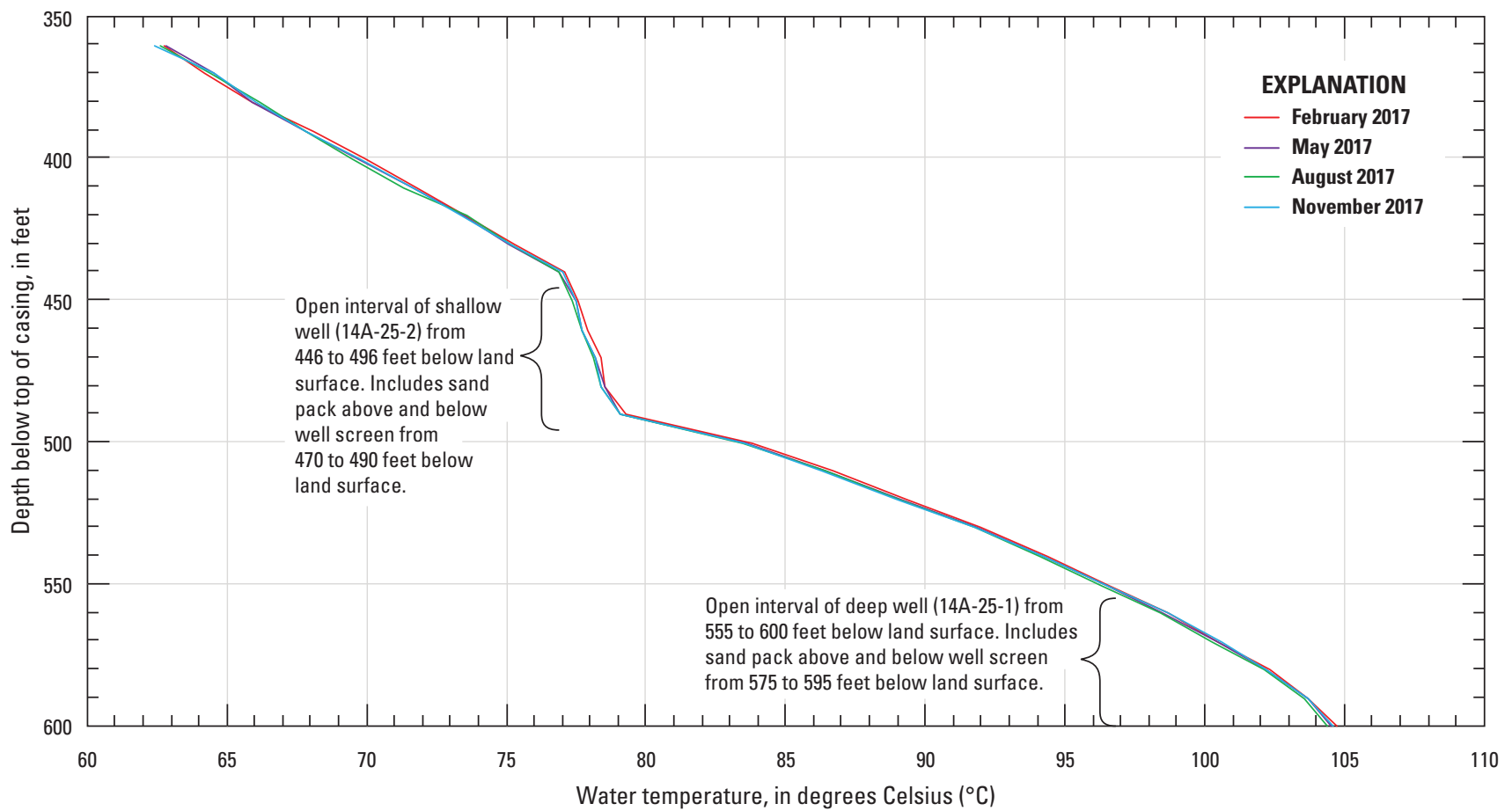

Figure 14. Water-temperature by depth below top of casing for well 14A-25-1, Mammoth Lakes area, California, 2017.

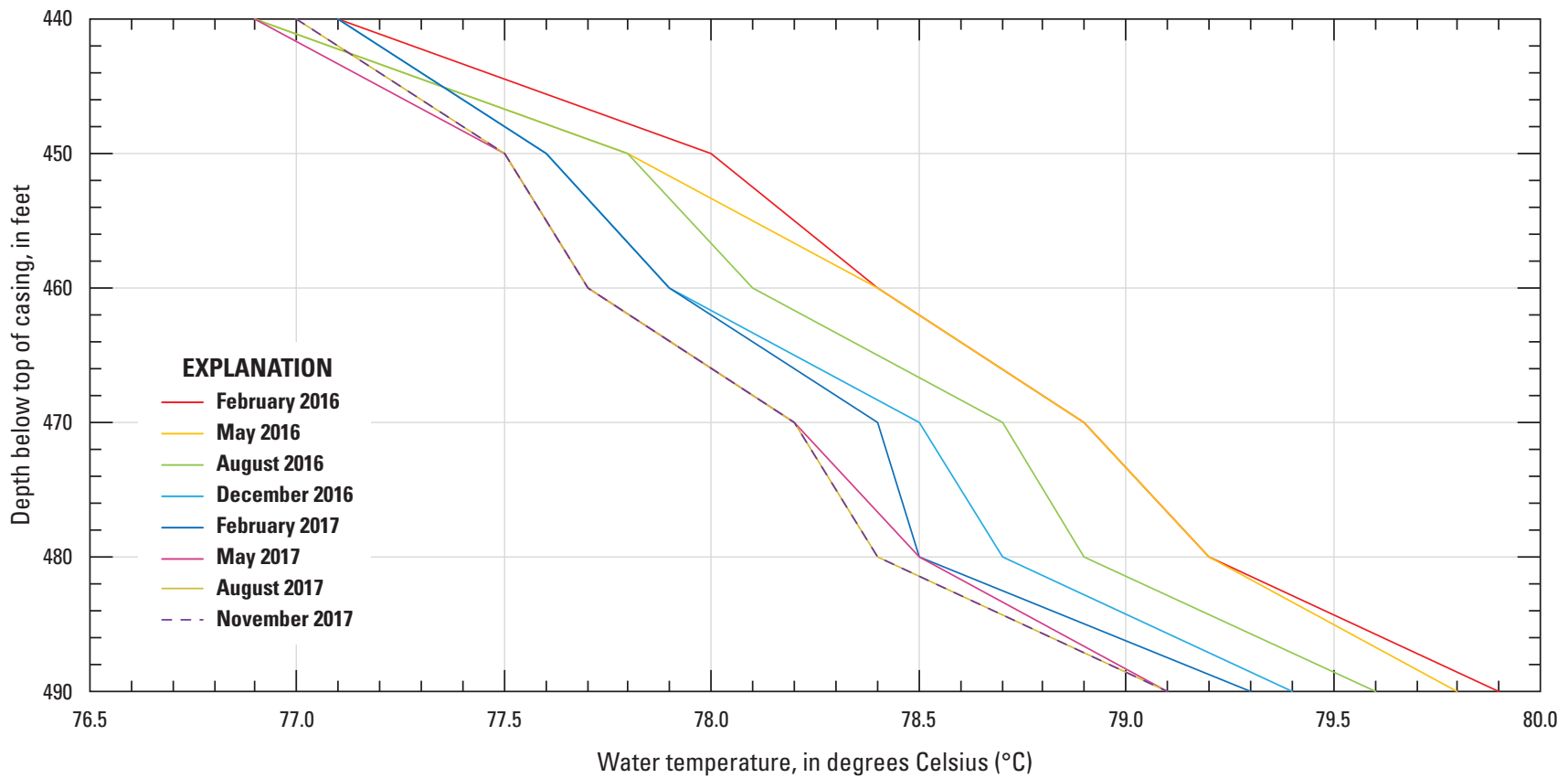

Figure 15. Water-temperature profiles in well 14A-25-1 for the depth interval from 440 to 490 feet below top of casing from 2016 to 2017 in the Mammoth Lakes area, California. 


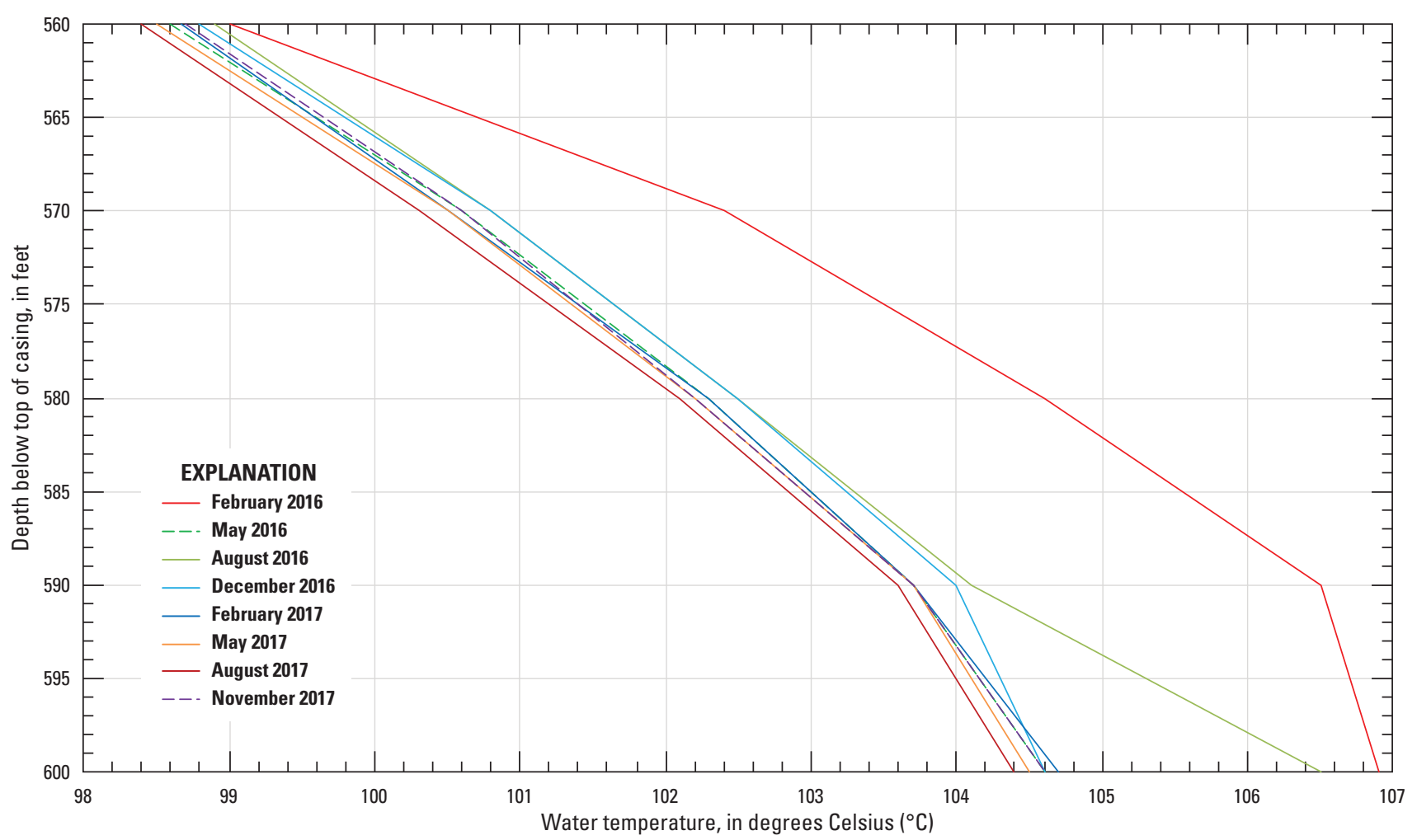

Figure 16. Water-temperature profiles for the depth interval 560 to 600 feet below top of casing for well 14A-25-1 from 2016 to 2017 , Mammoth Lakes area, California.

\section{Well 28A-25-1}

The water-temperature profile for well 28A-25-1 was characterized by four different temperature gradients (fig. 17). The upper $10 \mathrm{ft}$ of the water column (340 to $350 \mathrm{ft} \mathrm{BTC}$ ) had the greatest average temperature gradient of $0.09^{\circ} \mathrm{C} / \mathrm{ft}$. Below the upper $10 \mathrm{ft}$ is a 150 - $\mathrm{ft}$-long section $(350$ to $500 \mathrm{ft}$ BTC) that had an average temperature gradient of $0.04^{\circ} \mathrm{C} / \mathrm{ft}$; that section is underlain by a 40 -ft-long section $(500$ to $540 \mathrm{ft}$ BTC) that had an average temperature gradient of $0.02{ }^{\circ} \mathrm{C} / \mathrm{ft}$ (fig. 17). From $540 \mathrm{ft} \mathrm{BTC}$ to the bottom of the well, there was a temperature reversal to a cooling gradient of $-0.01{ }^{\circ} \mathrm{C} / \mathrm{ft}$. The maximum water temperature in well 28A-25-1 typically was at $540 \mathrm{ft} \mathrm{BTC}$, just above the temperature reversal, which averaged $53.2^{\circ} \mathrm{C}$ during $2016-17$ (figs. 17 and 18). In well 28A-25-1, the water-temperature gradient decreased with depth, in contrast with well 14A-25-1, where, in general, the thermal gradient increased with depth. See appendix table 3-2 for water-temperature profile data in well 28A-25-1 from 2016 to 2017.
During 2016, the water-temperature profiles in well 28A-25-1 were all within $0.3{ }^{\circ} \mathrm{C}$ of sequential profiles for any given depth, with two exceptions. In February 2016, there was a $-0.5^{\circ} \mathrm{C}$ difference at a depth of $470 \mathrm{ft}$, and in August, there was a $0.4^{\circ} \mathrm{C}$ increase at a depth of $570 \mathrm{ft}$ (fig. 17), which was the highest water temperature $\left(53.5^{\circ} \mathrm{C}\right)$ recorded in well $28 \mathrm{~A}$ 25-1 from 2016 to 2017. Each of these temperature differences was at the open interval of the shallow or deep well (28A-25-2 and 28A-25-1), respectively (appendix fig. 1-2), and represent transient pulses of slightly cooler and warmer water.

In August 2017, the temperature logging equipment malfunctioned, and no log was recorded for well 28A-25-1. The February, May, and November temperatures were all within $0.3{ }^{\circ} \mathrm{C}$ at any given depth, except for the November profile for 340 to $430 \mathrm{ft} \mathrm{BTC} \mathrm{(fig.} \mathrm{18).} \mathrm{Between} \mathrm{May} \mathrm{and}$ November 2017, the water temperature in well 28A-25-1 declined by 1.3 to $1.5^{\circ} \mathrm{C}$ throughout the 340 to $370 \mathrm{ft}$ interval BTC. This was attributed to the injection of fluids during the drilling of nearby well 28-25 (fig. 3) during October 2017. 


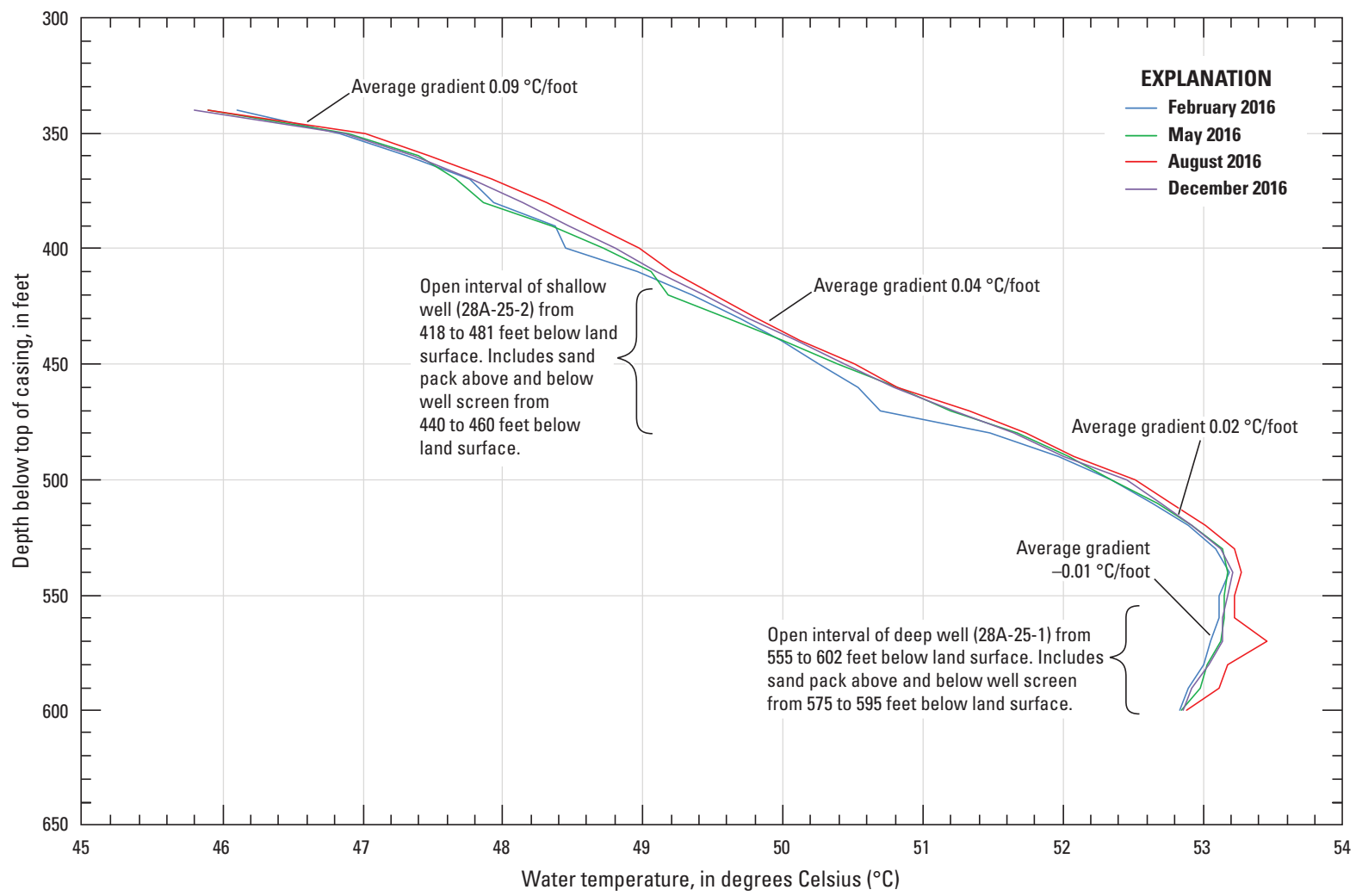

Figure 17. Water-temperature by depth below top of casing for well 28A-25-1, Mammoth Lakes area, California, 2016. ${ }^{\circ} \mathrm{C} /$ foot, degree Celsius per foot.

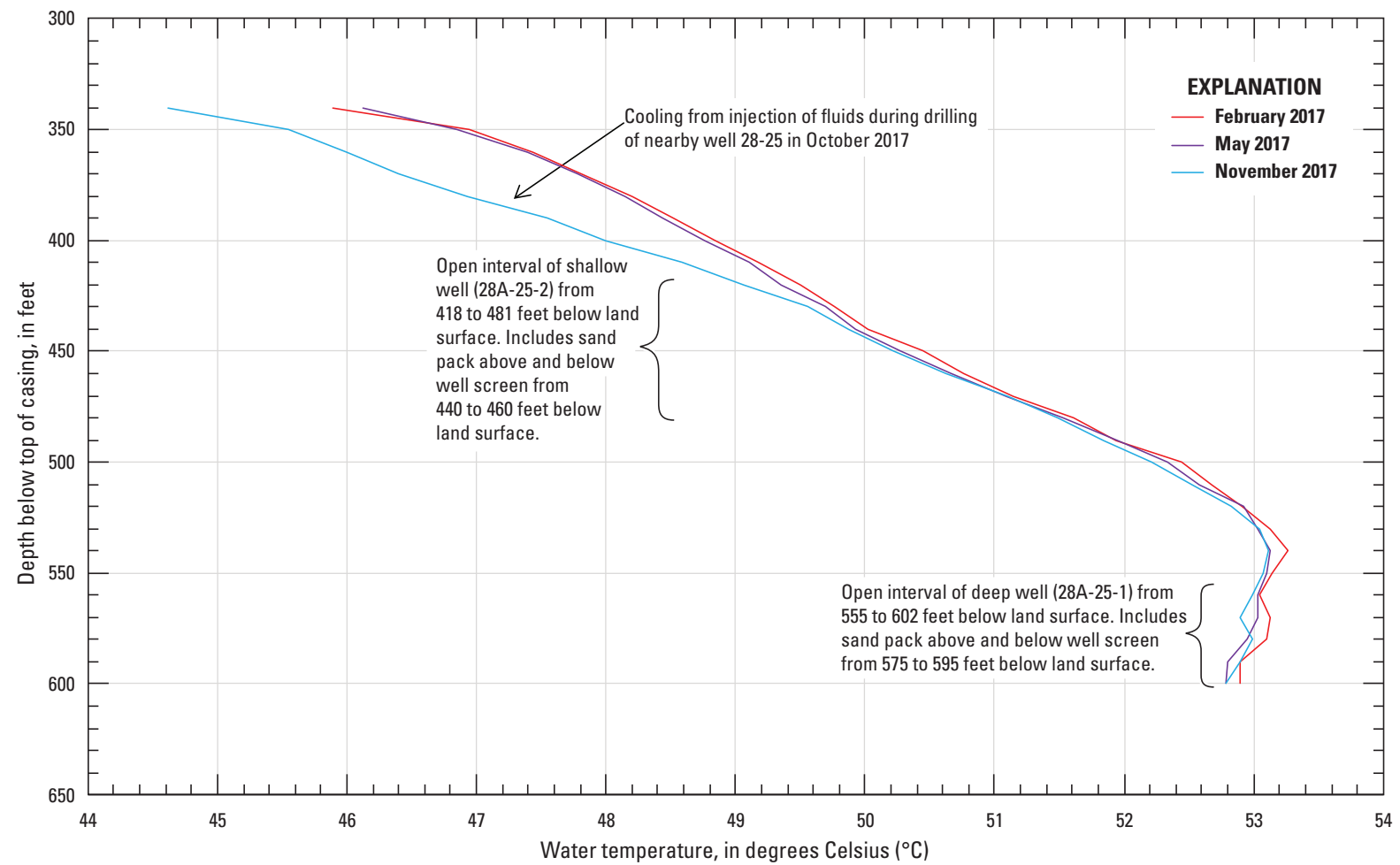

Figure 18. Water-temperature by depth below top of casing for well 28A-25-1, Mammoth Lakes area, California, 2017. No data for August 2017 because of equipment malfunction. 


\section{Water-Chemistry Comparisons}

The chemical characteristics of the groundwater sampled from the multi-layered aquifer system in the Mammoth Lakes area are presented in this section. Table 3 shows results for samples collected mostly in October and November 2017 from the seven MCWD production wells; MCWD monitoring well M26; and monitoring wells 14A-25-1, 14A-25-2, 28A-25-1, and 28A-25-2. The MCWD production wells P1, P6, P15, P16, $\mathrm{P} 20$, and $\mathrm{P} 25$, which had relatively low water temperatures, can be considered representative of non-thermal groundwater in the study area. Well P17 is a MCWD production well that showed some geothermal characteristics, as discussed later. The above-normal water temperatures in monitoring wells M26, 14A-25-1, 14A-25-2, 28A-25-1, and 28A-25-2 were indicative of geothermal influence. These wells are also in or near areas of high conductive heat flow, however. Chemistry data for groundwater from the sampled wells for all sampling dates are available at https://waterdata.usgs.gov/nwis. See table 1 for a list of USGS site identifiers. For comparison of chemistry, a published analysis of water collected in 2006 from geothermal production well 57-25 (Brown and others, 2013) is also presented in table 3.

\section{Analyzed Constituents}

The suite of constituents analyzed was selected to characterize the geochemistry of groundwater - thermal and non-thermal - in the Mammoth Lakes area (table 2). Some of the constituents, for example, magnesium $(\mathrm{Mg})$, are typically more abundant in non-thermal groundwater and have lower concentrations in thermal water. Other constituents, such as chloride $(\mathrm{Cl})$, bromide $(\mathrm{Br})$, boron $(\mathrm{B})$, lithium $(\mathrm{Li})$, arsenic (As), and silica $\left(\mathrm{SiO}_{2}\right)$, are typically more abundant in thermal water; some of them (for instance, chloride) can be a hundred times more abundant than in non-thermal water. The differences in these characteristics are evident in table 3, where non-thermal groundwater sources are compared to geothermal water from well 57-25. Some of these constituents (particularly chloride and boron) are considered to be conservative constituents (Shevenell and others, 1987; Sorey and others, 1991); that is, once dissolved from the host rocks, they are largely unreactive and stay in solution during groundwater flow, cooling, and dilution. Conservative constituents are of particular interest to this study because they can be used to evaluate mixing between thermal and nonthermal groundwater. Although arsenic is highly enriched in thermal water and is of interest in water-supply wells from a public health standpoint, it is reactive in groundwater systems and is not generally considered a conservative constituent.

\section{Chloride Concentrations in Groundwater from Mammoth Community Water District Production Wells}

Water chemistry in groundwater can be expected to vary through time in response to natural and human influences. The temporal variability of chemistry in water from the sampled wells was investigated in this monitoring program through a quarterly sampling schedule. Figure 19 shows the time series of chloride concentration in groundwater from the seven MCWD production wells. Groundwater from several of the wells (P6, P15, and P25) showed discernable variability, but no obvious seasonal patterns. Chloride concentrations in groundwater from well P17, the only MCWD production well that had groundwater with a chloride concentration greater than 3 milligrams per liter $(\mathrm{mg} / \mathrm{L})$, declined 40 percent during the monitoring period.

Assuming samples from wells P1, P6, P15, P16, P20, and $\mathrm{P} 25$ were representative of non-thermal groundwater in the study area, it is clear from figure 19 that non-thermal groundwater in this area dissolved very little chloride from the local rocks. The elevated chloride in water from well P17, together with its warmer water temperature than in other MCWD production wells (Kenneth D Schmidt and Associates, 2018), indicated that the well taps a source of thermal water rich in chloride. The ratio of the conservative constituents chloride and boron was used to investigate this. 
Table 3. Water chemistry of selected groundwater samples, Mammoth Lakes vicinity, California.

[Water temperature, specific conductance, $\mathrm{pH}$, and alkalinity are field measurements except for wells at sites $14 \mathrm{~A}$ and $28 \mathrm{~A}$, where the alkalinity value is a laboratory measurement of acid neutralizing capacity, and water temperature is the average of downhole values measured as a vertical profile in the screened interval. Constituents other than bromide are for filtered water. $\delta \mathrm{D}$ is the shift in the ratio of deuterium to hydrogen and $\delta^{18} \mathrm{O}$ is the shift in the ratio of oxygen-18 to oxygen-16, both relative to Vienna Standard Mean Ocean Water. $\delta \mathrm{D}$, and $\delta^{18} \mathrm{O}$ are for unfiltered water. Screen depths for Mammoth Community Water District wells are total intervals from Kenneth D. Schmidt and Associates, 2018. Abbreviation: mg/L, milligram per Liter; nr, not reported; YYYYMMDD, Year Month Day; ${ }^{\circ} \mathrm{C}$, degrees Celsius; $\mu \mathrm{s} / \mathrm{cm}$, microsiemen per centimeter; $\mu \mathrm{g} / \mathrm{L}$, microgram per Liter; >, greater than; <, less than]

\begin{tabular}{|c|c|c|c|c|c|c|c|c|c|c|c|c|c|c|}
\hline \multirow{4}{*}{$\begin{array}{l}\text { Water chemistry } \\
\text { parameter }\end{array}$} & \multirow{4}{*}{ Units } & \multicolumn{13}{|c|}{ Well name } \\
\hline & & P1 & P6 & P15 & P16 & P17 & P20 & P25 & M26 & $14 A-25-1$ & $14 A-25-2$ & $28 A-25-1$ & $28 A-25-2$ & $157-25$ \\
\hline & & \multicolumn{13}{|c|}{ Sample date (YYYYMMDD) } \\
\hline & & 20171010 & 20171011 & 20171011 & 20171011 & 20171011 & 20171011 & 20171011 & 20171011 & 20171129 & 20160518 & 20171128 & 20171128 & 20061012 \\
\hline $\begin{array}{l}\text { Screened interval, depths } \\
\text { below land surface }\end{array}$ & feet & $200-370$ & $146-670$ & $407-720$ & $420-680$ & $400-710$ & $420-710$ & $340-530$ & $621-686$ & $575-595$ & $470-490$ & $575-595$ & $440-460$ & $>600$ \\
\hline Temperature, water & ${ }^{\circ} \mathrm{C}$ & 7.5 & 9.4 & 9.1 & 18.2 & 22.6 & 15.6 & 8.2 & 35.2 & 102.8 & 79.3 & 52.9 & 50.2 & 175 \\
\hline Specific conductance & $\mu \mathrm{S} / \mathrm{cm}$ & 213 & 455 & 241 & 530 & 449 & 365 & 237 & 540 & 866 & 528 & 530 & 543 & 1,850 \\
\hline $\mathrm{pH}$ & $\mathrm{pH}$ units & 7.0 & 7.1 & 7.3 & 6.4 & 6.9 & 6.4 & 7.0 & 6.9 & 6.2 & 5.7 & 6.5 & 6.3 & 5.9 \\
\hline $\begin{array}{l}\text { Alkalinity as calcium } \\
\text { carbonate }\end{array}$ & $\mathrm{mg} / \mathrm{L}$ & 92.6 & 218 & 116 & 275 & 199 & 187 & 110 & 261 & 304 & 81.9 & 221 & 224 & 454 \\
\hline Ammonia as nitrogen & $\mathrm{mg} / \mathrm{L}$ & $<0.01$ & $<0.01$ & $<0.01$ & $<0.01$ & $<0.01$ & $<0.01$ & $<0.01$ & $<0.01$ & 0.64 & 0.06 & 0.01 & $<0.01$ & $\mathrm{nr}$ \\
\hline Nitrite as nitrogen & $\mathrm{mg} / \mathrm{L}$ & $<0.001$ & $<0.001$ & $<0.001$ & $<0.001$ & $<0.001$ & $<0.001$ & $<0.001$ & $<0.001$ & $<0.001$ & $<0.001$ & $<0.001$ & $<0.001$ & $\mathrm{nr}$ \\
\hline Nitrite + nitrate as nitrogen & $\mathrm{mg} / \mathrm{L}$ & 0.105 & 0.207 & 0.082 & $<0.04$ & 0.088 & 0.067 & 0.209 & 0.072 & $<0.04$ & $<0.04$ & $<0.04$ & $<0.04$ & $<0.05$ \\
\hline $\begin{array}{l}\text { Orthophosphate as } \\
\text { phosphorus }\end{array}$ & $\mathrm{mg} / \mathrm{L}$ & 0.325 & 0.169 & 0.490 & 0.122 & 0.240 & 0.097 & 0.170 & 0.200 & 0.210 & 0.985 & 0.369 & 0.401 & $<0.15$ \\
\hline Calcium & $\mathrm{mg} / \mathrm{L}$ & 6.08 & 33.1 & 4.32 & 21.2 & 15.6 & 15.2 & 8.63 & 12.6 & 39.4 & 25.5 & 13.9 & 15.0 & 5.05 \\
\hline Magnesium & $\mathrm{mg} / \mathrm{L}$ & 12.5 & 30.6 & 17.0 & 28.8 & 16.0 & 20.6 & 15.2 & 25.0 & 1.90 & 6.05 & 13.1 & 14.8 & 0.1 \\
\hline Sodium & $\mathrm{mg} / \mathrm{L}$ & 15.7 & 18.4 & 20.2 & 54.8 & 56.6 & 32.9 & 16.5 & 61.8 & 71.0 & 49.2 & 79.3 & 77.9 & 409 \\
\hline Potassium & $\mathrm{mg} / \mathrm{L}$ & 3.2 & 6.7 & 4.0 & 6.9 & 8.0 & 4.4 & 3.3 & 9.8 & 110 & 35.9 & 12.0 & 14.8 & 43.2 \\
\hline Chloride & $\mathrm{mg} / \mathrm{L}$ & 1.33 & 0.94 & 1.30 & 0.60 & 7.38 & 0.78 & 2.34 & 7.76 & 22.3 & 18.0 & 11.5 & 11.5 & 253 \\
\hline Sulfate & $\mathrm{mg} / \mathrm{L}$ & 7.04 & 39.3 & 8.04 & 12.3 & 11.4 & 5.96 & 9.34 & 9.88 & 56.9 & 125 & 29.9 & 36.3 & 111 \\
\hline Fluoride & $\mathrm{mg} / \mathrm{L}$ & 0.33 & 0.20 & 0.43 & 0.57 & 0.62 & 0.49 & 0.24 & 0.66 & 0.21 & 0.23 & 0.63 & 0.53 & 11.4 \\
\hline Silica & $\mathrm{mg} / \mathrm{L}$ & 48.5 & 46.9 & 51.7 & 78.6 & 96.3 & 74.4 & 46 & 132 & 270 & 270 & 144 & 158 & 285 \\
\hline Arsenic & $\mu \mathrm{g} / \mathrm{L}$ & 4.3 & 38.9 & 10.8 & 5.6 & 98.0 & 5.7 & 3.6 & 166 & 146 & 47.4 & 219 & 155 & 1,540 \\
\hline Boron & $\mu \mathrm{g} / \mathrm{L}$ & 30 & 97 & 52 & 98 & 346 & 65 & 33 & 426 & 3,280 & 1,550 & 656 & 673 & 11,100 \\
\hline Chloride to boron ratio & $\mu \mathrm{g} / \mu \mathrm{g}$ & 44.3 & 9.7 & 25.0 & 6.2 & 21.3 & 12.0 & 70.9 & 18.2 & 6.8 & 11.6 & 17.5 & 17.1 & 22.8 \\
\hline Iron & $\mu \mathrm{g} / \mathrm{L}$ & 46 & 59 & $<10$ & 33 & 136 & 389 & 21 & 65 & $<10$ & 53 & 98 & $<10$ & 170 \\
\hline Manganese & $\mu \mathrm{g} / \mathrm{L}$ & 3.38 & 290 & $<0.2$ & 55.8 & 28.1 & 90.4 & 2.3 & 191 & 229 & 814 & 226 & 29.9 & 15 \\
\hline Lithium & $\mu \mathrm{g} / \mathrm{L}$ & 59.3 & 195 & 39.9 & 177 & 169 & 114 & 63.7 & 203 & 120 & 84.1 & 225 & 242 & 3,210 \\
\hline Chloride to lithium ratio & $\mu \mathrm{g} / \mu \mathrm{g}$ & 22.4 & 4.8 & 32.6 & 3.4 & 43.7 & 6.8 & 36.7 & 38.2 & 185.8 & 214.0 & 51.1 & 47.5 & 78.8 \\
\hline Unfiltered bromide & $\mu \mathrm{g} / \mathrm{L}$ & 29 & 6.8 & 16 & 3.1 & 23 & 4.6 & 33 & 31 & 62 & 46 & 33 & 32 & 480 \\
\hline$\delta \mathrm{D}$ & per mil & -105 & -113 & -108 & -112 & -114 & -114 & -106 & -117 & -117 & -121 & -115 & -116 & -117 \\
\hline$\delta^{18} \mathrm{O}$ & per mil & -14.19 & -15.47 & -14.55 & -15.59 & -15.52 & -15.57 & -14.21 & -15.77 & -15.18 & -15.87 & -15.66 & -15.68 & -14.70 \\
\hline $\begin{array}{l}\text { Total dissolved solids dried } \\
\text { at } 180^{\circ} \mathrm{C}\end{array}$ & $\mathrm{mg} / \mathrm{L}$ & 140 & 298 & 169 & 352 & 330 & 256 & 165 & 386 & 740 & 593 & 414 & 434 & $\mathrm{nr}$ \\
\hline
\end{tabular}

${ }^{1}$ Analysis of geothermal well 57-25 published by Brown and others (2013). 


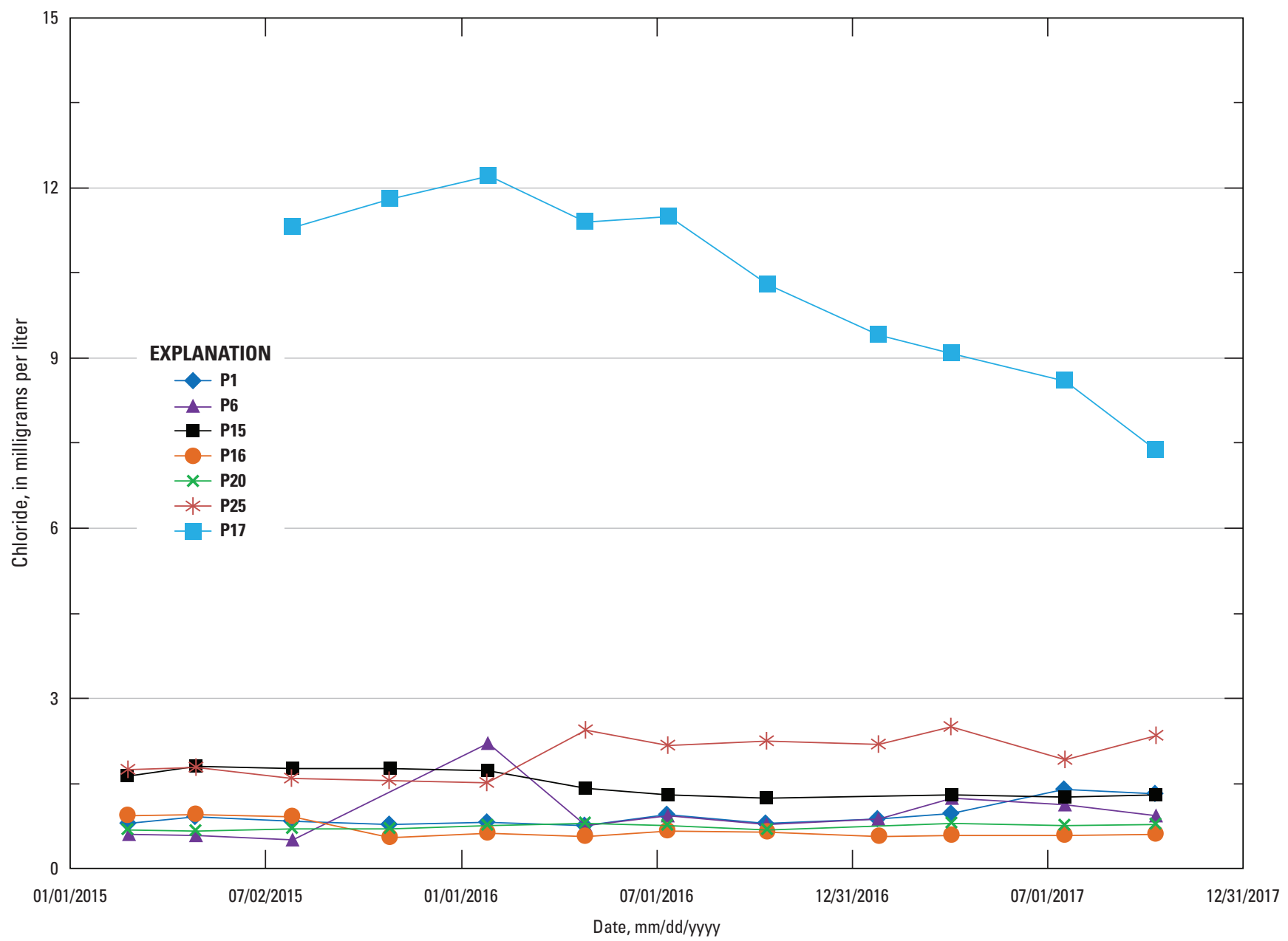

Figure 19. Time series of chloride concentrations in groundwater from Mammoth Community Water District production wells, 2015-17, Mammoth Lakes, California. No data for well P17 before July 2015.

\section{Chloride to Boron Ratio}

Numerous studies published in the past few decades have concluded that the nearly constant chloride to boron ratio of about 23 in thermal water samples from Long Valley Caldera links them all to a common deep geothermal reservoir (Shevenell and others, 1987; White and others, 1990; Sorey and others, 1991; Evans, 2017). A long residence time (probably centuries) in this hot reservoir, northwest of the CD-4 project area, allows the water to dissolve substantial quantities of chloride and boron from the host metasedimentary basement rocks. During subsequent flow southeastward, the thermal groundwater is progressively diluted by non-thermal groundwater, which does not contain enough chloride or boron to alter the chloride to boron ratio. Figure 20 shows the chloride and boron data for groundwater from a suite of geothermal wells and thermal springs in Long Valley Caldera sampled in 2005-07 and reported by Brown and others (2013). As in previous studies (Shevenell and others, 1987; Sorey and others, 1991), the data follow a dilution line that runs from well 44-16, the westernmost well (fig. 1) and the one having the highest downhole water temperature $\left(214^{\circ} \mathrm{C}\right)$, through wells and hot springs to the east as far as spring BAL (fig. 1), where the dilution is substantial. This dataset includes the newer geothermal production wells 57-25 and 66-25 (fig. 20) and shows that groundwater from these wells followed the same mixing line as in earlier studies. The regression line through this suite of thermal water yields a chlorine to boron ratio of $22.4\left(\mathrm{R}^{2}=0.97\right)$.

Farrar and others (2003) provided chloride and boron data for groundwater from two other sites that showed greater dilution, the approximately $100{ }^{\circ} \mathrm{C}$ Long Valley exploratory well (LVEW) on the resurgent dome (fig. 1) and a slightly thermal $\left(15.6^{\circ} \mathrm{C}\right)$ spring, Fish Hatchery CD spring group (FHCD), at the Hot Creek State Fish Hatchery (fig. 1). Only a small percentage of the spring discharge is thermal water, so the spring plotted near the origin but on the regression line through all the other thermal water sources (fig. 20). 


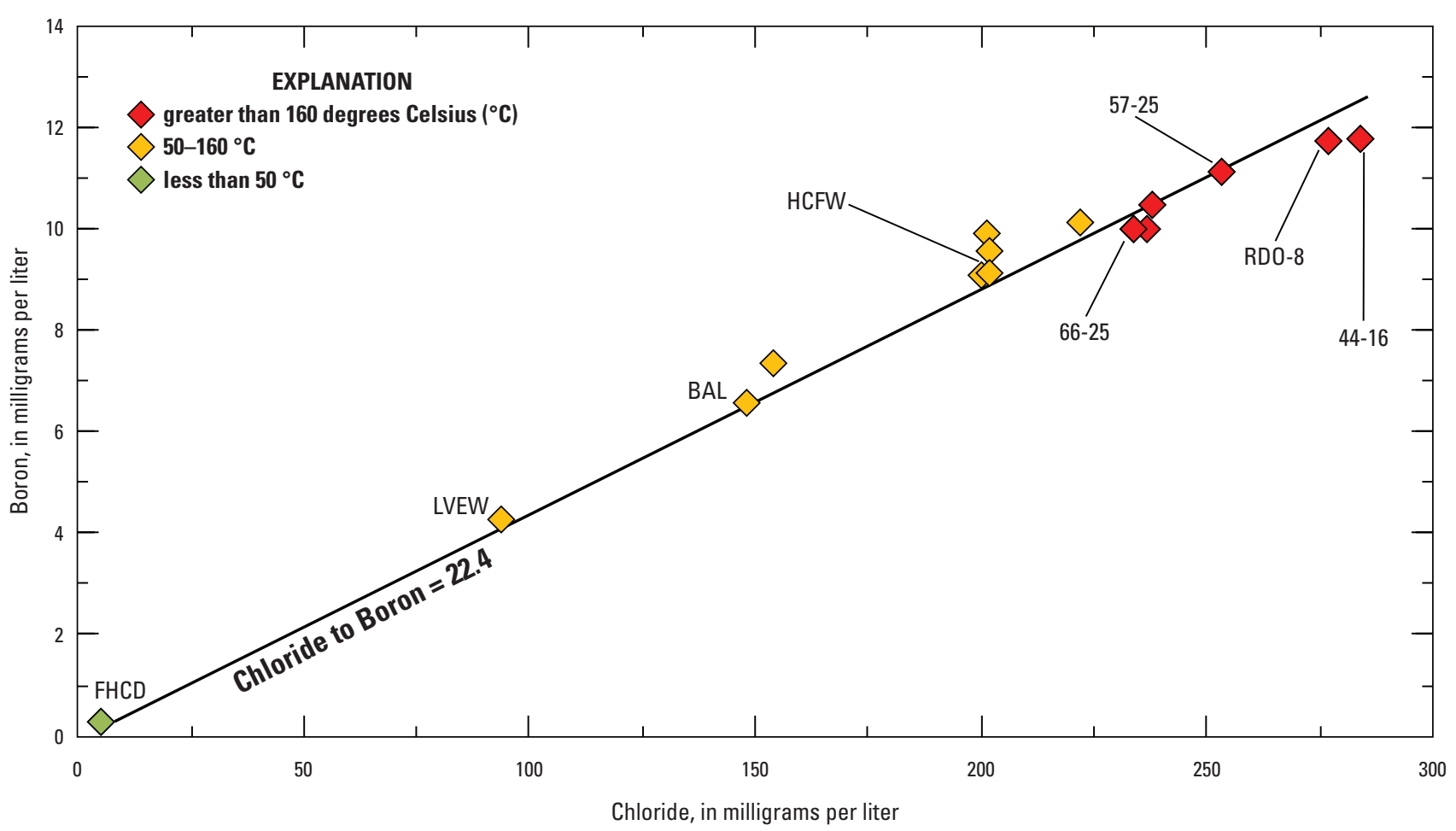

Figure 20. Correlation of chloride and boron concentrations in groundwater from a suite of Long Valley Caldera, California, geothermal wells (including wells 44-16, RD0-8, 57-25, and 66-25) and thermal springs in Hot Creek Gorge (HCFW) and at Big Alkali Lake (BAL) sampled in 2005-07 and reported by Brown and others (2013) and from the Long Valley exploratory well (LVEW) and warm springs at the fish hatchery (FHCD) sampled in 1999-2001 and reported by Farrar and others (2003). Points are color coded by discharge temperature for springs and maximum downhole temperature for wells. See figure 1 for the locations of 44-16, LVEW, FHCD, HCFW, BAL and figure 3 for the locations of RD0-8, 57-25 and 66-25.

Figure 21 shows the chloride and boron concentrations measured during the quarterly sampling of groundwater production and monitoring wells. The axes are much shorter than those in figure 20, and water from the geothermal wells and thermal springs in the study by the Brown and others (2013) plots far off-scale to the right, but the thermal-water trend line from figure 20 is retained. The MCWD production wells, except P17, access groundwater that acquired chloride and boron from precipitation inputs and low-temperature weathering of surficial rocks. The average chloride to boron ratios ranged from 6 to 49, but the low concentrations of chloride and boron plotted in a tight cluster near the origin. The average of all these non-thermal groundwater samples is shown by the black circle on figure 21. Samples that contained a mixture of the average non-thermal groundwater and the deep geothermal water should plot along the thermal-water trend line originating at the black circle, as does water from the fish hatchery spring group FHCD. Groundwater from MCWD production well P17 and monitoring wells M26 and 28A-25 (both depths) plotted along the thermal-water trend line. Well P17 groundwater composition remained near the geothermal trend line as boron and chloride concentrations decreased during the study period; this can be attributed to a change in mixing proportions of the thermal and non-thermal end-members (increased non-thermal component, possibly due in part to the extremely wet winter of 2016-17). Groundwater from monitoring well 14A-25 plotted off the thermal-water trend line and did not appear to be a mixture of the nonthermal and deep geothermal water, based on chloride and boron ratios. Groundwater from this well is discussed further in a subsequent section.

The Mammoth Mountain ski area (fig. 1) applies salt (sodium chloride) to some runs in late winter and spring to improve skiing conditions. As a result, surface and groundwater at the ski area are enriched in chloride from this source; for example, a value of $19 \mathrm{mg} / \mathrm{L}$ was reported for a sample from a well at the ski area by Farrar and others (2003). The chloride to boron ratio in this sample was 950. Combining this result with two analyses of runoff from a creek that drains the ski area (Evans and Bergfeld, 2017) yielded an average chloride to boron ratio of about 1,660 for water in the ski area. Groundwater affected by ski-area salting would be expected to plot on a line having a different slope than the thermal-water trend line (fig. 21). None of the groundwater sampled in this study showed any chloride contribution from ski-area salting. 


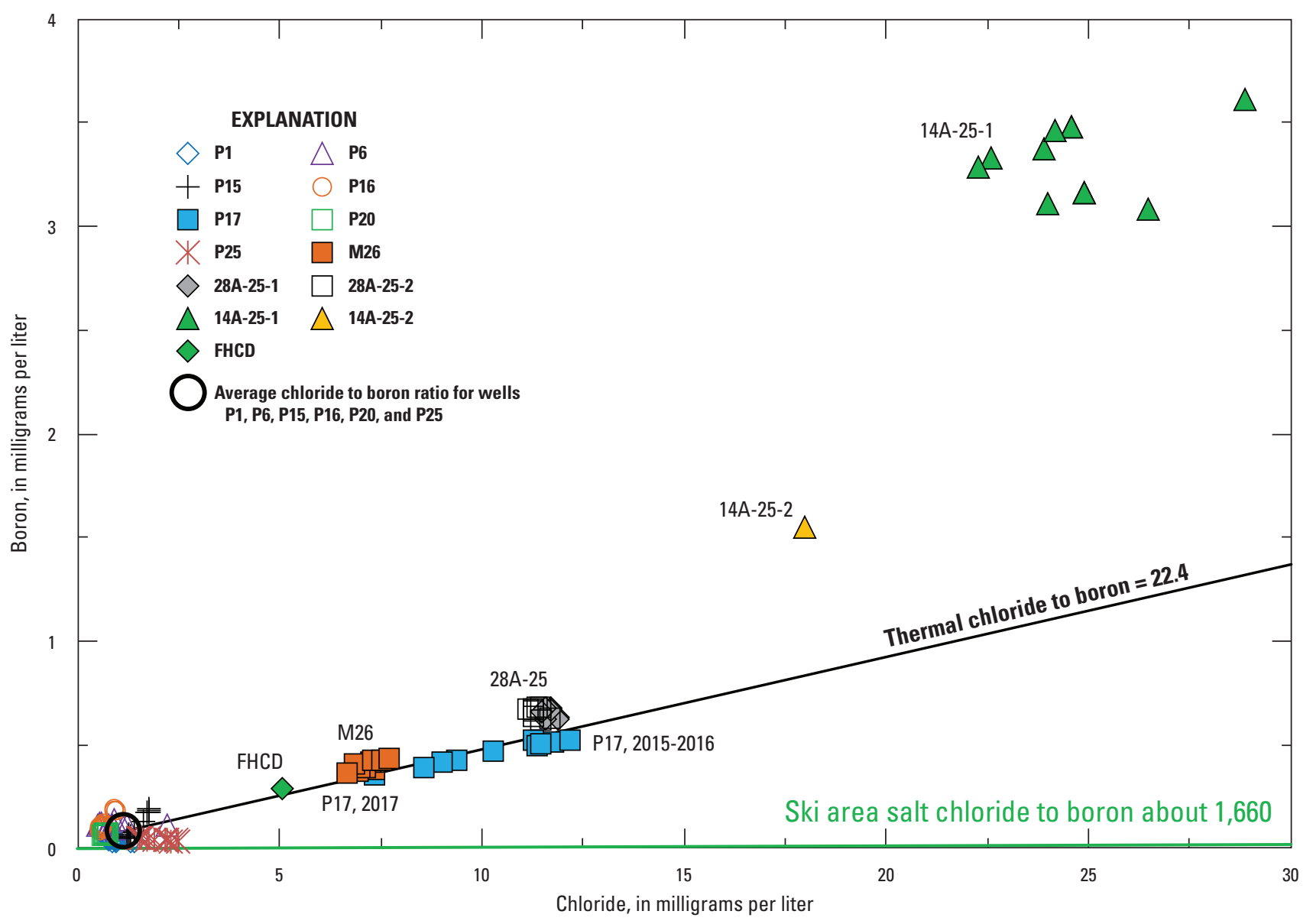

Figure 21. Chloride and boron data for groundwater from Mammoth Community Water District wells (P1, P6, P15, P16, P17, P20, P25, M26) and monitoring wells (14A-25-1, 14A-25-2, 28A-25-1, 28A-25-2) for samples collected 2015-17 and warm springs at the fish hatchery sampled in 1999-2001 and reported by Farrar and others (2003), Mammoth Lakes area, California.

\section{Chloride to Bromide and Chloride to Lithium Ratios}

Other chemical constituents, such as bromide and lithium, are also often considered to be conservative in geothermal systems. White and Peterson (1991) showed that lithium and chloride concentrations in geothermal water in Long Valley conformed to a mixing line having a chloride to lithium ratio of about 100 . The lithium, bromide, and chloride data from the geothermal water samples reported by Brown and others (2013) are plotted in figure 22. Mixing lines are shown with a chloride to lithium ratio of $87\left(\mathrm{R}^{2}=0.60\right)$ and a chloride to bromide ratio of $540\left(\mathrm{R}^{2}=0.31\right)$ - but the scatter about the lines was much greater than for chloride to boron. Another shortcoming of using chloride to bromide and chloride to lithium ratios was evident when the axes were shortened (figs. 23 and 24). Groundwater composition from the MCWD production wells (excluding P17) showed more scatter, and the average compositions of water from these wells (black circles) were shifted substantially from the origin.
Variations in the sources (precipitation and low-temperature rock weathering) of bromide and lithium were apparently greater than variations in the sources of boron in non-thermal groundwater. Nevertheless, groundwater from the MCWD production well P17 and monitoring wells M26 and 28A-25 (both depths) plotted reasonably close to the geothermalwater trend lines originating from the average non-thermal groundwater composition (black circles) on figures 23 and 24. Again, groundwaters affected by ski-area salting would be expected to plot on lines of a different slope, given chloride to bromide and chloride to lithium ratios reported for samples of stream water draining the ski area (Evans and Bergfeld, 2017). Thus, the chloride to bromide and chloride to lithium ratios were consistent with the thermal-water mixing scenario deduced from the chloride to boron ratios. The thermalgroundwater component would constitute as much as 5 percent of the water in well 28A-25 and the most chloride-rich water sample from well P17, assuming a chloride concentration of about $240 \mathrm{mg} / \mathrm{L}$ as the thermal end member, similar to that of water from the two geothermal wells 57-25 and 66-25. 


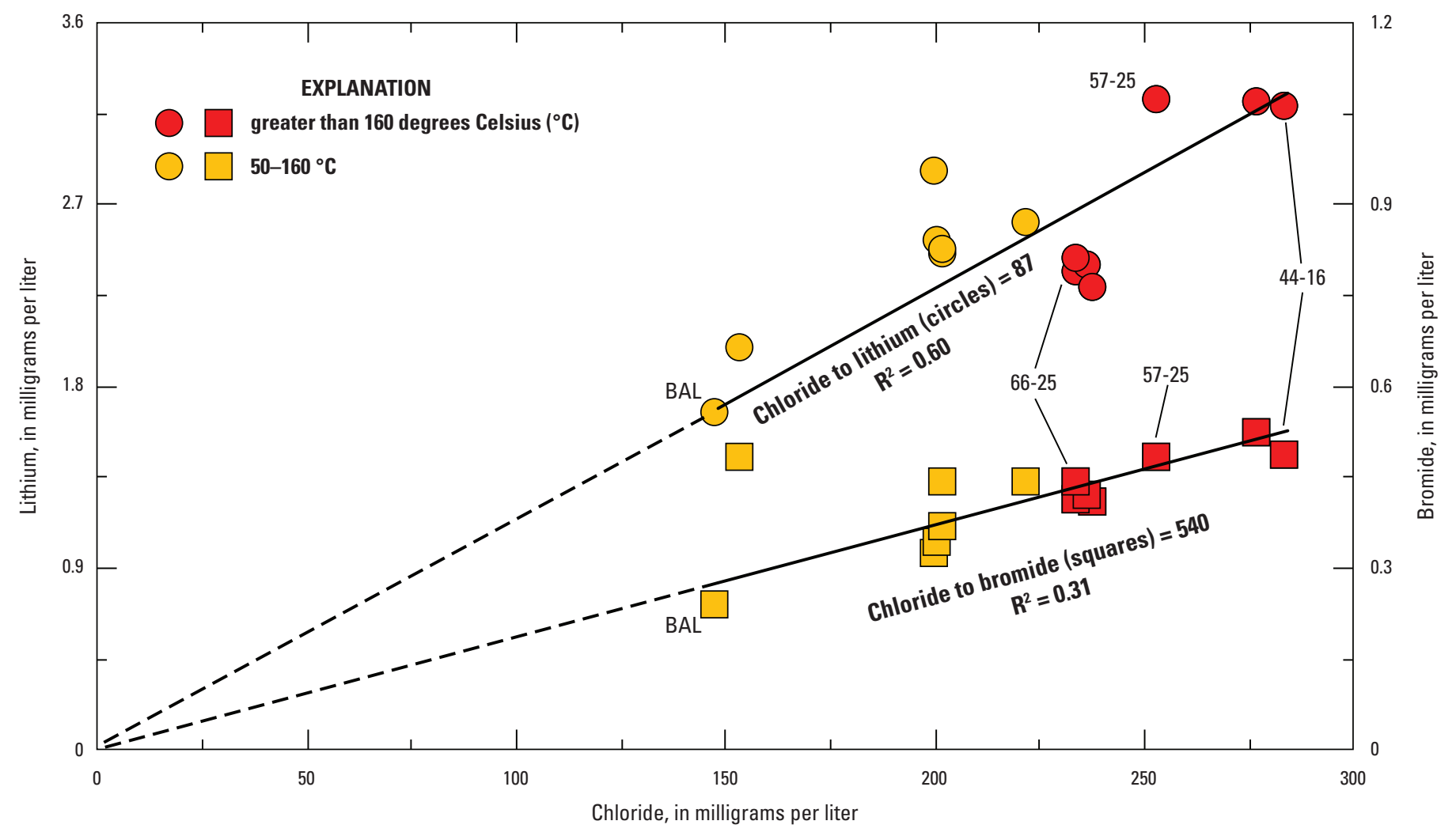

Figure 22. Correlations of chloride to lithium and chloride to bromide concentrations for water samples from sites shown in figure 20, including geothermal wells 44-16, 57-25, and 66-25 and Big Alkali Lake (BAL), Long Valley Caldera, California; data from Brown and others (2013). Points are color coded by discharge temperature for springs and maximum downhole temperature for wells. 


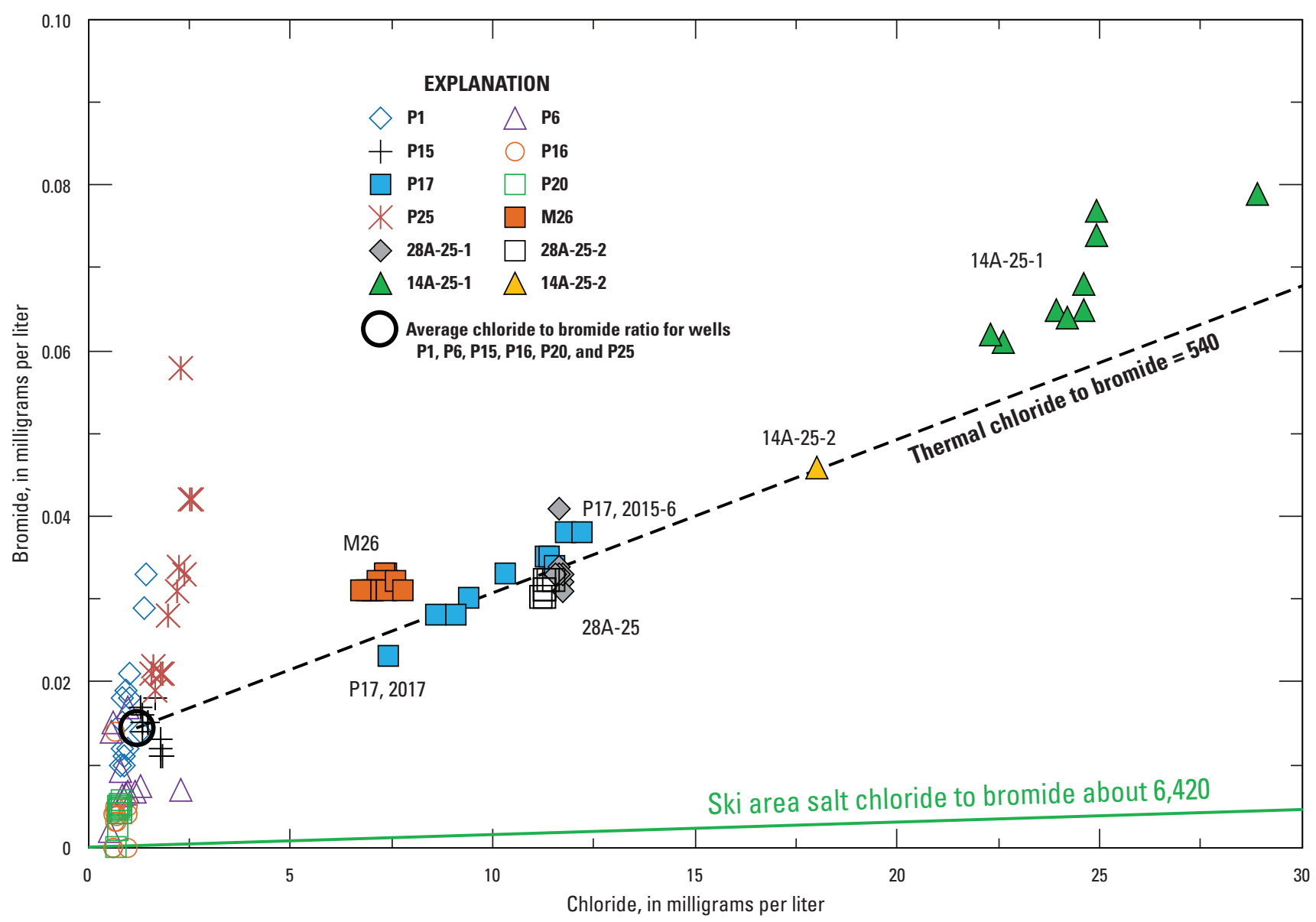

Figure 23. Correlation of chloride and bromide concentrations for groundwater from Mammoth Community Water District wells (P1, P6, P15, P16, P17, P20, P25, M26) and monitoring wells (14A-25-1, 14A-25-2, 28A-25-1, 28A-25-2) collected in 2015-17, Mammoth Lakes area, California.

Groundwater from wells 14A-25-1 and 14A-25-2 plotted near the thermal-water trend for chloride to bromide (fig. 23), but far from the thermal-water trends for chloride to boron and chloride to lithium (figs. 21 and 24); thus, the chemistry cannot be explained in the same way as that from the other monitoring wells. Other aspects of this chemistry are anomalous compared to other groundwater and geothermal water in the Long Valley area, such as the predominance of potassium (K) among the cations (table 3 ). Contamination by drilling fluids from drilling the nearby (105 ft distant) deep geothermal well 14-25 was suspected when the well was first sampled in February 2016, but enough water has been removed from the wellbore during subsequent samplings that contamination is an unlikely explanation for the anomalous chemical composition. The anomalous chemistry, which could result from extensive interaction with the local host rocks (rhyolitic lava), obscures the nature of any connections the water in well 14A-25 might have with either the deep geothermal water or the local groundwater in the MCWD production wells. 


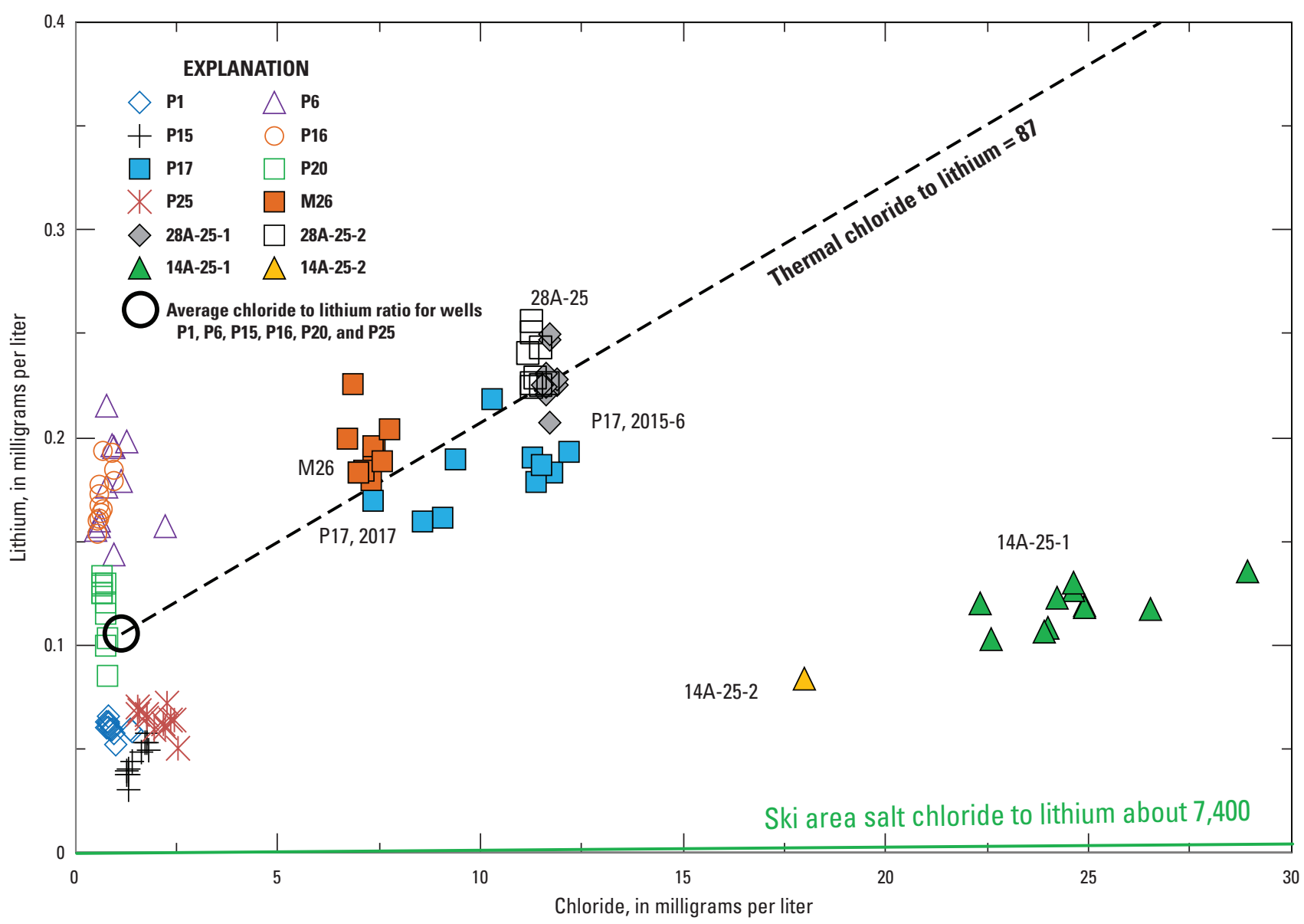

Figure 24. Correlation of chloride and lithium concentrations for groundwater from Mammoth Community Water District wells (P1, P6, P15, P16, P17, P20, P25, M26) and monitoring wells (14A-25-1, 14A-25-2, 28A-25-1, 28A-25-2) collected during 2015-17, Mammoth Lakes area, California.

\section{Stable Isotopes}

Previous studies in the Long Valley area have shown that the ratios of stable isotopes of hydrogen and oxygen in thermal and non-thermal water plotted on different trend lines (White and others, 1990; Sorey and others, 1991). Nonthermal groundwater plotted along or near the Global Meteoric Water Line (GMWL), and values became progressively lighter (more negative) from west to east across the caldera (White and others, 1990). Geothermal water plotted to the right of this line because of an oxygen-isotope shift during waterrock interaction at high temperatures in the deep geothermal reservoir (Sorey and others, 1991). Groundwater from the hottest, westernmost well (44-16, fig. 1) showed the extent of this shift, about 1.5 per mil. Figure 25 shows the stable-isotope compositions measured during the quarterly monitoring, the GMWL, and the trend line through the 2005-07 samples of geothermal water samples described previously. The groundwater from the production and monitoring wells (excluding well 14A-25-1) plotted reasonably close to the GMWL, and the geothermal water samples showed mixing between the geothermal source water (in well 44-16) and non-thermal water that was isotopically lighter than any of the local groundwater sampled in this study, as discussed by White and others (1990) and Sorey and others (1991).

Three of the MCWD production wells, P1, P15, and P25, are close to Mammoth Creek (fig. 2), and samples from them had isotopic values similar to those reported by Sorey and others (1991) for cold springs and streams draining Mammoth Mountain, shown as "Mammoth Mountain" on fig. 25. The slight shift to the right of the GMWL could indicate evaporation prior to recharge, perhaps in lakes along the upstream reaches of Mammoth Creek. Water from the other production wells, including P17, and most monitoring wells, had isotopic values characteristic of groundwater from points farther east, such as the southwest rim of the Long Valley Caldera (fig. 1; Sorey and others, 1991). In general, these results agreed with groundwater-flow models for the Mammoth Lakes area (Kenneth D Schmidt and Associates, 2018). Wells P1, P15, and P25 are thought to tap groundwater flowing out of the Mammoth "Lakes Basin" at the southeastern base of Mammoth Mountain; the other wells tap recharge areas further east. 


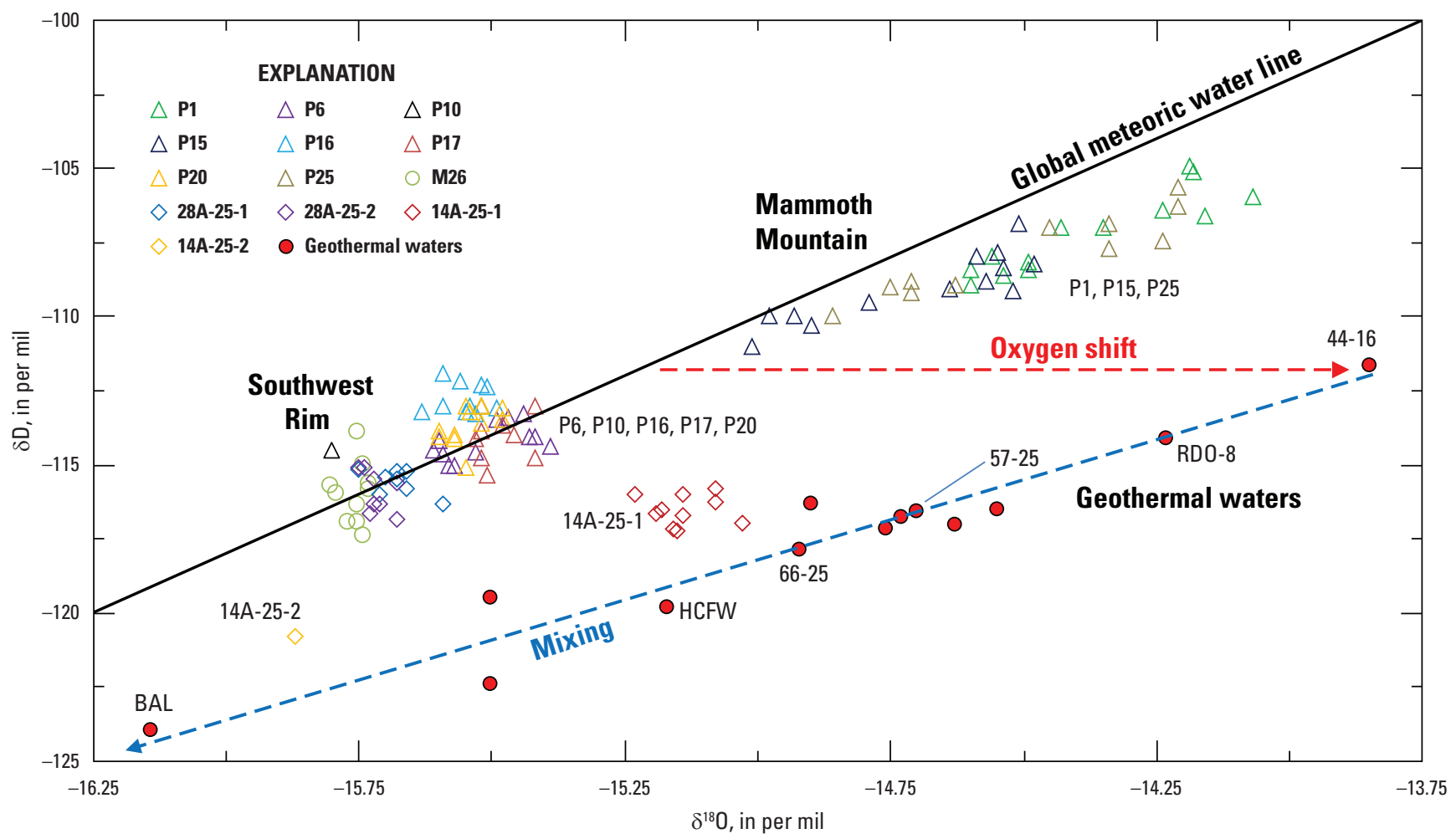

Figure 25. Relation between stable isotope ratios of hydrogen $(\delta D)$ and oxygen $\left(\delta^{18} 0\right)$ in water for Mammoth Community Water District wells (P1, P6, P15, P16, P17, P20, P25, M26) and monitoring wells (14A-25-1, 14A-25-2, 28A-25-1 and 28A-25-2) for samples collected 2015-17 in Mammoth Lakes area, California. Geothermal-water samples from Brown and others (2013) shown as red dots. GMWL, Global Meteoric Water Line $\left(\delta \mathrm{D}=8 \times \delta^{18} 0+10\right)$; HCFW, Hot Creek Gorge Spring. Red arrow shows oxygen shift in deep geothermal reservoir; blue line shows progressive mixing of reservoir water (well 44-16) with non-thermal groundwater.

Mixing with geothermal water would shift the isotopic values of any groundwater from the GMWL toward the geothermal trend shown on figure 25. The expected shift was too small to be discernable for groundwater from wells P17, M26, 28A-25-1, and 28A-25-2, which as discussed previously, contained as much as 5 percent geothermal water. Water from 14A-25-1 and 14A-25-2 showed a strong shift and plotted between the non-thermal and geothermal trend lines, however. A one-to-one mixture of geothermal water, similar to that in wells 66-25 and 57-25, and of non-thermal groundwater, similar to that in some MCWD production wells (P6 and P10), would plot within the array of points for water from 14A-251. A one-to-one mixture of these fluids, however, would also have a chloride concentration near $120 \mathrm{mg} / \mathrm{L}$, much greater than the measured value of $22.3 \mathrm{mg} / \mathrm{L}$ for $14 \mathrm{~A}-25-1$ (table 3 ). The sample from 14A-25-2 plotted well away from the nearby geothermal wells and the local groundwater. Simple mixing between the deep geothermal water and local groundwater for 14A-25-1 and 14A-25-2 is thus inconsistent with the chemistry of the groundwater from this well. The nature of the connection between this water and either the deep geothermal water or the local groundwater remains unclear.

\section{Water-Level Variations During a Flow Test of a Geothermal Production Well}

\section{Description of Flow Test}

From August 26 to September 22, 2017, Ormat carried out a flow test for the geothermal production well 14-25 (fig. 3), which had been idle since it was drilled in 2010. The purpose of the flow test was to evaluate the production rate and temperature of geothermal water from this well, which is completed in the Bishop Tuff. The produced fluid was reinjected into the geothermal aquifer through well 12-25, approximately 1,480 ft north of 14-25 (fig. 3). The 600 -ft-deep monitoring well 14A-25-1 is about $105 \mathrm{ft}$ southwest of production well 14-25, and is completed in the early rhyolite (appendix fig. 1-1). The 600-ft-deep monitoring well $28 \mathrm{~A}-25-1$ is $2,600 \mathrm{ft}$ to the southeast of the $14 \mathrm{~A}-25$ well site (fig. 3). At site 28A-25, both the deep (28A-25-1) and the shallow (28A-25-2) wells are completed in the early rhyolite (appendix fig. 1-2). The following section describes the filtered water-level data from the monitoring wells before, during, and after the 28-day flow test of production well 14-25. 


\section{Filtered Water-Levels at Sites 14A-25 and 28A-25 Before, During, and After the Flow Test}

For several months prior to the flow test, steadily rising water levels were measured in wells 14A-25-1, 28A25-1, and 28A-25-2 (figs. 8 and 9). When pumping began in production well 14-25 on August 26, the water level in the nearby monitoring well $14 \mathrm{~A}-25-1$ rose approximately $0.27 \mathrm{ft}$ in 5 hours before returning to the pre-test water level on August 30 (fig. 26).

An abrupt rise and subsequent fall in water level in the hydrostratigraphic units above a pumped unit is known as a "reverse water-level fluctuation" or "Noordbergum effect" (Hsieh, 1996; Wang, 2000, p. 218-221). The rise in water level is due to a poroelastic effect (mechanical response of the aquifer matrix due to strain). At the onset of production from well 14-25, the decrease in fluid pressure in the produced unit (Bishop Tuff) resulted in a contraction of the aquifer matrix. This localized contraction in the producing unit, in turn, induced contraction of the overlying early rhyolite units, increasing the fluid pressure in those units, and causing a rise in water level after pumping started. After the initial contraction, the increased fluid pressure in the overlying early rhyolite units gradually dissipated, and the water level in well 14A-25-1 recovered to a pre-test level (fig. 26). A plot of the detrended, filtered, water-level response in well 14A-25-1 to the flow test is shown in appendix 2 (appendix fig. 2-16).

No poroelastic response at the start of pumping was discernable in the more distant monitoring wells 28A-25-1 and 28A-25-2 (fig. 26). Instead, the water level in both 28A25 wells continued to rise steadily throughout the flow test. These water-level records serve as a background or reference to compare to the water-level record in well 14A-25-1 during the 28-day flow test (see appendix figure 2-17 for a longer period of record for the filtered water levels in the monitoring wells at sites $14 \mathrm{~A}-25$ and $28 \mathrm{~A}-25$ that includes the period of the flow test).

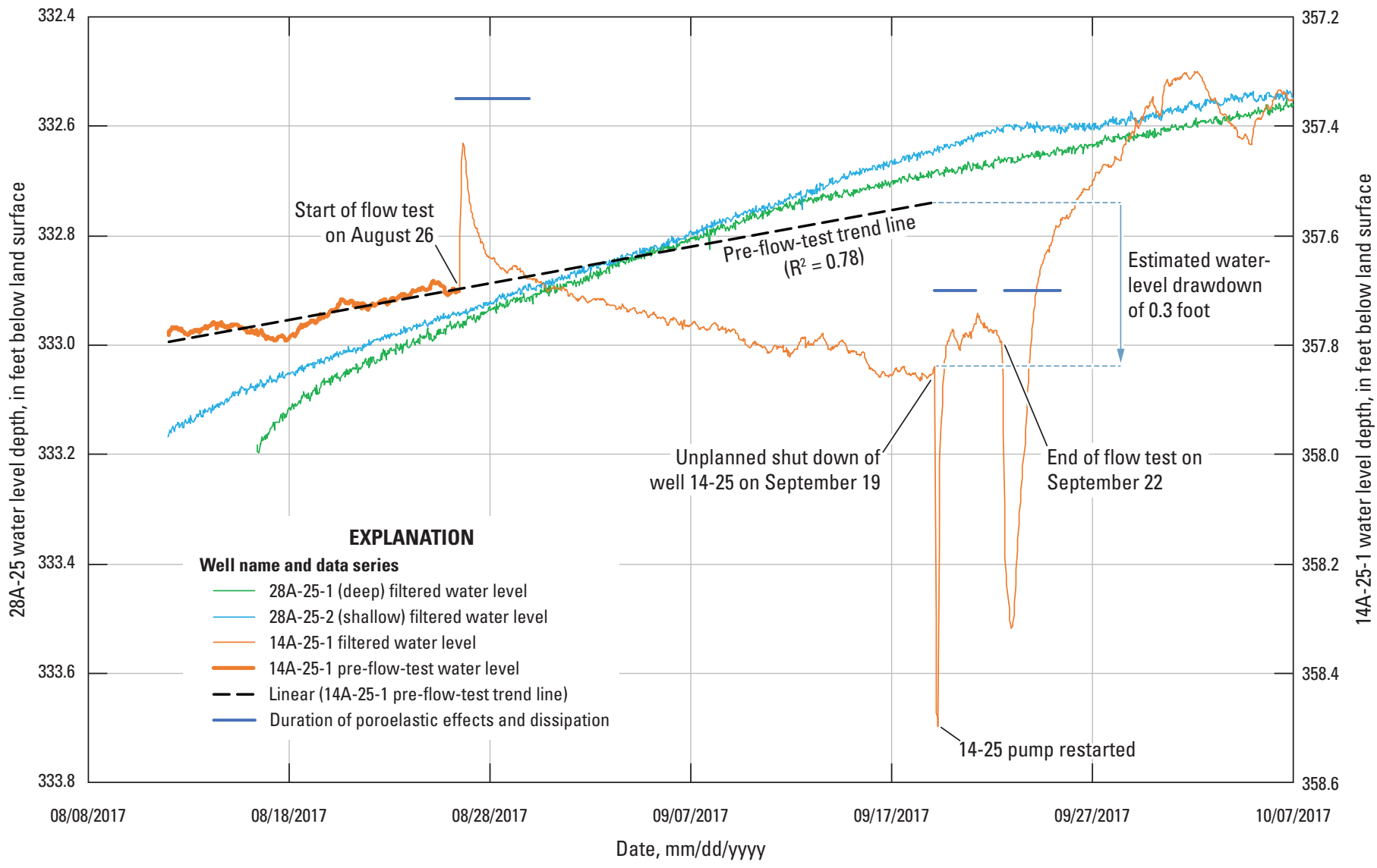

Figure 26. Digitally filtered water-level data for wells 14A-25-1, 28A-25-1, and 28A-25-2, Mammoth Lakes area, California, from August 12 to October 6, 2017. 
By August 30, after the dissipation of the reverse waterlevel response, the water level in well 14A-25-1 began a steady decline, reversing the upward pre-test trend (fig. 26). The steady water-level decline in 14A-25-1 persisted until September 19, when the pump in production well 14-25 unexpectedly shut down for 5 hours. When the fluid production stopped, a second poroelastic "reverse water-level fluctuation" was observed in well 14A-25-1. In this case, however, the fluid pressure recovery in the deep geothermal aquifer (Bishop Tuff) caused a relative expansion of the aquifer matrix, which, in turn, expanded the overlying early rhyolite units. The expansion or dilation of the aquifer matrix in the overlying early rhyolite units caused the fluid pressure (water level) to abruptly drop approximately $0.66 \mathrm{ft}$ (fig. 26). After five hours the pumping resumed, which caused a third reverse water-level response, in this case an increase in water level superimposed on the response from the second downward reverse water-level fluctuation. Note that the third reverse water-level response, when superimposed on the dissipation phase of the second reverse water-level response, caused a much shorter dissipation period compared to the first reverse water-level response. From early on September 20 until the flow test ended on September 22, the water level in 14A-25-1 fluctuated about the $357.8 \mathrm{ft}$ level (fig. 26). The water level during this period primarily represents the combined responses of the unplanned shutdown and the restart of pumping. This is because the Noordbergum effect can take several days or more to dissipate, as indicated by the dissipation phase of the initial response to the start of production. When production well $14-25$ was intentionally shut down on September 22, there was a fourth reverse waterlevel fluctuation (fig. 26). The reverse water-level fluctuation in this instance was a drop of approximately $0.51 \mathrm{ft}$. Following the $0.51 \mathrm{ft}$ drop, the water level in well 14A-25-1 began a steep $0.72 \mathrm{ft}$ rise (poroelastic dissipation) that continued until early on September 25 (fig. 26). By September 25, after the dissipation of the poroelastic effects the water level in well 14A-25-1 was at a level higher than the start of the flow test and returned to an upward trend.

\section{Analysis of Water-Level Changes}

Prior to the start of pumping, the water level in well 14A-25-1 showed a steadily rising trend (fig. 26). Starting on August 30, after the start of pumping and dissipation of poroelastic effects, the water level began a steady decline until the unplanned shutdown on September 19. By September 25, after the planned shutdown and dissipation of poroelastic effects, the water level had risen to a level higher than at the start of the flow test and returned to an upward trend. Collectively, the temporal changes in the water-level trends indicated hydraulic drawdown in the early rhyolite units monitored by well 14A-25-1 during the 28-day flow test. The hydraulic drawdown in well 14A-25-1 during the flow test $(0.3 \mathrm{ft})$ was estimated as the difference between the best-fit $\left(\mathrm{R}^{2}=0.78\right)$, pre-flow-test trend line for well 14A25-1 and the digitally filtered water level in well 14A-25-1 on September 19, prior to the unplanned shutdown of the pump in well 14-25 (fig. 26). This drawdown in the digitally filtered water-level data indicated that, near wells 14-25 and 14A-25-1, there is some hydraulic connection between the deep geothermal aquifer and the shallow aquifer in the early rhyolite units. The connection pathways are unknown but could be either subvertical through the early rhyolite matrix, through interconnected fracture networks in the early rhyolite, or through nearby high-angle faults (Hildreth, 2014). The degree of hydraulic connection (principally, the vertical hydraulic conductivity) between the deep geothermal aquifer and the shallow-aquifer system in the vicinity of wells 14-25 and 14A-25-1 is uncertain; however, the nature of the connection could be resolved better by numerical simulations of the flow test and by collecting additional data from, and simulations of, longer term flow tests. Furthermore, a calibrated groundwater-flow model (numerical simulation) that includes the shallow aquifer and deep geothermal aquifer could integrate the hydraulic monitoring data of both systems to improve assessments of potential effects on the shallow-aquifer system caused by the development of the geothermal resource.

\section{Potential Physical and Chemical Influences on Water-Level Data}

This section presents a discussion of potential physical and chemical influences to determine whether they could have had a substantive effect on the unfiltered water-level records for wells 14A-25-1, 28A-25-1, and 28A-25-2 during the 28-day flow test in August and September of 2017 of geothermal production well 14-25.

As described previously, water level in the shallow groundwater wells was monitored with an up-hole pressure transducer connected to a nitrogen-gas-filled line with a gas regulator (fig. 4). Placement of the nitrogen-gas-filled line in the upper $25 \mathrm{ft}$ of the water column used with a low-range (that is, high resolution, about $0.01 \mathrm{ft}$ ) pressure transducer provides sensitive measurements of water-level changes. A record obtained in this manner, however, reflects pressure changes in the groundwater system at the screened interval (575-595 ft below land surface) as well as density changes in the 2-inch diameter well above the screened interval. The pressure at the screened interval $\left(\mathrm{P}_{\mathrm{SCR}}\right)$ can be calculated using equation 3 : 


$$
P_{S C R}=\rho \times g \times h
$$

where

$\rho \quad$ is water density (kilograms per liter, $\mathrm{kg} / \mathrm{L}$ ),

$g \quad$ is the fixed gravitational acceleration (meters per second squared, $\mathrm{m} / \mathrm{s}^{2}$ ), and

$h$ is the height (meters, $\mathrm{m}$ ) of the water column above the screen.

A change in water density results in a change in $h$, even if $P_{S C R}$ is constant. Water-density changes could be induced by variations in temperature or salinity. Discussed in the next section are various scenarios that could have caused density changes during the 28-day flow test, the calculated effect on water level, and a comparison between these calculated effects and the observed $0.3-\mathrm{ft}$ water-level drawdown in well 14A-25-1.

\section{Temperature-Induced Density Changes}

\section{Vapor-Phase Conditions at Well 14A-25-1}

Formation of a vapor (steam) phase resulting from groundwater boiling would cause a large change in the bulk fluid density. Figure 27 shows the water-temperature profiles in well 14A-25-1 measured before and after the flow test of well 14-25. The difference between these two profiles is barely discernable at this scale. The boiling-point depth (BPD) curve shows the temperature at which water boils at the water-level elevation (approximately 7,424 ft) and the increase in boiling temperature by depth due to the increase in hydrostatic pressure. The boiling temperature at the watersurface elevation $\left(93^{\circ} \mathrm{C}\right)$ is much hotter than the measured temperature (approximately $62.5^{\circ} \mathrm{C}$ ), and the difference increases with depth. Thus, the formation of a steam phase in well 14A-25-1 during the flow test is unrealistic.

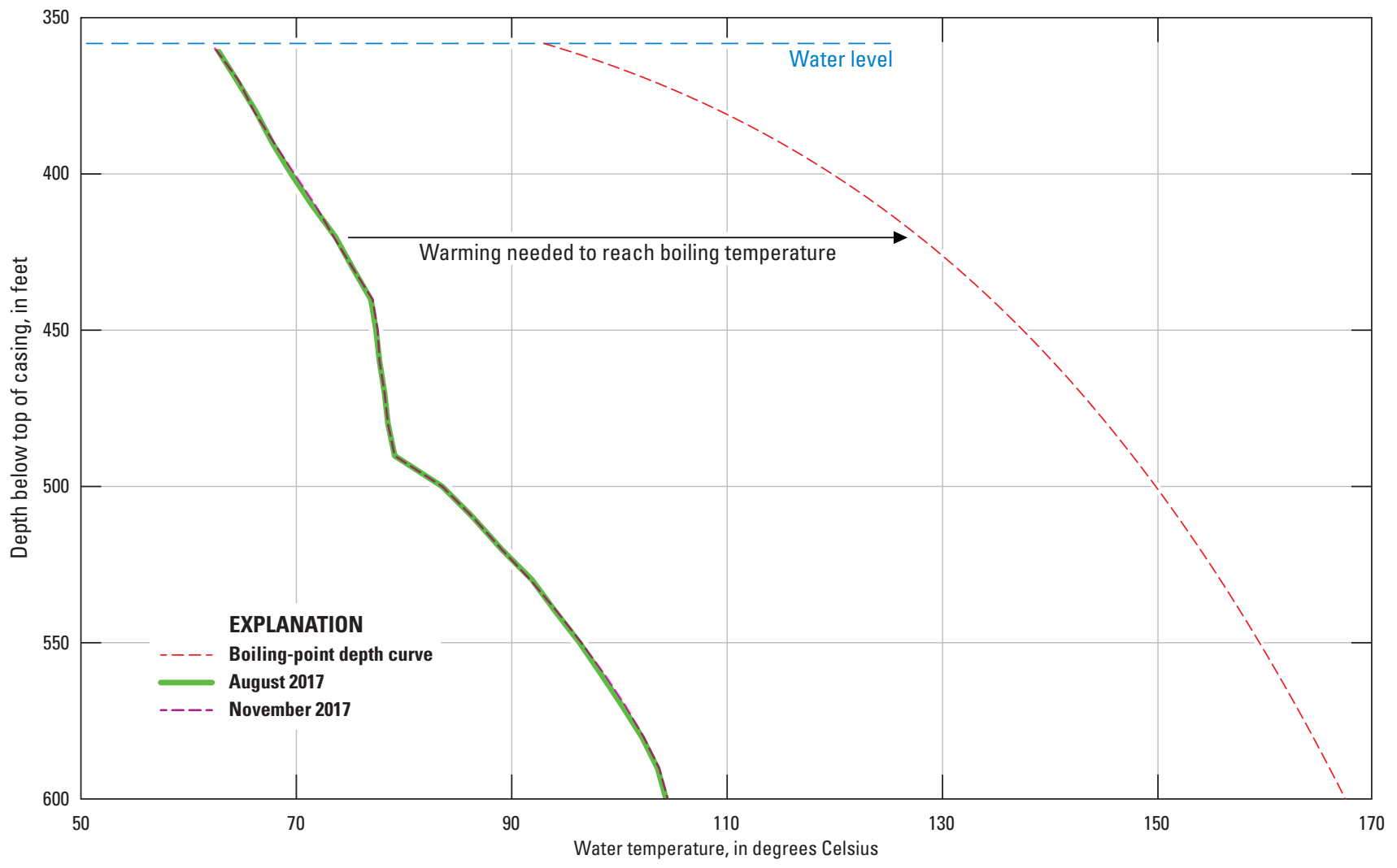

Figure 27. Well 14A-25-1 water-temperature profiles in August and November of 2017, Mammoth Lakes area, California (before and after the flow test of well 14-25), and boiling-point depth (BPD) curve. The boiling-point depth curve was calculated for a water table elevation of 7,424 feet and a barometric pressure of 78 kilopascals. 


\section{Thermal Conduction Due to Nearby Production Well 14-25}

Upward flow of hot geothermal water in production well 14-25 during the flow test would have heated the groundwater surrounding the well by conduction through the well casing. Conductive heat transfer from piping is a well-studied process and can be modeled after Carslaw and Jaeger (1959, p. 334-337). Using the measured temperature conditions at well 14-25 during the flow test (about $170{ }^{\circ} \mathrm{C}$ ) and reasonable assumptions about the heat capacity ( 1 kilojoule per kilogram per degree Celsius) and thermal conductivity ( 2 watts per meter per degree Celsius) of the surrounding rocks, temperature increases greater than $1{ }^{\circ} \mathrm{C}$ would be confined to a $16-\mathrm{ft}$ radius around the well during the 28 -days of the flow test. Some boiling or vapor-phase conditions could have existed within this radius, but this would not be expected to influence groundwater density $105 \mathrm{ft}$ away at well 14A-25-1. Additionally, a temperature increase would reduce groundwater density at well 14A-25-1, which would cause a rise in water level rather than the observed $0.3-\mathrm{ft}$ decline.

\section{Variations in Water-Temperature Profiles During the Flow Test}

Variations in the water-temperature profiles of well 14A25-1 have been relatively small (fig. 28), and the differences were difficult to discern. Overall, there was a slight warming of the water column between August and November of 2017 (appendix table 3-1). The resultant decrease in water density, calculated from standard equations of state for the density and compressibility of water as a function of temperature (Jones and Harris, 1992; Wagner and Pruss, 2002), would produce a rise in water level of $0.013 \mathrm{ft}$ - barely detectable by the monitoring instruments. A temperature decrease of $2.0{ }^{\circ} \mathrm{C}$ at every depth in the water column could account for a 0.3 -ft water-level decline, as was measured by the pressure transducer. Although this hypothetical temperature decrease could be distributed through the water column differently from what is shown in figure 28, the cooling required far exceeds the water-temperature variability observed in this well (fig. 28).

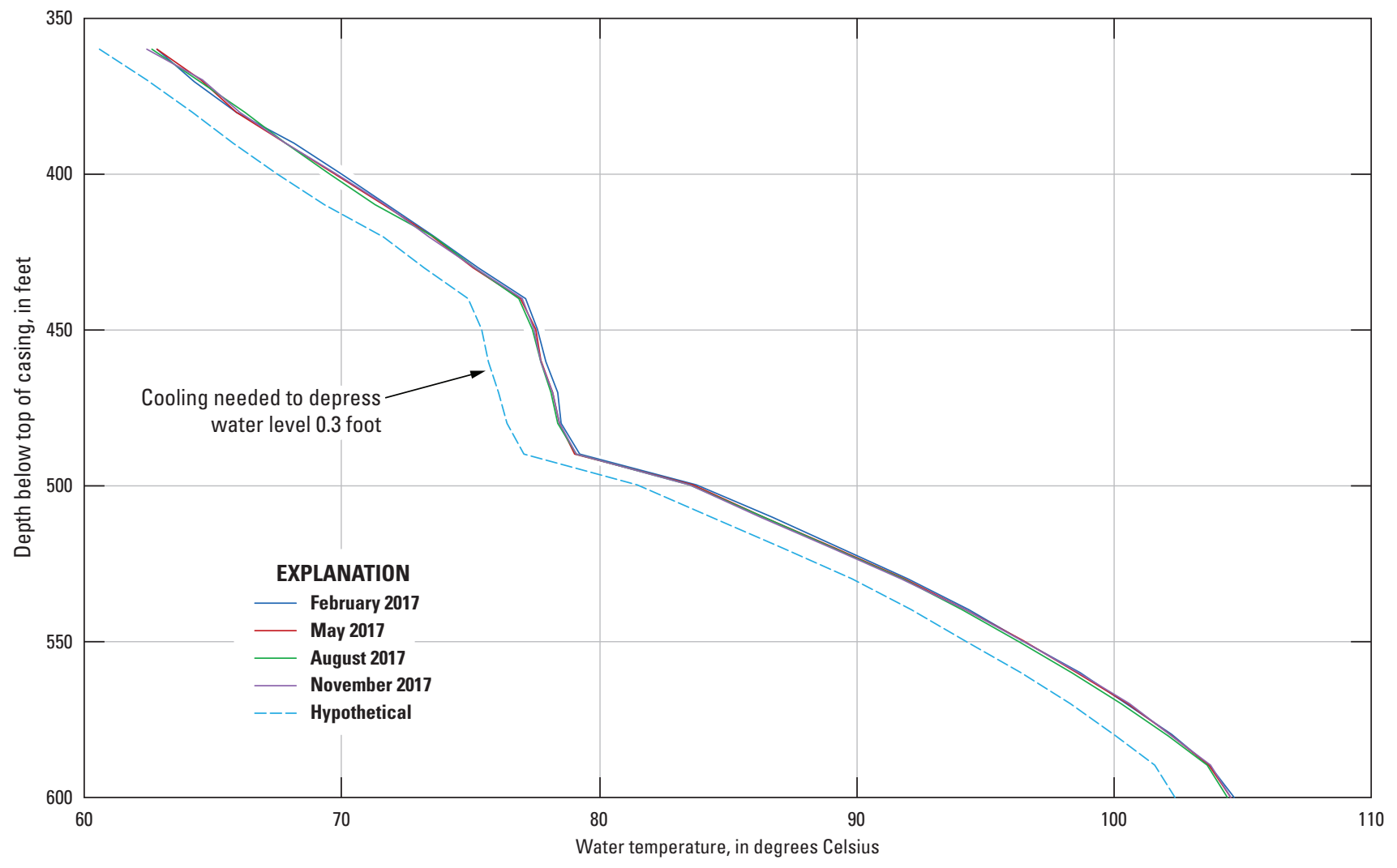

Figure 28. Well 14A-25-1 in Mammoth Lakes area, California, water-temperature profiles measured during 2017 and a hypothetical cooling profile. 
Possible temperature-induced water-density changes must also be considered at well 28A-25, because it was used as the reference well for water-level change in well 14A-25-1 (fig. 26). For example, a temperature increase of $2.6{ }^{\circ} \mathrm{C}$ in groundwater at well $28 \mathrm{~A}-25$ during the flow test would cause a 0.3 -ft rise in water level that could resemble a 0.3 -ft decline in the water level in well 14A-25-1. Figure 29 shows watertemperature profiles at well 28A-25-1 from December 2016 through November 2017. Excluding the upper 100 feet of the November 2017 profile, which was affected by the nearby drilling of well 28-25, as discussed previously, the profiles showed relatively little variability through time; nothing in the measured profiles showed an increase of $2.6^{\circ} \mathrm{C}$.

\section{Gas-Temperature Changes Above the Water Column}

Temperature changes in the approximately 358 -ft column of air above the water surface in well 14A-25-1 could cause density changes in the nitrogen-gas-filled line, previously described. A nitrogen-gas temperature drop could register as a water-level drop in the pressure-transducer output. To assess the possible magnitude of this effect, it was assumed that the air temperature in the well casing above the water surface would not be warmer than the $62.6^{\circ} \mathrm{C}$ temperature of water near the water surface in August 2017 (appendix table 3-1). If the pressure transducer was calibrated to the water surface under these conditions, and then the entire air column cooled to $0{ }^{\circ} \mathrm{C}$, the apparent water-level drop would be $0.125 \mathrm{ft}$. It is implausible that such extreme changes in air temperature were reached in well 14A-25-1 during the flow test. Seasonal temperature changes in the well casing are probably limited to a few degrees Celsius, and associated water-level changes would be approximately $0.01 \mathrm{ft}$.

\section{Chemistry-Induced Density Changes}

Water density increases with increasing total dissolved solids (TDS) concentration, the sum of all chemical species dissolved in a given water. The precise relation between TDS and density depends on chemical composition, but the relation between TDS concentration and density is well known for common salt (sodium chloride) solutions within a temperature range of $40-110^{\circ} \mathrm{C}$ (equation 4; Rogers and Pitzer, 1982):

$$
\Delta \rho=0.677 \times \Delta \mathrm{NaCl}
$$

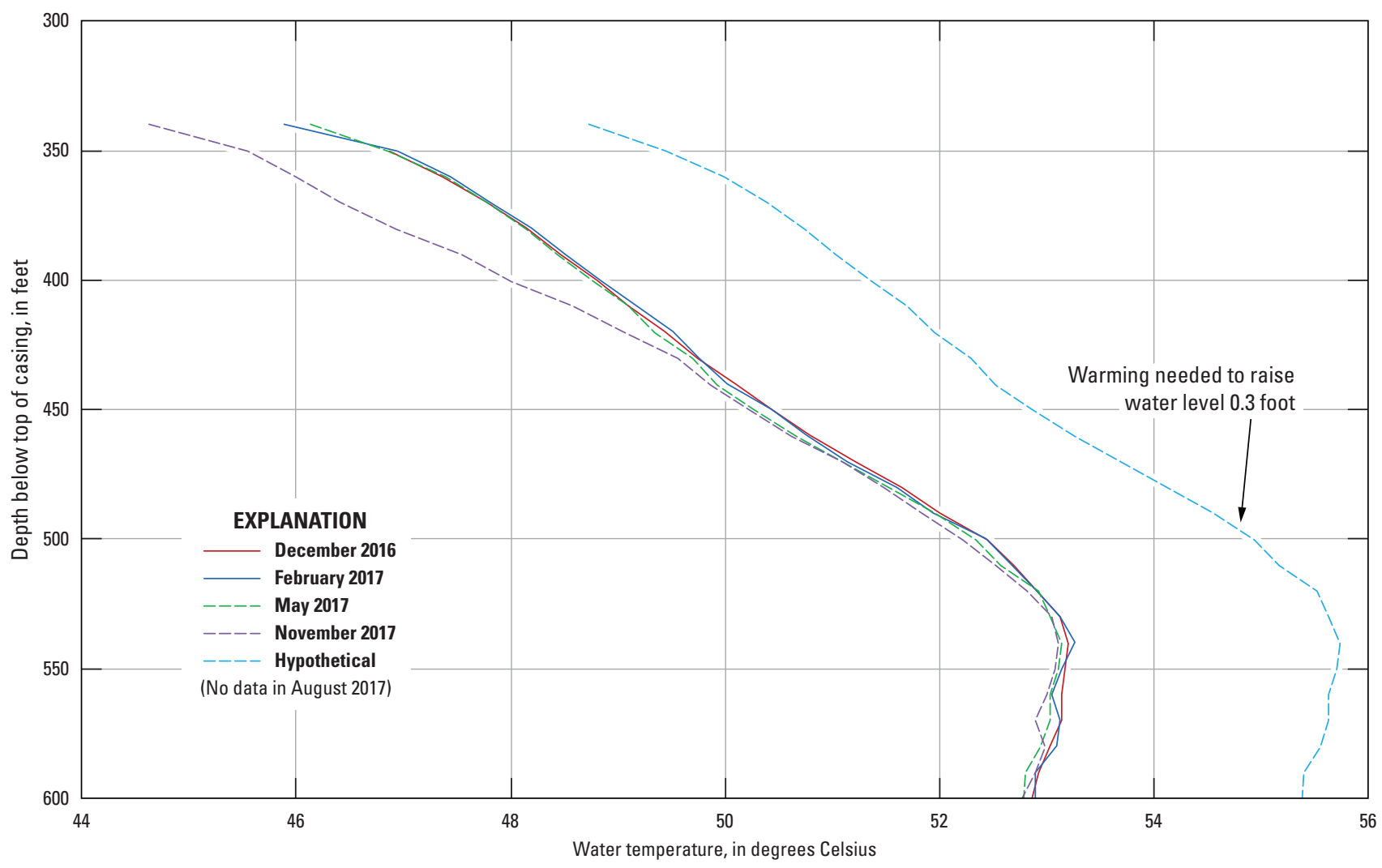

Figure 29. Water-temperature profiles measured in well 28A-25-1 in Mammoth Lakes area, California, from December 2016 to November 2017 and hypothetical warming profile. 
In this equation, $\Delta \rho$ is the change in density in grams per liter $(\mathrm{g} / \mathrm{L})$ for each gram per kilogram $(\mathrm{g} / \mathrm{kg})$ concomitant change in the concentration of sodium chloride, and the multiplication factor (0.677) varies by less than 4 percent between 40 and $110^{\circ} \mathrm{C}$. A generic, empirical formula exists for mixed salt solutions, like those for water in well 14A-25-1 (equation 5; Kharaka and others, 1988):

$$
\Delta \rho=0.688 \times \Delta \mathrm{TDS}
$$

In this equation, the TDS concentration change is in grams per liter. Using either the measured TDS values for well 14A-25-1 in equation 5 or substituting TDS for $\mathrm{NaCl}$ in equation 4 yields similar results. The TDS concentration would need to increase to about $2,750 \mathrm{mg} / \mathrm{L}$ to increase the density of water in well 14A-25-1 enough to decrease the water level by $0.3 \mathrm{ft}$. Such an increase far exceeds the variability in TDS concentration measured in samples collected from the screened interval at 575-595 ft (fig. 30). Furthermore, the hypothetical increase in TDS concentration would have to occur at all water depths inside the cased well bore to cause this water-level decrease.

Chemistry-induced water-density changes must also be considered at the monitoring well 28A-25. The TDS concentration of water samples from well 28A-25-01 (deep well) showed little change through time (fig. 31); even a drop in TDS concentration to $0 \mathrm{mg} / \mathrm{L}$ would not produce a waterlevel rise of $0.3 \mathrm{ft}$.

\section{Summary of Potential Physical and Chemical Influences on Water-Level Data}

On the basis of the available data and a range of reasonable assumptions regarding ambient environmental conditions, the water-level decline of approximately 0.3 foot in well 14A-25-1 observed during the 28-day flow test cannot be attributed to density changes induced by variations in water temperature, water chemistry, or gas temperature in wells 14A-25-1, 28A-25-1, or 28A-25-2. The observed water-level decline in well 14A-25-1 represents a hydraulic head change at the depth of the screened interval. Furthermore, the waterlevel records at wells 14A-25-1 and 28A-25 are suitable for long-term monitoring of hydraulic head in the shallow-aquifer system in the CD-4 project area.

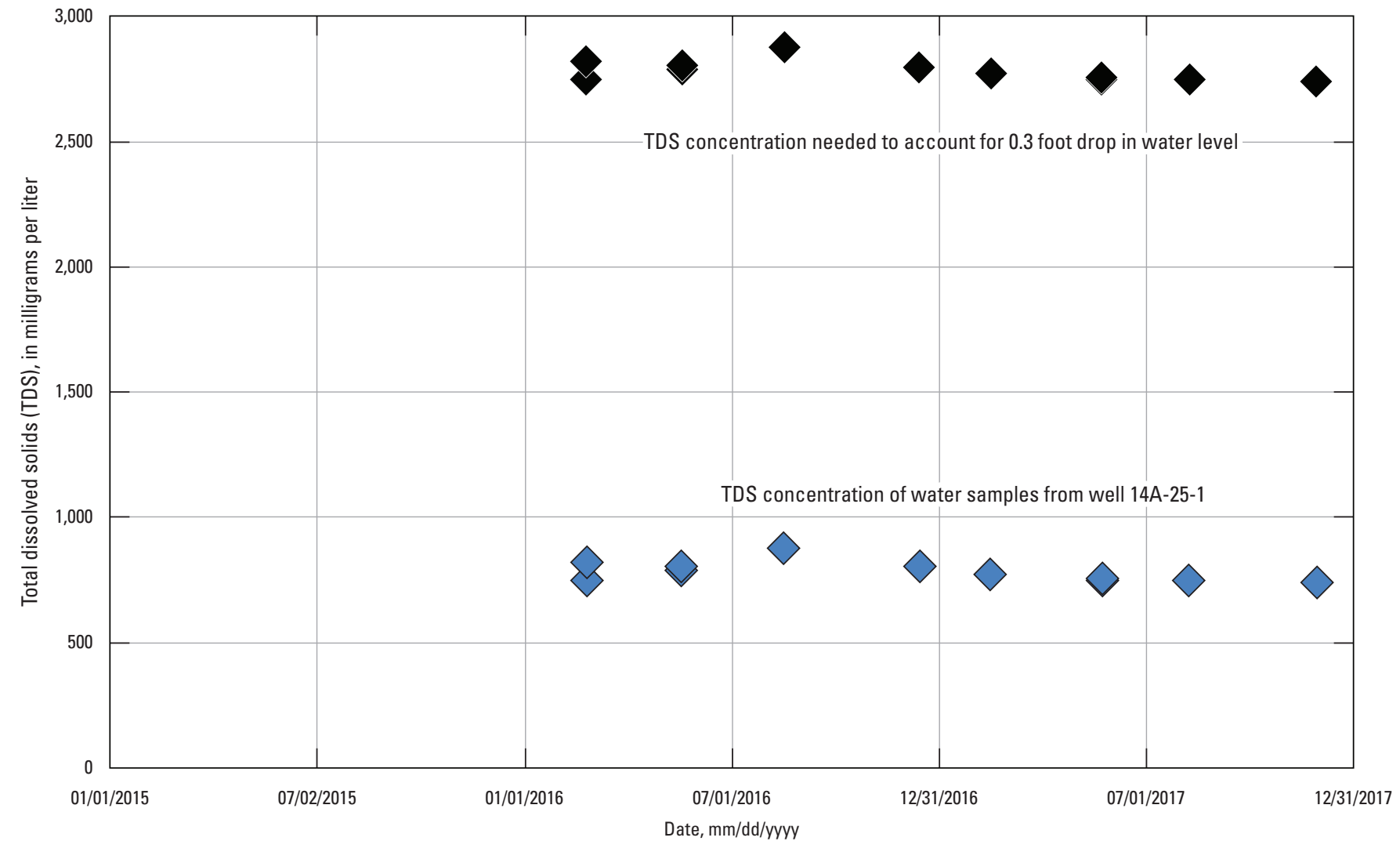

Figure 30. Time series of total dissolved solids (TDS) concentration in well 14A-25-1 in Mammoth Lakes area, California, during calendar years 2016-17, and hypothetical increase in the TDS concentrations. 


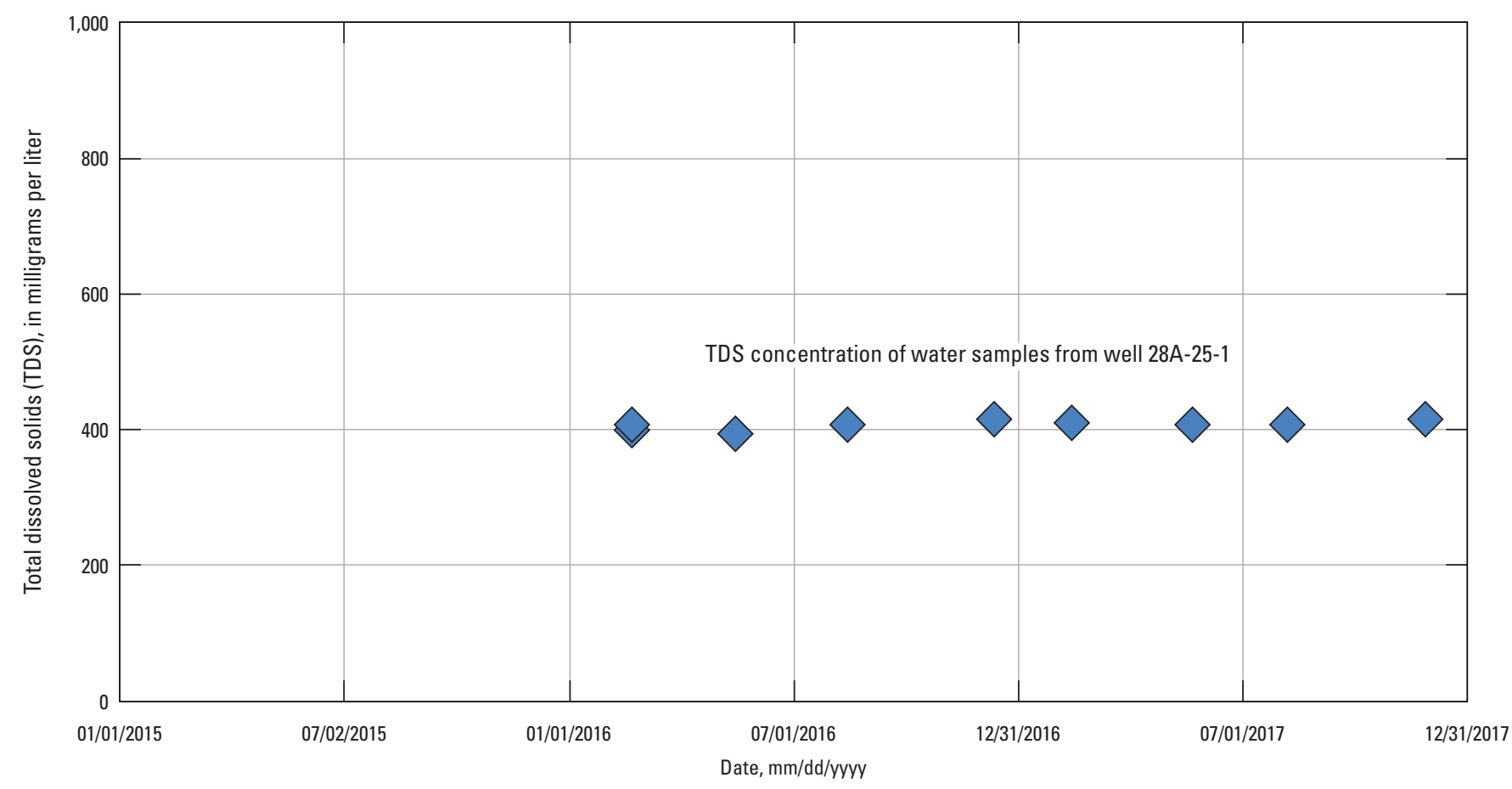

Figure 31. Time series of total dissolved solids (TDS) concentrations in water from well 28A-25-1 in Mammoth Lakes area, California, showing the low variability in TDS concentrations during calendar years 2016-17.

\section{Summary}

The purpose of the U.S. Geological Survey (USGS) groundwater-monitoring program in relation to the CD-4 project is to provide high-quality, publicly available data to Federal, State, County, and municipal agencies responsible for making resource-management decisions regarding the thermal and cold groundwater resources.

The purposes and scope of this report are to (1) describe the monitoring-well network near Mammoth Lakes, as of late 2017; (2) document the methods used to collect groundwaterlevel data, groundwater-temperature profiles, groundwaterchemistry data, and associated quality-control measures; (3) describe the development of digital filters used to remove or reduce barometric pressure and Earth-tide effects in waterlevel records; (4) present baseline water-level and temperature datasets collected from late 2015 to 2017; (5) compare the chemical constituents, constituent ratios, and isotopes of groundwater to the known characteristics of the deep geothermal water; (6) discuss digitally filtered water-level records from the monitoring wells during a 28-day flow test of a geothermal well (14-25); (7) demonstrate the accuracy of water-level data collected at the shallow monitoring wells; and (8) demonstrate the utility of water-level, water-temperature, and water-chemistry data to evaluate the degree of hydrologic connection between shallow groundwater and deep geothermal water. This report presents an initial evaluation of monitoring data collected for the period 2015 to 2017; it is not intended to be a comprehensive assessment of the shallow groundwater and deep geothermal systems in the Mammoth Lakes area.

The monitoring program uses two approximately 600-foot (ft) -deep wells (14A-25 and 28A-25) with deep and shallow completion depths (14A-25-1 and 14A-25-2; 28A-25-1 and 28A-25-2, respectively) that are in hydraulic communication with the shallow-aquifer system. Monitoring data from these wells include continuous water-level data, quarterly water-temperature profiles, and quarterly waterchemistry data. Quarterly water-chemistry data are also collected at seven Mammoth Community Water District (MCWD) production wells and one monitoring well.

The continuous water-level data, water-temperature profiles, and water-chemistry data were collected using established USGS methods, and procedures were incorporated into the various types of data collection for quality control. For monitoring wells 14A-25-1, 28A-25-1, and 28A-25-2 digital filters were developed to remove the water-level responses to atmospheric loading from the unfiltered water-level records. A simplified version of the workflow process used to develop the digital atmospheric-loading and Earth-tide filters applied to the water-level time series is described in the main text. A detailed description of the workflow, including intermediate steps and specifics of the methods used to develop the digital atmospheric-loading and Earth-tide filters, and the resulting filtered water-level records are in appendix 2.

Unfiltered water-level records at sites 14A-25 and 28A25 tracked groundwater-level declines in the shallow-aquifer system resulting from years of below-normal precipitation. 
After the above-normal precipitation during the winter of 2016-17, the groundwater levels at both sites began rising in the first half of 2017 and continued to rise through the remainder of the year.

Because water-level responses to barometric-pressure variations (atmospheric loading) and solid Earth tides can potentially mask subtle water-level responses to other hydrologic stresses, it was essential to filter the water-level records for atmospheric-loading and Earth-tide effects. For well 14A-25-1, the effects of both barometric pressure changes and solid Earth tides were filtered from the water-level data, whereas only the effects of atmospheric loading were filtered from the water-level data of wells 28A-25-1 and 28A-25-2, because there were no solid Earth tide effects detected in these water-level records. The mathematical filters effectively removed or substantially reduced the sinusoidal effects of atmospheric loading, thereby revealing subtle water-level responses to other hydrologic stresses.

The quarterly water-temperature profiles for the monitoring wells 14A-25-1 and 28A-25-1 had sufficient resolution to track subtle changes associated with groundwater flow through the surrounding formations through time. Although most water-temperature changes were within the open intervals of either the shallow or deep wells at both sites, water-temperature changes in other sections of the profiles were also observed.

The suite of chemical constituents measured on a quarterly schedule was used to determine the water-chemistry variability of groundwater in each well, evaluate source areas of groundwater recharge, assess the degree of connection between thermal and non-thermal groundwater, and detect changes in the mixing of thermal and non-thermal water as well as changes in source areas through time.

Conservative elements in water-chemistry data showed that MCWD production well P17 and monitoring wells M26 and 28A-25 (both depths) contained a small percentage of thermal water, which was consistent with a limited hydraulic connection between the shallow non-thermal and deep geothermal systems along the northern periphery of the study area. Although the flow paths that account for this natural mixing are unknown, samples from wells like P17 (and to a lesser extent M26) that varied in composition along the thermal-water trend lines, demonstrate how relative mixing proportions of thermal and non-thermal groundwater can change over time.
Stable isotope composition results for water samples from MCWD production wells and most monitoring wells were consistent with available groundwater-flow models. Results for monitoring wells 14A-25-1 and 14A-25-2, however, were inconsistent with available groundwater-flow models so additional information is needed to account for the source of water at this site.

Water-level records digitally filtered for the effects of atmospheric loading and solid Earth tides helped clarify if changes in the water levels were caused by natural or human-induced processes. Filtered water-level data from monitoring well 14A-25-1 collected during a 28-day flow test of geothermal production well 14-25 indicated there is some hydraulic connection between the deep geothermal aquifer and the shallow-aquifer system at this location. The flow paths are unknown and could be subvertical through the early rhyolite matrix, through interconnected fracture networks in the early rhyolite, or through nearby high-angle faults. The degree of hydraulic connection (vertical hydraulic conductivity) between the deep geothermal aquifer and the shallow-aquifer system in the vicinity of wells $14-25$ and 14A-25-1 is also unknown; however, the nature of the connection could be resolved better by numerical simulations of the flow test and using additional data from and simulations of longer term flow tests. Furthermore, a calibrated groundwater-flow model (numerical simulation) that includes the shallow-aquifer and deep geothermal aquifer could integrate the hydraulic monitoring data for both systems to improve assessments of potential effects on the shallow-aquifer system caused by the development of the geothermal resource.

The water-level decline of approximately 0.3 foot in well 14A-25-1 during the 28-day flow test cannot be attributed to density changes induced by variations in water-temperature, water-chemistry, or gas-temperature in monitoring wells 14A-25-1, 28A-25-1, or 28A-25-2. The observed water-level decline in well 14A-25-1 represented a hydraulic head change at the depth of the screened interval.

The specialized equipment used to produce the continuous water-level records at sites 14A-25 and 28A-25 was suitable for monitoring-network objectives, including long-term monitoring of hydraulic head in the shallow-aquifer system of the CD-4 project area. The multi-disciplinary USGS groundwater-monitoring network described in this report has the capability to track conditions (static or dynamic) in the shallow-aquifer system. 


\section{References Cited}

Bailey, R.A., Dalrymple, G.B., and Lanphere, M.A., 1976, Volcanism, structure, and geochronology of the Long Valley caldera, Mono County, California: Journal of Geophysical Research, v. 81, no. 5, p. 725-744, https://doi.org/10.1029/JB081i005p00725.

Bergfeld, D., Evans, W.C., Howle, J.F., and Farrar C.D., 2006, Carbon dioxide emissions from vegetation-kill zones around the resurgent dome of Long Valley Caldera, eastern California, USA: Journal of Volcanology and Geothermal Research, v. 152, no. 1-2, p. 140-156, https://doi.org/10.1016/j.jvolgeores.2005.11.003.

Bergfeld, D., Vaughan, R.G., Evans, W.C., and Olsen, E., 2015, Monitoring ground-surface heating during expansion of the Casa Diablo production well field at Mammoth Lakes, California: Geothermal Resources Council Transactions, v. 39, p. 1007-1013, https://www.geothermal-library.org/index.php?mode=pubs \&action=view\&record $=1032246$.

Brown, S.T., Kennedy, B.M., DePaolo, D.J., Hurwitz, S., and Evans, W.C., 2013, Ca, Sr, O and D isotope approach to defining the chemical evolution of hydrothermal fluids-Example from Long Valley, CA, USA: Geochimica et Cosmochimica Acta, v. 122, p. 209-225, https://doi.org/10.1016/j.gca.2013.08.011.

Bureau of Land Management, 2013, Record of Decision, Casa Diablo IV Geothermal Development Project, Case File Number: CACA 054722: Bishop, California, 19 p., https://openei.org/w/images/7/7c/CD-IV_Final_BLM_ ROD_081213.pdf.

Bureau of Land Management, 2018, CD-IV Geothermal Development Project - Groundwater Monitoring and Response Plan, version 1.1 dated January 19, 2018, 29 p.

Carslaw, H.S., and Jaeger, J. C., 1959, Conduction of heat in solids, (2d ed.): London, Oxford University Press, $510 \mathrm{p}$.

Cunningham, W.L., and Schalk, C.W., 2011, Groundwater technical procedures of the U.S. Geological Survey: U.S. Geological Survey Techniques and Methods 1-A1, 151 p., https://doi.org/10.3133/tm1A1.

Evans, W.C., 2017, Overview of the Long Valley hydrothermal system after decades of study, in Hildreth, W., and Fierstein, J., 2017, Geologic field-trip guide to Long Valley Caldera, California: U.S. Geological Survey Scientific Investigations Report 2017-5022-L, p. 99-119, https://doi.org/10.3133/sir20175022L.
Evans, W.C., and Bergfeld, D., 2017, Groundwater resources of the Devils Postpile National Monument-Current conditions and future vulnerabilities: U.S. Geological Survey Scientific Investigations Report 2017-5048, 31 p., https://doi.org/10.3133/sir20175048.

Farrar, C.D., Sorey, M.L., Roeloffs, E.R., Galloway, D.L., Howle, J.F., and Jacobsen, R., 2003, Inferences on the hydrothermal system beneath the resurgent dome in Long Valley Caldera, east-central California, USA, from pumping tests and geochemical sampling: Journal of Volcanology and Geothermal Research, v. 127, p. 305-328, https://doi.org/10.1016/S0377-0273(03)00174-4.

Farrar, C.D., DeAngelo, J., Williams, C.F., and Hurwitz, S., 2010, Temperature data from wells in Long Valley Caldera, California: U.S. Geological Survey Data Series 523, https://doi.org/10.3133/ds523.

Fulford, J.M., and Clayton, C.S., 2015, Accuracy testing of steel and electric groundwater-level measuring tapes-Test method and in-service tape accuracy: U.S. Geological Survey Open-File Report 2015-1137, 31 p., https://doi.org/10.3133/ofr20151137.

Galloway, D.L., 2019, Atmospheric-loading frequency response functions and groundwater levels filtered for the effects of atmospheric loading and solid Earth tides for three monitoring wells near Mammoth Lakes, California, 2015-2017: U.S. Geological Survey data release, https://doi.org/10.5066/P9ON8U5U.

Galloway, D.L., and Rojstaczer, S.A., 1989, Inferences about formation elastic and fluid flow properties from the frequency response of water levels to atmospheric loads and Earth tides: 4th Canadian/American Conference on Hydrogeology, Fluid flow, heat transfer and mass transport in fractured rocks, Banff, Alberta, Canada, June 21-24, 1988, p. 100-113.

Goff, F., Wollenberg, H.A., Brookins, D.C., and Kistler, R.W., 1991, A Sr-isotopic comparison between thermal waters, rocks, and hydrothermal calcites, Long Valley Caldera, California: Journal of Volcanology and Geothermal Research, v. 48, nos. 3-4, p. 265-281, https://doi.org/10.1016/0377-0273(91)90046-3.

Hildreth, W., 2004, Volcanological perspectives on Long Valley, Mammoth Mountain, and Mono Craters-Several contiguous but discrete systems: Journal of Volcanology and Geothermal Research, v. 136, nos. 3-4, p. 169-198, https://doi.org/10.1016/j.jvolgeores.2004.05.019.

Hildreth, W., 2017, Fluid-driven uplift at Long Valley Caldera, California: Geologic perspectives. Journal of Volcanology and Geothermal Research, v. 341, p. 269-286, https://doi.org/10.1016/j.jvolgeores.2017.06.010. 
Hildreth, W., Fierstein, J., Champion, D., Calvert, A., 2014, Mammoth Mountain and its mafic periphery-A late Quaternary volcanic field in eastern California: Geosphere, v. 10, p. 1315-1365, https://doi.org/10.1130/GES01053.1.

Hill, D.P., Bailey, R.A., and Ryall, A.S., 1985, Active tectonic and magmatic processes beneath Long Valley Caldera, eastern California-An overview: Journal of Geophysical Research, v. 90, no. B13, p. 11111-11120, https://doi.org/10.1029/JB090iB13p11111.

Howle, J.F., and Farrar, C.D., 1996, Hydrologic data for Long Valley Caldera, Mono County, California, 1978-93: U.S. Geological Survey Open-File Report 96-382, 286 p., https://doi.org/10.3133/ofr96382.

Howle, J.F., and Farrar, C.D., 2001, Hydrologic data for Long Valley Caldera, Mono County, California, 1994-96: U.S. Geological Survey Open-File Report 2000-230, 155 p., https://doi.org/10.3133/ofr00230.

Howle, J.F., Langbein, J.O., Farrar, C.D., and Wilkinson, S.K., 2003, Deformation near the Casa Diablo geothermal well field and related processes, Long Valley Caldera, Eastern California, 1993-2000: Journal of Volcanology and Geothermal Research, v. 127, nos. 3-4, p. 365-390, https://doi.org/10.1016/S0377-0273(03)00177-X.

Hsieh, P.A., 1996, Deformation-induced changes in hydraulic head during ground-water withdrawal: Ground Water, v. 34, no. 6, p. 1082-1089, https://doi.org/10.1111/j.1745-6584.1996.tb02174.x.

Hurwitz, S., Farrar, C.D. and Williams, C.F., 2010, The thermal regime in the resurgent dome of Long Valley Caldera, California: Inferences from precision temperature logs in deep wells: Journal of Volcanology and Geothermal Research, v. 198, nos. 1-2, p. 233-240, https://doi.org/10.1016/j.jvolgeores.2010.08.023.

Jacob, C.E., 1940, On the flow of water in an elastic artesian aquifer: American Geophysical Union Transactions, v. 21, no. 2, p. 574-586, https://doi.org/10.1029/TR021i002p00574.

Jones, F.E., and Harris, G.L., 1992, ITS-90 Density of water formulation for volumetric standards calibration: Journal of Research of the National Institute of Standards and Technology, v. 97, no. 3, p. 335-340, https://nvlpubs.nist.gov/nistpubs/jres/097/jresv97n3p335 Alb.pdf.

Kenneth D. Schmidt and Associates, 2018, Annual report on results of Mammoth Community Water District groundwater monitoring program for October 2016September 2017: Report prepared for Mammoth Community Water District, Mammoth Lakes, California, $87 \mathrm{p}$.
Kharaka, Y.K., Gunter, W.D., Aggarwal, P.K., Perkins, E.H., and DeBraal, J.D., 1988, SOLMINEQ.88-A computer program for geochemical modeling of waterrock interactions: U.S. Geological Survey WaterResources Investigations Report 88-4227, 420 p., https://doi.org/10.3133/wri884227.

Mueller, D.K., Schertz, T.L., Martin, J.D., and Sandstrom, M.W., 2015, Design, analysis, and interpretation of field quality-control data for water-sampling projects: U.S. Geological Survey Techniques and Methods, book 4, chap. C4, 54 p., https://doi.org/10.3133/tm4C4.

Peacock, J.R., Mangan, M.T., McPhee, D., and Wannamaker, P.E., 2016, Three-dimensional electrical resistivity model of the hydrothermal system in Long Valley Caldera, California, from magnetotellurics: Geophysical Research Letters, v. 43, no. 15, p. 7953-7962, https://doi.org/10.1002/2016GL069263.

Quilty, E.G., and Roeloffs, E.A., 1991, Removal of barometric pressure response from water level data: Journal of Geophysical Research, v. 96, no. B6, p. 10209-10218, https://doi.org/10.1029/91JB00429.

Rogers, P.S.Z., and Pitzer, K.S., 1982, Volumetric properties of aqueous sodium chloride solutions: Journal of Physical and Chemical Reference Data, v. 11, p. 15-81, https://doi.org/10.1063/1.555660.

Rojstaczer, S., 1988a, Determination of fluid flow properties from the response of water levels in wells to atmospheric loading, Water Resources Research, v. 24, no. 11, p. 1927 1938, https://doi.org/10.1029/WR024i011p01927.

Rojstaczer, S., 1988b, Intermediate period response of water levels in wells to crustal strain-Sensitivity and noise level: Journal of Geophysical Research, v. 93, no. B11, p. 1361913634, https://doi.org/10.1029/JB093iB11p13619.

Rojstaczer, S., and Agnew, D.C., 1989, The influence of formation material properties on the response of water levels in wells to Earth tides and atmospheric loading: Journal of Geophysical Research, v, 94, no. B9, p. 1240312411, https://doi.org/10.1029/JB094iB09p12403.

Sauer, V.B., and Turnipseed, D.P., 2010, Stage measurement at gaging stations: U.S. Geological Survey Techniques and Methods book 3, chap. A7, 45 p., https://doi.org/10.3133/tm3A7.

Shevenell, L., Goff, F., Grigsby, C.O., Janik, C.J., Trujillo Jr., P.E., and Counce, D., 1987, Chemical and isotopic characteristics of thermal fluids in the Long Valley Caldera lateral flow system, California: Geothermal Resources Council Transactions, v. 11, p. 195-201, https://www.geothermal-library.org/index.php?mode=pubs \&action=view\&record $=1001612$. 
Sorey, M.L., 1985, Evolution and present state of the hydrothermal system in Long Valley Caldera: Journal of Geophysical Research, v. 90, no. B13, p. 11219-11228, https://doi.org/10.1029/JB090iB13p11219.

Sorey, M.L., Suemnicht, G.A., Sturchio, N.C., and Nordquist, G.A., 1991, New evidence on the hydrothermal system in Long Valley Caldera, California, from wells, fluid sampling, electrical geophysics, and age determinations of hot-spring deposits: Journal of Volcanology and Geothermal Research, v. 48, p. 229-263, https://doi.org/10.1016/0377-0273(91)90045-2.

Sorey, M.L., Evans, W.C., Kennedy, B.M., Farrar, C.D., Hainsworth, L.J., and Hausback, B., 1998, Carbon dioxide and helium emissions from a reservoir of magmatic gas beneath Mammoth Mountain, California: Journal of Geophysical Research, v, 103, no. B7, p. 15303-15323, https://doi.org/10.1029/98JB01389.

Spane, F.A., 2002, Considering barometric pressure in groundwater flow investigations, Water Resources Research, v. 38, no. 6, p. 14-1-14-18, https://doi.org/10.1029/2001WR000701.

Suemnicht, G.A., and Varga, R.J., 1988, Basement structure and implications for hydrothermal circulation patterns in the western moat of Long Valley Caldera, California: Journal of Geophysical Research, v. 93, no. B11, p. 13191-13207, https://doi.org/10.1029/JB093iB11p13191.
U.S. Geological Survey, 2014, National Field Manual for the collection of water-quality data: U.S. Geological Survey Techniques of Water-Resources Investigations, book 9, version 2.0, chaps. A1-A9, https://pubs.water.usgs.gov/twri9A.

Vaughan, R.G., Bergfeld, D., Evans, W.C., Wilkinson, S., Miwa, C., and Diabat, M., 2018, A baseline thermal infrared survey of ground heating around the Casa Diablo Geothermal Plant, Mammoth Lakes, California: Geothermal Resources Council Transactions, v. 42, p. 962-976, https://www.geothermal-library.org/index.php?mode=pubs \&action $=$ view\&record $=1033957$.

Wagner, W., and Pruss, A., 2002, The IAPWS formulation 1995 for the thermodynamic properties of ordinary water substance for general and scientific use: Journal of Physical and Chemical Reference Data, v. 31, no. 2, p. 387-535, http://thermophysics.ru/pdf_doc/IAPWS_1995.pdf.

Wang, H.F., 2000, Theory of linear poroelasticity with applications to geomechanics and hydrogeology: Princeton, New Jersey, Princeton University Press, 304 p.

White, A.F., and Peterson, M.L., 1991, Chemical equilibrium and mass balance relationships associated with the Long Valley hydrothermal system, California, USA: Journal of Volcanology and Geothermal Research v. 48, p. 283-302, https://doi.org/10.1016/0377-0273(91)90047-4.

White, A.F., Peterson, M.L., Wollenberg, H., and Flexser, S., 1990, Sources and fractionation processes influencing the isotopic distribution of $\mathrm{H}, \mathrm{O}$, and $\mathrm{C}$ in the Long Valley hydrothermal system, California, USA: Applied Geochemistry, v. 5, p. 571-585. 


\section{Appendix 1. U.S. Geological Survey Research Drilling Program Drilling Methods, Borehole Geophysical Techniques and Well-Construction Schematics for Wells 14A-25, 28A-25, and BLM-1 near Mammoth Lakes, California}

\section{Drilling Methods}

The U.S. Geological Survey (USGS) Research Drilling Program used gravity-advancing ODEX casing with rotary air hammer for the upper 320 feet (ft) of the 14A-25 hole, upper $310 \mathrm{ft}$ of the 28A-25 hole, and upper $260 \mathrm{ft}$ of the BLM-1 hole. The 9-inch-diameter gravity-advancing ODEX casing with rotary air-hammer technique avoids the high-pressure forcing of drilling mud used by mud rotary drilling, which can plug the fracture permeability of the formation or contaminate the chemistry of the formation water. Below the previously mentioned depths in wells 14A-25, 28A-25, and BLM-1, competent rock was encountered, and a 7-inch-diameter rotary air-hammer was used to total depth. See figures 1-1, 1-2, and 1-3 for details of the well depths, well-construction materials, and depths of the screened intervals for wells 14A-25-1, 14A25-2, 28A-25-1, 28A-25-2, BLM-1-1, and BLM-1-2.

\section{Borehole Geophysical Logs}

Once the total depth in wells 14A-25, 28A-25, and BLM-1 was reached, a suite of borehole geophysical logs were collected to help characterize the hydro-geologic properties of the surrounding formation and determine where the screened intervals would be constructed.

A brief description of the geophysical logging in the open boreholes below the bottom of the ODEX casing previously described follows. Except for the gamma log, most of logs yielded spurious or null signals in the interval of the ODEX casing.
The three-arm caliper log is a measurement of the borehole diameter; it is used to define zones of competent and incompetent wall rock. Caliper logs are useful for identifying zones of fractured rock that collapse into the well bore when the drill bit is removed.

The gamma-ray log is a measurement of natural gamma radiation emitted by the decay of potassium, thorium, and uranium in clay minerals. Clay-rich, hydrothermally altered zones produce 'peaks' in the log. Gamma-ray logs are useful for identifying potential zones of low permeability in the surrounding rock.

Conductivity, which is also referred to as electrical conductivity (EC), is a measure of the electrical conductivity of the fluid in the well bore. Conductivity logs are useful for identifying zones of solute-rich water flow into the well bore.

Resistivity logs (short normal-16-inch separation between electrodes - and long normal - 64-inch separation between electrodes) are useful for differentiating lowresistivity clay-rich layers from high-resistivity sand- and gravel-rich layers.

Temperature logs are useful for identifying zones of fluid inflow. Deviations in the thermal gradient can be indicative of changes in the hydraulic permeability of the surrounding formation.

Sonic delta-T, also referred to as "delta-T," is an acoustic penetration measurement. Dense and compact wall rock have a relatively short return time of the acoustic pulse. As the fracture density and fracture depth increases in the surrounding rock, the return time of the acoustic pulse or delta- $\mathrm{T}$ increases proportionally. 


\section{Well-Construction Schematics}

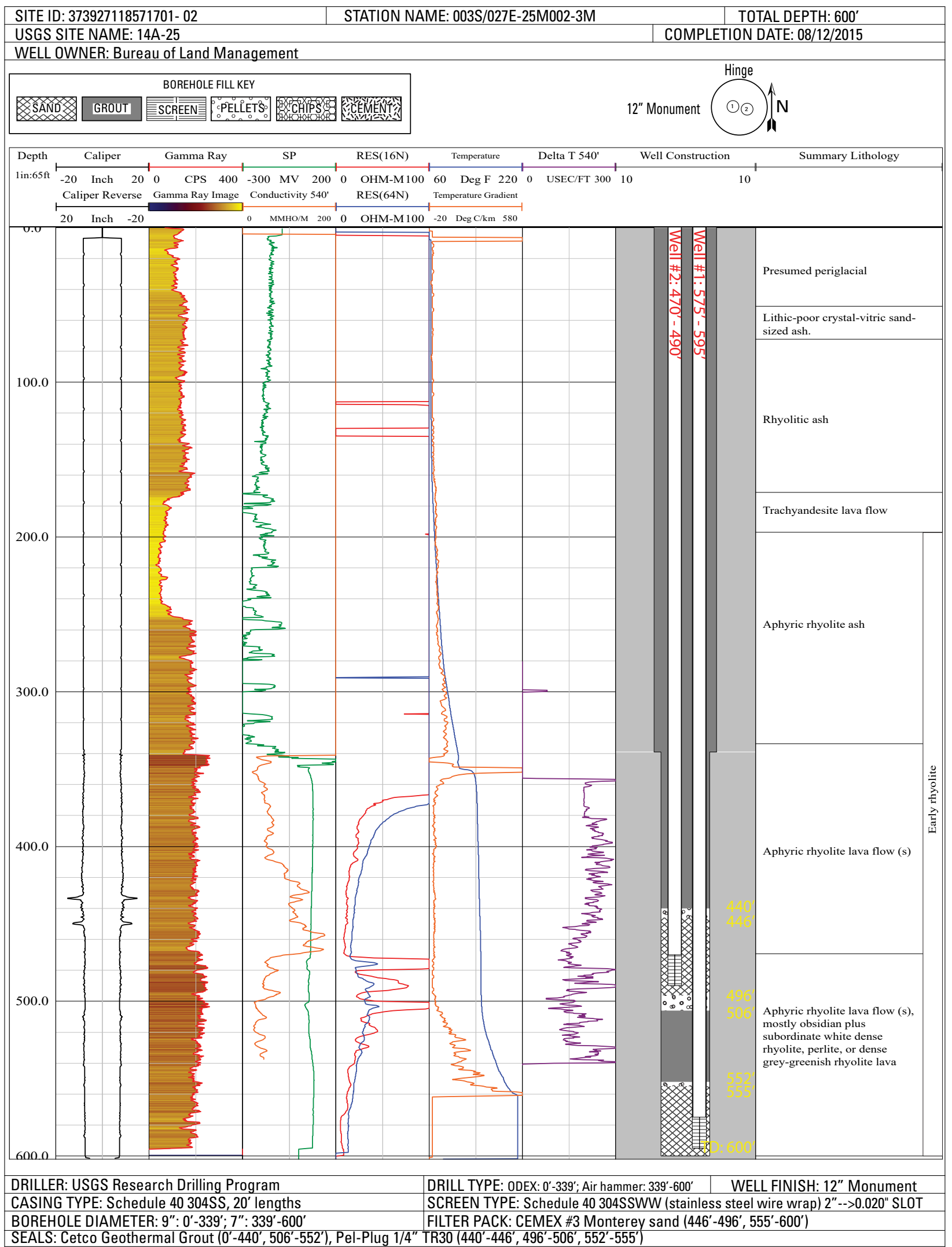

Figure 1-1. Borehole geophysical logs, well construction, and lithology summary for monitoring well 14A-25, Mammoth Lakes, California. 


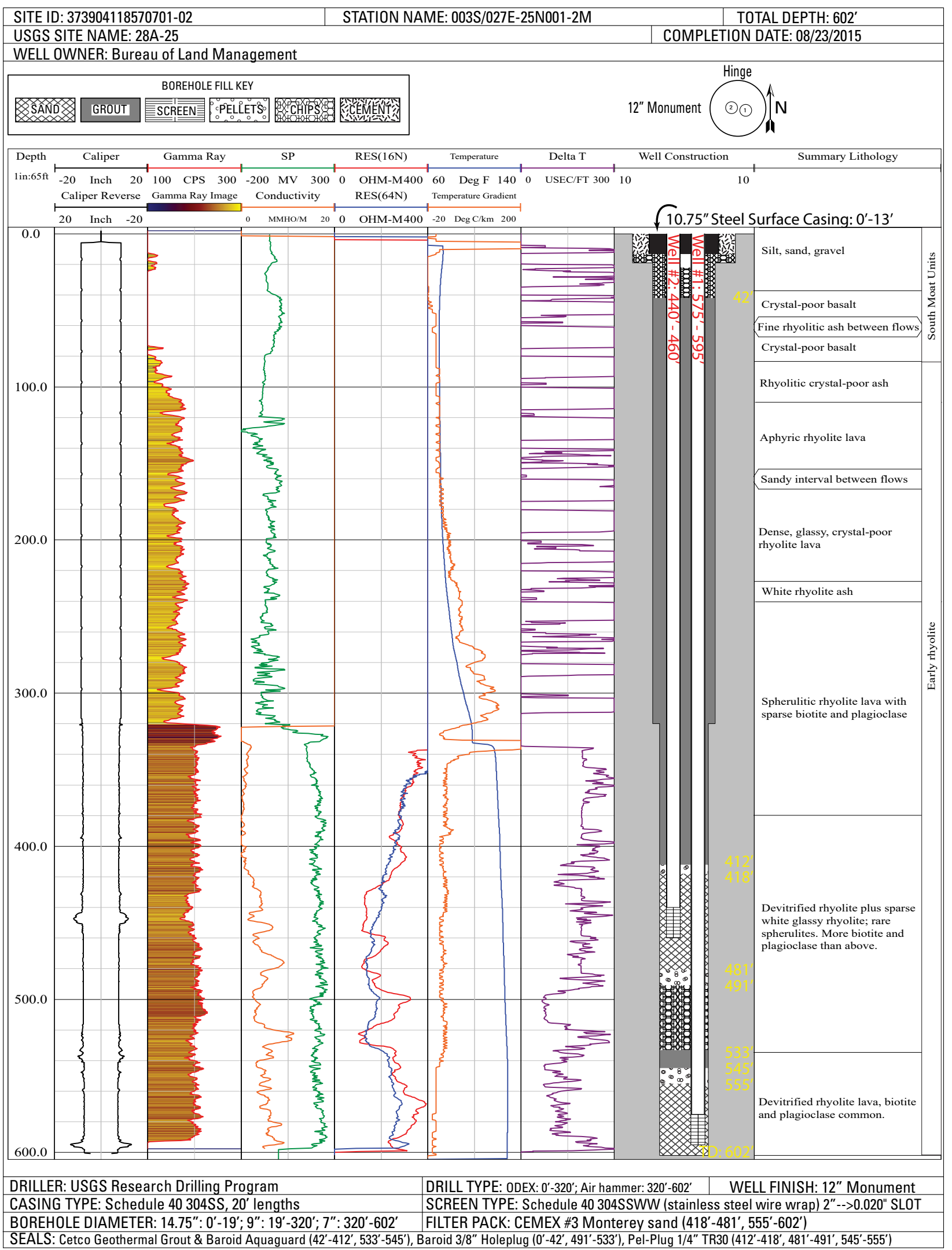

Figure 1-2. Borehole geophysical logs, well construction, and lithology summary for monitoring well 28A-25, Mammoth Lakes, California. 


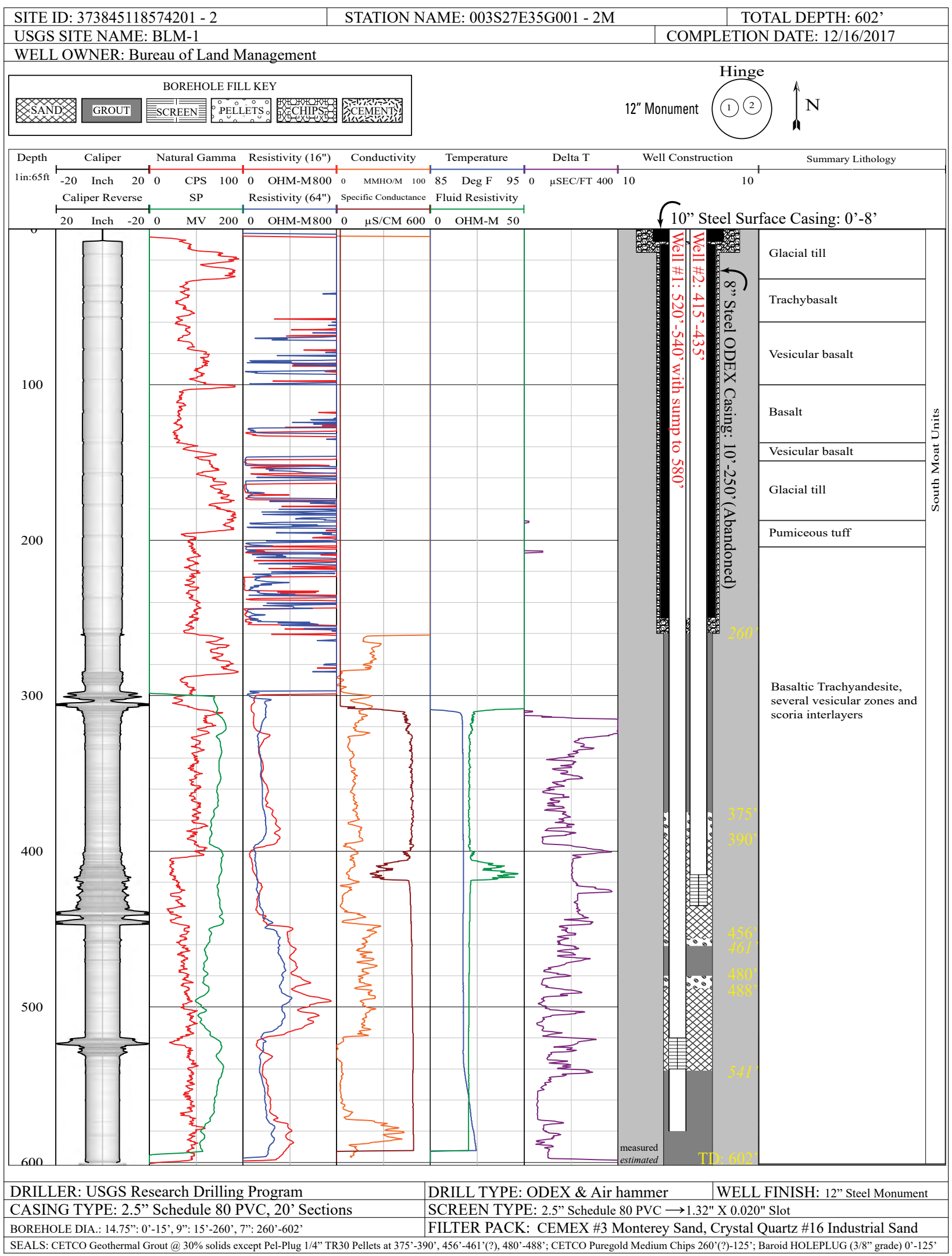

Figure 1-3. Borehole geophysical logs, well construction, and lithology summary for monitoring well BLM-1, Mammoth Lakes, California. 


\section{Appendix 2. Development of Digital Atmospheric-Loading and Earth-Tide Filters}

The processing of raw data and the development of digital atmospheric-loading and Earth-tide filters were done using MATLAB ${ }^{\circledR}$ with the MATLAB ${ }^{\circledR}$ Signal Processing Toolbox software (release R2018A). For monitoring wells 28A-25-1, 28A-25-2, and 14A-25-1, water-level responses to changes in barometric pressure (atmospheric loading) and the solid Earth tide were evaluated and filtered from the raw water-level record. An overview of the workflow with intermediate steps is shown in figure $2-1$. Details of the methods used to develop the digital atmospheric-loading and Earth-tide filters as well as the resulting digitally filtered water levels follow. Note, the water levels used here were measured as depth-to-water below land surface, and references to water level in the following discussions refer to the depthto-water level rather than water-level elevation or head, unless otherwise stated.

All times are reported in Pacific Standard Time (PST, or Coordinated Universal Time minus 8 hours (hr)). To facilitate working with time in the algorithms developed to process the time series, time was converted from calendar dates (yr:month:day:hr:min) to decimal days (dd) referenced to day-of-the-year value for January 1, 2015; for example, noon on January 1, 2015, was dd 1.5. The raw water-level and barometric-pressure data were processed as continuous "unpaired," variable length (accounting for data gaps) waterlevel and barometric-pressure time series. "Unpaired" was used to indicate that the time-series lengths (or spans) and sample times were variable. For water-level and barometricpressure time series, data gaps less than or equal to $3 \mathrm{hr}$ were retained in the time series. The time series were resampled at even (on the hour) hourly intervals, and the retained data gaps were filled using cubic spline interpolation (fig. 2-1, box a). The resulting unpaired, variable-length, continuous time series are referred to here as "pieces." The raw, hourly resampled water-level and barometric-pressure time-series pieces are shown in figure 2-2 and given in Galloway (2019), referenced in the "Digitally Filtered Water-Level Time Series" section of this appendix. The individual pieces, except for $14 \mathrm{~A}-25-1$ piece 12 , were subsequently parsed to achieve the longest length of paired (temporally coincident) barometricpressure and water-level, continuous, hourly sampled time series (referred to as 'parsed' series here) (figs. 2-1, box b, and $2-3)$. The parsed series number was designated by the suffix ' \#' (where \# refers to the parsed series number) appended to the well number. For example, parsed series 8 for 14A-25-1 was designated as 14A-25-1_8 and refers to a set of paired, continuous water-level and barometric-pressure time series identified by the well from which the water-level series was derived. Piece 12 for 14A-25-1 was not parsed because it is short (about 12 days long), and spans the end of the record (end of 2017) selected for analysis.

Parsed series 3 for 14A-25-1 (14A-25-1_3) was omitted from these analyses because the water level was affected by a coseismic response to a distant earthquake, and it was too short ( $23 \mathrm{hr}$ ) to determine response characteristics to Earth tides and barometric-pressure variations. Other longer parsed series with water-level responses to flow testing or disturbances from nearby drilling were further subdivided into modified parsed water-level series in which these water-level responses were absent, and paired with modified barometricpressure time series (fig. 2-1, box c). The modified parsed water-level series ideally contained predominately seasonal and annual hydrologic effects, atmospheric-loading responses, and any responses to Earth tides. These modified parsed series included (1) 28A-25-2_7modA and _ 7modB, which omitted an intervening period of record from 28A-25-2_7 that was affected by several water-level responses attributed to nearby drilling during Oct. 10-15, 2017, and (2) 14A-25-1 10mod, which omitted approximately the first half of $14 \mathrm{~A}-25-1 \_10$ that was affected by a flow test in the nearby $14-25$ production well (discussed in the "Water-Level Variations During a Flow Test of a Geothermal Production Well" section in the main report and later in this appendix).

The parsed barometric-pressure series were detrended by removing a linear trend determined by least-squares regression of barometric pressure on time. The parsed water-level series were detrended using either a first- (linear) or higher-order polynomial determined by least-squares regression of water level on time, depending on the nature of the water-level trend for each parsed series (fig. 2-1, box d). Detrending was aimed at removing the longer period (seasonal) hydrologic and barometric effects. Table $2-1$ lists various time parameters, derivations with respect to the originating time-series pieces, and detrending polynomial orders for the parsed time series. Barometric-pressure time series collected from the barometer at well site 28A-25 were used for all the 28A-25-1 and 28A25-2 parsed series and for the 14A-25-1_1 to 14A-25-1_8 parsed series; barometric-pressure time series collected from a newly installed barometer at well site 14A-25 were used for the 14A-25-1_9 to 14A-25-1_11 parsed series. The use of the 28A-25 barometer for most of the 14A-25-1 parsed series is satisfactory given the proximity of the two well sites (about 0.5 mile) and the small elevation difference (about $7 \mathrm{ft}$ ). Selected detrended, parsed water-level and barometricpressure time series are given in Galloway (2019) (referenced in the "Digitally Filtered Water-Level Time Series" section of this appendix). 


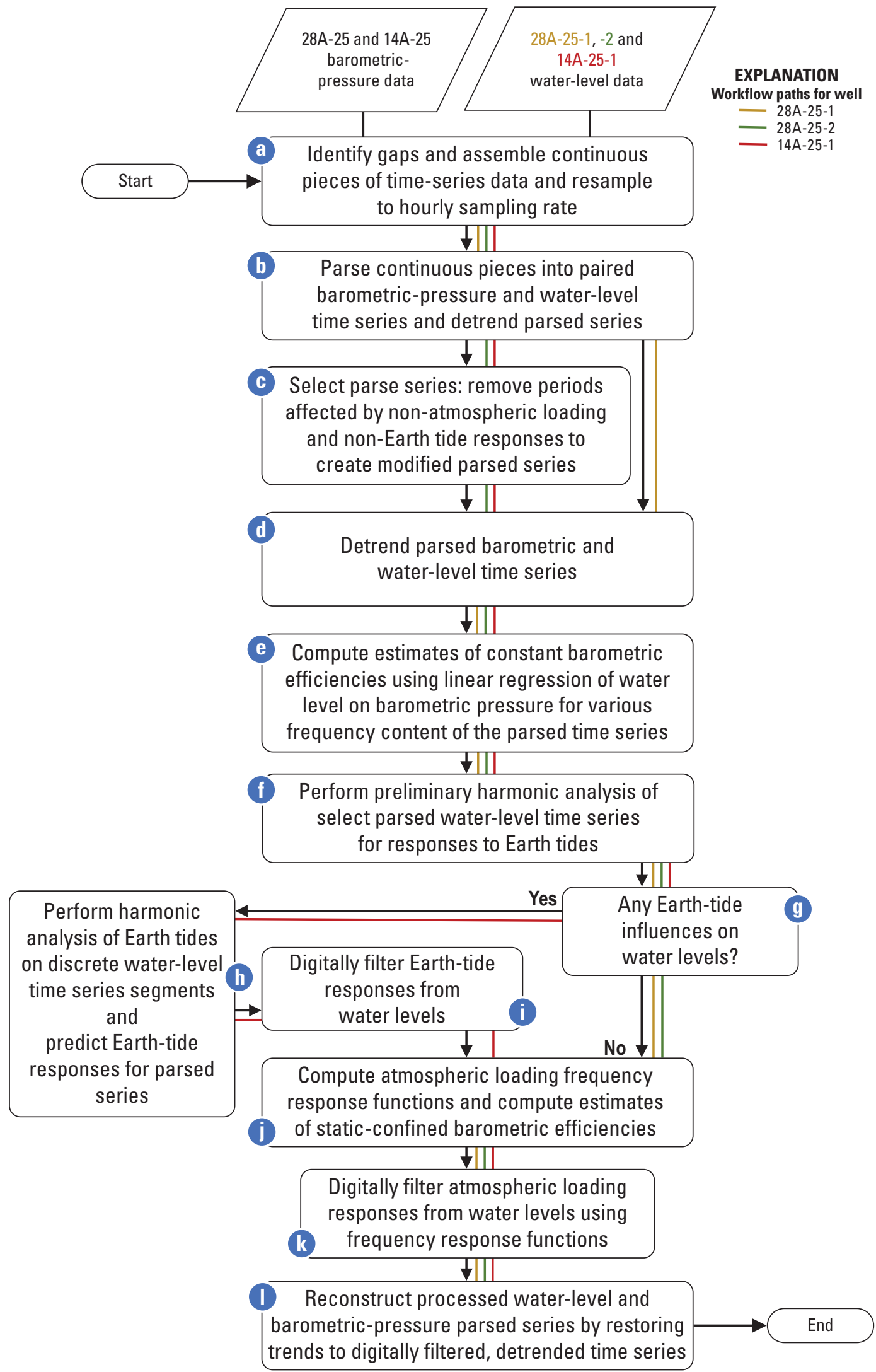

Figure 2-1. Workflow process used to develop the digital atmospheric-loading and Earth-tide filters for water levels from monitoring wells 28A-25-1, 28A-25-2, and 14A-25-1 in the area of Mammoth Lakes, California. 

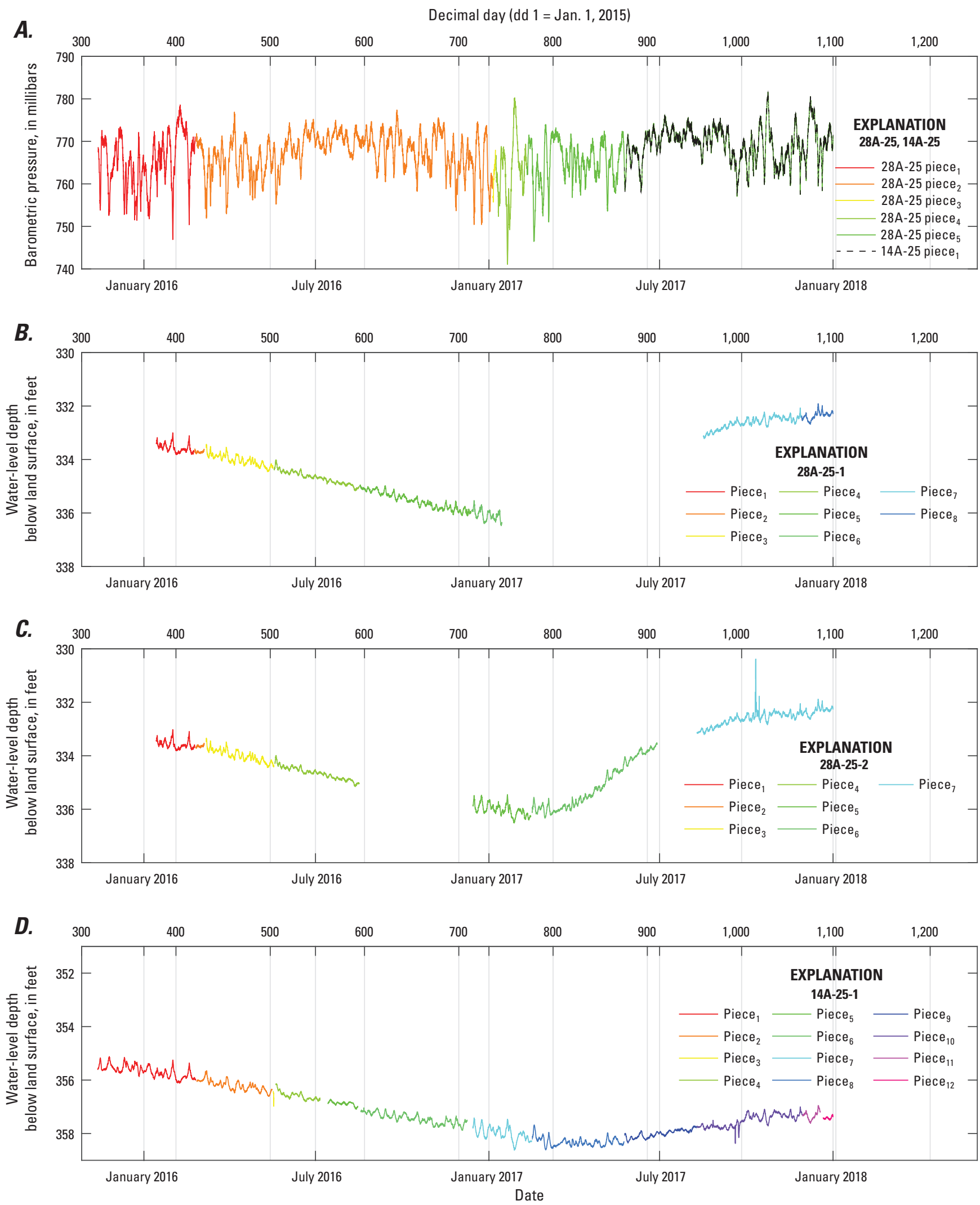

Figure 2-2. Continuous time-series pieces for wells 28A-25-1, 28A-25-2, and 14A-25-1 in the area of Mammoth Lakes, California: $A$, raw barometric-pressure for well sites 28A-25 during November 13, 2015-December 31, 2017, and 14A-25 during May 24, 2017-January 1, 2018; $B$, raw water-level time series for well 28A-25-1 during January 14, 2016-December 31, 2017; $C$, raw water-level time series for well 28A-25-2 during January 14, 2016-December 31, 2017; D, raw water-level time series for well 14A-25-1 during November 13, 2015December 31, 2017. 

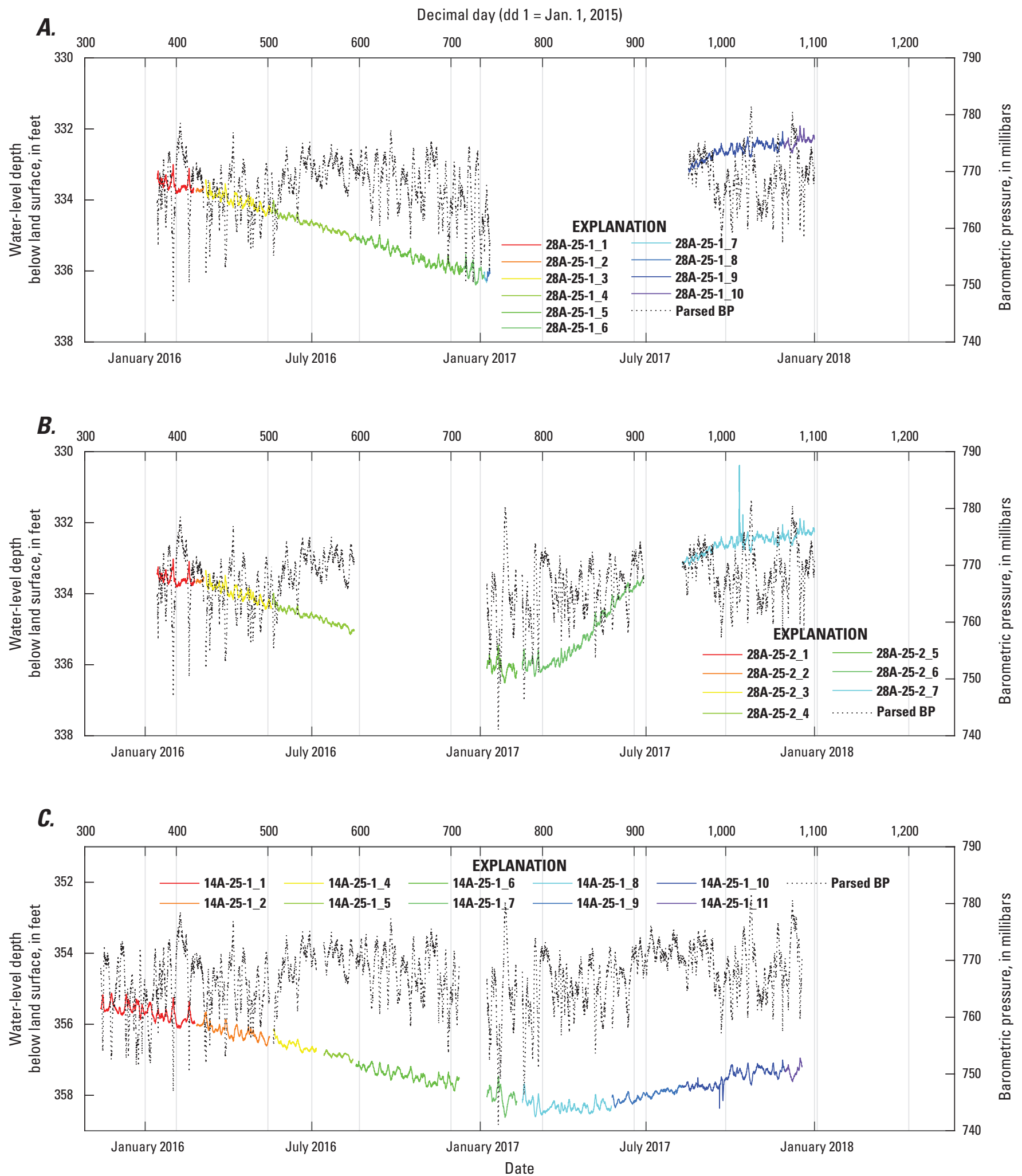

Figure 2-3. Parsed, coincident (paired) water-level and barometric-pressure (BP) time series for wells in the area of Mammoth Lakes, California: A, 28A-25-1, January 14, 2016-December 31, 2017; B, 28A-25-2, January 14, 2016-December 31, 2017; and C, 14A-25-1, November 13, 2015-December 18, 2017. 
Table 2-1. Parsed time-series parameters for wells 28A-25-1 during January 14, 2016-December 31, 2017, 28A-25-2 during January 14, 2016-December 31, 2017, and 14A-25-1 during November 13, 2015-December 18, 2017, in the area of Mammoth Lakes, California.

[Series numbers in bold-italic font denote series analyzed for Earth-tide and atmospheric loading frequency responses; series numbers in underline font denote series influenced by non-atmospheric loading and Earth-tide responses. Abbreviations: BP, barometric pressure; dd, decimal day (dd 1 = Jan. 1, 2015); hh:mm, hour:minute; mm/dd/yyyy, month/day/year; $\mathrm{N}$, number of hourly samples in the parsed time series; WL, water level]

\begin{tabular}{|c|c|c|c|c|c|c|c|c|c|}
\hline $\begin{array}{l}\text { Well/ } \\
\text { parsed } \\
\text { series }\end{array}$ & $\begin{array}{c}\text { Start date and time } \\
\text { (mm/dd/yyyy } \\
\text { hh:mm) }\end{array}$ & $\begin{array}{l}\text { End date and time } \\
\text { (mm/dd/yyyy } \\
\text { hh:mm) }\end{array}$ & Start dd & End dd & $\begin{array}{c}\mathbf{N} \\
\text { samples }\end{array}$ & $\begin{array}{l}\text { Time series } \\
\text { length } \\
\text { (days) }\end{array}$ & $\begin{array}{l}\text { From WL } \\
\text { piece }\end{array}$ & $\begin{array}{l}\text { From BP } \\
\text { piece }\end{array}$ & $\begin{array}{l}\text { WL detrending } \\
\text { polynomial } \\
\text { order }\end{array}$ \\
\hline \multicolumn{10}{|c|}{$28 \mathrm{~A}-25-1$} \\
\hline 1 & 01/14/2016 01:00 & 02/22/2016 23:00 & 379.0417 & 418.9583 & 959 & 39.9583 & 1 & $28 \mathrm{~A}-1$ & 1 \\
\hline 2 & 02/25/2016 13:00 & 03/04/2016 22:00 & 421.5417 & 429.9167 & 202 & 8.4167 & 2 & $28 \mathrm{~A}-2$ & 1 \\
\hline 3 & 03/07/2016 00:00 & 05/16/2016 23:00 & 432.0000 & 502.9583 & 1,704 & 71.0000 & 3 & $28 \mathrm{~A}-2$ & 1 \\
\hline 4 & 05/18/2016 00:00 & 08/15/2016 23:00 & 504.0000 & 593.9583 & 2,160 & 90.0000 & 4 & $28 \mathrm{~A}-2$ & 1 \\
\hline 5 & 08/17/2016 00:00 & $12 / 12 / 201623: 00$ & 595.0000 & 712.9583 & 2,832 & 118.0000 & 5 & $28 \mathrm{~A}-2$ & 1 \\
\hline 6 & $12 / 14 / 201600: 00$ & 01/04/2017 16:00 & 714.0000 & 735.6667 & 521 & 21.7083 & 6 & $28 \mathrm{~A}-2$ & 1 \\
\hline 7 & 01/05/2017 06:00 & 01/07/2017 22:00 & 736.2500 & 738.9167 & 65 & 2.7083 & 6 & $28 \mathrm{~A}-3$ & 1 \\
\hline 8 & 01/08/2017 04:00 & 01/11/2017 15:00 & 739.1667 & 742.6250 & 84 & 3.5000 & 6 & $28 \mathrm{~A}-4$ & 1 \\
\hline 9 & 08/16/2017 10:00 & 11/28/2017 13:00 & 959.4167 & 1063.5417 & 2,500 & 104.1667 & 7 & $28 \mathrm{~A}-5$ & 5 \\
\hline 10 & 11/28/2017 18:00 & 12/31/2017 23:00 & 1063.7500 & 1096.9583 & 798 & 33.2500 & 8 & $28 \mathrm{~A}-5$ & 1 \\
\hline \multicolumn{10}{|c|}{$28 \mathrm{~A}-25-2$} \\
\hline 1 & 01/14/2016 01:00 & 02/23/2016 23:00 & 379.0417 & 419.9583 & 983 & 40.9583 & 1 & $28 \mathrm{~A}-1$ & 1 \\
\hline 2 & 02/25/2016 13:00 & 03/05/2016 00:00 & 421.5417 & 430.0000 & 204 & 8.5000 & 2 & $28 \mathrm{~A}-2$ & 1 \\
\hline 3 & 03/07/2016 00:00 & 05/17/2016 23:00 & 432.0000 & 503.9583 & 1,728 & 72.0000 & 3 & $28 \mathrm{~A}-2$ & 1 \\
\hline 4 & 05/19/2016 00:00 & 08/16/2016 08:00 & 505.0000 & 594.3333 & 2,145 & 89.3750 & 4 & $28 \mathrm{~A}-2$ & 1 \\
\hline 5 & 01/08/2017 04:00 & 02/10/2017 00:00 & 739.1667 & 772.0000 & 789 & 32.8750 & 5 & $28 \mathrm{~A}-4$ & 1 \\
\hline 6 & 02/15/2017 15:00 & 06/28/2017 13:00 & 777.6250 & 910.5417 & 3,191 & 132.9583 & 6 & $28 \mathrm{~A}-5$ & 5 \\
\hline$\underline{7}$ & 08/09/2017 15:00 & 12/31/2017 23:00 & 952.6250 & 1096.9583 & 3,465 & 144.3750 & 7 & $28 \mathrm{~A}-5$ & 5 \\
\hline $7 \bmod A$ & 08/09/2017 15:00 & 10/10/2017 08:00 & 952.6250 & 1014.3333 & 1,482 & 61.7500 & 7 & $28 \mathrm{~A}-5$ & 1 \\
\hline $7 \operatorname{modB}$ & 10/15/2017 23:00 & 12/31/2017 23:00 & 1019.9583 & 1096.9583 & 1,849 & 77.0417 & 7 & $28 \mathrm{~A}-5$ & 1 \\
\hline \multicolumn{10}{|c|}{$14 \mathrm{~A}-25-1$} \\
\hline 1 & 11/13/2015 12:00 & 02/24/2016 09:00 & 317.5000 & 420.3750 & 2,470 & 102.9167 & 1 & $28 \mathrm{~A}-1$ & 1 \\
\hline 12 & 02/26/2016 01:00 & 05/15/2016 23:00 & 422.0417 & 501.9583 & 1,919 & 79.9583 & 2 & $28 \mathrm{~A}-2$ & 1 \\
\hline 4 & 05/20/2016 00:00 & 07/05/2016 23:00 & 506.0000 & 552.9583 & 1,128 & 47.0000 & 4 & 28A-2 & 1 \\
\hline 5 & 07/14/2016 00:00 & 08/14/2016 23:00 & 561.0000 & 592.9583 & 768 & 32.0000 & 5 & $28 \mathrm{~A}-2$ & 1 \\
\hline 6 & 08/18/2016 00:00 & $12 / 08 / 201623: 00$ & 596.0000 & 708.9583 & 2,712 & 113.0000 & 6 & $28 \mathrm{~A}-2$ & 1 \\
\hline 7 & 01/08/2017 04:00 & 02/10/2017 00:00 & 739.1667 & 772.0000 & 789 & 32.8750 & 7 & $28 \mathrm{~A}-4$ & 1 \\
\hline 8 & 02/15/2017 21:00 & 05/24/2017 07:00 & 777.8750 & 875.2917 & 2,339 & 97.4583 & 8 & $28 \mathrm{~A}-5$ & 1 \\
\hline 9 & 05/24/2017 20:00 & 08/09/2017 07:00 & 875.8333 & 952.2917 & 1,836 & 76.5000 & 9 & $14 \mathrm{~A}-1$ & 1 \\
\hline$\underline{10}$ & 08/09/2017 20:00 & 11/29/2017 08:00 & 952.8333 & 1064.3333 & 2,677 & 111.5417 & 10 & $14 \mathrm{~A}-1$ & 1 \\
\hline $10 \mathrm{mod}$ & 10/09/2017 00:00 & 11/29/2017 08:00 & 1013.0000 & 1064.3333 & 1,233 & 51.3750 & 10 & $14 \mathrm{~A}-1$ & 1 \\
\hline 11 & 11/29/2017 19:00 & 12/18/2017 10:00 & 1064.7917 & 1083.4167 & 448 & 18.6667 & 11 & $14 \mathrm{~A}-1$ & 1 \\
\hline
\end{tabular}

${ }^{1}$ Parsed series 14A-25-1 2 was not analyzed owing to a suspected time error in this time series. 
The detrended, parsed series were used for subsequent analyses. Figure 2-4 shows an example for each of three detrended, parsed series: 28A-25-1_9 (fig. 2-4A, B), 28A25-2 4 (fig. 2-4C, D), and 14A-25-1 8 (fig. 2-4E, F). For the detrended series, the units of water level were converted from feet $(\mathrm{ft})$ to centimeters $(\mathrm{cm})$, and the units of barometric pressure were converted from millibars (mbar) to equivalent centimeters of water. The unit conversions facilitated the time-series analyses and provided consistent units for water level and barometric pressure. The inverse relation between barometric pressure and water level (when plotted as decreasing depth-to-water below land surface) is evident in these plots (fig. 2-4B, $D, F$ ). The response of water level to changes in barometric pressure in a well open to the atmosphere is characterized by the barometric efficiency (BE) of the well (Jacob, 1940):

$$
B E=-\frac{\Delta y}{\Delta x}
$$

where

$\Delta y \quad$ is the change in head expressed as the change in the elevation of the water level in the well, and

$\Delta x \quad$ is the change in barometric pressure expressed in equivalent units of head:

$$
\Delta x=\Delta p_{x} /\left(\rho_{w} g\right)
$$

where

$$
\begin{aligned}
\Delta p_{x} & \text { is the change in barometric pressure, } \\
\rho_{w} & \text { is the density of water, and } \\
g & \text { is the gravitational acceleration constant. }
\end{aligned}
$$

Because water levels in monitoring wells were expressed as depth-to-water below land surface in this analysis, an increase in the level of the free-surface water level (the water-level elevation or head) in the wells (positive $\Delta y$ ) corresponded to a decrease in the depth-to-water below land surface.

Preliminary estimates of a constant BE for each of the detrended, parsed series shown in table 2-1, other than those series with series numbers in underline font (affected by non-atmospheric loading and Earth-tide responses) and series 14A-25-1_2 (suspected time error), were determined using several methods (fig. 2-1, box e). First, using method $1, \mathrm{BE}$ was estimated from a linear least-squares regression of detrended water level $(y)$ on detrended barometric pressure $(x)$. Second, using methods $2 \mathrm{a}$ and $2 \mathrm{~b}, \mathrm{BE}$ was estimated from a least-squares linear regression of low-pass (lp) or high-pass (hp) filtered detrended time series, for instance, $y_{l p}$ on $x_{l p}$ or $y_{h p}$ on $x_{h p}$, respectively, for a cutoff frequency of 0.7 cycles per day (cpd). Third, using method 3, BE was estimated from a linear least-squares regression of $\Delta y$ on $\Delta x$ using

$$
\begin{aligned}
& \Delta x(t)=x_{t}-x_{t-1} \\
& \Delta y(t)=y_{t}-y_{t-1} \text { for } t=2, N
\end{aligned}
$$

where

$$
\begin{gathered}
t \quad \text { is the index of hourly samples, and } \\
N \quad \text { is the number of samples in the detrended, } \\
\text { parsed time series. }
\end{gathered}
$$

Each of the methods tested different frequency content of the water-level responses to barometric-pressure variations. Method 1 estimated an approximate average response across the range of frequency content that was weighted more by the lower frequency content. Methods $2 \mathrm{a}$ and $2 \mathrm{~b}$ estimated approximate average responses for frequency content below (lp) and above (hp) $0.7 \mathrm{cpd}$, respectively. Method 3 estimated the response from hour-to-hour and was more representative of the highest resolvable frequency component $\left(\frac{f_{s}}{2}=12 \mathrm{cpd}\right.$, where $f$ is the sampling frequency of 24 samples per day) of the response. Table 2-2 lists the BEs estimated from each of the methods for the selected parsed series, and figure 2-5 shows an example of the detrended hydrographs, barographs and regressions for parsed series 14A-25-1_8. Note, the regressions were done using the negative of the depth-to-water level values to account for the inverse relation between depthto-water level and water-level elevation or head. Thus, the computed BEs were represented by the negative slope of the equation of the best-fit line determined from the linear leastsquares regression, consistent with equation 2-1.

The estimates of constant values of BE for each well (table 2-2) indicated that BE depended on the frequency content of the barometric-pressure time series $(x)$. For each well, there was a notable difference between the BE estimates derived from the lower frequency components (methods 1 and $2 \mathrm{a})$ and those derived from the higher frequency components (methods $2 \mathrm{~b}$ and 3). For wells 28A-25-1 and 28A-25-2, the higher frequency component mean $\mathrm{BE}$ estimates ranged from 0.93 to 1.02 , whereas the lower-frequency component mean estimates ranged from 0.60 to 0.71 . The estimates computed using method $2 \mathrm{~b}$ had higher coefficients of determination $\left(r^{2}\right)$ than estimates computed using the other methods for these wells. For well 14A-25-1, the corresponding higher and lower frequency component mean estimates ranged from 0.54 to 0.62 and from 0.78 to 0.79 , respectively. The responses for well 14A-25-1 were notably different, with higher BEs estimated from the lower frequency component responses (methods 1 and 2a) and with poorer $r^{2}$ values for the higher frequency component estimates (methods $2 \mathrm{~b}$ and 3 ). Also, the higher frequency component $\mathrm{BE}$ estimates for parsed series from well 14A-25-1 had poorer $r^{2}$ values than the higher frequency component $\mathrm{BE}$ estimates for parsed series from wells 28A-25-1 and 28A-25-2. 

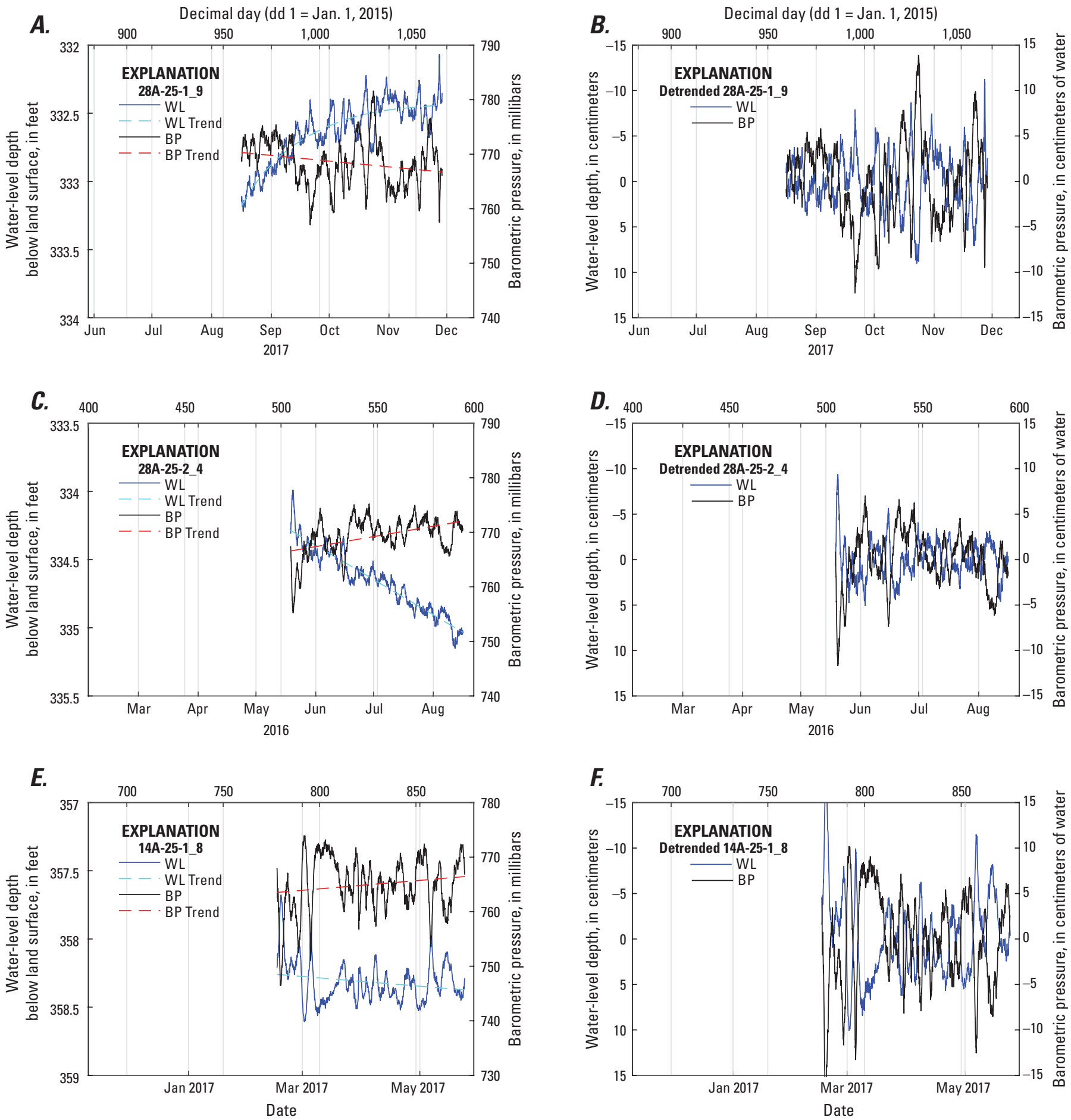

Figure 2-4. Trended and detrended water-level (WL) and barometric-pressure (BP) parsed time series 28A-25-1_9 during August 16November 28, 2017, 28A-25-2_4 during May 19-August 16, 2016, and 14A-25-1_8 during February 15-May 24, 2017, from wells 28A-25-1, 28A-25-2, and 14A-25-1 in the area of Mammoth Lakes, California: $A$, trended data for 28A-25-1_9; $B$, detrended data for 28A-25-1_9; $C$, trended data for 28A-25-2_4; $D$, detrended data for 28A-25-2_4; $E$, trended data for 14A-25-1_8; F, detrended data for 14A-25-1_8. 
Table 2-2. Estimates of constant barometric efficiency determined using methods 1, 2a, 2b, and 3 for each of the parsed time series shown in table 2-1, other than those with series numbers in underline font, for wells $28 \mathrm{~A}-25-1,28 \mathrm{~A}-25-2$, and $14 \mathrm{~A}-25-1$ in the area of Mammoth Lakes, California.

[BE1, BE2a, BE2b and BE3 refer to different methods for determining constant-valued barometric efficiency using least-squares linear regression. BE1, method 1; BE2a, method 2a; BE2b, method 2b; BE3, method 3; $\mathrm{r}^{2} 1$, coefficient of determination from method 1; $\mathrm{r}^{2} 2 \mathrm{a}$, coefficient of determination from method 2a; $r^{2} 2 b$, coefficient of determination from method $2 b ; r^{2} 3$, coefficient of determination from method 3. - , not applicable]

\begin{tabular}{|c|c|c|c|c|c|c|c|c|}
\hline $\begin{array}{l}\text { Well/parsed } \\
\text { series }\end{array}$ & BE 1 & $r^{2} 1$ & BE 2a & $r^{2} 2 a$ & BE $2 b$ & $r^{2} 2 b$ & BE 3 & $r^{2} 3$ \\
\hline \multicolumn{9}{|c|}{$28 A-25-1$} \\
\hline 2 & 0.822 & 0.932 & 0.761 & 0.925 & 0.965 & 0.955 & 0.934 & 0.820 \\
\hline 3 & 0.643 & 0.680 & 0.633 & 0.672 & 1.014 & 0.956 & 0.958 & 0.806 \\
\hline 6 & 0.697 & 0.759 & 0.694 & 0.759 & 1.036 & 0.849 & 0.911 & 0.698 \\
\hline 7 & 1.060 & 0.924 & 1.070 & 0.919 & 1.044 & 0.940 & 0.927 & 0.776 \\
\hline 8 & 0.903 & 0.823 & 0.936 & 0.736 & 0.852 & 0.847 & 0.746 & 0.514 \\
\hline 9 & 0.558 & 0.645 & 0.548 & 0.638 & 0.992 & 0.964 & 0.970 & 0.824 \\
\hline 1 & 0.643 & 0.726 & 0.634 & 0.721 & 0.993 & 0.940 & 0.950 & 0.854 \\
\hline 2 & 0.811 & 0.882 & 0.715 & 0.880 & 1.073 & 0.926 & 0.993 & 0.795 \\
\hline 3 & 0.652 & 0.692 & 0.642 & 0.686 & 1.021 & 0.937 & 0.956 & 0.808 \\
\hline 4 & 0.473 & 0.492 & 0.462 & 0.483 & 1.020 & 0.938 & 0.975 & 0.741 \\
\hline 5 & 0.597 & 0.682 & 0.593 & 0.679 & 0.985 & 0.959 & 0.903 & 0.841 \\
\hline 6 & 0.582 & 0.623 & 0.574 & 0.618 & 1.012 & 0.944 & 0.945 & 0.824 \\
\hline $7 \bmod A$ & 0.570 & 0.534 & 0.555 & 0.519 & 1.044 & 0.964 & 0.979 & 0.828 \\
\hline $7 \operatorname{modB}$ & 0.594 & 0.602 & 0.585 & 0.596 & 1.021 & 0.928 & 0.966 & 0.799 \\
\hline mean & 0.615 & - & 0.595 & - & 1.021 & - & 0.958 & - \\
\hline \multicolumn{9}{|c|}{$14 \mathrm{~A}-25-1$} \\
\hline 7 & 0.879 & 0.940 & 0.883 & 0.944 & 0.523 & 0.456 & 0.512 & 0.630 \\
\hline 8 & 0.833 & 0.866 & 0.837 & 0.869 & 0.573 & 0.612 & 0.537 & 0.641 \\
\hline 9 & 0.712 & 0.771 & 0.716 & 0.780 & 0.616 & 0.518 & 0.541 & 0.514 \\
\hline $10 \mathrm{mod}$ & 0.780 & 0.885 & 0.783 & 0.889 & 0.652 & 0.663 & 0.593 & 0.690 \\
\hline 11 & 0.815 & 0.959 & 0.818 & 0.964 & 0.694 & 0.683 & 0.595 & 0.683 \\
\hline mean & 0.787 & - & 0.790 & - & 0.618 & - & 0.539 & - \\
\hline
\end{tabular}


A.

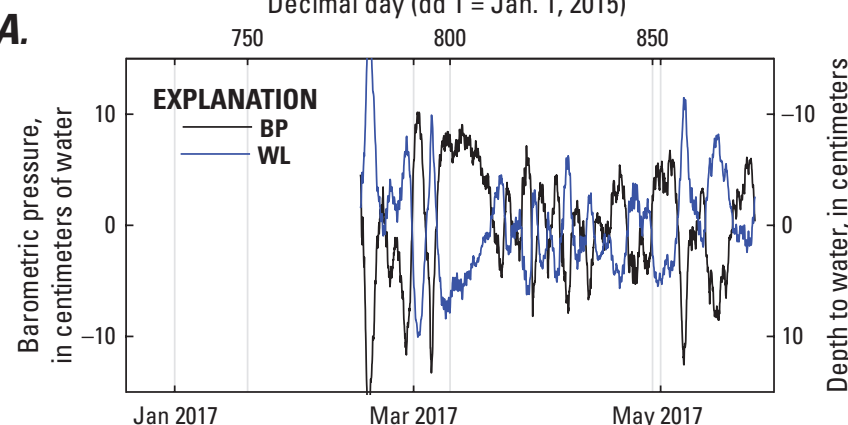

C.

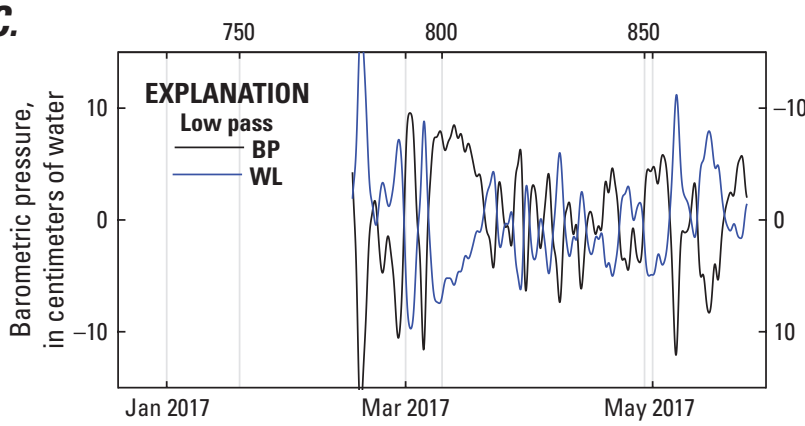

E.

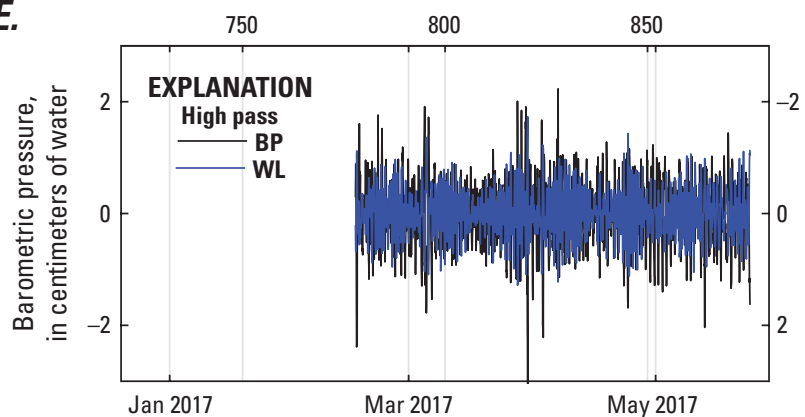

G.

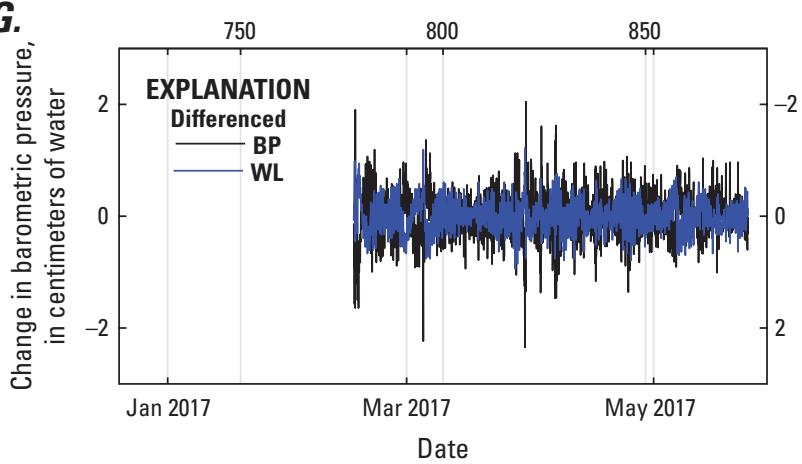

B.

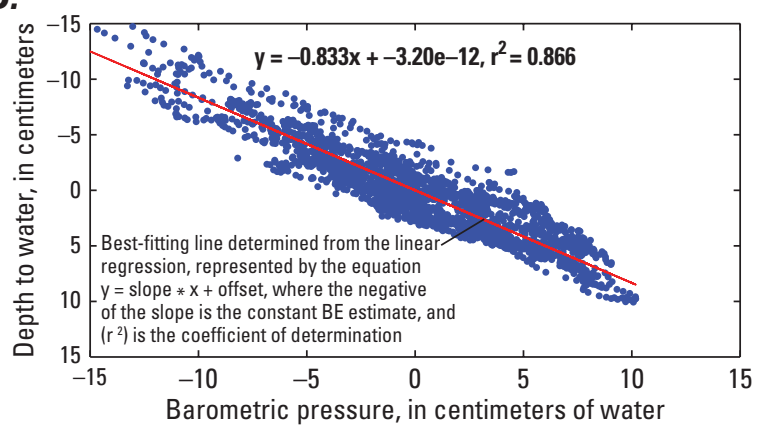

D.

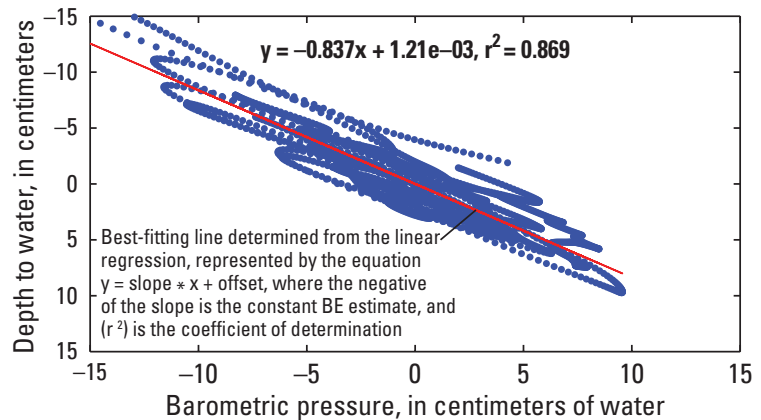

F.

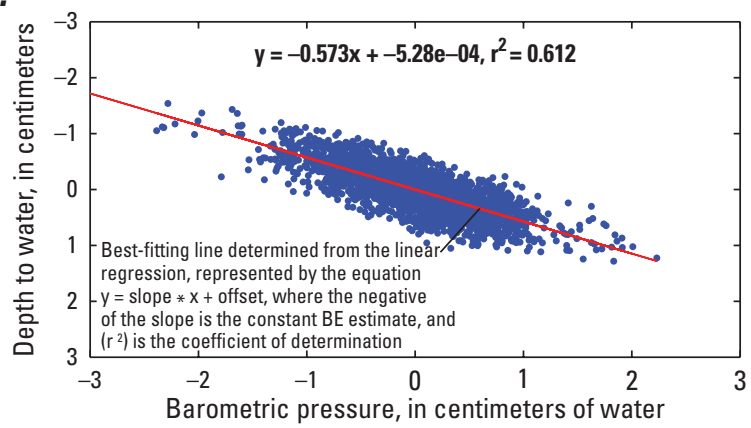

H.

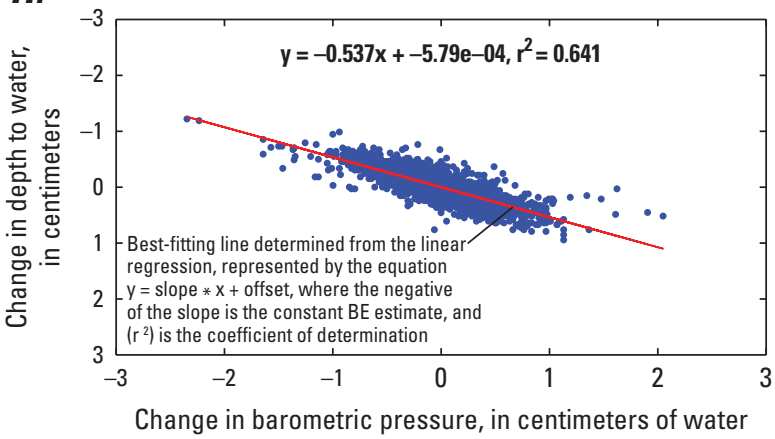

Figure 2-5. Estimates of constant barometric efficiency (BE) for detrended, parsed time series 14A-25-1_8, February 15-May 24, 2017, from well 14A-25-1 in the area of Mammoth Lakes, California, based on linear least-squares regression of water level (WL) on barometric pressure (BP) using methods $1,2 \mathrm{a}, 2 \mathrm{~b}$, and 3 . $A$, detrended series used for method $1 ; B$, linear regression of detrended series for method 1; $C$, low-pass detrended series used for method 2a; $D$, linear regression of low-pass detrended series for method 2a; $E$, highpass detrended series used for method $2 \mathrm{~b}$; $F$, linear regression of high-pass detrended series for method $2 \mathrm{~b} ; G$, differenced, detrended series used for method 3 ; and $H$, linear regression of differenced, detrended series for method 3. 
Filtered, detrended water-level estimates $(\tilde{y})$ based on the BEs estimated using methods $1,2 \mathrm{a}$ and $2 \mathrm{~b}$ were computed as follows:

$$
\tilde{y}_{B E}(t)=y_{t}-\hat{y}_{B E_{t}} \text { for } t=1, N
$$

where

$$
\begin{gathered}
\hat{y}_{B E_{t}} \quad \text { is the predicted water-level, } \\
\hat{y}_{B E_{t}}=-B E x_{t}
\end{gathered}
$$

For method 3, $\tilde{y}_{B E}(t)$ was computed as follows:

$$
\tilde{y}_{B E}(t)=y_{t}-\hat{y}_{B E_{t}} \text { for } t=2, N
$$

where

$$
\hat{y}_{B E_{t}}=-B E \sum_{i=2}^{N}\left(\Delta x_{i}\right)+\hat{y}_{B E_{1}}
$$

where

$$
\begin{aligned}
\sum_{i=2}^{N}\left(\Delta x_{i}\right) & \begin{array}{r}
\text { represents the cumulative sums of } \Delta x_{i}(t) \text { for } \\
t=2, N \text { from equation } 2-3, \text { and }
\end{array} \\
\hat{y}_{B E_{1}} & \text { is } \hat{y}_{B E} \text { computed from equation } 2-5 \text { for } t=1 .
\end{aligned}
$$

Equations 2-6 and 2-7, as formulated, are equivalent to equations $2-4$ and $2-5$ where BE estimated using method 3 is used in equation 2-5. The filtered results for the 28A-25-1_9, 28A-25-2_4, and 14A-25-1_4 detrended, parsed series using the constant BE estimates from the $1 p$ (using method $2 \mathrm{a}$ ) and hp (using method 2b) filtered time series (fig. 2-6) and for all of the parsed series listed in table 2-2 showed that a singlevalued, frequency-independent $\mathrm{BE}$ could not adequately account for the atmospheric-loading responses measured in each well (fig. 2-1, box e).

\section{Water-Level Responses to the Solid Earth Tide}

Water-level responses in each well to the principal tides of the solid Earth tide were evaluated using harmonic analysis (for example, Hsieh and others, 1987; Galloway and Rojstaczer, 1989; Cutillo and Bredehoeft, 2011). Use of the terms 'tide' and 'tidal' here refer specifically to Earth tides in terms of the known frequencies of the principal constituents of the Earth tide and do not imply a more general reference that includes barometric tides. Table 2-3 lists the frequencies and periods of the six principal Earth tides (Godin, 1972), which constitute about 95 percent of the tidal potential. These tides result from the relative motions of the moon, sun, and Earth.

The tides are designated as lunar $\left(\mathrm{O}_{1}, \mathrm{Q}_{1}, \mathrm{M}_{2}, \mathrm{~N}_{2}\right)$, solar $\left(\mathrm{S}_{2}\right)$, or mixed $\left(\mathrm{K}_{1}\right)$ and by their mode (diurnal, ${ }_{1}$, or semidiurnal, ${ }_{2}$ ).

The detrended, parsed water-level time series were digitally filtered using a high-pass Butterworth filter (Butterworth, 1930) (order 7) with a cut-off frequency of $0.7 \mathrm{cpd}$ to generally separate the responses at higher frequencies $(0.7-12 \mathrm{cpd})$ containing diurnal and semidiurnal tidal and atmospheric-loading responses from the responses at lower frequencies dominated by atmospheric-loading effects. At mid-latitudes, fluctuations in barometric pressure at 1 and $2 \mathrm{cpd}$ are caused by solar heating of the atmosphere. The well responses at these frequencies, especially at $2 \mathrm{cpd}$, are dominated by atmospheric-loading effects, to which the responses to Earth tides are superimposed at nearby or coincident frequencies, such as for the $\mathrm{K}_{1}$ and $\mathrm{S}_{2}$ tides. Therefore, although the analysis included each of the tides in table 2-3, a focus was placed on the responses to the lunar tides $\left(\mathrm{M}_{2}, \mathrm{O}_{1}, \mathrm{~N}_{2}, \mathrm{Q}_{1}\right.$, listed in order of decreasing tidal potential).

The theoretical tidal potential and resulting body tides of a solid Earth (oceanless) produced by the moon and sun were computed from gravitational and astronomical theory for the locations and open-interval elevations of the monitoring wells at the sample times for each of the parsed series using the Harrison (1971) model. The Earth's crust undergoes volumetric strains, $\varepsilon_{v}$, due to variations in the tide-generating forces:

$$
\varepsilon_{v}=\varepsilon_{\theta \theta}+\varepsilon_{\lambda \lambda}+\varepsilon_{r r}
$$

where

$$
\begin{aligned}
& \varepsilon_{\theta \theta} \quad \text { is the component strain in the north principal } \\
& \text { axis, } \\
& \varepsilon_{\lambda \lambda} \quad \text { is the component strain in the east principal } \\
& \varepsilon_{r r} \quad \text { axis, and } \\
& \text { (down component strain in the radial } \\
& \text { principal axis. }
\end{aligned}
$$

Near the Earth's surface (within the upper $10 \mathrm{~km}$ or more), most of the stress is plane stress, and the resultant strain tide is predominantly an areal strain, $\varepsilon_{\text {Areal }}$ (Melchior, 1966; Rojstaczer and Agnew, 1989):

$$
\varepsilon_{\text {Areal }}=\varepsilon_{\theta \theta}+\varepsilon_{\lambda \lambda}
$$



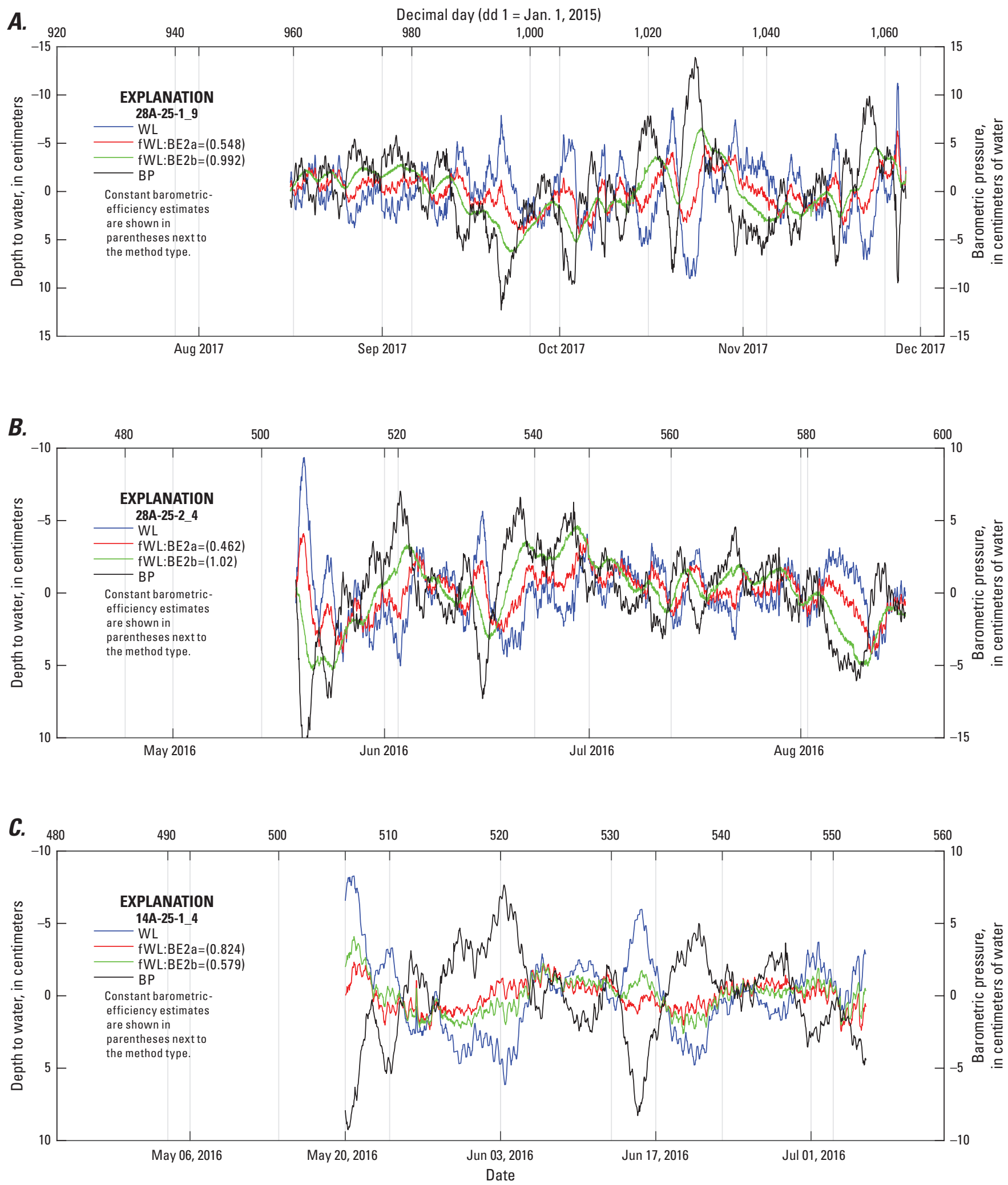

Figure 2-6. Digitally filtered water levels fWL:BE2a and fWL:BE2b for detrended, parsed water-level (WL) and barometric-pressure (BP) time series from wells 28A-25-1, 28A-25-2, and 14A-25-1 in the area of Mammoth Lakes, California, using the constant barometricefficiency (BE) estimates determined from method 2a (low-pass) and method 2b (high-pass): A, 28A-25-1_9, August 16-November 28, 2017; B, 28A-25-2_4, May 19-August 18, 2016; C, 14A-25-1_4, May 20-July 5, 2016. 
Table 2-3. Frequencies, periods, and indices used in the analysis of the six principal Earth tides (Godin, 1972).

\begin{tabular}{lccc}
\hline Tide & $\begin{array}{c}\text { Frequency } \\
\text { (cycles per solar day) }\end{array}$ & $\begin{array}{c}\text { Period } \\
\text { (solar hours) }\end{array}$ & $\begin{array}{c}\text { Constituent index } \\
\text { (k) }\end{array}$ \\
\hline $\mathrm{Q}_{1}$ & 0.89324406 & 26.8683567 & 6 \\
$\mathrm{O}_{1}$ & 0.92953571 & 25.8193416 & 5 \\
$\mathrm{~K}_{1}$ & 1.00273791 & 23.9344696 & 4 \\
$\mathrm{~N}_{2}$ & 1.89598197 & 12.6583482 & 3 \\
$\mathrm{M}_{2}$ & 1.93227361 & 12.4206012 & 2 \\
$\mathrm{~S}_{2}$ & 2.00000000 & 12.0000000 & 1 \\
\hline
\end{tabular}

The areal-strain tide (positive for dilatation following the convention of Harrison, 1971) was computed in parts per billion (nanostrain) as a scaled function of the tidal potential (Munk and McDonald, 1960; Melchior, 1966; Bredehoeft, 1967):

$$
\varepsilon_{\text {Areal }}=(2 \bar{h}-6 \bar{l}) \frac{V}{r_{e} g} \times 10^{9}
$$

where

$$
\begin{aligned}
& \bar{h} \quad \text { is a Love number taken to be } 0.638 \text {, } \\
& \bar{l} \quad \text { is a Love number taken to be } 0.088 \text {, } \\
& V \quad \text { is the tidal potential, } \\
& r_{e} \quad \text { is the distance between the center of the Earth } \\
& \text { and the observation point on or near the } \\
& \text { Earth's surface, and } \\
& g \quad \text { is the gravitational acceleration constant. }
\end{aligned}
$$

Similar to the detrended, parsed water-level time series, the computed areal-strain tide time series were detrended and digitally filtered using a high-pass Butterworth filter (Butterworth, 1930) (order 7) with a cut-off frequency of $0.7 \mathrm{cpd}$. The amplitudes and phases of water level and the theoretical areal-strain tide at the principal tidal frequencies (table 2-3) were computed by multiple least-squares fitting for each tidal constituent of the respective parsed time series to the following functions:

$$
\begin{aligned}
& y_{h p}\left(t_{j}\right)=\sum_{k=1}^{6}\left(a_{k} \cos \left(2 \pi f_{k} t_{j}\right)+b_{k} \sin \left(2 \pi f_{k} t_{j}\right)\right)+R y_{h p_{j}} \\
& \varepsilon_{\text {Areal hp }}\left(t_{j}\right)=\sum_{k=1}^{6}\left(c_{k} \cos \left(2 \pi f_{k} t_{j}\right)+d_{k} \sin \left(2 \pi f_{k} t_{j}\right)\right)+R \varepsilon_{\text {Areal hp }}
\end{aligned}
$$

where

$$
\begin{aligned}
& t_{j} \quad \text { is time in decimal days (for } j=1 \text { to the } \\
& \text { number of samples, N); } \\
& \begin{array}{l}
y_{h p} \quad \text { is the high-pass, detrended water-level } \\
\text { series; } \\
\mathcal{E}_{\text {Areal hp }} \quad \text { is the high-pass, areal-strain tide series; }
\end{array}
\end{aligned}
$$

$$
\begin{aligned}
& f_{k} \quad \text { is the frequency in cycles per day of the } k^{\text {th }} \\
& \text { tidal constituent (for } k=1,6 \text { corresponding } \\
& \text { to the six tides in table 2-3); } \\
& a_{k}, b_{k} \quad \text { are the coefficients of the regression for the } \\
& \text { high-pass water-level series; } \\
& c_{k}, d_{k} \quad \text { are the coefficients of the regression for the } \\
& \text { high-pass, areal-strain tide series; } \\
& R y_{h p_{j}} \quad \text { are the residuals for the high-pass, water-level } \\
& \text { series; and } \\
& R \varepsilon_{\text {Areal } h p_{j}} \quad \text { are the residuals for the high-pass, areal-strain } \\
& \text { tide series. }
\end{aligned}
$$

The summation terms in equations $2-11$ and $2-12$ represent the predicted values of the regressions $\hat{y}_{\text {hpet }}$ and $\hat{\varepsilon}_{\text {Areal } h p}$, respectively. Figure 2-7 shows the predicted fits to the high-pass, detrended, parsed water-level and theoretical areal-strain tide time series for 14A-25-1_5. Predicted fits to the theoretical areal-strain tide (fig. 2-7B) were much better than the predicted fits to water level (fig. 2-7A), reflecting that the six principal Earth tides accounted for almost all of the variation in the theoretical areal-strain tide and a much smaller proportion of the high-pass, detrended water-level variation.

The amplitudes ( $\left.A y_{k}, A \varepsilon_{\text {Area }_{k}}\right)$ and phases $\left(\phi y_{k}, \phi \varepsilon_{\text {Areal }_{k}}\right.$ expressed in degrees) referenced to the starting time of the individual parsed series were computed for each tidal constituent $(k)$ in each time series $\left(\hat{y}_{h p}, \hat{\varepsilon}_{A r e a l}\right)$ using the following equations:

$$
\begin{aligned}
& A y_{k}=\sqrt{a_{k}^{2}+b_{k}^{2}} ; A \varepsilon_{\text {Areal }_{k}}=\sqrt{c_{k}^{2}+d_{k}^{2}} \\
& \phi y_{k}=\operatorname{atan} 2\left(b_{k}, a_{k}\right) ; \phi \varepsilon_{\text {Areal }_{k}}=\operatorname{atan} 2\left(d_{k}, c_{k}\right)
\end{aligned}
$$

where

$$
\begin{array}{cl}
A y_{k} & \text { and } A \varepsilon_{\text {Areal }_{k}} \\
\text { atan2 } & \text { are the positive roots of the arguments, and } \\
\text { is the two-argument arctangent. }
\end{array}
$$

The phase shift of the water-level response to each tidal constituent ( $\mathrm{k}=1$ to 6$)$ in the forcing theoretical areal-strain tide was computed using the following equation:

$$
\eta_{k}=\phi y_{k}-\phi \varepsilon_{\text {Areal }_{k}},-180^{\circ} \leq \eta_{k} \leq 180^{\circ}
$$

Because an increasing tidal dilatation would be expected to cause an increasing depth-to-water level, the ideal waterlevel response in terms of depth-to-water level would be in-phase with the tidal dilatation. The phases and phase shifts were mapped in the interval -180 to +180 degrees $\left(^{\circ}\right)$ (eqn. 2-14). Thus, for the conventions used here to compute phases and phase shifts, positive (greater than $0^{\circ}$ ) phase shifts represented a phase lag of the water-level response to the tidal dilatation and negative phase shifts represented a phase advance. In terms of water-level elevation or head, the ideal water-level response would be antiphase (for example, $-180^{\circ}$ ) with the tidal dilatation, and the phase shifts as computed here (eqn. $2-14$ ) would need to be added to $-180^{\circ}$ to reflect the expected antiphase response. 

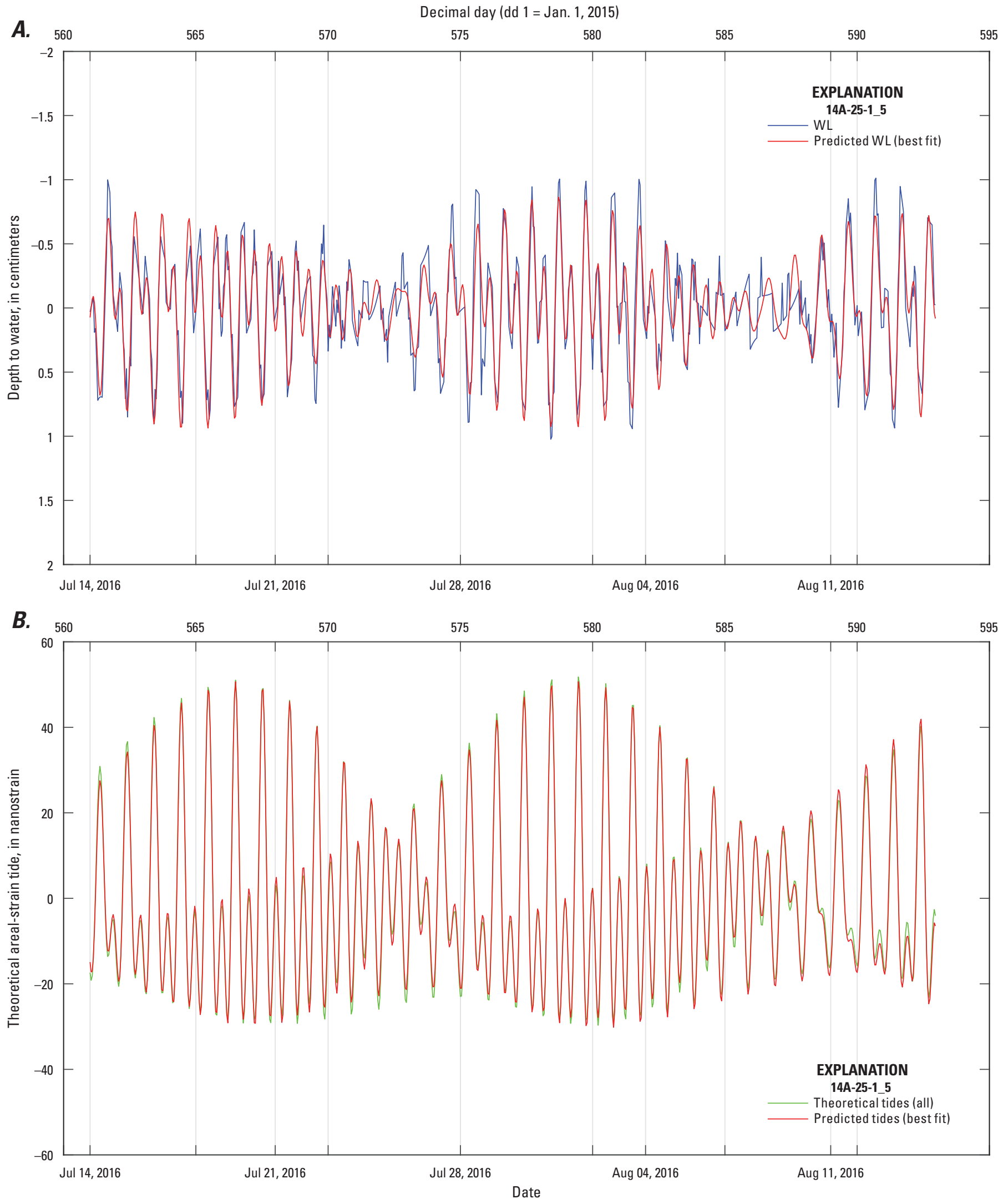

Figure 2-7. Predicted fits, $\hat{y}_{\text {hpet }}$ (Predicted WL) and $\hat{\varepsilon}_{\text {Areal }}$ (Predicted tides), to the high-pass, detrended, parsed water-level $\left(y_{h p^{\prime}}\right.$, or WL) and theoretical areal-strain tide, $\varepsilon_{\text {Areal }}$ (Theoretical tides) time series, respectively, for 14A-25-1_5 during July 14-August 14, 2016, from well 14A-25-1 in the area of Mammoth Lakes, California: $A$, WL and Predicted WL; and $B$, Theoretical tides and Predicted tides. 


\section{Preliminary Earth-Tide Analyses of Parsed Series}

A preliminary analysis was done for each of the parsed series indicated by series numbers in bold-italic font in table $2-1$ to determine whether water levels responded to Earth tides (fig. 2-1, box f). The preliminary analysis comprised computing the amplitude, phase, and phase shift using equations 2-13 and 2-14 for each tidal constituent for each of the parsed series analyzed for 28A-25-1, 28A-25-2, and 14A-25-1 (table 2-4). Parsed series 28A-25-2 7 and 14A-25-1_10 were not analyzed because they contained some water-level responses not attributable to atmospheric-loading and Earth tides, such as responses in 14A-25-1_10 to the flow test in production well 14-25. The modified versions of these parsed series, 28A-25-2_7modA and _ $7 \operatorname{modB}$, and 14A-251_10mod were analyzed instead. Additionally, only parsed series with lengths greater than 1 lunar month were analyzed. This resulted in a total of 21 parsed series preliminarily analyzed for tides (indicated by series numbers in bold-italic font in table 2-1).

Because at the exact frequencies of the lunar Earth tides $\left(\mathrm{M}_{2}, \mathrm{~N}_{2}, \mathrm{O}_{1}\right.$, and $\left.\mathrm{Q}_{1}\right)$ there is little power in the barometric pressure signal, the presence of discernable water-level amplitudes at the frequencies of the principal lunar tides $\left(\mathrm{M}_{2}\right.$ and $\mathrm{O}_{1}$ ) is an indication that a water-level response at these frequencies may be due to Earth tides. The estimated tidal constituent parameters in table 2-4 show, as expected, that the $\mathrm{S}_{2}$ (solar) and $\mathrm{K}_{1}$ (mixed) tides dominated the water-level amplitude responses at these tidal frequencies for 28A-25-1 and 28A-25-2. For 14A-25-1, the $\mathrm{M}_{2}$ and to a lesser extent the $\mathrm{O}_{1}$ amplitude responses were co-dominant with the $\mathrm{S}_{2}$ and $\mathrm{K}_{1}$ tidal-amplitude responses. Table 2-4 shows mean $\mathrm{M}_{2}$ waterlevel amplitudes of about $0.27 \mathrm{~cm}$ for $14 \mathrm{~A}-25-1$ and only about $0.05 \mathrm{~cm}$ for 28A-25-1 and 28A-25-2. All the lunar tidal amplitude responses in 28A-25-1 and 28A-25-2, and the lesser lunar $\left(\mathrm{N}_{2}\right.$ and $\left.\mathrm{Q}_{1}\right)$ tidal amplitude responses in 14A-25-1, were weak. Except for the $\mathrm{S}_{2}$ component in each well that was dominated by responses to atmospheric loading, and the $\mathrm{M}_{2}$ and $\mathrm{O}_{1}$ components in 14A-25-1, the great variability in the computed phase shifts likely resulted from the small spectral power in the water-level responses at the tidal frequencies and further indicated that the water-level responses for all the lunar tides in 28A-25 wells and the lesser lunar tides in 14A-25-1 were negligible. Note that the means and standard deviations listed in table 2-4 do not represent the true population means and variances because the length (number of samples) for each parsed series (table 2-1) varied widely. Because the principal lunar tidal responses were potentially important in well 14A25-1, and to compute relevant population statistics, the $14 \mathrm{~A}-$ 25-1 series analyzed previously were further analyzed for tidal responses.

\section{Earth-Tide Analysis of Discrete Segments of Select 14A-25-1 Time Series}

The 14A-25-1 detrended, parsed time series selected for further tidal analysis (fig. 2-1, box h) were divided into fifteen 32-day discrete (non-overlapping) segments: three each from parsed series 14A-25-1_1,_6, and _8; two from _9; and one each from $44,5, \ldots 7$, and 10 mod. A segment length of 32 days was chosen primarily because it is sufficiently longer than 1 lunar month and preserves a maximum total number of discrete segments obtainable from the parsed water-level time series. A constant segment length simplified the computation of population statistics for the tidal responses. Table 2-5 lists the water-level and strain amplitudes and phases (mapped in the interval -180 to $+180^{\circ}$ ), and the ratio of the waterlevel amplitude to the theoretical areal-strain amplitude computed for each of the principal tidal constituents in units of centimeters per nanostrain using equation 2-15:

$$
\mathrm{A}_{k}=\frac{A y_{k}}{A \varepsilon_{\text {Areal }_{k}}}
$$

The computed phase shift ( $\eta_{k}$, eqn. $\left.2-14\right)$ is also shown for each of the principal tides in table 2-5.

The segments were numbered sequentially ( $\mathrm{nd}=1-15$ ) by the numerical order of the parsed series from which they were derived (for example, nd 1-3 were from 14A-25-1_1, and nd 15 was from 14A-25-1_10mod). The responses (table 2-5) showed similar results as those obtained in the preliminary tidal analysis for 14A-25-1 (table 2-4), described previously with some minor differences. For the $\mathrm{M}_{2}$ and $\mathrm{O}_{1}$ tides, the mean water-level amplitudes, 0.27 and $0.18 \mathrm{~cm}$, and the mean phase shifts, 5.75 and $-11.1^{\circ}$, respectively, were essentially equivalent to those computed in the preliminary analysis. However, the uncertainty in the $\mathrm{O}_{1}$ phase shifts was much greater (more than a factor of two) than that computed in the preliminary analysis with a standard deviation greater than more than twice the mean, possibly indicating that the water-level responses at the $\mathrm{O}_{1}$ tidal frequency were at least partially contaminated by atmospheric-loading effects. The greater uncertainty in the $\mathrm{O}_{1}$ phase shift might simply be because most of the data were broken into shorter segments than for the preliminary analysis. For the preliminary analysis (table 2-4), the mean length of the data series for 14A-25-1 was about 72 days, compared with 32 days for the discrete tidal analysis (table 2-5). Results from longer series are expected to be less variable than results from shorter series, especially for lower frequency constituents (for example, $\mathrm{O}_{1}$ ). The computed values of $\mathrm{A}_{k}$ and $\eta_{k}$ indicated that the water-level responses for each tide were not due solely to the theoretical areal-strain tide. This was especially true for tidal frequencies other than the principal lunar tides $\left(\mathrm{M}_{2}\right.$ and $\left.\mathrm{O}_{1}\right)$ for which water-level responses likely contained substantial barometric-pressure inputs. For $\mathrm{M}_{2}$ and $\mathrm{O}_{1}, \mathrm{~A}_{k}$ may represent the areal-strain sensitivity of water-level response to the theoretical areal strain at these tidal frequencies. 
Table 2-4. Results of tidal harmonic analysis of selected, detrended, parsed time series for wells 28A-25-1 during January 14, 2016December 31, 2017, 28A-25-2 during January 14, 2016-December 31, 2017, and 14A-25-1 during November 13, 2015-November 29, 2017, in the area of Mammoth Lakes, California.

[Phase and phase shift in units of degrees; Strain (areal strain) is in units of nanostrain; Water level (WL) is in units of centimeters. Abbreviation: -, not applicable]

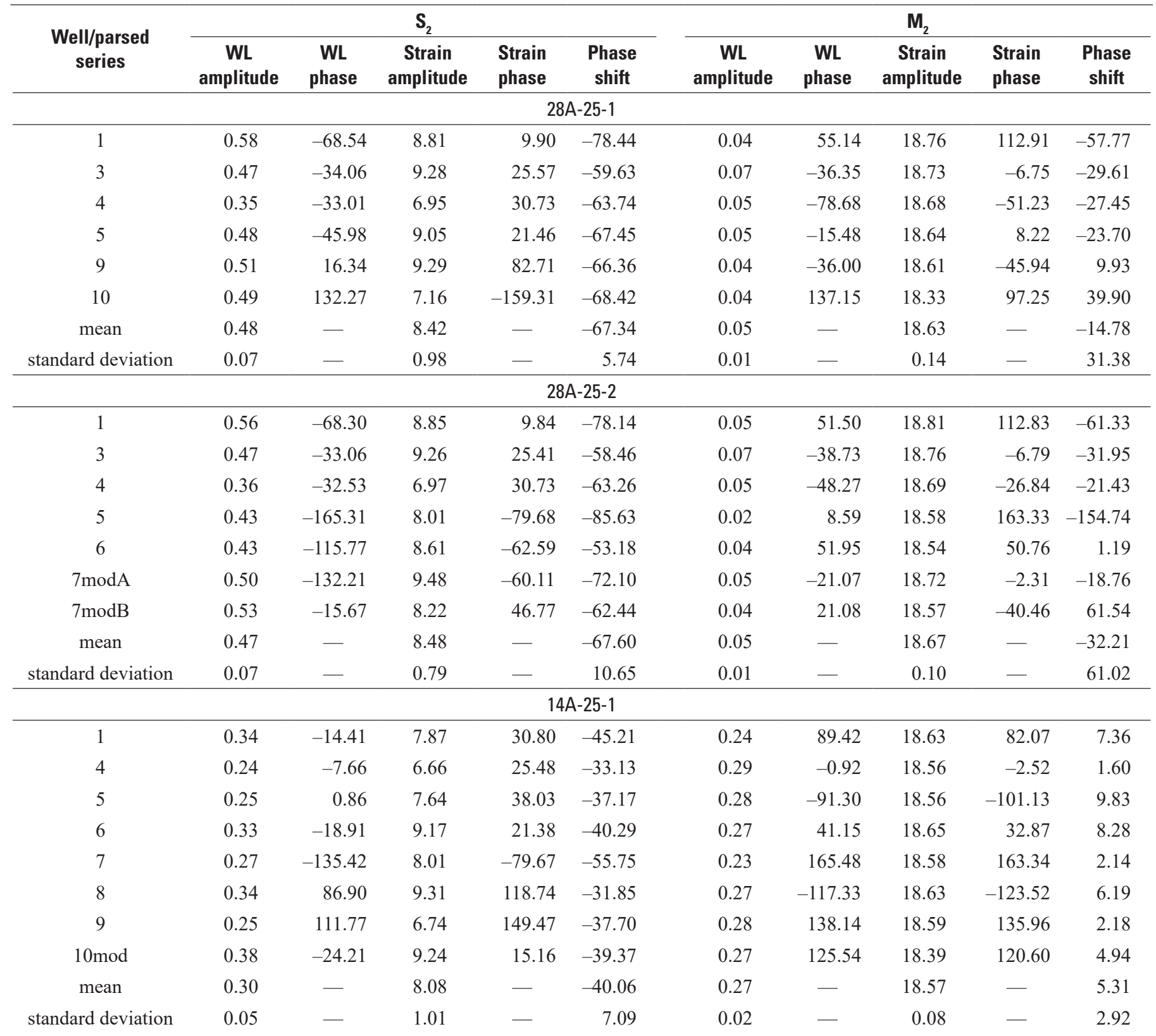


Table 2-4. Results of tidal harmonic analysis of selected, detrended, parsed time series for wells 28A-25-1 during January 14, 2016December 31, 2017, 28A-25-2 during January 14, 2016-December 31, 2017, and 14A-25-1 during November 13, 2015-November 29, 2017, in the area of Mammoth Lakes, California.-Continued

[Phase and phase shift in units of degrees; Strain (areal strain) is in units of nanostrain; Water level (WL) is in units of centimeters. Abbreviation: -, not applicable]

\begin{tabular}{|c|c|c|c|c|c|c|c|c|c|c|}
\hline \multirow{2}{*}{$\begin{array}{l}\text { Well/parsed } \\
\text { series }\end{array}$} & \multicolumn{5}{|c|}{$\mathbf{N}_{2}$} & \multicolumn{5}{|c|}{$K_{1}$} \\
\hline & $\begin{array}{c}\text { WL } \\
\text { amplitude }\end{array}$ & $\begin{array}{c}\text { WL } \\
\text { phase }\end{array}$ & $\begin{array}{c}\text { Strain } \\
\text { amplitude }\end{array}$ & $\begin{array}{l}\text { Strain } \\
\text { phase }\end{array}$ & $\begin{array}{l}\text { Phase } \\
\text { shift }\end{array}$ & $\begin{array}{c}\text { WL } \\
\text { amplitude }\end{array}$ & $\begin{array}{c}\text { WL } \\
\text { phase }\end{array}$ & $\begin{array}{c}\text { Strain } \\
\text { amplitude }\end{array}$ & $\begin{array}{l}\text { Strain } \\
\text { phase }\end{array}$ & $\begin{array}{l}\text { Phase } \\
\text { shift }\end{array}$ \\
\hline \multicolumn{11}{|c|}{ 28A-25-1-Continued } \\
\hline 1 & 0.05 & -148.48 & 3.13 & 92.43 & 119.09 & 0.05 & 70.42 & 15.52 & -3.58 & 74.01 \\
\hline 3 & 0.04 & 44.31 & 4.31 & -61.05 & 105.36 & 0.22 & 85.12 & 11.79 & -74.48 & 159.60 \\
\hline 9 & 0.03 & -93.44 & 3.37 & -44.22 & -49.22 & 0.32 & -44.52 & 12.09 & -11.92 & -32.60 \\
\hline 10 & 0.02 & -94.75 & 4.42 & 20.29 & -115.04 & 0.37 & 148.95 & 19.91 & 128.13 & 20.83 \\
\hline mean & 0.04 & - & 3.75 & - & 0.11 & 0.24 & - & 14.86 & - & 22.07 \\
\hline standard deviation & 0.01 & - & 0.50 & - & 84.42 & 0.10 & - & 2.94 & - & 76.43 \\
\hline 4 & 0.06 & 117.22 & 3.33 & 145.01 & -27.79 & 0.17 & 160.97 & 17.00 & -126.57 & -72.46 \\
\hline 5 & 0.03 & -117.55 & 3.41 & 152.38 & 90.07 & 0.01 & 155.35 & 17.38 & -42.27 & -162.38 \\
\hline 6 & 0.02 & -64.65 & 3.82 & -163.22 & 98.57 & 0.02 & -177.80 & 13.55 & 91.32 & 90.88 \\
\hline $7 \bmod A$ & 0.02 & -109.24 & 3.24 & -95.94 & -13.30 & 0.52 & -119.46 & 11.37 & -62.79 & -56.67 \\
\hline $7 \operatorname{modB}$ & 0.03 & -46.50 & 3.98 & 31.75 & -78.26 & 0.26 & 112.48 & 16.87 & 88.32 & 24.16 \\
\hline mean & 0.04 & - & 3.59 & - & 42.43 & 0.19 & - & 14.77 & - & 6.75 \\
\hline standard deviation & 0.02 & - & 0.41 & - & 74.29 & 0.16 & - & 2.34 & - & 102.34 \\
\hline \multicolumn{11}{|c|}{ 14A-25-1-Continued } \\
\hline 1 & 0.05 & -3.96 & 3.21 & -33.25 & 29.29 & 0.33 & -119.13 & 17.02 & -122.99 & 3.86 \\
\hline 9 & 0.05 & 118.70 & 3.98 & 115.21 & 3.49 & 0.24 & -128.92 & 17.73 & -69.45 & -59.47 \\
\hline $10 \mathrm{mod}$ & 0.06 & 91.78 & 3.53 & 107.84 & -16.07 & 0.31 & 61.81 & 14.28 & 72.90 & -11.10 \\
\hline mean & 0.06 & - & 3.56 & - & 5.46 & 0.25 & - & 15.61 & - & -14.39 \\
\hline standard deviation & 0.01 & - & 0.30 & - & 19.27 & 0.08 & - & 2.34 & - & 27.01 \\
\hline
\end{tabular}


Table 2-4. Results of tidal harmonic analysis of selected, detrended, parsed time series for wells 28A-25-1 during January 14, 2016December 31, 2017, 28A-25-2 during January 14, 2016-December 31, 2017, and 14A-25-1 during November 13, 2015-November 29, 2017, in the area of Mammoth Lakes, California.-Continued

[Phase and phase shift in units of degrees; Strain (areal strain) is in units of nanostrain; Water level (WL) is in units of centimeters. Abbreviation: -, not applicable]

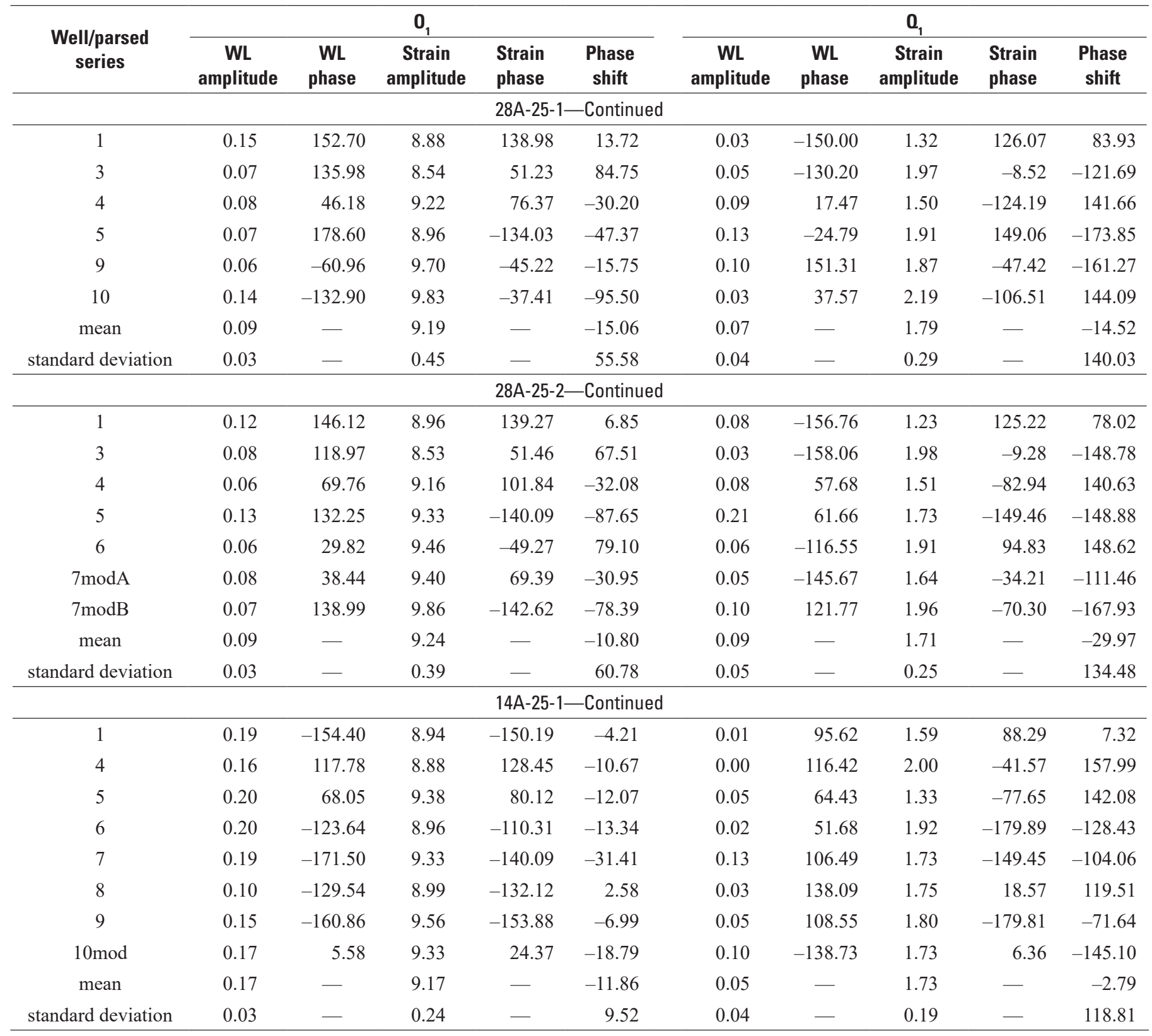


Table 2-5. Results of tidal analysis of water-level responses to the six principal Earth tides for discrete segments of selected, detrended, parsed time series from well 14A-25-1 in the area of Mammoth Lakes, California, during November 13, 2015-November 9 , 2017.

[Phase and phase shift is in units of degrees; Strain (areal strain) is in units of nanostrain; water level (WL) is in units of centimeters. Abbreviations: nd, segment number of the discrete (32-day long) time series; - , not applicable]

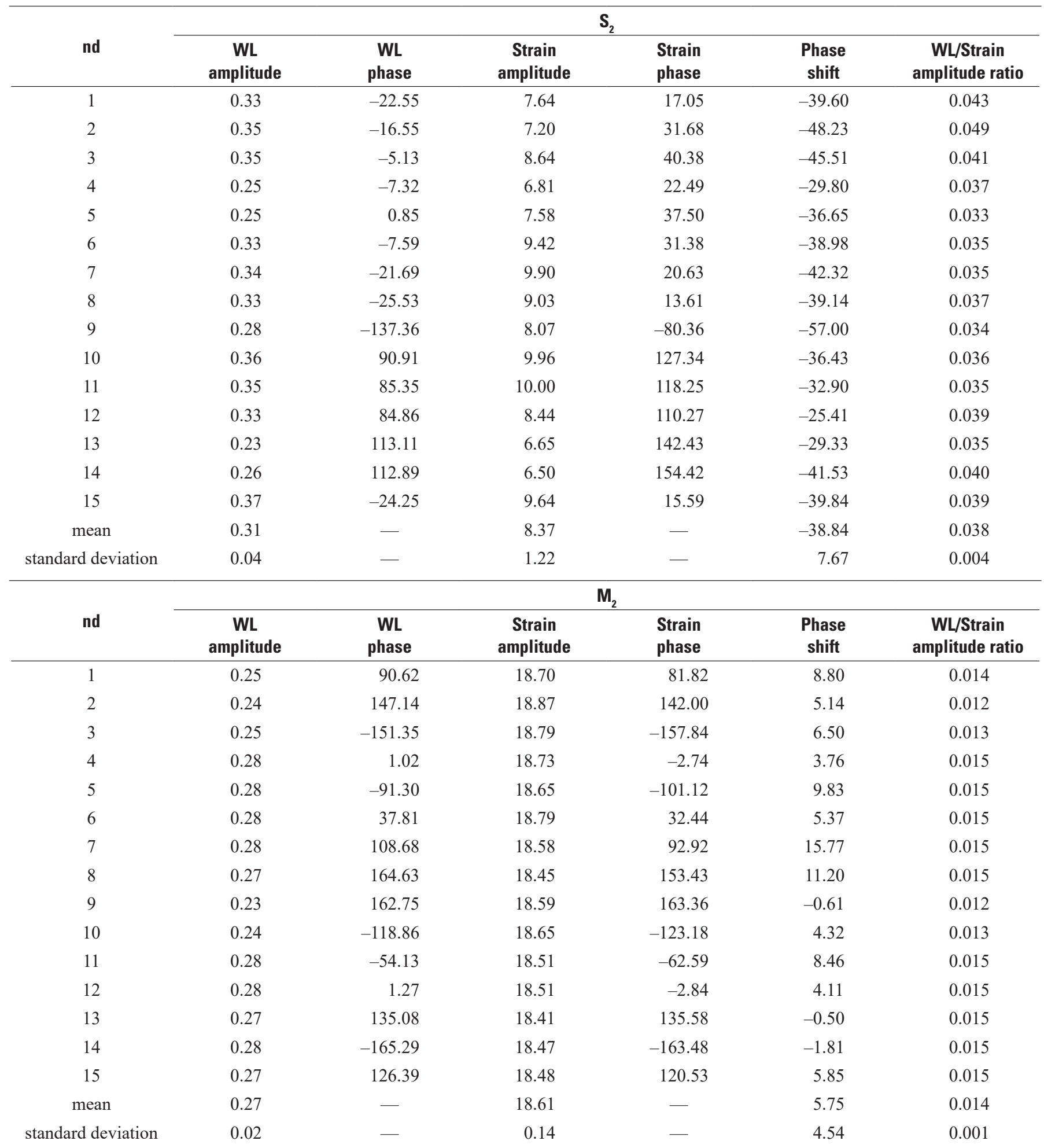


Table 2-5. Results of tidal analysis of water-level responses to the six principal Earth tides for discrete segments of selected, detrended, parsed time series from well 14A-25-1 in the area of Mammoth Lakes, California, during November 13, 2015-November 9, 2017.-Continued

[Phase and phase shift is in units of degrees; Strain (areal strain) is in units of nanostrain; water level (WL) is in units of centimeters. Abbreviations: nd, segment number of the discrete (32-day long) time series; —, not applicable]

\begin{tabular}{|c|c|c|c|c|c|c|}
\hline \multirow[b]{2}{*}{ nd } & \multicolumn{6}{|c|}{$\mathbf{N}_{2}$} \\
\hline & $\begin{array}{c}\text { WL } \\
\text { amplitude }\end{array}$ & $\begin{array}{c}\text { WL } \\
\text { phase }\end{array}$ & $\begin{array}{c}\text { Strain } \\
\text { amplitude }\end{array}$ & $\begin{array}{l}\text { Strain } \\
\text { phase }\end{array}$ & $\begin{array}{l}\text { Phase } \\
\text { shift }\end{array}$ & $\begin{array}{c}\text { WL/Strain } \\
\text { amplitude ratio }\end{array}$ \\
\hline 2 & 0.03 & 85.02 & 2.97 & 84.44 & 0.59 & 0.011 \\
\hline 3 & 0.05 & -103.90 & 3.24 & -144.34 & 40.44 & 0.014 \\
\hline 6 & 0.09 & -42.98 & 3.43 & -31.52 & -11.46 & 0.026 \\
\hline 7 & 0.04 & 52.65 & 4.03 & 88.34 & -35.69 & 0.009 \\
\hline 8 & 0.09 & -136.98 & 4.44 & -160.41 & 23.43 & 0.019 \\
\hline 9 & 0.03 & -176.80 & 3.31 & 152.64 & 30.56 & 0.009 \\
\hline 13 & 0.06 & 137.09 & 4.30 & 118.24 & 18.86 & 0.014 \\
\hline 14 & 0.06 & -130.78 & 4.04 & -128.34 & -2.43 & 0.015 \\
\hline 15 & 0.06 & 83.66 & 3.56 & 108.93 & -25.26 & 0.016 \\
\hline mean & 0.06 & - & 3.62 & - & 7.21 & 0.015 \\
\hline \multirow[t]{2}{*}{ standard deviation } & 0.02 & - & 0.47 & - & 25.71 & 0.005 \\
\hline & \multicolumn{6}{|c|}{$K_{1}$} \\
\hline nd & $\begin{array}{c}\text { WL } \\
\text { amplitude }\end{array}$ & $\begin{array}{c}\text { WL } \\
\text { phase }\end{array}$ & $\begin{array}{c}\text { Strain } \\
\text { amplitude }\end{array}$ & $\begin{array}{l}\text { Strain } \\
\text { phase }\end{array}$ & $\begin{array}{l}\text { Phase } \\
\text { shift }\end{array}$ & $\begin{array}{c}\text { WL/Strain } \\
\text { amplitude ratio }\end{array}$ \\
\hline 1 & 0.40 & -138.10 & 18.43 & -140.67 & 2.57 & 0.022 \\
\hline 7 & 0.33 & 87.65 & 10.14 & 96.99 & -9.34 & 0.032 \\
\hline 8 & 0.42 & 52.62 & 15.04 & 56.06 & -3.44 & 0.028 \\
\hline 9 & 0.26 & -44.82 & 17.71 & -43.20 & -1.62 & 0.015 \\
\hline 10 & 0.18 & 51.82 & 10.89 & 24.43 & 27.38 & 0.016 \\
\hline 11 & 0.19 & 6.48 & 10.24 & -37.56 & 44.04 & 0.018 \\
\hline 12 & 0.05 & -134.59 & 15.25 & -74.69 & -59.90 & 0.004 \\
\hline 13 & 0.18 & -150.52 & 18.85 & -80.14 & -70.39 & 0.009 \\
\hline 14 & 0.33 & -153.49 & 18.51 & -95.71 & -57.78 & 0.018 \\
\hline 15 & 0.31 & 71.68 & 13.13 & 71.41 & 0.27 & 0.024 \\
\hline mean & 0.27 & - & 15.30 & - & -14.26 & 0.019 \\
\hline standard deviation & 0.10 & - & 3.27 & - & 33.16 & 0.008 \\
\hline
\end{tabular}


Table 2-5. Results of tidal analysis of water-level responses to the six principal Earth tides for discrete segments of selected, detrended, parsed time series from well 14A-25-1 in the area of Mammoth Lakes, California, during November 13, 2015-November 9, 2017.-Continued

[Phase and phase shift is in units of degrees; Strain (areal strain) is in units of nanostrain; water level (WL) is in units of centimeters. Abbreviations: nd, segment number of the discrete (32-day long) time series; —, not applicable]

\begin{tabular}{|c|c|c|c|c|c|c|}
\hline \multirow[b]{2}{*}{ nd } & \multicolumn{6}{|c|}{$0_{1}$} \\
\hline & $\begin{array}{c}\text { WL } \\
\text { amplitude }\end{array}$ & $\begin{array}{c}\text { WL } \\
\text { phase }\end{array}$ & $\begin{array}{c}\text { Strain } \\
\text { amplitude }\end{array}$ & $\begin{array}{l}\text { Strain } \\
\text { phase }\end{array}$ & $\begin{array}{l}\text { Phase } \\
\text { shift }\end{array}$ & $\begin{array}{c}\text { WL/Strain } \\
\text { amplitude ratio }\end{array}$ \\
\hline 2 & 0.16 & -57.92 & 9.52 & -59.01 & 1.09 & 0.017 \\
\hline 3 & 0.23 & 35.78 & 9.45 & 30.93 & 4.85 & 0.024 \\
\hline 6 & 0.20 & -121.95 & 8.91 & -109.18 & -12.77 & 0.023 \\
\hline 7 & 0.28 & -61.12 & 9.26 & -14.66 & -46.45 & 0.030 \\
\hline 8 & 0.17 & 96.89 & 9.57 & 75.82 & 21.07 & 0.018 \\
\hline 9 & 0.20 & -173.25 & 9.67 & -140.95 & -32.30 & 0.020 \\
\hline 13 & 0.19 & -148.72 & 9.76 & -152.55 & 3.83 & 0.019 \\
\hline 14 & 0.16 & -90.78 & 9.74 & -61.86 & -28.92 & 0.016 \\
\hline 15 & 0.20 & -17.44 & 10.06 & 27.20 & -44.64 & 0.020 \\
\hline mean & 0.18 & - & 9.50 & - & -11.14 & 0.019 \\
\hline \multirow[t]{2}{*}{ standard deviation } & 0.04 & - & 0.27 & - & 23.42 & 0.005 \\
\hline & \multicolumn{6}{|c|}{$0_{1}$} \\
\hline nd & $\begin{array}{c}\text { WL } \\
\text { amplitude }\end{array}$ & $\begin{array}{c}\text { WL } \\
\text { phase }\end{array}$ & $\begin{array}{c}\text { Strain } \\
\text { amplitude }\end{array}$ & $\begin{array}{l}\text { Strain } \\
\text { phase }\end{array}$ & $\begin{array}{l}\text { Phase } \\
\text { shift }\end{array}$ & $\begin{array}{c}\text { WL/Strain } \\
\text { amplitude ratio }\end{array}$ \\
\hline 1 & 0.06 & -159.23 & 1.73 & 88.36 & 112.42 & 0.035 \\
\hline 7 & 0.08 & 95.06 & 2.03 & -18.26 & 113.32 & 0.038 \\
\hline 8 & 0.10 & 99.82 & 2.24 & 121.19 & -21.37 & 0.043 \\
\hline 9 & 0.14 & 103.79 & 1.74 & -149.18 & -107.03 & 0.080 \\
\hline 10 & 0.07 & 75.30 & 1.48 & 18.56 & 56.74 & 0.046 \\
\hline 11 & 0.09 & 74.74 & 1.80 & 169.74 & -95.00 & 0.048 \\
\hline 12 & 0.11 & 93.83 & 2.07 & -45.21 & 139.04 & 0.053 \\
\hline 13 & 0.03 & 72.96 & 2.37 & -169.17 & -117.86 & 0.014 \\
\hline 14 & 0.07 & -55.55 & 2.02 & -28.22 & -27.33 & 0.033 \\
\hline 15 & 0.04 & -156.68 & 1.91 & 14.90 & -171.59 & 0.021 \\
\hline mean & 0.07 & - & 1.83 & - & -6.73 & 0.040 \\
\hline standard deviation & 0.03 & - & 0.27 & - & 103.07 & 0.017 \\
\hline
\end{tabular}


The computed mean ratio of the water-level amplitude to the theoretical areal-strain amplitude for $\mathrm{O}_{1}$ $\left(\overline{\mathrm{A}}_{5}=0.019 \mathrm{~cm} /\right.$ nanostrain) was larger than that for $\mathrm{M}_{2}$, $\left(\overline{\mathrm{A}}_{2}=0.014 \mathrm{~cm} /\right.$ nanostrain; table $\left.2-5\right)$. The relative increased water-level responses to the $\mathrm{O}_{1}$ tide compared to the $\mathrm{M}_{2}$ tide could be further indication of atmospheric-loading contamination at the $\mathrm{O}_{1}$ tidal frequency. It could also possibly be explained by an inhomogeneity in the physical setting owing to topographic effects (Berger and Beaumont, 1976) or the presence of the nearby generally north-south trending fault. For example, owing to the orthogonality of the principal directions of $\mathrm{M}_{2}$ and $\mathrm{O}_{1}$ theoretical areal strains, a compliant fault that is in hydraulic connection with the aquifer penetrated by the well could impart an anisotropic response to the two principal lunar tides by amplifying the water-level response to the $\mathrm{O}_{1}$ tide, which has a principal strain axis oriented east-west, approximately perpendicular to the fault (Hanson and Owen, 1982; Hanson, 1984). Without more information, however, and given the evidence for possible contamination of the $\mathrm{O}_{1}$ tidal response by atmospheric-loading effects, the following analysis assumed a homogenous tidal response that could be characterized by the response computed here for the $\mathrm{M}_{2}$ tide with respect to $\overline{\mathrm{A}}_{2}$. Under this assumption, the estimated homogenous tidal response of $0.014 \mathrm{~cm} /$ nanostrain computed for $\mathrm{M}_{2}$ was used to digitally filter Earth tides from the 14A-25-1 high-pass, detrended, parsed water-level time series to improve the subsequent analysis of the frequency response of the tidally filtered time series to atmospheric loading for well 14A-25-1.

\section{Digital Earth-Tide Filters for 14A-25-1 Time Series}

The predicted water-level responses at the six principal Earth-tide frequencies (from eqn. 2-11) contained mixed atmospheric-loading and Earth-tide responses at some of the frequencies, especially at the frequencies of the solar and lunisolar tides, $\mathrm{S}_{2}$ and $\mathrm{K}_{1}$, respectively. Because the water-level response at the frequency of the $\mathrm{M}_{2}$ tide likely represented more of a purely Earth-tide response, the water-level response to the $\mathrm{M}_{2}$ tide was used to scale water-level responses to the other five Earth tides (table 2-4). The $\mathrm{M}_{2}$-scaled responses were computed from the unscaled water-level responses to the tides on the basis of the mean ratio of the water-level amplitude and the theoretical areal-strain amplitude for the $\mathrm{M}_{2}$ tide $\left(\overline{\mathrm{A}}_{2}\right)$, the computed areal-strain amplitudes for each of the Earth tides ( $A \varepsilon_{\text {Areal }_{k}}$ ), and the mean phase shift of the water-level response for the $\mathrm{M}_{2}$ tide $\left(\bar{\eta}_{2}=5.75^{\circ}\right)$. The equation used to compute the $\mathrm{M}_{2}$-scaled water-level responses was developed as follows:
1. The predicted, unscaled water-level response for the high-pass, detrended water levels at the frequencies of the six principal Earth tides from equation 2-11 is

$$
\hat{y}_{\text {hpet }}\left(t_{j}\right)=\sum_{k=1}^{6}\left(a_{k} \cos \left(2 \pi f_{k} t_{j}\right)+b_{k} \sin \left(2 \pi f_{k} t_{j}\right)\right)
$$

Using $a_{k}=A_{y_{k}} \cos \left(\phi_{y_{k}}\right)$ and $b_{k}=A_{y_{k}} \sin \left(\phi_{y_{k}}\right)$, and the trigonometric identity for the expansion of the cosine sum of differences between two angles, equation 2-16 can be rewritten as

$$
\begin{aligned}
\hat{y}_{\text {hpet }}\left(t_{j}\right)= & \sum_{k=1}^{6} A y_{k} \cos \left(\phi y_{k}\right) \cos \left(2 \pi f_{k} t_{j}\right) \\
& +A y_{k} \sin \left(\phi y_{k}\right) \sin \left(2 \pi f_{k} t_{j}\right) \\
= & \sum_{k=1}^{6} A y_{k} \cos \left(2 \pi f_{k} t_{j}-\phi y_{k}\right)
\end{aligned}
$$

2. Applying $\mathrm{M}_{2}$ scaling is done in two steps:

1. First, multiplying the argument of summation by the ratio of $\overline{\mathrm{A}}_{2}$ to $\mathrm{A}_{k}$ gives this:

$$
\hat{y}_{\text {hpetM2 }}\left(t_{j}\right)=\sum_{k=1}^{6} \frac{\overline{\mathrm{A}}_{2}}{\mathrm{~A}_{k}} A y_{k} \cos \left(2 \pi f_{k} t_{j}-\phi y_{k}\right)
$$

where

$\hat{y}_{\text {hpetM2 }}$ is the predicted value of the $\mathrm{M}_{2}$-scaled response.

2. Next, expressing $\phi y_{k}$ in terms of the mean $\mathbf{M}_{2}$ phase $\operatorname{shift}\left(\bar{\eta}_{2}\right)$, where $\phi y_{k}=\phi \varepsilon_{\text {Areal }_{k}}+\bar{\eta}_{2}$, gives this:

$\hat{y}_{\text {hpetM2 }}\left(t_{j}\right)=\sum_{k=1}^{6} \frac{\overline{\mathrm{A}}_{2}}{\mathrm{~A}_{k}} A y_{k} \cos \left(2 \pi f_{k} t_{j}-\phi \varepsilon_{\text {Areal }_{k}}-\bar{\eta}_{2}\right)$

3. Finally, substituting $2-15$ into $2-19$, and moving $\overline{\mathrm{A}}_{2}$ outside the summation gives equation 2-20:

$\hat{y}_{\text {hpetM2 }}\left(t_{j}\right)=\sum_{k=1}^{6} A \varepsilon_{\text {Area }_{k}} \cos \left(2 \pi f_{k} t_{j}-\phi \varepsilon_{\text {Areal }_{k}}-\bar{\eta}_{2}\right)$ 
The summation term is a function of the amplitude and phase of the theoretical tidal strain signal and the mean phase shift of the water-level response at the $\mathrm{M}_{2}$ tidal frequency. The $\mathrm{M}_{2}$-scaled water-level response is a constant factor multiplied by this term. The uses of $\bar{A}_{2}$ for this constant factor and of $\bar{\eta}_{2}$ to modify the phase of the response are reasonable because $M_{2}$ is the principal lunar tide for which power at principally solar frequencies in the barometric pressure signal is least among the other principal Earth tide frequencies. Values for $A \varepsilon_{\text {Area }} l_{k}$ and $\phi \varepsilon_{\text {Areal }_{k}}$ for each parsed series analyzed are available in table 2-4, and the values for $\overline{\mathrm{A}}_{2}$ and $\bar{\eta}_{2}$ are available in table 2-5. This results in $\hat{y}_{\text {hpet } M 2}$ with $\mathrm{M}_{2}$-scaled amplitude and phase responses to Earth tides computed for each of the analyzed parsed series. Figure 2-8 shows the predicted, discrete amplitudes for the six principal tides (table 2-3) for (1) the theoretical areal-strain tide and (2) the unscaled ( $\hat{y}_{\text {hpet }}$, or WL:ET) and $\mathrm{M}_{2}$-scaled ( $\hat{y}_{\text {hpetM } 2}$, or WL:ETM2) waterlevel responses, computed using the high-pass, detrended areal-strain tide and water-level time series, respectively, for 14A-25-1_5 (fig. 2-1, box h). Digitally filtered water-level responses at tidal frequencies for each high-pass, detrended, parsed water-level time series analyzed (table 2-4) were computed using the following:

$$
\begin{gathered}
\hat{y}_{\text {hpet }}\left(t_{j}\right)=y_{\text {hp }}\left(t_{j}\right)-\hat{y}_{\text {hpet }}\left(t_{j}\right) \\
\hat{y}_{\text {hpetM2 }}\left(t_{j}\right)=y_{\text {hp }}\left(t_{j}\right)-\hat{y}_{\text {hpetM } 2}\left(t_{j}\right)
\end{gathered}
$$

Here, $y_{h p}$ is the high-pass, detrended water level used in equation 2-11. Figure 2-9 shows the predicted, unscaled ( $\hat{y}_{\text {hpet }}$, or WL:ET) and the $\mathrm{M}_{2}$-scaled ( $\hat{y}_{\text {hpet } M 2}$, or WL:ETM2), high-pass water-level responses to the six principal Earth tides compared to the high-pass, water levels $\left(y_{h p}\right.$, or WL); and the resulting tidally filtered, unscaled ( $\tilde{y}_{\text {hpet }}$, or fWL:ET) and $\mathrm{M}_{2}$-scaled ( $\tilde{y}_{\text {hpetM } 2}$, or fWL:ETM2), high-pass water levels for the detrended series 14A-25-1_5. The filtered results from the $\mathrm{M}_{2}$-scaled water-level responses (eqn. 2-22) retained slightly more atmospheric-loading effects than did those from the unscaled water-level responses at the frequencies of the six principal Earth tides (eqn. 2-21).

To digitally filter the tidal responses from the high-pass, detrended 14A-25-1 _ 10 full (unmodified), parsed water-level time series affected by flow testing, predicted, unscaled, highpass water-level responses to the six principal Earth tides were computed using equation 2-23:

$$
\hat{y}_{\text {hpet }}\left(t_{j}\right)=\sum_{k=1}^{6} \mathrm{~A}_{k}^{m o d} A \varepsilon_{\text {Areal }} \cos \left(2 \pi f_{k} t_{j}-\phi_{\text {sAreal }}-\eta_{k}{ }_{k}^{m o d}\right)
$$

where

$$
\begin{gathered}
\mathrm{A}_{k} \text { is the ratio of the water-level amplitude to the } \\
\text { theoretical areal-strain amplitude for each } \\
\text { of the principal Earth tides in the modified } \\
\text { parsed series (14A-25-1_10mod), and } \\
\eta_{k} \text { is the phase shift of the water-level response } \\
\text { for each of the principal Earth tides in the } \\
\text { modified parsed series (14A-25-1_10mod). }
\end{gathered}
$$

The $\mathrm{M}_{2}$-scaled water-level responses to the Earth tides were computed for the affected high-pass, detrended, full parsed series using equation 2-23. The terms $A \varepsilon_{\text {Areal }_{k}}$ and $\phi \varepsilon_{\text {Areal }_{k}}$ for the affected full parsed series (14A-25-1_10) are the theoretical areal-strain amplitude and phase, respectively (referenced to the start of the full parsed series), and are not presented in table $2-4$. For the $\mathrm{k}^{\text {th }}$ tidal constituents $1-6$, the computed $A \varepsilon_{\text {Areal }}$ values for 14A-25-1_10 were 9.31, 18.59, $3.42,12.21,9.41$, and 1.64 nanostrain, and the computed $\phi \varepsilon_{\text {Area }_{k}}$ values were $143.33,-146.76,128.18,-153.33,-1.26$, and $-90.25^{\circ}$, respectively.

Unscaled and $\mathrm{M}_{2}$-scaled, tidally filtered water-level responses for each of the detrended parsed series for 14A-25-1 in table 2-4 and the affected, full parsed series 14A-25-1_10 (table 2-1; fig. 2-1, box i) were computed as follows:

$$
\begin{gathered}
\tilde{y}_{e t}\left(t_{j}\right)=\tilde{y}_{\text {hpet }}\left(t_{j}\right)+y_{l p}\left(t_{j}\right) \\
\tilde{y}_{\text {etM } 2}\left(t_{j}\right)=\tilde{y}_{\text {hpetM } 2}\left(t_{j}\right)+y_{l p}\left(t_{j}\right)
\end{gathered}
$$

where

$$
\begin{aligned}
& \tilde{y}_{e t}\left(t_{j}\right) \quad \text { is the unscaled tidally filtered water level; } \\
& \tilde{y}_{e t M 2}\left(t_{j}\right) \quad \text { is the } \mathrm{M}_{2} \text {-scaled tidally filtered water level; } \\
& y_{l p}\left(t_{j}\right) \quad \text { is the residual low-pass, detrended water level } \\
& \left(y\left(t_{j}\right)-y_{h p}\left(t_{j}\right)\right) ; \text { and } \\
& y_{h p}\left(t_{j}\right) \quad \text { is the high-pass, detrended water level used in } \\
& \text { equation 2-11. }
\end{aligned}
$$

The unscaled and $\mathrm{M}_{2}$-scaled tidally filtered detrended water levels, equations 2-24 and 2-25, respectively, for 14A25-1_10 and 14A-25-1_10mod are shown in figure 2-10. The offset between the $14 \mathrm{~A}-25-1 \_10$ and 14A-25-1_10mod series, evident after the 14A-25-1_10mod starting date of October 9,2017 , was caused by the separate linear detrending functions used for the two series. The 14A-25-1_10 series contains the period of the flow test, which is shown at a larger scale (fig. 2-10C). The effects of digitally filtering Earth tides from the water levels were small compared to the effects of atmospheric loading on the water levels. 
A.

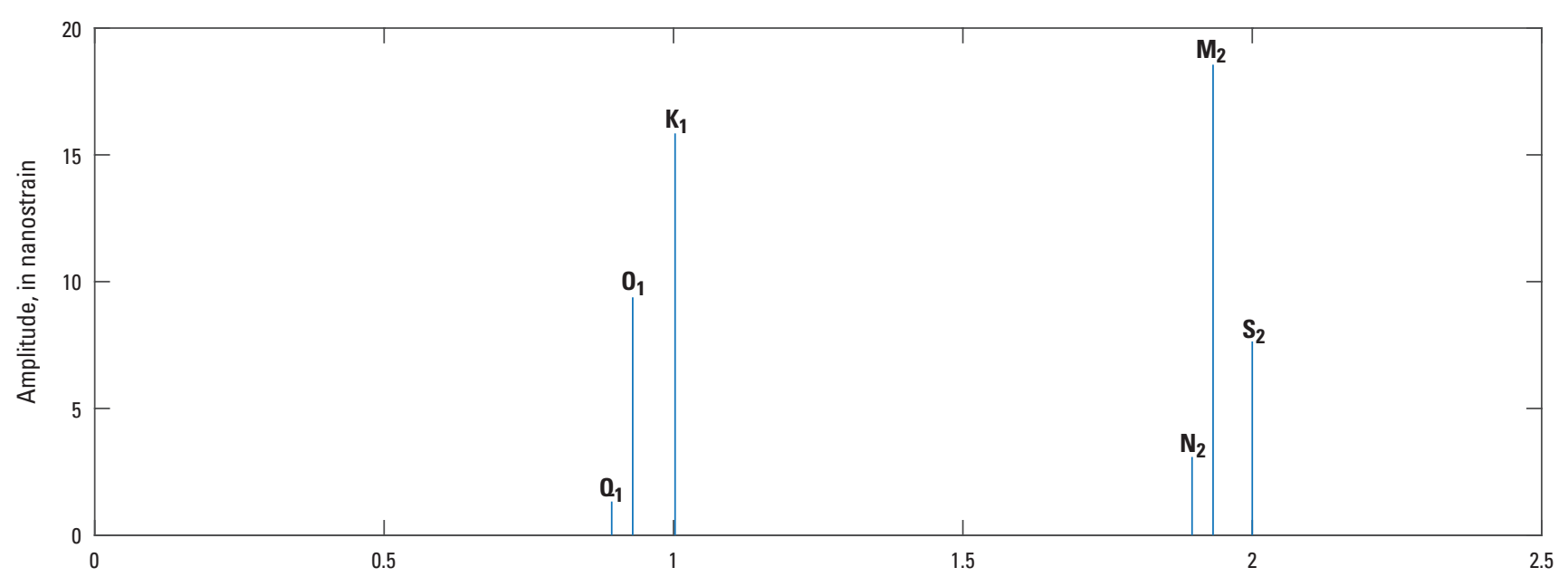

B.

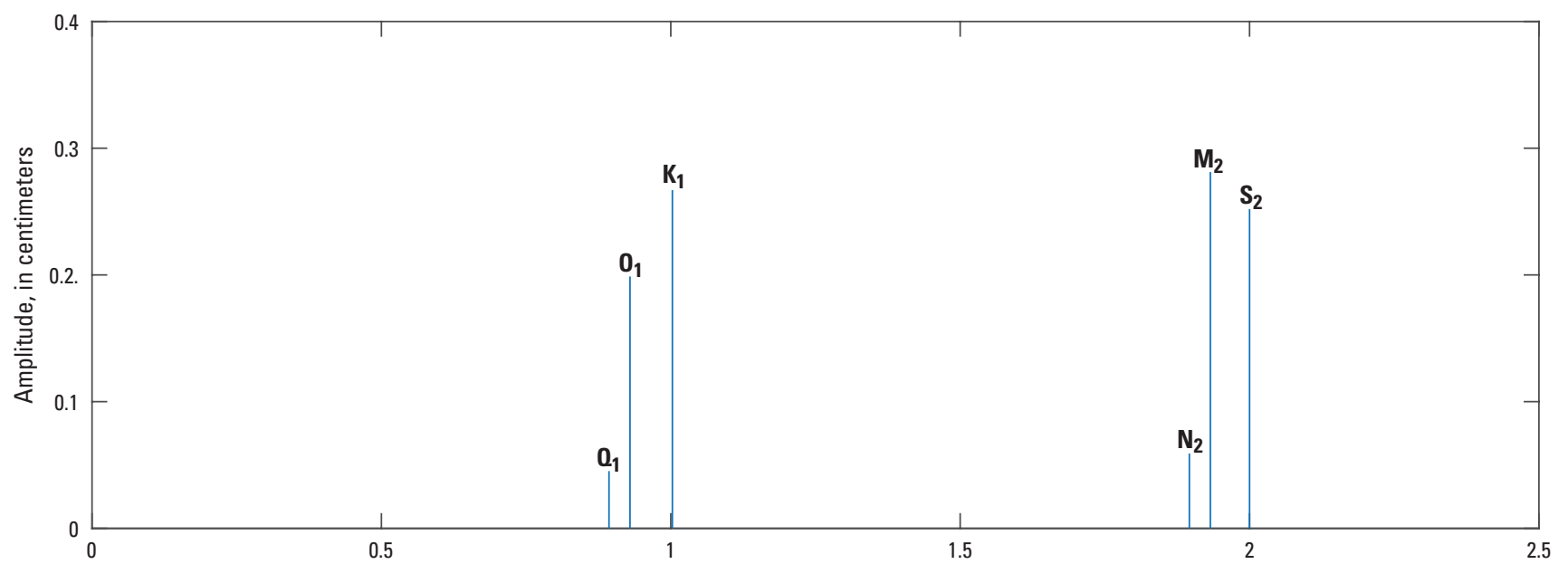

C.

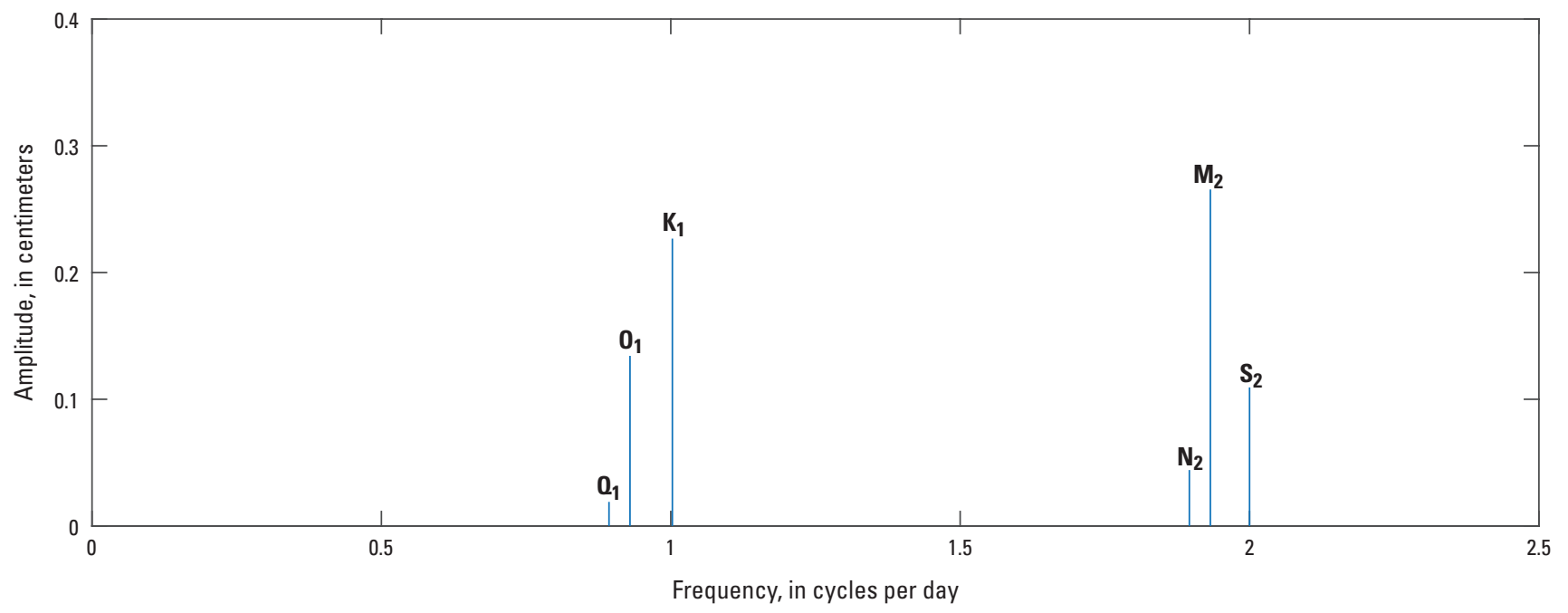

Figure 2-8. Predicted discrete amplitudes of the six principal Earth tides shown in table 2-3 computed for the high-pass (greater than 0.7 cycles per day, cpd), detrended theoretical areal-strain tide and unscaled (WL:ET) and $\mathrm{M}_{2}$-scaled (WL:ETM2) water levels for 14A-25-1_5 during July 14-August 14, 2016, from well 14A-25-1 in the area of Mammoth Lakes, California: $A$, theoretical areal-strain tide amplitudes; $B$, WL:ET amplitudes; and $C$, WL:ETM2 amplitudes. 

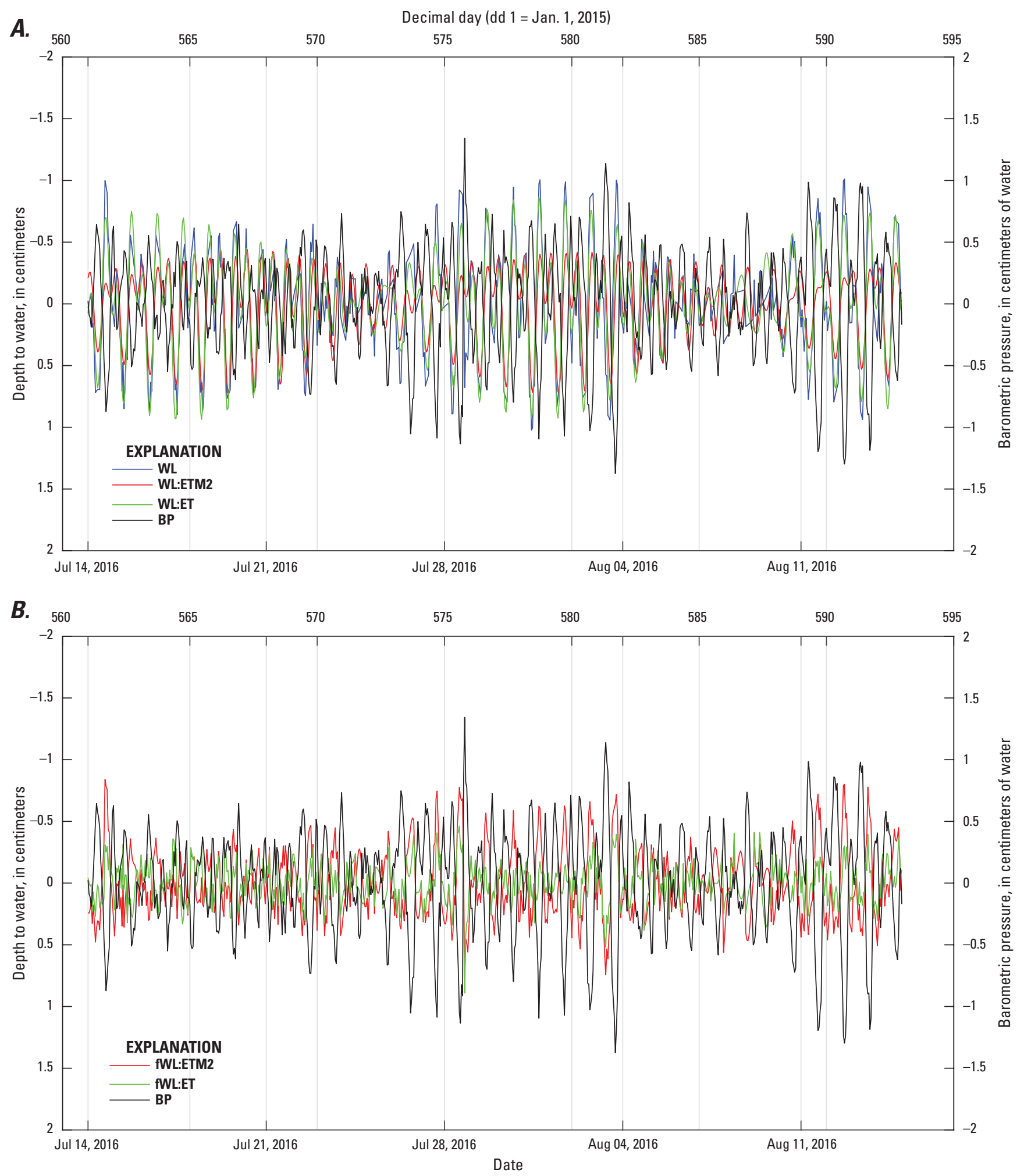

Figure 2-9. Predicted unscaled (WL:ET) and $\mathrm{M}_{2}$-scaled (WL:ETM2) water-level responses to the six principal Earth tides shown in table 2-3 for the high-pass (greater than 0.7 cycles per day, cpd), detrended water levels (WL); and the tidally filtered, unscaled (fWL:ET) and $\mathrm{M}_{2}$-scaled (fWL:ETM2), high-pass water levels for 14A-25-1_5 during July 14-August 14, 2016, from well 14A-25-1 in the area of Mammoth Lakes, California: $A, \mathrm{WL}, \mathrm{WL}: \mathrm{ET}$ and WL:ETM2 shown with high-pass (greater than 0.7 cycles per day, $\mathrm{cpd}$ ), detrended barometric pressure (BP); and $B$, fWL:ET and fWL:ETM2 shown with high-pass (greater than 0.7 cycles per day, cpd), detrended barometric pressure (BP). 

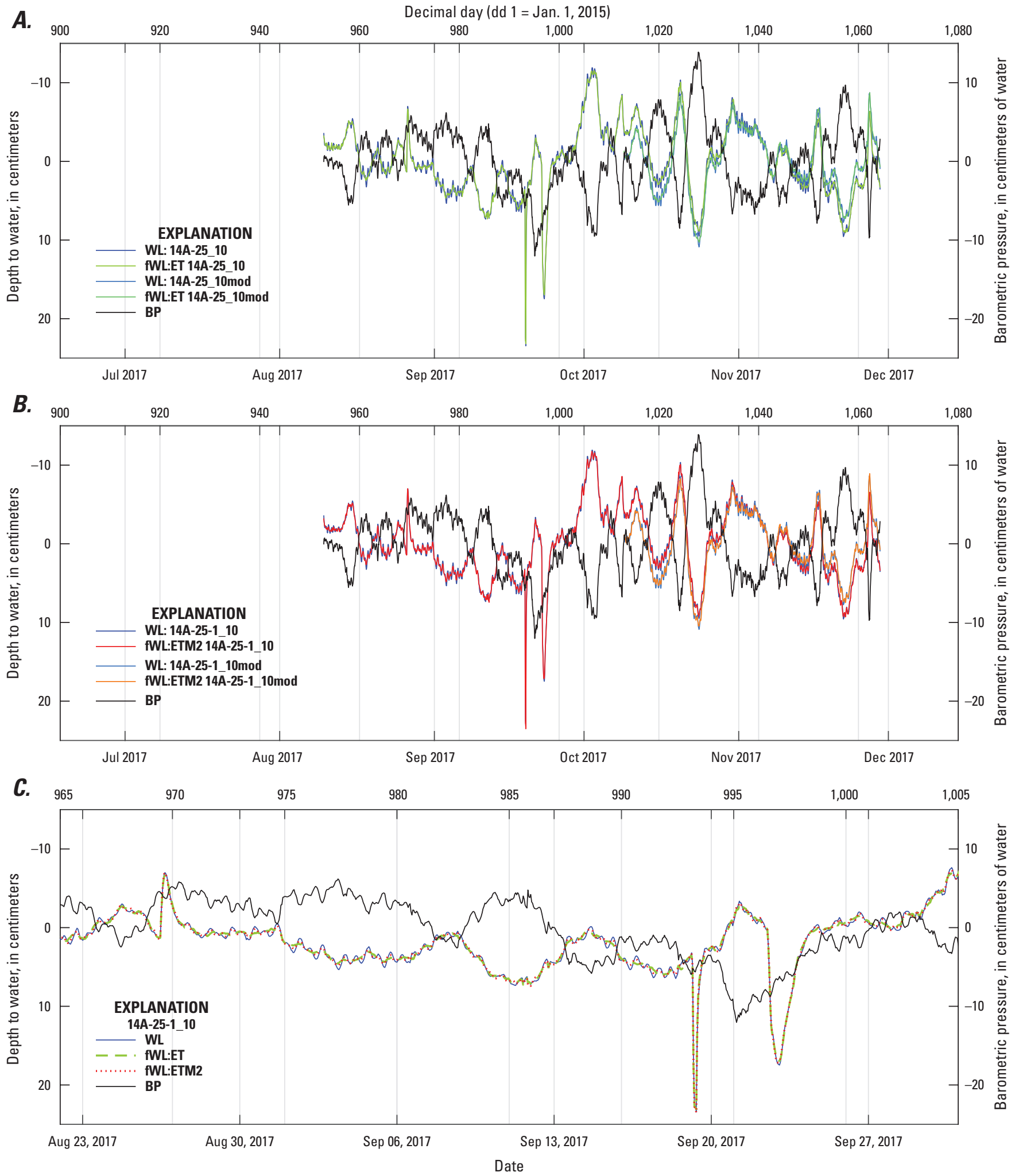

Figure 2-10. Unscaled (fWL:ET) and $\mathrm{M}_{2}$-scaled (fWL:ETM2) tidally filtered water levels for the detrended, parsed time series 14A-251_10 during August 9-November 29, 2017, and 14A-25-1_10mod during October 9-November 29, 2017, from well 14A-25-1 in the area of Mammoth Lakes, California, shown with detrended water levels (WL) and barometric pressure (BP): $A$, fWL:ET, WL and BP for 14A-251_10 and 14A-25-1_10mod; $B$, fWL:ETM2, WL and BP for 14A-25-1_10 and 14A-25-1_10mod; and C, fWL:ET, fWL:ETM2, WL and BP for 14A-25-1_10 at a larger scale spanning the period of the flow test. 


\section{Frequency Responses of Water Levels to Atmospheric Loading}

Although the primary purpose of this section is to describe the methods used to remove the effects of atmospheric loading from the water-level time series, it is also useful to describe the physical effects of atmospheric loading on ideal wells and aquifer systems to understand the computed frequency responses that were used to filter the water levels. Physically, a frequency-dependent response can be indicative of vertical fluid flow effects, either in the aquifers penetrated by the wells or, for example, between a shallower aquifer and a deeper, monitored aquifer where there is some impedance to vertical flow between the two aquifers, or both. The physical interpretation of the characteristics of a frequency-dependent response to atmospheric loading has been described by others (for example, Weeks, 1979; Rojstaczer, 1988a; Rojstaczer and Agnew, 1989).

\section{Idealized Well and Aquifer Response to Atmospheric Loading}

Note, in this section, water level refers to the waterlevel elevation or head and as such, is oppositely sensed with respect to water level measured as depth-to-water; for example, a decreasing water-level elevation corresponds to an increasing depth-to-water. Because aquifers are commonly imperfectly confined and their transmissivity can range over orders of magnitude, the water-level response of a well and aquifer to atmospheric loading does not always reflect the coupled hydraulic and mechanical response of the well and aquifer in the absence of fluid flow effects, referred to as the undrained or static-confined response. Figure 2-11 shows four idealized responses of water levels in wells that are open to the atmosphere to loads imposed by barometric pressure at the land surface. For each of the idealized responses, lateral flow exchanged between the well and the aquifer is shown on the plots for completeness, but for purposes of the following discussions it was assumed that there is no impedance to flow between the wellbore and the aquifer; for example, wellbore storage effects were assumed to be negligible. The BE for a well tapping a perfectly confined aquifer of infinite extent that has large transmissivity and no drainage effects (fig. 2-11A) represents the equilibrated balance between the air pressure imposed directly on the free-surface water level in the well and the mechanical response of the aquifer to the change in load (pressure) imposed on the land surface and translated to the saturated rock matrix (aquifer matrix or skeleton). For example, for a step increase in barometric pressure $\left(\Delta x_{0}\right)$, initially, water level in the well would be forced downward in an amount equal to the change in barometric pressure (in equivalent units of head), and water would flow from the well to the aquifer. This response would be balanced by the increased load on the saturated aquifer matrix, which would compress, reduce porosity slightly, and increase heads in the aquifer and, in turn, cause water to flow from the aquifer to the well and water level in the well to increase, recovering a portion of the initial water-level decrease. If the permeability of the aquifer is large and the hydraulic connection between the well and aquifer does not impede flow, these effects would be simultaneous, and the resultant water level in the well $\left(\Delta y_{0}\right)$ would represent the balanced response of the well and aquifer to the step increase in barometric pressure. As such, this ideal response in the ideal well tapping the ideal confined aquifer occurs under conditions absent of fluid-flow (drainage) effects, such as those related to the degree of confinement of the aquifer (discussed later).

Figure 2-11B shows the response of an ideal unconfined aquifer to a step increase in barometric pressure $\left(\Delta x_{0}\right)$ where the water table is shallow or the air permeability of the unsaturated zone is large. In this case, the air pressure at the water table equilibrates rapidly with the barometric pressure change at land surface. As such, because there is no pressure imbalance between the water level in the open well and the water table, there is no change in water level in the well $\left(\Delta y_{0}=0\right)$ and BE is zero. There is a negligible mechanical response to loading because any small decrease in storage owing to compression of the aquifer matrix is accommodated by the relatively large storage capacity provided by the available porosity in these unconfined systems, resulting in negligible change in aquifer hydraulic head. By contrast, figure 2-11C shows the response of an unconfined aquifer to a step increase in barometric pressure $\left(\Delta x_{0}\right)$ where the water table is deep or the air permeability in the unsaturated zone is sufficiently small to delay equilibration of air pressure at the water table $\left(\Delta x_{t=0}<\Delta x_{0}\right)$ with barometric pressure at land surface. Here, there is an initial pressure imbalance between the water level and the water table. Initially, the change in water level in the well $\left(\Delta y_{t=0}\right)$ is equal to $-B E \Delta x_{0}$, approximating a confined aquifer response. With time, however, as the air pressure at the water table equilibrates with the step increase in barometric pressure at land surface $\left(\Delta x_{t \gg 0} \rightarrow \Delta x_{0}\right)$, the change in water level in the well approaches zero $\left(\Delta y_{t \gg 0} \rightarrow 0\right)$. For this case, described in detail by Weeks (1979) and Rojstaczer and Riley (1990), the computed barometric efficiency $\left(B E_{t}=-\Delta y_{t} / \Delta x_{t}\right)$ is time dependent, a function of the transient diffusion of air pressure through the unsaturated zone. 
A.

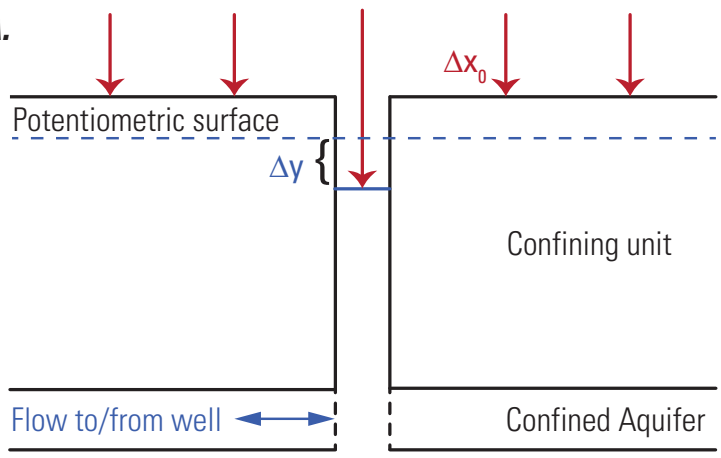

B.

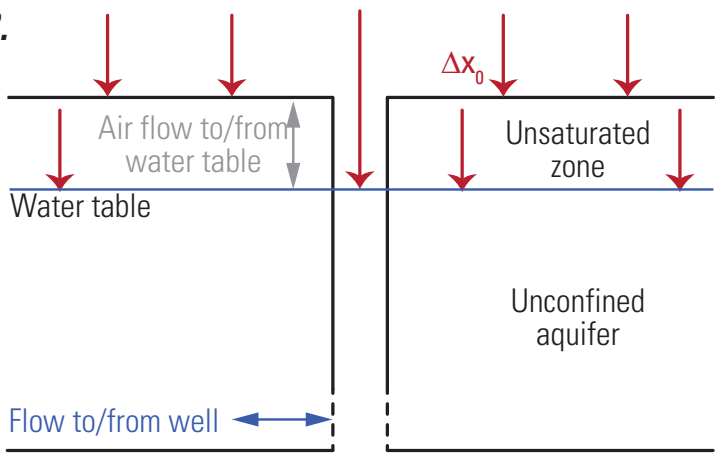

C.

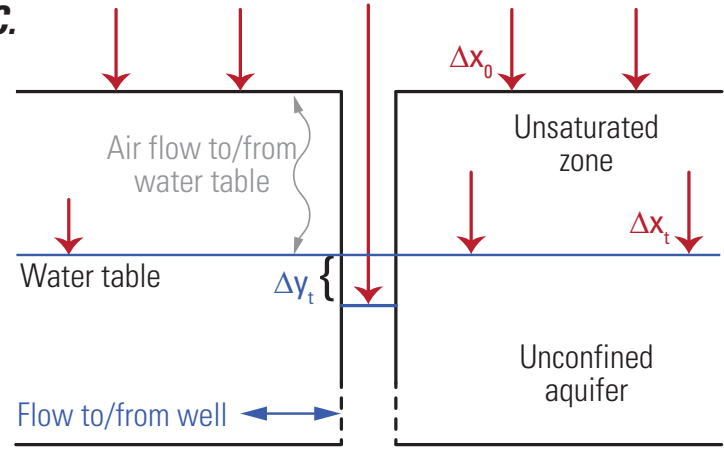

D.

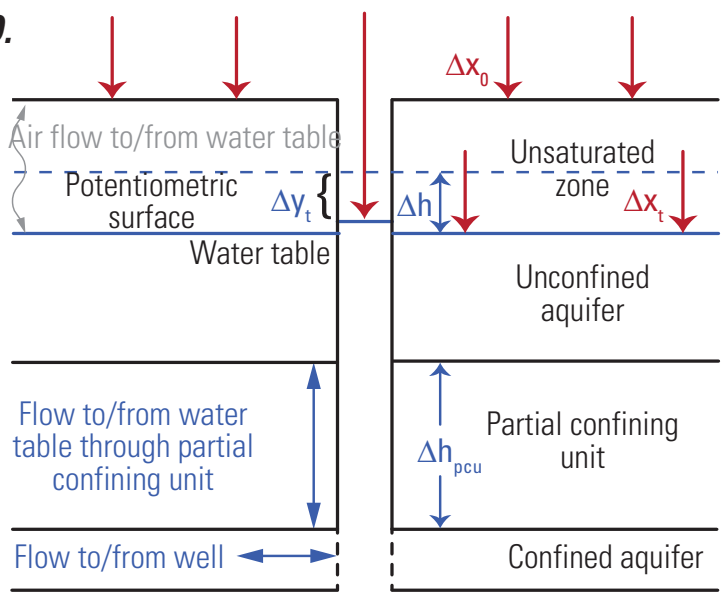

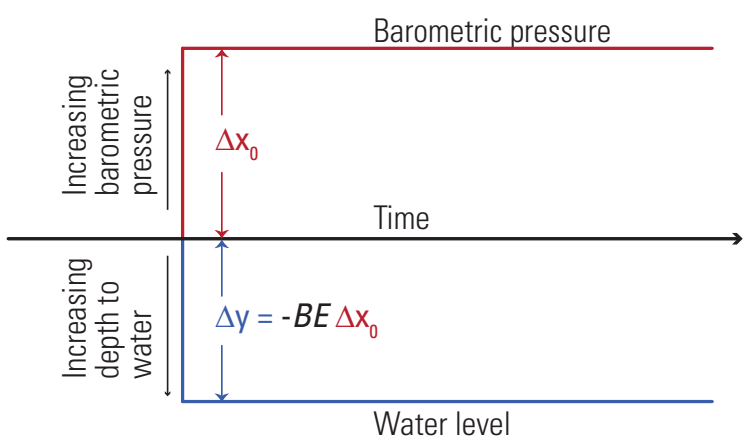

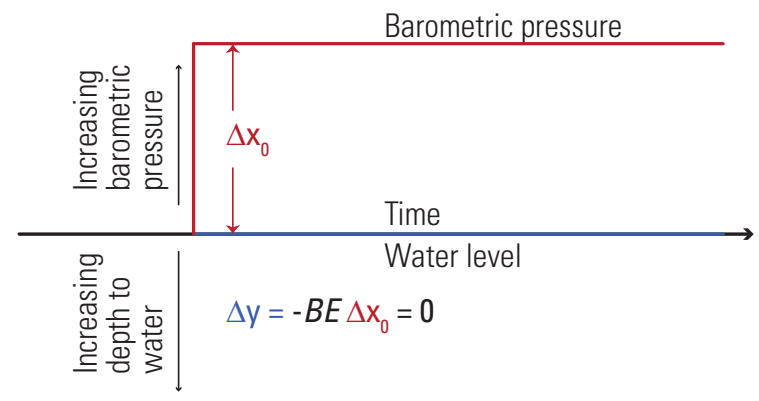

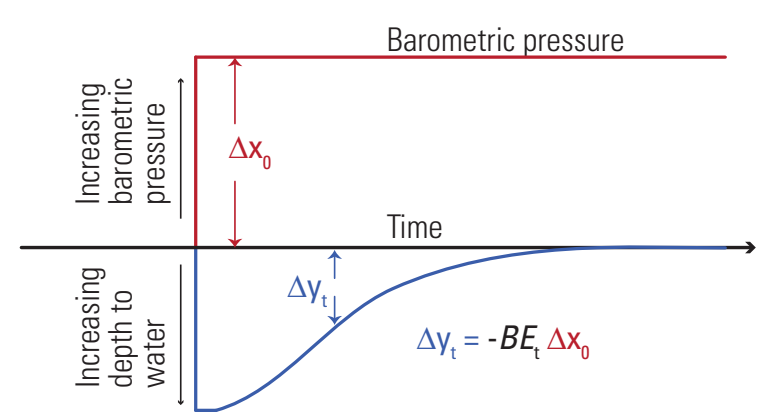

Water level

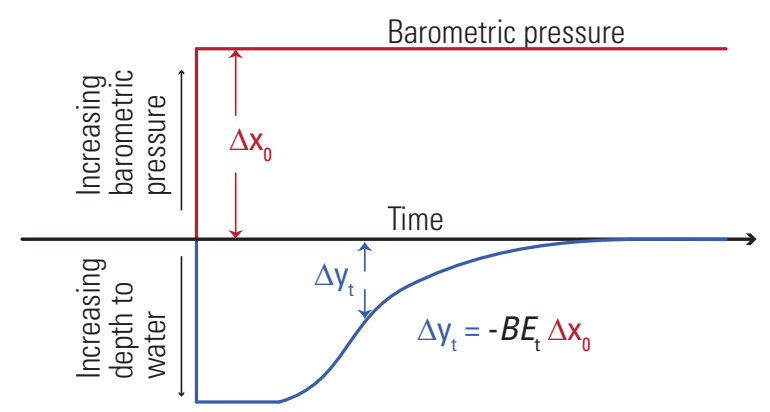

Water level

Figure 2-11. Cross sections of idealized aquifer systems showing idealized well responses to atmospheric loading with principal sources of attenuation owing to drainage (flow) effects and idealized water-level responses to a step increase in barometric pressure or load (right plots). Note, in this figure water level refers to the water-level elevation or head and as such, is oppositely sensed with respect to water level measured as depth-to-water; for example, a decreasing water-level elevation or head corresponds to an increasing depth-to-water. $A$, confined aquifer; $B$, unconfined aquifer (shallow or with large unsaturated-zone air permeability); $C$, unconfined aquifer (deep or with small unsaturated-zone air permeability); and $D$, partially confined aquifer overlain by unconfined aquifer (shallow or with small unsaturated-zone air permeability). 
Figure $2-11 D$ shows the response of a partially confined aquifer overlain by an unconfined aquifer to a step increase in barometric pressure at land surface. Here, the unconfined aquifer is shallow or the air permeability in the unsaturated zone is sufficiently large enough to facilitate rapid equilibration of air pressure at the water table with barometric pressure at land surface. There is a background head difference $(\Delta h)$ between the water table and the confined aquifer equal to the background head difference across the partial confining unit $\left(\Delta h_{p c u_{<0}}\right)$ indicating upward flow from the confined aquifer through the partial confining unit to the unconfined aquifer. Similar to the response described for a deep unconfined aquifer, initially, the change in water level in the well $\left(\Delta y_{t=0}\right)$ is equal to $-B E \Delta x_{0}$ approximating an undrained confined aquifer response. Owing to the increased head in the confined aquifer caused by the mechanical loading of the aquifer, approximately equal to $(1-B E) \Delta x_{0}, \Delta h_{p c u_{<0}}$ is increased by that amount. Increased groundwater flow from the confined aquifer through the partial confining unit to the unconfined aquifer is induced by the increased head gradient across the partial confining unit until this drainage dissipates the head increase in the partially confined aquifer as $\Delta h_{p c u_{t \gg 0}} \rightarrow \Delta h$. The resulting water-level change in the well re-equilibrates with the background head in the confined aquifer $\left(\Delta y_{t \gg 0} \rightarrow 0\right.$ ), which has re-equilibrated with the unconfined aquifer having a $B E=0$. For this case, described in more detail by Rojstaczer (1988a), the computed barometric efficiency $B E_{t}=-\Delta y_{t} / \Delta x_{t}$ is time dependent, a function of transient fluid-pressure diffusion through the partial confining unit.

The time-dependent responses associated with a deep unconfined aquifer and drainage of a partially confined aquifer through a partial confining unit may exist in combination and further complicate the characterization of the time-dependence of BE for a well influenced by both governing processes. As a result of these time-dependent water-level responses, the BE of a well is a function of the length of time (period) or frequency of the barometric pressure (atmospheric load) fluctuation. Analytical approaches to resolving the effects of these processes in terms of the frequency response of water levels in wells to atmospheric loading are presented by Rojstaczer (1988a, 1988b).

\section{Computed Frequency Responses}

The frequency response of water level to atmospheric loading can be defined by this relation:

$$
Y(\omega)=H(\omega) X(\omega)
$$

where frequency (f) by $\mathrm{f}=\frac{\omega}{2 \pi}$,
$Y(\omega)$
is the discrete Fourier transform of the detrended water-level responses to barometric pressure,
$X(\omega) \quad$ is the discrete Fourier transform of the detrended barometric-pressure time series, and
$H(\omega) \quad$ is the frequency response function (Rojstaczer 1988a,b; Quilty and Roeloffs, 1991), which represents the barometric efficiency in the frequency domain.

The frequency response function was computed using equation 2-27:

$$
H(\omega)=\frac{G_{x y}(\omega)}{G_{x x}(\omega)}
$$

where

$$
\begin{gathered}
G_{x y}(\omega) \quad \begin{array}{l}
\text { is the cross-spectral density of the paired } \\
\text { detrended barometric-pressure and water- } \\
\text { level time series, and }
\end{array} \\
G_{x x}(\omega) \quad \begin{array}{l}
\text { is the auto-spectral density of the barometric- } \\
\text { pressure time series (fig. } 2-1 \text {, box j). }
\end{array}
\end{gathered}
$$

The cross- and auto-spectral densities were computed using the Welch (1967) method. The gain (amplitude) and phase shift of the frequency response function were calculated as follows:

$$
\begin{aligned}
& A(\omega)=|H(\omega)| \\
& \phi_{s}(\omega)=\operatorname{atan} 2(H(\omega))
\end{aligned}
$$

where

$A(\omega)$ is the amplitude or gain,

$|\mathrm{H}(\omega)| \quad$ is the magnitude of the complex valued $(a+b i)$ frequency response function computed using $|a+b i|=\sqrt{a^{2}+b^{2}}$, and

$\phi_{s}(\omega) \quad$ is the phase shift of the water-level response relative to the forcing atmospheric load computed using $\operatorname{atan} 2(b, a)$.

The squared coherence at each frequency $\left(\gamma^{2}(\omega)\right)$ was computed using equation 2-29 (Bendat and Piersol, 1986):

$$
\gamma^{2}(\omega)=\frac{\left|G_{x y}(\omega)\right|^{2}}{G_{x x}(\omega) G_{y y}(\omega)}
$$


The amplitude of the frequency response represents the barometric efficiency (BE) of the response at the evaluated angular frequencies $(\omega=2 \pi f)$. The phase shift represents the phase shift of the measured water-level response relative to the phase of the forcing atmospheric load (for example, phase of the load minus phase of the water-level response). Phase shifts were computed in the interval -180 to $+180^{\circ}$ and adjusted by adding the result to $-180^{\circ}$. The adjustment arises from the fact that the water-level response in terms of water level measured as depth-to-water level are nearly in-phase with the atmospheric load compared with the nearly antiphase waterlevel response in terms of water level measured as elevation or head. Thus, phase shifts were portrayed in a manner that was consistent with the nearly antiphase water-level elevation or head response, where the ideal (absent of drainage effects) water-level response has a phase shift of exactly $-180^{\circ}$, and is consistent with the representation of phase shift in Rojstaczer (1988a). As such, the adjustment facilitates comparisons of phase-shift responses presented here to responses presented in other studies. However, because this convention computes phase shifts of the water-level responses relative to the forcing atmospheric loads, the phase shifts are oppositely sensed compared to phase shifts computed for the water-level responses to Earth tides (discussed previously), which were computed relative to the phases of the measured depth-towater level responses. Thus, here phase-shift angles greater than $-180^{\circ}$ (for example, $-160^{\circ}$ ) represented phase advanced water-level responses with respect to the atmospheric load (in this example, advanced by $20^{\circ}$ ), and angles less than $-180^{\circ}$ represented phase lagged water-level responses.

Frequency response functions were computed for those parsed series analyzed for Earth tides shown in table 2-4 and indicated by series numbers in bold-italic font in table 2-1. For parsed series from wells 28A-25-1 and 28A-25-2, which responded negligibly to Earth-tide strains, the frequency responses to atmospheric loading were computed using the detrended depth-to-water $(y(t))$ and detrended barometricpressure $(x(t))$ parsed time series. For parsed series from well 14A-25-1, frequency responses to atmospheric loading were computed using the unscaled and $\mathrm{M}_{2}$-scaled, tidally filtered, detrended, parsed water-level time series, $\tilde{y}_{e t}(t)$ and $\tilde{y}_{e t M 2}(t)$ (eqns. 2-24 and 2-25), respectively, and the detrended, parsed barometric-pressure time series $(x(t))$. To compare the effects of tidal filtering on the computed frequency-response functions for well 14A-25-1, frequency responses were also computed using the tidally unfiltered, detrended, parsed waterlevel series as done for the 28A-25 wells (see fig. 2-13C, D and accompanying discussion later in this section).

To compute $H(\omega)$, lengths or spans in hours (the sample rate or interval) were specified for the number of discrete Fourier transform points $(n f f t)$, window, and overlap parameters in the computations of the power spectra. A Hamming window was used to reduce spectral leakage of the computed spectral estimates. Values for $n f f t$, window, and overlap were chosen to preserve frequency resolution in the sub-tidal frequencies (less than $0.7 \mathrm{cpd}$ ). The specified values were determined by trial and error to minimize the ratio of variances of filtered to detrended water levels (discussed later). For each $H(\omega)$ computed using the specified values of $n f f t$, window, and overlap, a second $H(\omega)$ was computed after resampling the original $H(\omega)$ at a specified resampling rate. The resampled $H(\omega)$ was designated $r e H(\omega)$. The resampling rate was specified as a multiple of the original rate. The resampling factor (ref) was computed to ensure the period associated with the minimum resampled frequency was less than the span in hours of the parsed time series $(N)$. Resampling was achieved using an antialiasing finite-impulse response low-pass filter (order $=20 \times[N-10]$; Kaiser window shape factor, $\beta=5$ ). The original sampling and resampling frequencies ranged from $\frac{24}{r e f \times n f f t}$ to $12 \mathrm{cpd}$, the Nyquist frequency, where $n f f t$ is in hours and $r e f=1$ for the original sampling rate. The use of relatively large $n f f t$ s to enhance resolution in the low-frequency range limited computed values of ref, which ranged from 1.1 to 1.9. Nevertheless, in most cases, resampling improved the frequency response function estimates and the filtered results, especially in the important sub-tidal frequency range where most of the crossspectral power resides. Table 2-6 lists the parameters used to compute the power spectra for each parsed series analyzed (indicated by series numbers in bold-italic font in table 2-1). Figure 2-12 shows the auto- and cross-spectral density power spectra computed for non-tidally filtered, detrended, parsed series 28A-25-1_9, 28A-25-2_4, and 14A-25-1_8. For each time series, much of the spectral power was concentrated at lower frequencies (less than about $0.3 \mathrm{cpd}$ ), with peaks at lower levels of spectral power at diurnal and semi-diurnal frequencies in the 28A-25 wells and at the semidiurnal frequency in 14A-25-1_8. The peaks at $3 \mathrm{cpd}$ in each plot are harmonics (integer multiples of the fundamental frequency) that arose with the Fourier transform of the imperfect sinusoid of the fundamental frequency at $1 \mathrm{cpd}$. In this case, it is an odd harmonic (3 times the fundamental frequency). No attempt was made to remove these harmonics from the time series prior to computing the frequency-response functions.

The computed frequency responses in terms of amplitude (BE) and phase shift for 28A-25-1_4 and 28A-25-2_4 (detrended, parsed series of the same period) and 14A-251 10mod are shown in figure $2-13$. For the $28 \mathrm{~A}-25$ wells, two responses are shown for each tidally unfiltered parsed series, one based on the original sampling rate, $H_{\text {frfbp }}(\omega)$ (or FRF), and another based on the resampled rate, $H_{\text {refirfbp }}(\omega)$ (or reFRF). For series 14A-25-1_10mod, the responses at the original and resampled rates are shown for both the tidally unfiltered (FRF and reFRF) and the $\mathrm{M}_{2}$-scaled, tidally filtered time series, $H_{f r f b p: M 2}(\omega)$ and $H_{\text {refiffb:M2 }}(\omega)$ (or FRF:ETM2) and reFRF:ETM2). The squared coherences, $\gamma_{f i f b p}^{2}(\omega)$ (or $\mathrm{Coh}^{2}$ for FRF), and $\gamma_{\text {frfbp:etM } 2}^{2}(\omega)$ (or $\mathrm{Coh}^{2}$ :ETM2 for FRF:ETM2), are also shown on the respective phase plots (fig. 2-13B, $D, F$ ). 
Table 2-6. Parameters used to compute frequency-response functions for the parsed time series analyzed for frequency response to atmospheric loading for wells $28 \mathrm{~A}-25-1$ during January 14, 2016-December 31, 2017, 28A-25-2 during January 14, 2016-December 31, 2017, and 14A-25-1 during November 13, 2015November 29, 2017, in the area of Mammoth Lakes, California.

[hrs, hours; N, number of hourly samples in the parsed time series; nfft, number of discrete Fourier transform points]

\begin{tabular}{|c|c|c|c|c|c|}
\hline $\begin{array}{l}\text { Well/ } \\
\text { parsed } \\
\text { series }\end{array}$ & $\begin{array}{c}\mathbf{N} \\
\text { samples }\end{array}$ & $\begin{array}{c}\text { nfft } \\
\text { (hrs) }\end{array}$ & $\begin{array}{c}\text { Window } \\
\text { (hrs) }\end{array}$ & $\begin{array}{c}\text { Overlap } \\
\text { (hrs) }\end{array}$ & $\begin{array}{l}\text { Resampling } \\
\text { factor }\end{array}$ \\
\hline \multicolumn{6}{|c|}{$28 \mathrm{~A}-25-1$} \\
\hline 1 & 959 & 840 & 480 & 96 & 1.130 \\
\hline 3 & 1,704 & 1,200 & 720 & 96 & 1.412 \\
\hline 4 & 2,160 & 1,920 & 720 & 96 & 1.120 \\
\hline 5 & 2,832 & 1,920 & 1,200 & 72 & 1.470 \\
\hline 9 & 2,500 & 1,320 & 1,200 & 96 & 1.886 \\
\hline 10 & 798 & 720 & 360 & 24 & 1.094 \\
\hline \multicolumn{6}{|c|}{$28 \mathrm{~A}-25-2$} \\
\hline 1 & 983 & 840 & 480 & 96 & 1.158 \\
\hline 3 & 1,728 & 1,200 & 720 & 96 & 1.432 \\
\hline 4 & 2,145 & 1,920 & 720 & 96 & 1.112 \\
\hline 5 & 789 & 720 & 360 & 24 & 1.082 \\
\hline 6 & 3,191 & 1,920 & 1,200 & 120 & 1.657 \\
\hline $7 \bmod A$ & 1,482 & 1,200 & 480 & 72 & 1.227 \\
\hline $7 \operatorname{modB}$ & 1,849 & 1,680 & 600 & 48 & 1.095 \\
\hline \multicolumn{6}{|c|}{ 14A-25-1 } \\
\hline 1 & 2,470 & 1,320 & 1,200 & 96 & 1.864 \\
\hline 4 & 1,128 & 960 & 600 & 72 & 1.165 \\
\hline 5 & 768 & 600 & 360 & 96 & 1.263 \\
\hline 6 & 2,712 & 1,920 & 1,200 & 24 & 1.407 \\
\hline 7 & 789 & 720 & 360 & 48 & 1.082 \\
\hline 8 & 2,339 & 1,800 & 1,200 & 72 & 1.294 \\
\hline 9 & 1,836 & 1,680 & 840 & 144 & 1.087 \\
\hline $10 \bmod$ & 1,233 & 960 & 360 & 96 & 1.274 \\
\hline
\end{tabular}

Generally, the signal-to-noise ratios of the computed frequency responses, as indicated by the power spectral densities (for example, fig. 2-12), were low for frequencies higher than about $2.5 \mathrm{cpd}$, and the squared coherences were highly variable and generally small. Spuriously high correlations are possible when the signal-to-noise ratios are small. Thus, including frequencies beyond the tidal frequencies, greater than about $2.5 \mathrm{cpd}$, was not that useful for demonstrating and analyzing the frequency responses of water levels to atmospheric loading because most of the signal power resided at frequencies less than about $2.5 \mathrm{cpd}$. Computed responses for frequencies greater than $5 \mathrm{cpd}$ are not shown here. The computed frequency responses for the full frequency range up to $12 \mathrm{cpd}$ were used in the analysis, however.

The responses showed a strong frequency dependence. BEs for 28A-25-1_4 and 28A-25-2_4 were similar and distinctly different from the BEs in 14A-25-1_10mod. Average BEs in the supra-tidal frequencies (more than $2.5 \mathrm{cpd}$ ) approached values of 1 and about 0.55 for the 28A-25 parsed series and 14A-25-1_10mod, respectively. For supra-tidal frequencies, average phase shifts approached values of $-178^{\circ}$ and $-175^{\circ}$ in $28 \mathrm{~A}-25-1 \_4$ and $28 \mathrm{~A}-25-2 \_4$, respectively, and about $-192^{\circ}$ in $14 \mathrm{~A}-25-1 \_10 \mathrm{mod}$. This part of the response, where BE and phase shift approached constant values at higher frequencies, is indicative of the 'static-confined' response (Rojstaczer, 1988a, 1988b) and represents the classic concept of barometric efficiency in terms of a simple loading response without the influence of fluidflow effects. The phase shift of the static-confined response in 14A-25-1_10mod, corresponding to a phase lag of about $12^{\circ}$ $\left(-180^{\circ}-\left(-192^{\circ}\right)\right)$, agreed reasonably well with the phase lag of about $5^{\circ}$ measured for the $\mathrm{M}_{2}$ tide in this series (table 2-4, phase shift $=4.94^{\circ}$ ). Although the difference was small and likely within the error range of the analytical methods and field measurements, it could indicate a small difference in the responses to vertical loading imposed by atmospheric pressure and the responses to principally areal (plane-stress) loading imposed by the Earth tides. Removal of the $\mathrm{M}_{2}$-scaled tidal responses generally improved the frequency response to atmospheric loading around the diurnal and especially the semi-diurnal frequencies (fig. 2-13C, D), and this was generally true of the other frequency responses computed for the 14A-25-1 parsed time series. At sub-tidal frequencies, the frequency responses in each well showed an increase in BE (slight for the 28A-25-2 wells) shifted toward lower frequencies for 14A-25-1_10mod, followed by a decrease in $\mathrm{BE}$ accompanied by generally concomitant increasing phase shifts (phase advances). These frequency responses of water level to atmospheric loading for each well are consistent with the theoretical responses of either a partially confined or a deep unconfined aquifer (Rojstaczer, 1988a; Rojstaczer and Riley, 1990) with drainage (vertical fluid-flow) effects manifest at frequencies of the imposed load below about $0.8 \mathrm{cpd}$ in the $28 \mathrm{~A}-25$ wells and below about $0.4 \mathrm{cpd}$ in well 14A-25-1. The effects of resampling $H(\omega)$ at the higher rates indicated by the resampling factor ( $r e f)$ in table 2-6 had minimal effects on the character of the BEs and phase shifts of the computed frequency responses.

The frequency responses computed for other parsed series from the same wells were typified by the responses shown here. The computed frequency responses in the full frequency range for the original sampled frequency without tidal filtering (FRF) for all parsed time series analyzed (indicated by series numbers in bold-italic font in table 2-1) in each well are given in Galloway (2019) along with the computed frequency responses at the resampled frequencies without tidal filtering (reFRF) for the 28A-25-1 and 28A-25-2 parsed time series and with $\mathrm{M}_{2}$-scaled tidal filtering (reFRF:ETM2) for the 14A-25-1 series. 

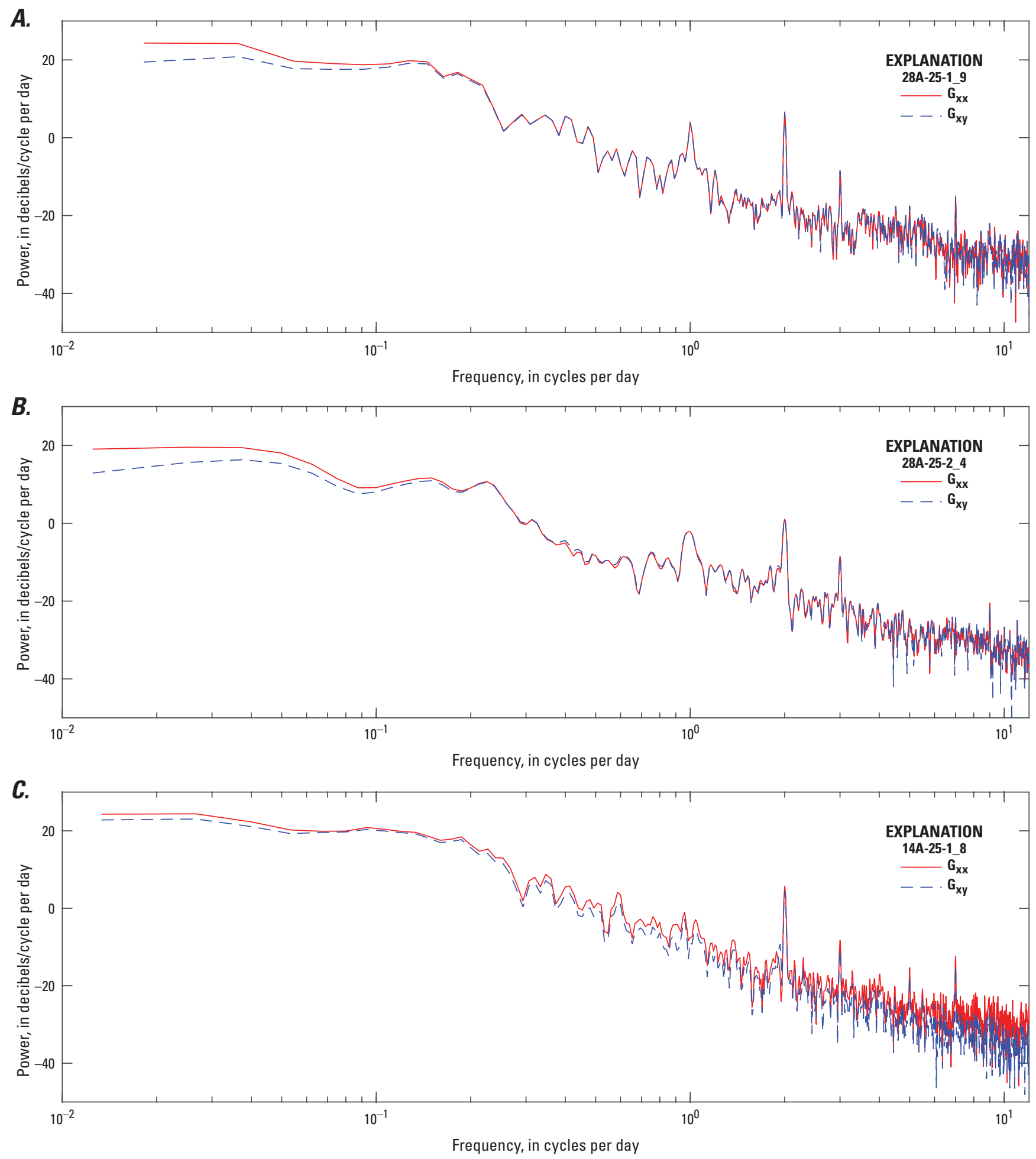

Figure 2-12. Power spectral densities $\left(G_{x x^{\prime}} G_{x y}\right.$ from eqn. 2-27) computed for the parameters listed in table 2-6 for the non-tidally filtered, detrended, parsed series 28A-25-1_9 during August 16 to November 28, 2017, 28A_25-2_4 during May 19 to August 16, 2016, and 14A-25-1_8 during February 15 to May 24, 2017, from wells 28A-25-1, 28A-25-2, and 14A-25-1, in the area of Mammoth Lakes, California: A, 28A-25-1_9; B, 28A_25-2_4; and C, 14A-25-1_8. 

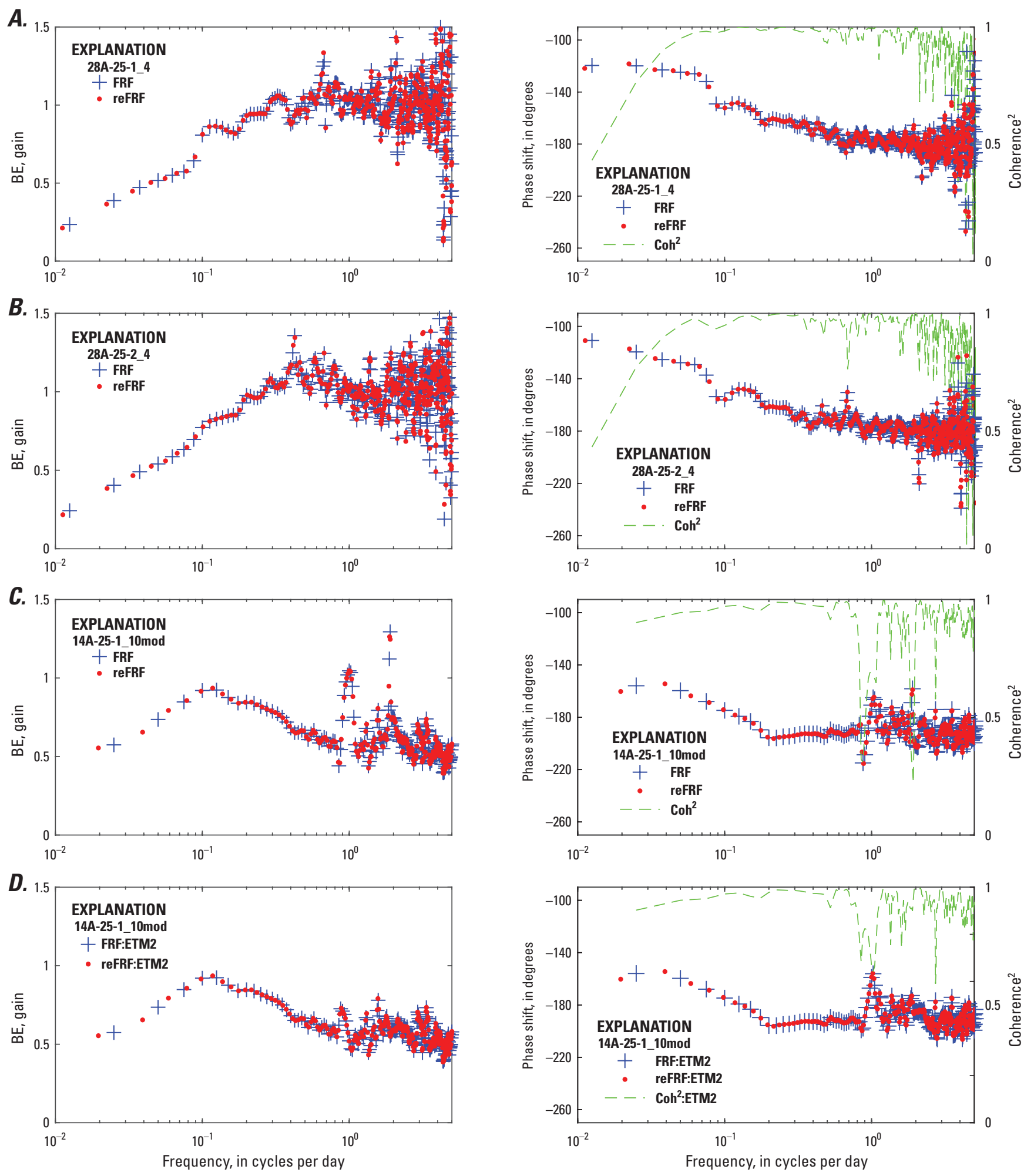

Figure 2-13. Computed atmospheric-loading frequency responses of water levels in terms of barometric efficiency (BE), phase shift, and squared coherence (Coh ${ }^{2}$ for FRF, and Coh²:ETM2 for FRF:ETM2) for selected, detrended, parsed time series for wells 28A-25-1, 28A-25-2 and 14A-25-1 in the area of Mammoth Lakes, California. For the parsed series from the 28A-25 wells, two frequency response functions are shown for each well, one based on the original sampling rate (FRF) and another based on the resampled rate (reFRF). For the parsed series from well 14A-25-1, the responses at the original and resampled rates are shown for both the tidally unfiltered (FRF, reFRF) and the $\mathrm{M}_{2}$-scaled, tidally filtered (FRF:ETM2, reFRF:ETM2) time series. A, 28A-25-1_4, from May 18 to August 15, 2016, FRF, reFRF, and Coh²; B, 28A-25-2_4, from May 19 to August 16, 2016, FRF, reFRF, and Coh²; C, 14A-25-1_10mod, from 0ctober 9 to November 29, 2017, FRF, reFRF, and Coh²; and D, 14A-25-1_10mod, from October 9 to November 29, 2017, FRF:ETM2, reFRF:ETM2, and Coh²:ETM2. 
The predicted time-domain responses of water levels to atmospheric loading were computed using the four frequency response functions models, FRF, reFRF, FRF:ETM2, and reFRF:ETM2. For each well, the predicted time-domain waterlevel responses were computed for each parsed series analyzed using the FRF and reFRF models. For 14A-25-1, predicted time-domain water-level responses were also computed for each parsed series analyzed using the FRF:ETM2 and reFRF:ETM2 models. The predicted time-domain responses were computed by taking the inverse discrete Fourier transform of $Y(\omega)$ in equation 2-26 for the different frequency response function models as follows:

$$
\begin{aligned}
& \hat{y}_{f i f b p}(t)=\operatorname{Re}\left(i f f t\left(Y_{f t t b p}(\omega)\right)\right) \\
& \hat{y}_{\text {reffifp }}(t)=\operatorname{Re}\left(i f f t\left(Y_{\text {refffbp }}(\omega)\right)\right) \\
& \hat{y}_{f f f b p: t M^{2}}(t)=\operatorname{Re}\left(i f f t\left(Y_{f f t b p: t M 2}(\omega)\right)\right) \\
& \hat{y}_{\text {refiftbp:etM2 }}(t)=\operatorname{Re}\left(i f f t\left(Y_{\text {refffbp:etM2 }}(\omega)\right)\right)
\end{aligned}
$$

where

$$
\begin{aligned}
& Y_{f i f b p}(\omega) \quad \text { is the transformed water-level response from } \\
& \text { the FRF model, } \\
& Y_{\text {reffftbp }}(\omega) \text { is the transformed water-level response from } \\
& \text { the reFRF model, } \\
& Y_{f r t b p: e t M 2}(\omega) \text { is the transformed water-level response from } \\
& \text { the FRF:ETM2 model, } \\
& Y_{\text {refffbp:etM2 }}(\omega) \text { is the transformed water-level response from } \\
& \text { the reFRF:ETM2 model, } \\
& \text { ifft is the inverse Fourier transform operator, } \\
& \mathrm{Re} \quad \text { is the real part of the complex-valued } \\
& \text { argument, } \\
& \hat{y}_{f i f b p}(t) \quad \text { is the predicted time-domain water-level } \\
& \text { response for the FRF model, } \\
& \hat{y}_{\text {refiftpp }}(t) \quad \text { is the predicted time-domain water-level } \\
& \text { response for the reFRF model, } \\
& \hat{y}_{f i t b p: e t M 2}(t) \quad \text { is the predicted time-domain water-level } \\
& \text { response for the FRF:ETM2 model, and }
\end{aligned}
$$

$\hat{y}_{\text {refiffp:etM } 2}(t)$ is the predicted time-domain water-level response for the reFRF:ETM2 model.

\section{Digitally Filtered Water-Level Time Series}

The predicted water-level responses (eqn. 2-30) computed using the FRF, reFRF, FRF:ETM2 and reFRF:ETM2 models were used to digitally filter atmosphericloading responses from the detrended water levels (fig. 2-1, box k). The filtered, detrended water levels were computed using equation 2-31:

$$
\begin{aligned}
& \tilde{y}_{f i t b p}\left(t_{j}\right)=y\left(t_{j}\right)-\hat{y}_{f i f b p}\left(t_{j}\right) \\
& \tilde{y}_{\text {refiffbp }}\left(t_{j}\right)=y\left(t_{j}\right)-\hat{y}_{\text {refiftop }}\left(t_{j}\right) \\
& \tilde{y}_{f i f b p: e t M 2}\left(t_{j}\right)=y\left(t_{j}\right)-\hat{y}_{f i f b p: t M 2}\left(t_{j}\right) \\
& \tilde{y}_{\text {refiffbp:etM2 }}\left(t_{j}\right)=y\left(t_{j}\right)-\hat{y}_{\text {reffffbp:etM2 }}\left(t_{j}\right)
\end{aligned}
$$

where

$\tilde{y}_{f r f b p} \quad$ is the filtered, detrended water-level timeseries computed using the predicted timedomain water-level response from the FRF model;

$$
\begin{aligned}
& \tilde{y}_{\text {refitbp }} \text { is the filtered, detrended water-level time- } \\
& \text { series computed using the predicted } \\
& \text { time-domain water-level response from the } \\
& \text { reFRF model; } \\
& \tilde{y}_{f r t b p: e t M 2} \text { is the filtered, detrended water-level time- } \\
& \text { series computed using the predicted } \\
& \text { time-domain water-level response from the } \\
& \text { FRF:ETM2 model; and } \\
& \tilde{y}_{\text {refiftp:etM2 }} \text { is the filtered, detrended water-level time- } \\
& \text { series computed using the predicted } \\
& \text { time-domain water-level response from the } \\
& \text { reFRF:ETM2 model. }
\end{aligned}
$$




\section{Detrended, Parsed Time Series}

Figure 2-14 shows examples of filtered results $\tilde{y}_{f r f b p}$ (or ytFRF) and $\tilde{y}_{\text {refrftb }}$ (or ytreFRF) for the FRF and reFRF models, respectively, and detrended depth-to-water (WL) and barometric-pressure (BP) time series for the detrended, parsed time series 28A-25-1_1 and _9, 28A-25-2_1, and _5, and 14A-25-1_9; filtered results $\tilde{y}_{\text {frfbp:etM } 2}$ (or ytFRF:ETM2) and $\tilde{y}_{\text {refrfbp:etM2 }}$ (or ytreFRF:ETM2) for the FRF:ETM2 and reFRF:ETM2 models, respectively, are also shown for the detrended, parsed time series 14A-25-1_9. Also shown in each plot is the filtered result ytrescBE or ytetrescBE for the resampled time series using a constant (frequencyindependent) $\mathrm{BE}$ equal to the estimated static-confined $\mathrm{BE}$ (rescBE for the tidally unfiltered series and etrescBE for the $\mathrm{M}_{2}$-scaled, tidally filtered series) for each time series. The static-confined BE estimates were computed from the mean of the BEs for the respective frequency response function with $\gamma^{2}$ (squared coherence) values greater than 0.85 at the resampled frequencies greater than $3 \mathrm{cpd}$, and its value is shown in the explanation of each plot. Filtered results for all the detrended series for which frequency response functions were computed (table 2-6; indicated by series numbers in bold-italic font in table 2-1), and the full parsed series affected by nearby drilling (28A-25-2_7) and the flow test in geothermal well 14-25 (14A-25-1_10) (indicated by series numbers in underline font in table $2-1$ ), are given in Galloway (2019). The filtered, detrended water levels given in Galloway (2019) for wells 28A-25-1 and 28A-25-2, respectively, are ytreFRF computed using the reFRF atmospheric loading model. The filtered, detrended, water levels given in Galloway (2019) for well 14A-25-1 are ytreFRF:ETM2 computed using the reFRF:ETM2 atmospheric loading model.

Generally, the filtered results from the frequency response functions were acceptable, reducing variability in the resampled frequency-dependent filtered series compared with filtered results using constant BEs. In the well 14A25-1 tidally filtered series, the variability was reduced by factors between 2.1 (14A-25-1_5) and 19.1 (14A-25-1_1), and in the wells 28A-25-1 and 28A-25-2 series, variability was reduced by factors between 47.6 (28A-25-1_9) and 4.8 (28A-25-2_7modA). The filters generally performed less well at the ends ("heads" and "tails") of the parsed series, where there was some spectral leakage owing to depiction of the boundaries of the finite time series in the modeled frequency domain. Nevertheless, the heads and tails of the filtered results for each parsed time series were retained.

Next, for those parsed series presumed affected by nearby drilling or flow testing (28A-25-2_7 and 14A-25-1_10), the computed frequency response functions for the parts of those parsed series that were presumed affected mostly by atmospheric loading (28A-25-2_7modA) and by atmospheric loading and Earth tides (14A-25-1_10mod) were used to filter the responses to atmospheric loading. The tidally unfiltered parsed series was used to compute the frequency response functions for $28 \mathrm{~A}-25-2 \_7 \mathrm{mod}$, and the $\mathrm{M}_{2}$-scaled, tidally filtered parsed series was used to compute the frequency response functions for $14 \mathrm{~A}-25-1 \_10 \mathrm{mod}$. Figure $2-15$ shows the filtered results for time series 28A-25-2_7, which was influenced by nearby drilling beginning around noon on Oct. 10, 2017 (dd 1014). The filtered water levels computed using both the frequency-dependent BE filter (reFRF) and the constant BE filter (rescBE $=0.995$ ) for this series retained almost all the high-frequency peak water-level variations attributed to the effects of nearby drilling. A secondary peak effect from nearby drilling was also evident in the filtered results for Oct. 14, 2017 (dd 1018), and many smaller peaks were evident for Oct. 10-14. 2017 (dd 1014-1018), Oct. 15, 2017 (dd 1019), Oct. 23, 2017 (dd 1027), and Nov. 28, 2017 (dd 1063).

Figure 2-16 shows the digitally filtered results for time series 14A-25-1_10, which were influenced by flow testing (fluid withdrawal) of the nearby 14-25 production well that began around noon on Aug. 26, 2017 (dd 969), and stopped around noon on Sep. 22, 2017 (dd 996). The filtering process effectively removed the effects of Earth tides and atmospheric loading from the detrended series. The filtered water levels computed using both the frequency-dependent BE filter (reFRF:ETM2) and the constant BE filter (etrescBE $=0.590$ ) derived from parsed series 14A-25-1_10mod retained almost all the high-frequency peak water-level variations attributed to the flow test. The detrended, filtered water levels showed a period of declining water-level elevation (or increasing depth-to-water level) following an initial increase of about $8 \mathrm{~cm}$ in water-level elevation (or $8 \mathrm{~cm}$ decrease in the depthto-water level) at the onset of flow testing. The decline continued to about $8 \mathrm{~cm}$ of water-level elevation decrease (or $8 \mathrm{~cm}$ of depth-to-water level increase) since just prior to the onset of pumping, until production was unexpectedly stopped early on Sept. 19, 2017 (dd 993), and resumed shortly thereafter. A $20-\mathrm{cm}$ water-level elevation decrease (or $20 \mathrm{~cm}$ depth-to-water to level increase) accompanied the stoppage of production, and this was followed by a period of waterlevel recovery (increasing water-level elevation or decreasing depth-to-water level) to a level approximating the water level prior to the unexpected stoppage. Water-level elevations declined (or depth-to-water levels increased) slightly during the following days until production was stopped around noon on September 22, 2017 (dd 996). The increase and decrease in water-level elevations (or decrease and increase in depth-to-water levels) accompanying the onset and end of production, respectively, are considered 'reverse water-level responses' with respect to the expected decrease and increase in water level elevations (or increase and decrease in depth-towater levels) in response to the onset and end of production, respectively, from an aquifer system. The periods of waterlevel elevation decline and increase (depth-to-water level increase and decrease) following equilibration of the reverse water-level responses accompanying the period of production and the period following the cessation of production, respectively, were consistent with the expected response of an aquifer system subject to the onset and end of production. 

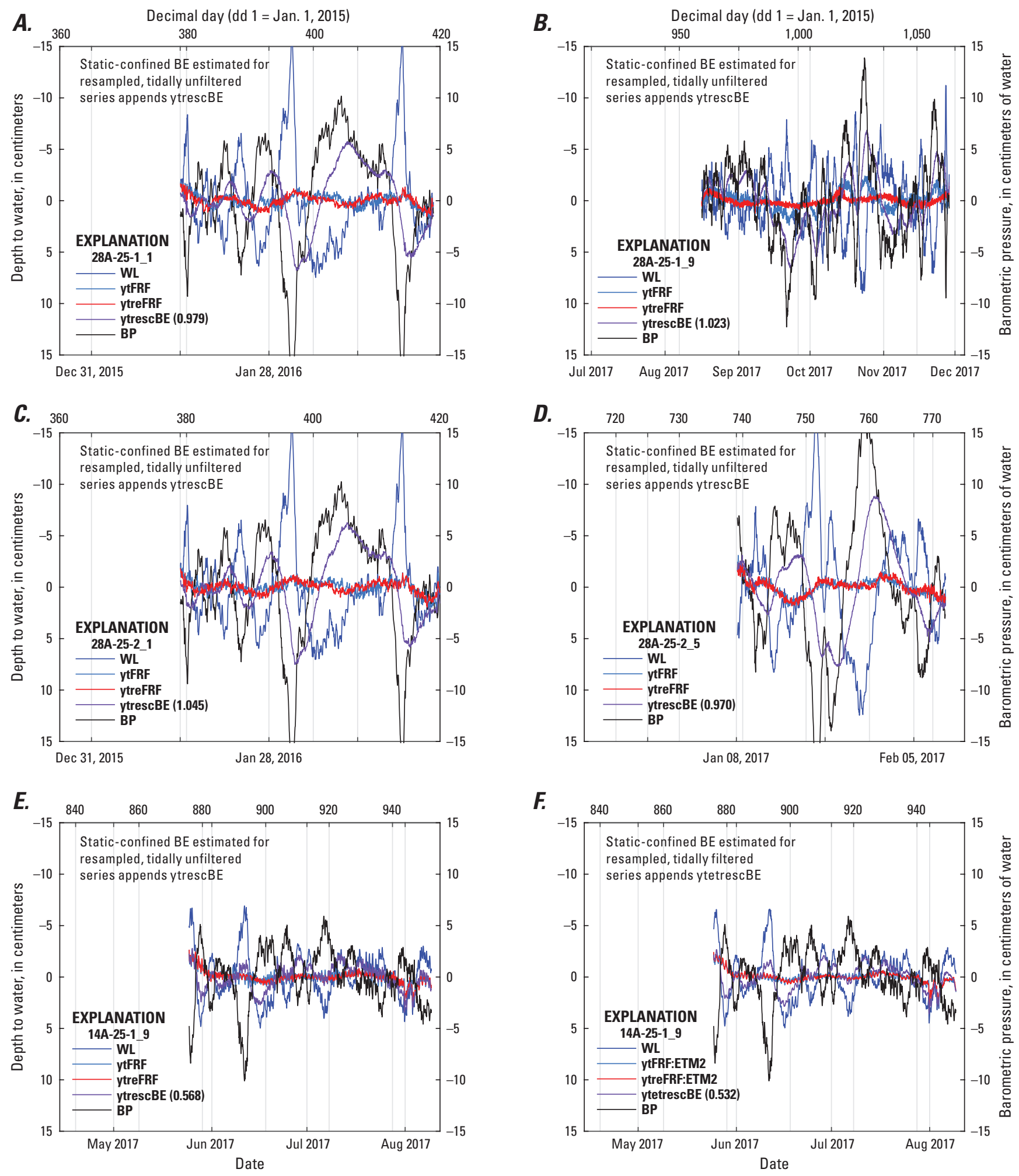

Figure 2-14. Filtered, detrended, parsed water-level time series shown with detrended water level (WL) and barometric pressure (BP) for parsed time series 28A-25-1_1 during January 14-February 22, 2016, 28A-25-1_9 during August 16-November 28, 2017, 28A-25-2_1 during January 14-February 23, 2016, 28A-25-2_5 during January 8-February 10, 2017 and 14A-25-1_9 during May 24-August 9, 2017, from wells 28A-25-1, 28A_25-2, and 14A-25-1 in the area of Mammoth Lakes, California: A, 28A-25-1_1, filtered time series ytFRF, ytreFRF, and ytrescBE; $B, 28 \mathrm{~A}-25-1$-9, filtered time series ytFRF, ytreFRF, and ytrescBE; $C, 28 \mathrm{~A}-25-2 \_1$, filtered time series ytFRF, ytreFRF, and ytrescBE; $D, 28 \mathrm{~A}-25-2$ _5, filtered time series ytFRF, ytreFRF, and ytrescBE; $E$, 14A-25-1_9, filtered time series ytFRF, ytreFRF, and ytrescBE; and $F$, 14A-25-1_9, filtered time series ytFRF:ETM2, ytreFRF:ETM2, and ytetresceBE. 

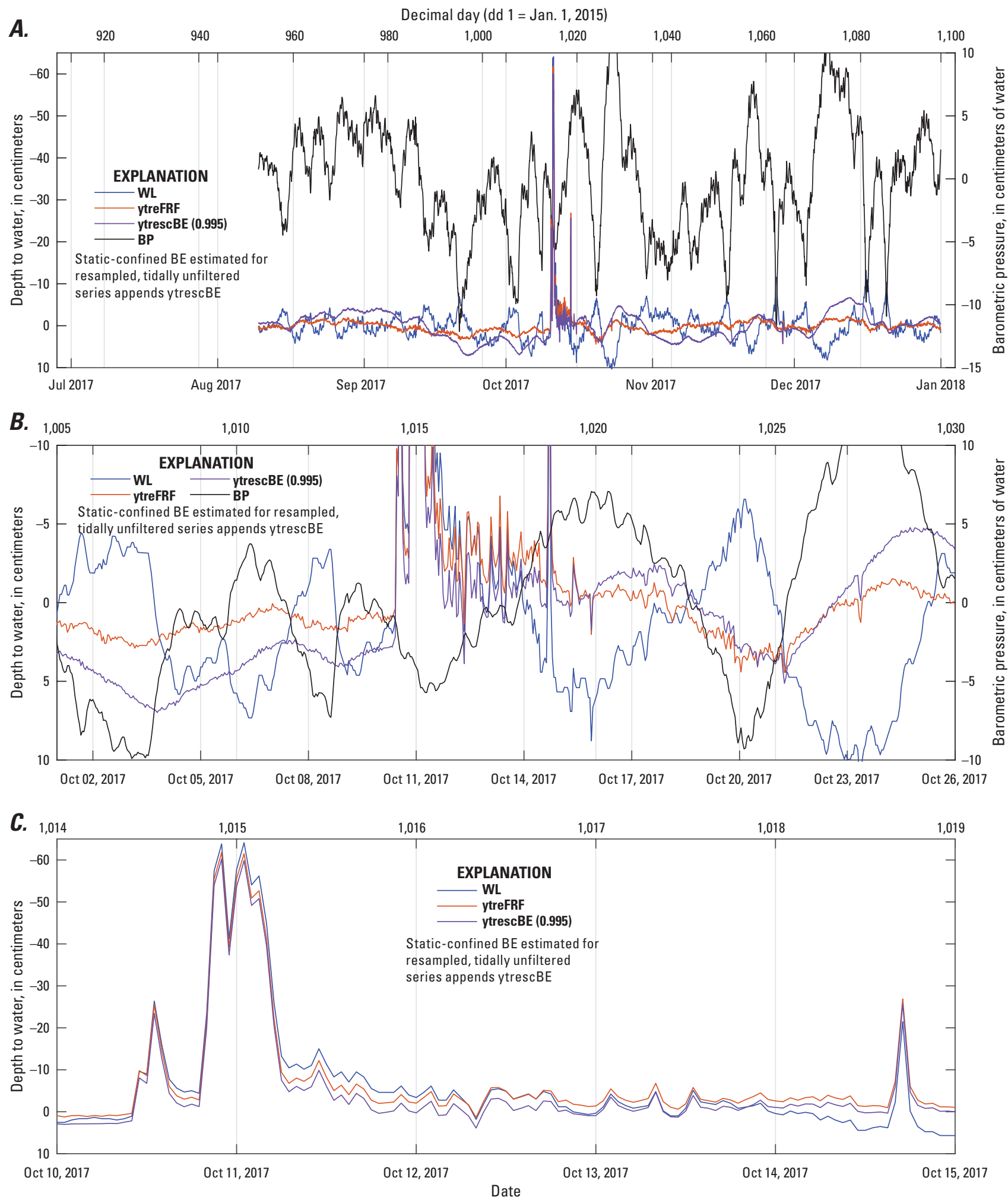

Figure 2-15. Filtered, detrended, parsed water-level time series ytreFRF and ytresceBE computed using the frequency response function model reFRF, and the static-confined barometric efficiency rescBE, respectively, shown with detrended, parsed water level (WL) and barometric pressure (BP) for parsed time series 28A-25-2_7, August 9-0ctober 10, 2017, from well 28A-25-2 in the area of Mammoth Lakes, California, for a period influenced by nearby drilling: $A$, Filtered time series ytreFRF and ytrescBE shown with WL and $B P$ for full length of parsed series; $B$, Filtered time series ytreFRF and ytrescBE shown with WL and BP for 25 days of parsed series bracketing the period influenced by nearby drilling; and $C$, Filtered time series ytreFRF and ytrescBE shown with WL and BP for 5 days of parsed series during the period influenced by nearby drilling. 

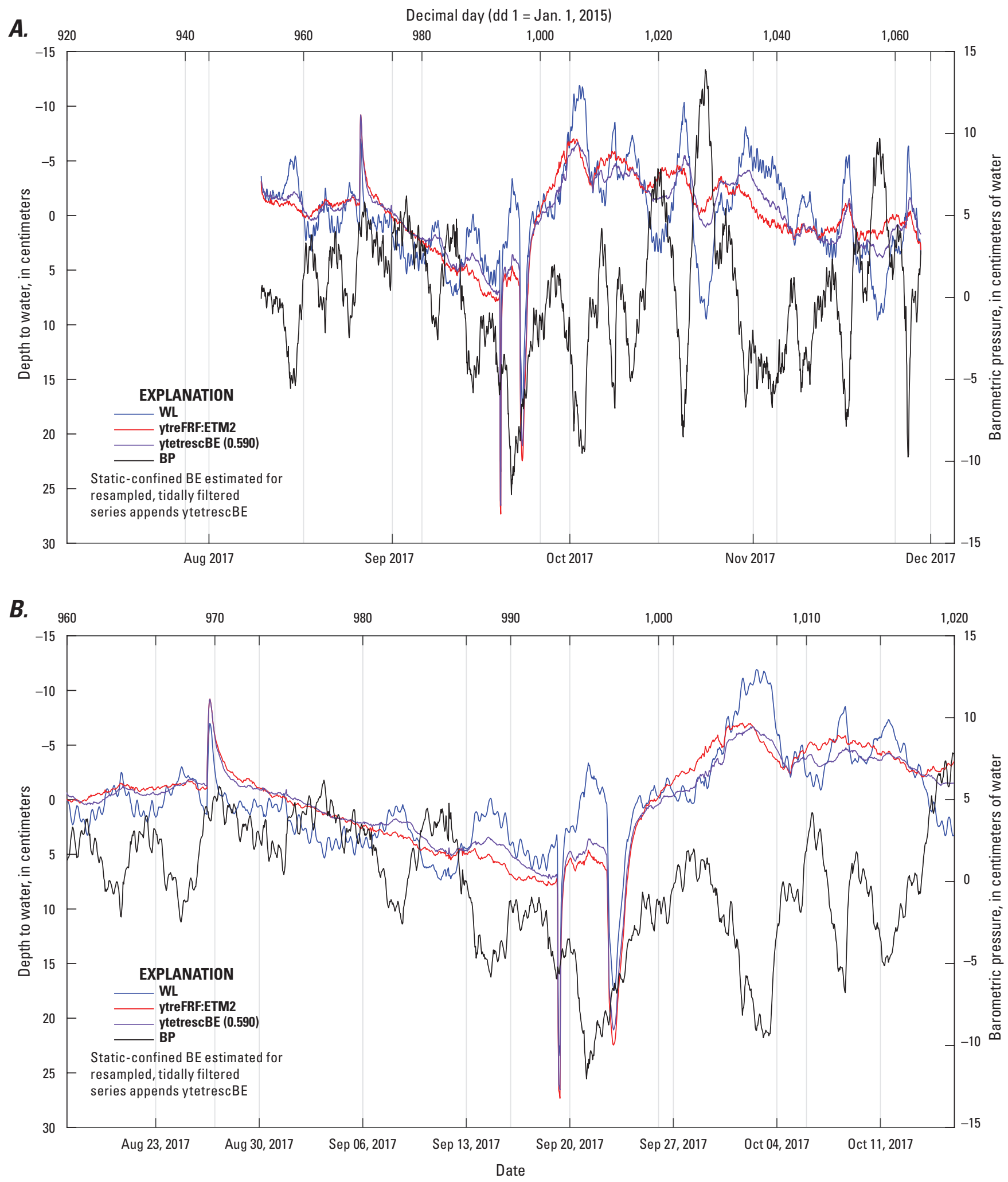

Figure 2-16. Filtered, detrended, parsed water-level time series ytreFRF:ETM2 and ytetrescBE, filtered using the frequency response function model reFRF:ETM2, and the estimated static-confined barometric efficiency etrescBE, respectively, shown with detrended, parsed water level (WL) and barometric pressure (BP) for parsed time series 14A-25-1_10, August 9-November 29, 2017, from well 14A-25-1 in the area of Mammoth Lakes, California, for a period influenced by flow testing in the nearby 14-25 production well: $A$, Filtered time series ytreFRF:ETM2 and ytetrescBE shown with WL and BP for full length of parsed series; and $B$, Filtered time series ytreFRF:ETM2 and ytetrescBE shown with WL and BP for 60 days of parsed series bracketing the period influenced by flow testing. 


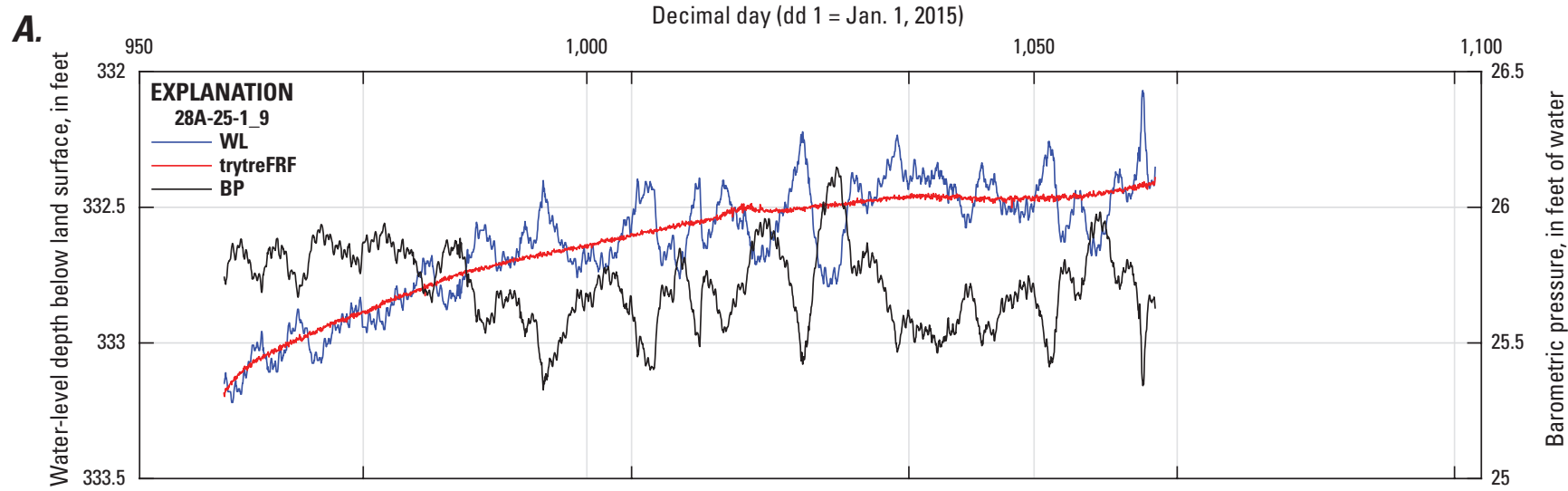

B.
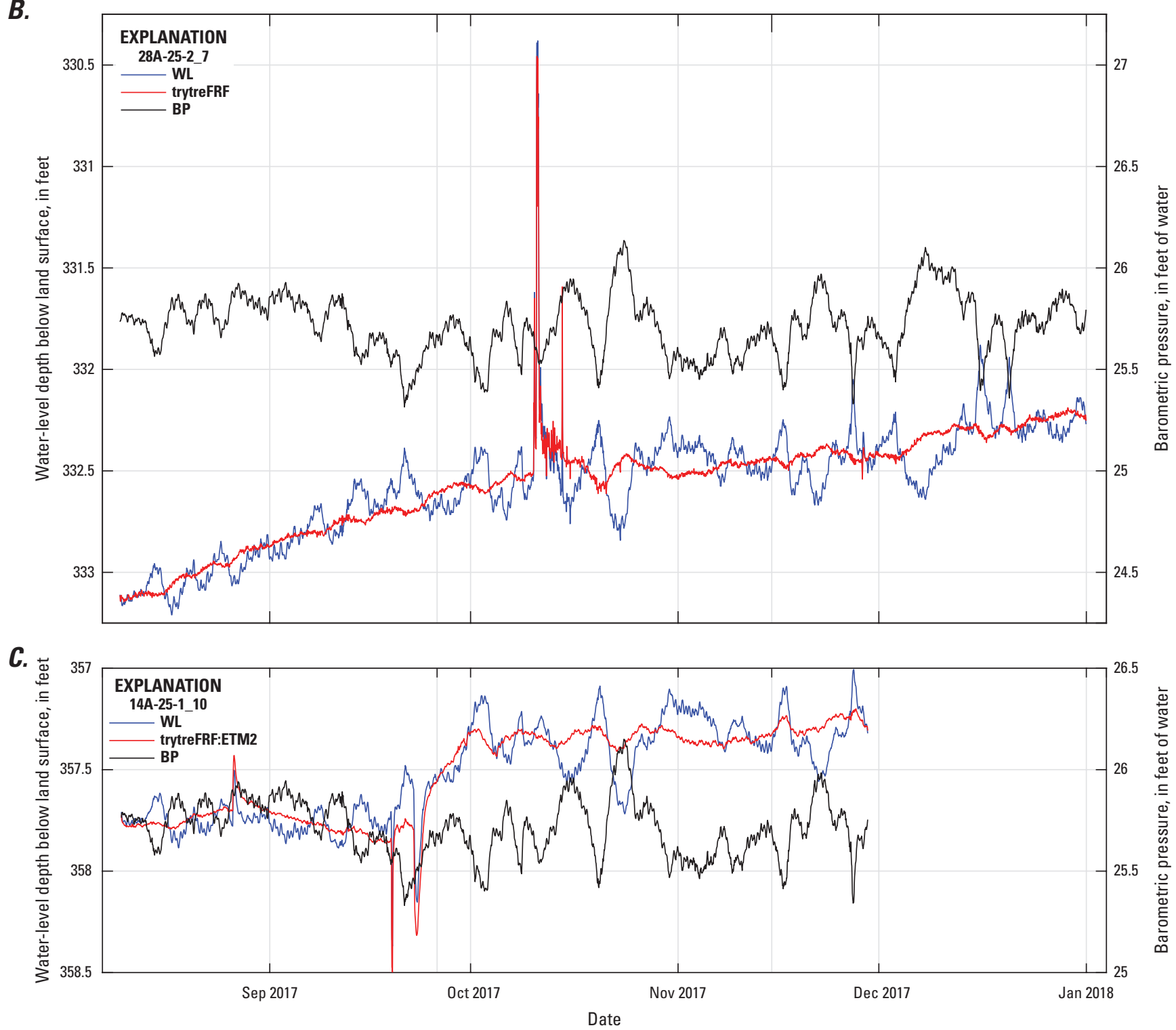

Figure 2-17. Reconstructed, digitally filtered water-levels trytreFRF or trytreFRF:ETM2 shown with water-level (WL) and barometricpressure (BP) for parsed time series from wells 28A-25-1, 28A-25-2, and 14A-25-1 in the area of Mammoth Lakes, California, for the period influenced by the flow test in production well 14-25: A, 28A-25-1_9, August 16-November 28, 2017, trytreFRF shown with WL and BP; B, 28A-25-2_7, August 9-December 31, 2017, trytreFRF shown with WL and BP; and C, 14A-25-1_10, August 9-November 29, 2017, trytreFRF:ETM2 shown with WL and BP. 


\section{Reconstructed, Parsed Time Series}

The trends removed to create the detrended time series were restored (added back) to the detrended, digitally filtered water-level time series computed using the reFRF and reFRF:ETM2 frequency response models to produce reconstructed filtered water-level time series (fig. 2-1, box 1). Figure 2-17 shows an example of the reconstructed time series trytreFRF for parsed series 28A-25-1_9 and 28A-25-2_7, and trytreFRF:ETM2 for parsed series $14 \overline{\mathrm{A}}-25-1110$ for the period that includes the flow test. Note, 'tr' prepended to ytreFRF and ytreFRF:ETM2 denotes the trend restored to the detrended filtered series computed using the reFRF and reFRF:ETM2 frequency response models, respectively. The water-level data are shown in units of feet of water for the corresponding calendar dates. Barometric pressure (in equivalent feet of water) from the barometer at site 28A-25 is shown with the 28A-25-2_7 reconstructed series. The responses, in terms of reconstructed filtered water levels in wells 28A-25-1, 28A-252 , and $14 \mathrm{~A}-25-1$, to the flow test in production well $14-25$ is discussed in more detail in the "Water-Level Variations During a Flow Test of a Geothermal Production Well" section of the report. Reconstructed, digitally filtered results for each of the selected parsed series shown in table $2-1$ indicated by parsed series numbers in bold-italic and underline fonts are given in Galloway (2019).

\section{References Cited}

Bendat, J.S., and Piersol, A.G., 1986, Random data analysis and measurement procedures: New York, John Wiley, 566 p.

Berger, J., and Beaumont, C., 1976, An analysis of tidal strain observations from the United States of America II. The inhomogeneous tide: Bulletin of the Seismological Society of America, v. 66, no. 6, p. 1821-1846.

Bredehoeft, J.D., 1967, Response of well-aquifer systems to Earth tides: Journal of Geophysical Research, v. 72, no. 12, p. $3075-3087$.

Butterworth, S., 1930, On the theory of filter amplifiers: Experimental Wireless and the Wireless Engineer, v. 7, p. 536-541.

Cutillo, P.A., and Bredehoeft, J.D., 2011, Estimating aquifer properties from the water level response to Earth tides: Groundwater, v. 49, no. 4, p. 600-610, https://doi.org/10.1111/j.1745-6584.2010.00778.x.

Galloway, D.L., 2019, Atmospheric-loading frequency response functions and groundwater levels filtered for the effects of atmospheric loading and solid Earth tides for three monitoring wells near Mammoth Lakes, California, 2015-2017: U.S. Geological Survey data release, https://doi.org/10.5066/P9ON8U5U.
Galloway, D.L., and Rojstaczer, S.A., 1989, Inferences about formation elastic and fluid flow properties from the frequency response of water levels to atmospheric loads and Earth tides: 4th Canadian/American Conference on Hydrogeology, Fluid flow, heat transfer and mass transport in fractured rocks, Banff, Alberta, Canada, June 21-24, 1988, p. 100-113.

Godin, G., 1972, The analysis of tides: Toronto and Buffalo, Univ. of Toronto Press, 264 p.

Hanson, J.M., 1984, Evaluation of subsurface fracture geometry using fluid pressure response to solid Earth tidal strain: Lawrence Livermore National Laboratory UCID20156, 135 p.

Hanson, J.M., and Owen, L.B., 1982, Fracture orientation analysis by the solid Earth tidal strain method: Society of Petroleum Engineers, https://doi.org/10.2118/11070-MS.

Harrison, J.C., 1971, New computer programs for the calculation of Earth tides: Cooperative Institute for Research in Environmental Sciences, National Oceanic and Atmospheric Administration, University of Colorado, $30 \mathrm{p}$.

Hsieh, P.A., Bredehoeft, J.D., and Farr, J.M., 1987, Determination of aquifer transmissivity from Earth tide analysis: Water Resources Research, v. 23, no. 10, p. 18241832, https://doi.org/10.1029/WR023i010p01824.

Jacob, C.E., 1940, The flow of water in an elastic artesian aquifer: Eos Transactions American Geophysical Union, v. 21, p. $574-586$.

Melchior, P., 1966, The Earth Tides: London, Pergamon Press, $458 \mathrm{p}$.

Munk, W.H., and MacDonald, G.J.F., 1960, The rotation of the Earth-A geophysical discussion: London, Cambridge University Press, 323 p.

Quilty, E.G., and Roeloffs, E.A., 1991, Removal of barometric pressure response from water level data: Journal of Geophysical Research, v. 96, no. B6, p. 10209-10218, https://doi.org/10.1029/91JB00429.

Rojstaczer, S., 1988a, Determination of fluid flow properties from the response of water levels in wells to atmospheric loading: Water Resources Research, v. 24, no. 11, p. 1927 1938, https://doi.org/10.1029/WR024i011p01927.

Rojstaczer, S., 1988b, Intermediate period response of water levels in wells to crustal strain-Sensitivity and noise level: Journal of Geophysical Research, v. 93, no. B11, p. 1361913634, https://doi.org/10.1029/JB093iB11p13619. 
Rojstaczer, S., and Agnew, D.C., 1989, The influence of formation material properties on the response of water levels in wells to Earth tides and atmospheric loading: Journal of Geophysical Research, v. 94, no. B9, p. 1240312411, https://doi.org/10.1029/JB094iB09p12403.

Rojstaczer, S., and Riley, F.S., 1990, Response of the water level in a well to Earth tides and atmospheric loading under unconfined conditions: Water Resources Research, v. 26, no. 8 , p. $1803-1817$.

Weeks, E.P., 1979, Barometric fluctuations in wells tapping deep unconfined aquifers: Water Resources Research, v. 15, no. 5 , p. 1167-1176.

Welch, P.D., 1967, The use of fast Fourier transform for the estimation of power spectra-A method based on time averaging over short, modified periodograms: Institute of Electrical and Electronics Engineers Transactions on Audio and Electroacoustics, v. AU-15, p. 70-73. 


\section{Appendix 3. Water-Temperature Profiles for Wells in the Vicinity of Mammoth Lakes, California, 2015-17}

Table 3-1. Vertical water-temperature profiles for well 14A-25-1, Mammoth Lakes, California, 2016-17.

\begin{tabular}{|c|c|c|c|c|c|c|c|c|}
\hline $\begin{array}{l}\text { Depth in feet } \\
\text { below top } \\
\text { of casing }\end{array}$ & \multicolumn{8}{|c|}{ Temperature in degrees Celsius } \\
\hline 1360 & 61.8 & 61.7 & 61.7 & 62.8 & 62.8 & 62.8 & 62.6 & 62.4 \\
\hline 370 & 63.6 & 63.5 & 63.7 & 64.3 & 64.2 & 64.5 & 64.4 & 64.6 \\
\hline 380 & 65.3 & 65.2 & 65.4 & 66.0 & 65.9 & 65.9 & 66.2 & 66.1 \\
\hline 390 & 67.7 & 67.6 & 67.7 & 68.2 & 68.1 & 67.8 & 67.8 & 67.8 \\
\hline 410 & 71.9 & 71.8 & 71.9 & 71.8 & 71.8 & 71.7 & 71.3 & 71.7 \\
\hline 420 & 73.9 & 73.7 & 73.8 & 73.6 & 73.6 & 73.5 & 73.6 & 73.4 \\
\hline 430 & 75.6 & 75.4 & 75.5 & 75.3 & 75.3 & 75.1 & 75.2 & 75.2 \\
\hline 440 & 77.1 & 76.9 & 76.9 & 77.1 & 77.1 & 76.9 & 76.9 & 77.0 \\
\hline 480 & 79.2 & 79.2 & 78.9 & 78.7 & 78.5 & 78.5 & 78.4 & 78.4 \\
\hline 490 & 79.9 & 79.8 & 79.6 & 79.4 & 79.3 & 79.1 & 79.1 & 79.1 \\
\hline 500 & 84.2 & 84.2 & 84.2 & 84.1 & 83.8 & 83.6 & 83.5 & 83.5 \\
\hline 510 & 86.7 & 86.9 & 87.1 & 87.0 & 86.7 & 86.4 & 86.4 & 86.3 \\
\hline 520 & 89.4 & 89.4 & 89.6 & 89.6 & 89.4 & 89.2 & 89.1 & 89.1 \\
\hline 530 & 92.0 & 92.1 & 92.3 & 92.2 & 92.0 & 91.9 & 91.8 & 91.8 \\
\hline 540 & 94.5 & 94.4 & 94.6 & 94.7 & 94.4 & 94.2 & 94.1 & 94.2 \\
\hline 550 & 96.7 & 96.7 & 96.8 & 96.8 & 96.6 & 96.5 & 96.3 & 96.5 \\
\hline 560 & 99.0 & 98.6 & 98.9 & 98.8 & 98.7 & 98.5 & 98.4 & 98.7 \\
\hline
\end{tabular}

${ }^{1}$ Subtract 1.7 feet to convert to depth in feet below land surface. 
Table 3-2. Vertical water-temperature profiles for well 28A-25-1, Mammoth Lakes, California, 2016-17.

\begin{tabular}{|c|c|c|c|c|c|c|c|c|}
\hline \multirow{2}{*}{$\begin{array}{l}\text { Depth in feet } \\
\text { below top } \\
\text { of casing }\end{array}$} & \multicolumn{8}{|c|}{ Temperature in degrees Celsius } \\
\hline & Feb 2016 & May 2016 & Aug 2016 & Dec 2016 & Feb 2017 & May 2017 & Aug 2017 & Nov 2017 \\
\hline${ }^{1} 340$ & 46.1 & 45.9 & 45.9 & 45.8 & 45.9 & 46.1 & $-^{2}$ & 44.6 \\
\hline 350 & 46.8 & 46.9 & 47.0 & 46.9 & 46.9 & 46.9 & - & 45.6 \\
\hline 360 & 47.3 & 47.4 & 47.5 & 47.4 & 47.4 & 47.4 & - & 46.0 \\
\hline 370 & 47.8 & 47.7 & 47.9 & 47.8 & 47.8 & 47.8 & - & 46.4 \\
\hline 380 & 47.9 & 47.9 & 48.3 & 48.1 & 48.2 & 48.1 & - & 46.9 \\
\hline 390 & 48.4 & 48.4 & 48.7 & 48.5 & 48.5 & 48.4 & - & 47.5 \\
\hline 400 & 48.4 & 48.7 & 49.0 & 48.8 & 48.8 & 48.8 & - & 48.0 \\
\hline 410 & 49.0 & 49.1 & 49.2 & 49.1 & 49.2 & 49.1 & - & 48.6 \\
\hline 420 & 49.4 & 49.2 & 49.5 & 49.4 & 49.5 & 49.4 & - & 49.1 \\
\hline 430 & 49.7 & 49.6 & 49.8 & 49.8 & 49.8 & 49.7 & - & 49.6 \\
\hline 440 & 50.0 & 50.0 & 50.1 & 50.1 & 50.0 & 49.9 & - & 49.9 \\
\hline 450 & 50.3 & 50.4 & 50.5 & 50.4 & 50.4 & 50.3 & - & 50.2 \\
\hline 460 & 50.5 & 50.8 & 50.8 & 50.8 & 50.8 & 50.7 & - & 50.6 \\
\hline 470 & 50.7 & 51.2 & 51.3 & 51.2 & 51.1 & 51.1 & - & 51.1 \\
\hline 480 & 51.5 & 51.7 & 51.7 & 51.7 & 51.6 & 51.5 & - & 51.5 \\
\hline 490 & 52.0 & 52.0 & 52.1 & 52.0 & 51.9 & 52.0 & - & 51.8 \\
\hline 500 & 52.3 & 52.4 & 52.5 & 52.5 & 52.4 & 52.3 & - & 52.2 \\
\hline 510 & 52.6 & 52.7 & 52.8 & 52.7 & 52.7 & 52.6 & - & 52.5 \\
\hline 520 & 52.9 & 52.9 & 53.0 & 52.9 & 52.9 & 52.9 & - & 52.8 \\
\hline 530 & 53.1 & 53.1 & 53.2 & 53.1 & 53.1 & 53.0 & - & 53.0 \\
\hline 540 & 53.2 & 53.2 & 53.3 & 53.2 & 53.3 & 53.1 & - & 53.1 \\
\hline 550 & 53.1 & 53.2 & 53.2 & 53.2 & 53.1 & 53.1 & - & 53.1 \\
\hline 560 & 53.1 & 53.2 & 53.2 & 53.1 & 53.0 & 53.0 & - & 53.0 \\
\hline 570 & 53.1 & 53.1 & 53.5 & 53.1 & 53.1 & 53.0 & - & 52.9 \\
\hline 580 & 53.0 & 53.0 & 53.2 & 53.0 & 53.1 & 52.9 & - & 53.0 \\
\hline 590 & 52.9 & 53.0 & 53.1 & 52.9 & 52.9 & 52.8 & - & 52.9 \\
\hline 600 & 52.8 & 52.8 & 52.9 & 52.9 & 52.9 & 52.8 & - & 52.8 \\
\hline
\end{tabular}

${ }^{1}$ Subtract 2.0 feet to convert to depth in feet below land surface.

${ }^{2}$ No temperature log because of equipment malfunction. 
For more information concerning the research in this report, contact the Director, California Water Science Center U.S. Geological Survey $6000 \mathrm{~J}$ Street, Placer Hall Sacramento, California 95819 https://ca.water.usgs.gov 


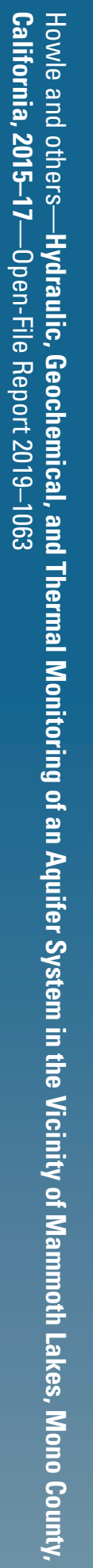

